\title{
Preliminary Design for a Maglev Development Facility
}

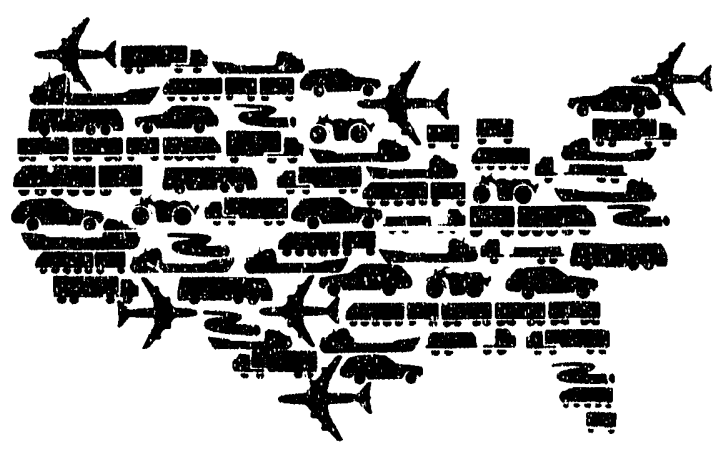

Center for Transportation Research Argonne National Laboratory

Operated by The Univorsity of Chicago. under Contract W-31-109-Eng-38, for the United States Department of Energy 


\section{Argonne National Laboratory}

Argonne National Laboratory, with facilities in the states of Illinois and Idaho, is owned by the United States govemment, and operated by the University of Chicago under the provisions of a contract with the Department of Energy.

This technical report is a product of Argonne's Energy Systems Division.

For information on the division's scientific and engineering activities, contact:

Director, Energy Systems Division

Argonne National Laboratory

Argonne, Illinois 60439-4815

Telephone (708) 252-3724

\section{Disclaimer}

This report was prepared as an account of work sponsored by an agency of the United States Govemment. Nelther the United States Govemment nor any agency thereof, nor any of their employees, makes any warranty, express or implied, or assumes any legal liability or responsibility for the accuracy, completeness, or usefulness of any information, apparatus, product, or process disclosed, or represents that its use would not infringe privately owned rights. Reference herein to any specific commercial product, process, or service by trade name, trademark, manufacturer, or otherwise, does not necessarily constitute or imply its endorsement, recommendation, or favoring by the United States Govemment or any agency thereot. The views and opinions of authors expressed herein do not necessarily state or reflect those of the United States Govemment or any agency thereof.

Available to DOE and DOE contractors from the Office of Scientific and Technical Information, P.O. Box 62, Oak Ridge, TN 37831; prices availabie from (615) 576-8401, FTS 626-8401.

Available to the public from the National Technical Information Senice, U.S. Departme tt of Commerce, 5285 Port Royal Road, Springfield, VA 22161. 


\section{Preliminary Design for a Maglev Development Facility}

by H.T. Coffey, J.L. He, S.L. Chang, J.X. Bouillard, S.S. Chen, "Y. Cai," L.O. Hoppie, S.A. Lottes, D.M. Rote, Z.Y. Zhang, ${ }^{*}$ G. Myers, ${ }^{*}$ A. Cvercko, ${ }^{*}$ and J.R. Williams ${ }^{*}$.

Center for Transportation Research, Energy Systerns Division, Argonne National Laboratory, 9700 South Cass Avenue, Argonne, Illinois 60439

Work sponsored by Illinois Department of Commerce and Community Affairs, Office of Technology Advancement and Development

'Chen and Cai are affiliated with Argonne's Materials and Components Technology Division; Zhang with the Polytechnic University of New York; Myers and Cvercko with Sterling Engineering. Westchester, Illipgisiprid Williams with Alfred Benesch and Co., Chicago, Illinois.

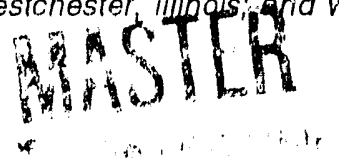




\section{CONTENTS}

ACKNOWLEDGMENTS $\ldots \ldots \ldots \ldots \ldots \ldots \ldots \ldots \ldots \ldots \ldots \ldots \ldots$

ABBREVIATIONS ........................... xiv

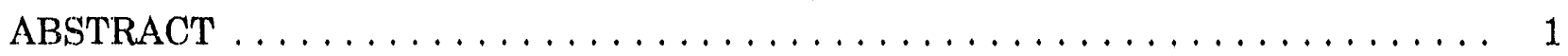

1 INTRODUCTION $\ldots \ldots \ldots \ldots \ldots \ldots \ldots \ldots \ldots \ldots \ldots \ldots \ldots \ldots$

1.1 System Description . . . . . . . . . . . . . . . . . . . . 3

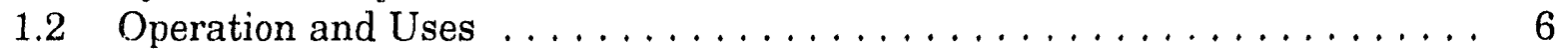

2 BACKGROUND $\ldots \ldots \ldots \ldots \ldots \ldots \ldots \ldots \ldots \ldots \ldots \ldots \ldots$

2.1 Development of Electrodynamic Systems $\ldots \ldots \ldots \ldots \ldots \ldots \ldots \ldots$

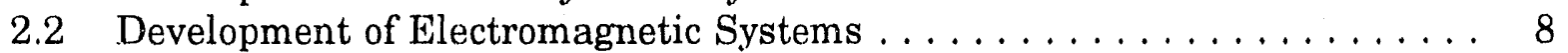

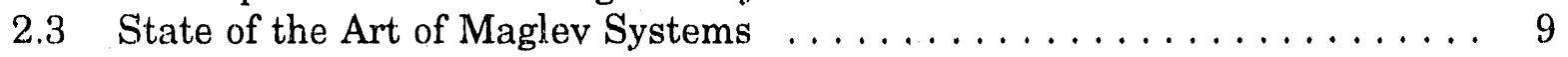

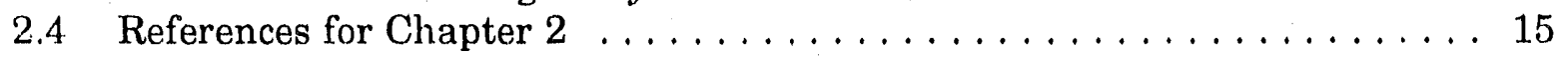

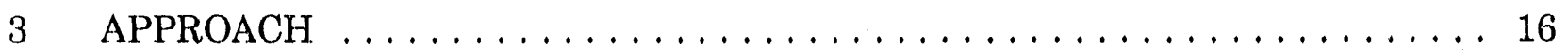

3.1 Introduction $\ldots \ldots \ldots \ldots \ldots \ldots \ldots \ldots \ldots \ldots \ldots \ldots \ldots$

3.2 Transportation Capabilities and Implications of Maglev Systems . . . . . . 16

3.3 Transportation Requirements for Maglev Systems . . . . . . . . . . . 17

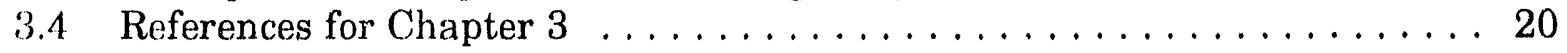

4 RESEARCH OPPORTUNITIES, TEST REQUIREMENTS, AND

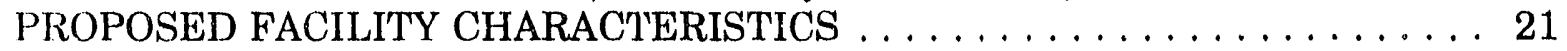

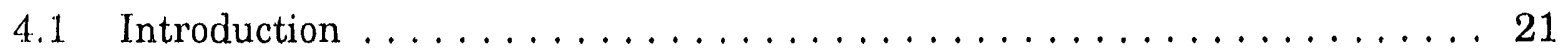

4.2 System Opportunities . . . . . . . . . . . . . . . . . . . 22

4.2.1 Vehicle/Train Opportunities and Test Requirements . . . . . . . . 22

4.2 .2 Guideway Opportunities and Test Requirements . . . . . . . . . . 25

4.2.3 Propulsion System Opportunities, Requirements, and

Characteristics .......................... 26

4.2.4 Control System Opportunities and Requirements . . . . . . . . 27

4.2.5 Power Supply Opportunities and Requirements . . . . . . . . . . . . 29

4.2 .6 All-Weather Research Opportunities . . . . . . . . . . . . . . 30

4.3 Subsystem and Component Development . . . . . . . . . . . . . . . 30

AERODYNAMIC CONSIDERATIONS $\ldots \ldots \ldots \ldots \ldots \ldots \ldots \ldots$

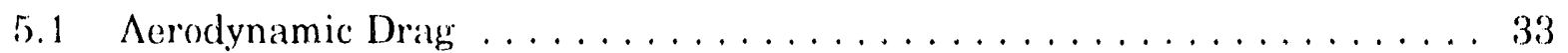

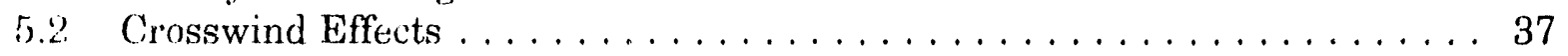

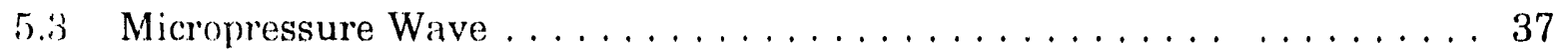

5.4 Aerodynamic Noise . . . . . . . . . . . . . . . . . . 38

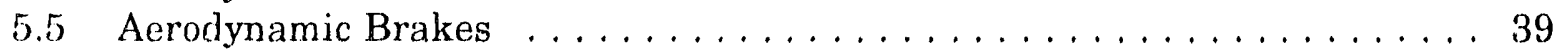

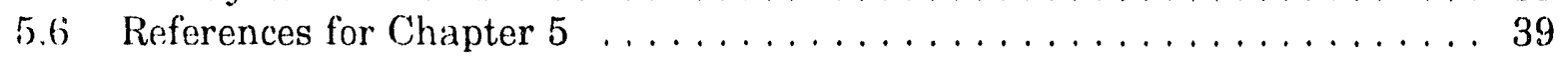




\section{CONTENTS (Cont'd)}

6 MAGLEV VEHICLE DESIGN $\ldots \ldots \ldots \ldots \ldots \ldots \ldots \ldots \ldots$

6.1 Vehicle Configuration, Shape, and Dimensions . . . . . . . . . . 41

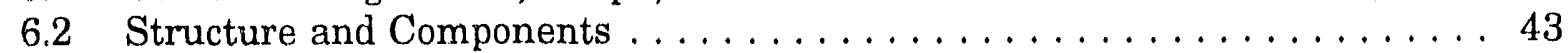

6.2 .1 Layout of Components . . . . . . . . . . . . . . 43

6.2 .2 Materials for Vehicle Body . . . . . . . . . . . . . . . 45

6.2.3 Weight and Strength of Vehicle Body and Frame Structure . . . . . 45

6.3 Wheel and Brake Systems $\ldots \ldots \ldots \ldots \ldots \ldots \ldots \ldots \ldots \ldots \ldots$

6.3.1 Supporting Wheels and Brakes .................. 47

6.3 .2 Guiding Wheels $\ldots \ldots \ldots \ldots \ldots \ldots \ldots \ldots \ldots \ldots \ldots$

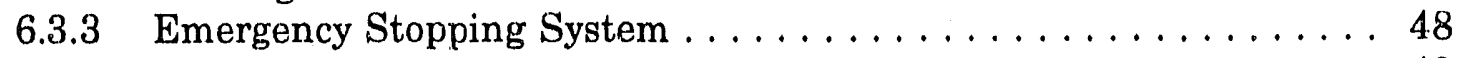

6.4 Accessories and Instrumentation $\ldots \ldots \ldots \ldots \ldots \ldots \ldots \ldots \ldots \ldots \ldots$

6.4.1 On-Board Power ....................... 49

6.4 .2 Accessories . . . . . . . . . . . . . . . . . . 49

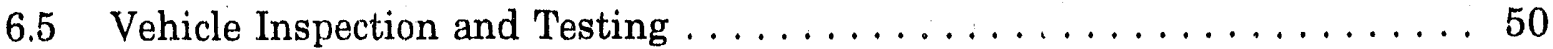

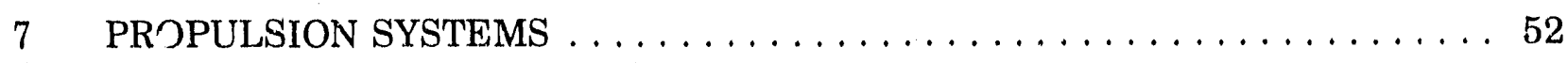

7.1 Long-Stator Air-Cored Linear Synchronous Motor . . . . . . . . . . . 52

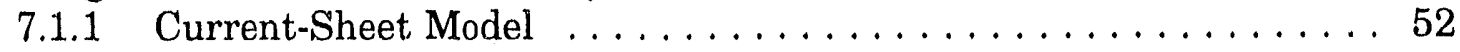

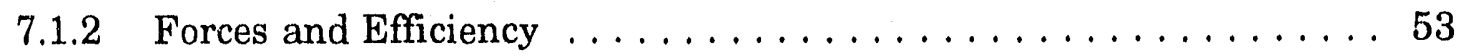

7.1 .3 Voltage, Current, and Power Factor ............... 57

7.2 Long-Stator Iron-Cored Linear Synchronous Motor . . . . . . . . . . 59

7.3 Analysis of a Cylindrical Maglev System . . . . . . . . . . . . . 61

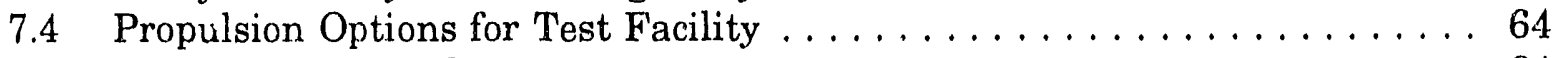

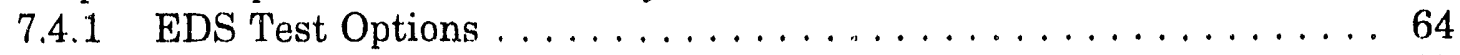

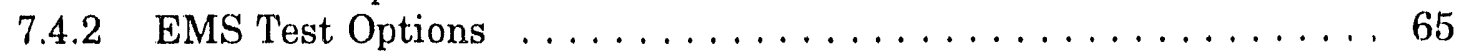

7.4.3 Linear Induction Motor Test Option . . . . . . . . . . . . . 68

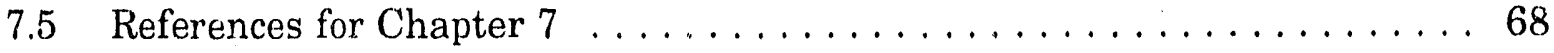

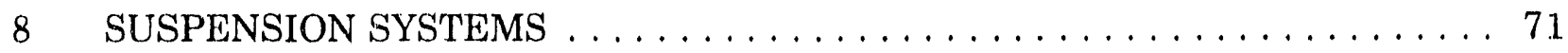

8.1 Continuous-Sheet Suspension . . . . . . . . . . . . . . . . 71

8.2 Loop-Shaped Coil Suspension . . . . . . . . . . . . . . . . 74

8.3 Design and Computer Simulation of Null-Flux Coil Suspension . . . . . . 76

8.4 References for Chapter $8 \ldots \ldots \ldots \ldots \ldots \ldots \ldots$

9 POWER SUPPLY AND DISTRIBUTION SYSTEM $\ldots \ldots \ldots \ldots \ldots \ldots \ldots$

9.1 Power Requirement . . . . . . . . . . . . . . . . . . 82

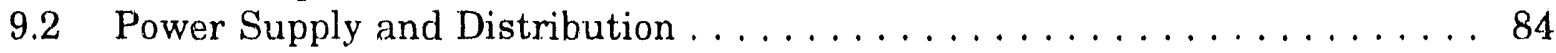

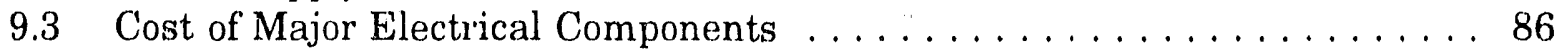

9.4 References for Chapter $9 \ldots \ldots \ldots \ldots \ldots \ldots \ldots \ldots \ldots$ 


\section{CONTENTS (Cont'd)}

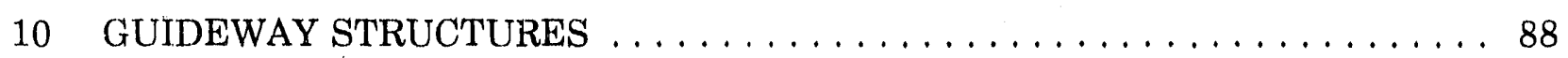

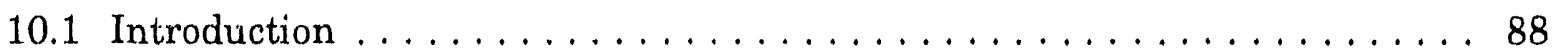

10.1 .1 General Requirements $\ldots \ldots \ldots \ldots \ldots \ldots \ldots \ldots \ldots$

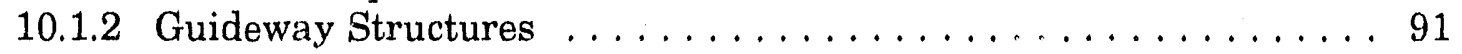

10.1 .3 Static Loads . . . . . . . . . . . . . . . . . . . . . . . . 92

10.1.4 Dynamic Vehicle/Guideway Interaction . . . . . . . . . . . . 93

10.1.5 Stabilization of Maglev Vehicles . . . . . . . . . . . . . . . 96

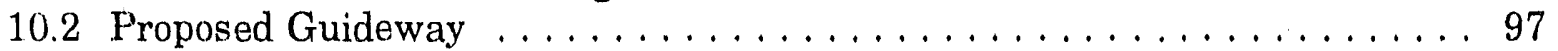

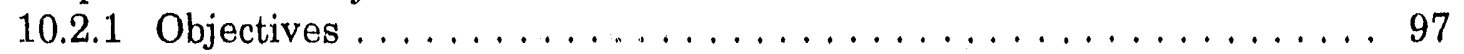

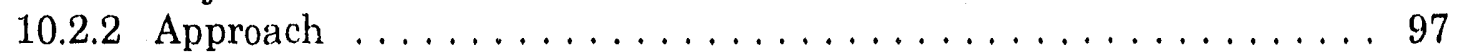

10.2.3 Detailed Design . . . . . . . . . . . . . . . . . . 99

10.3 Ride Quality . . . . . . . . . . . . . . . . . . . . . . . . 109

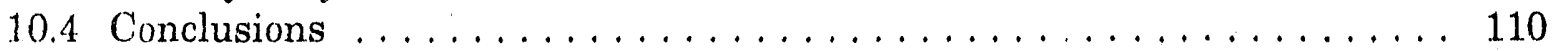

10.5 References for Chapter $10 \ldots \ldots \ldots \ldots \ldots \ldots \ldots \ldots \ldots \ldots$

11 CONTROI AND COMMUNICATIONS $\ldots \ldots \ldots \ldots \ldots \ldots \ldots \ldots \ldots \ldots$

11.1 Introduction $\ldots \ldots \ldots \ldots \ldots \ldots \ldots \ldots \ldots \ldots \ldots \ldots \ldots \ldots \ldots$

11.1.1 Control Response Time . . . . . . . . . . . . . . . 114

11.1 .2 Control Accuracy $\ldots \ldots \ldots \ldots \ldots \ldots \ldots \ldots \ldots \ldots \ldots$

11.1 .3 Adaptive Control ... . . . . . . . . . . . . . . . . 115

11.1.4 Fully Automatic Functions . . . . . . . . . . . . . . . . . . 115

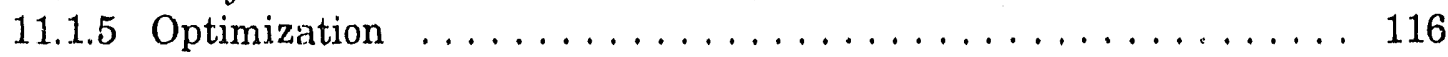

11.1.6 Decentralized Control and Data Processing . . . . . . . . . 116

11.1.7 Redundant Control Strategy . . . . . . . . . . . . . . . 117

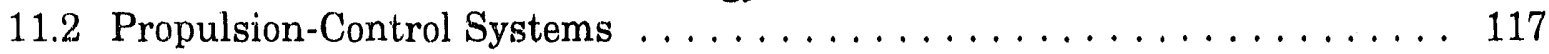

11.2.1 Foreign Propulsion-Control Systems . . . . . . . . . . . . . . 117

11.2.2 Test Facility Propulsion-Control Design . . . . . . . . . . . . . . . 119

11.2 .3 Speed Control . . . . . . . . . . . . . . . . . . . . . 120

11.2.4 Position Detection . . . . . . . . . . . . . . . . . . . 122

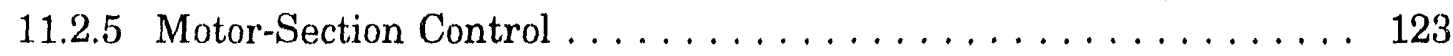

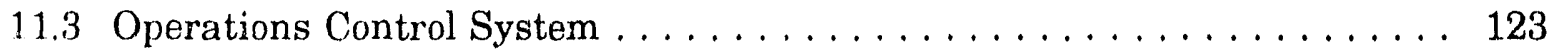

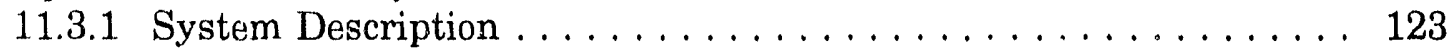

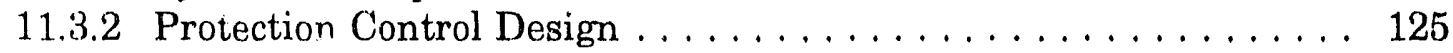

11.3 .3 Fault-Tolerant Design . . . . . . . . . . . . . . . . . 128

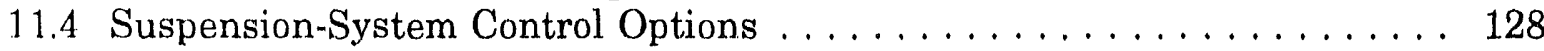

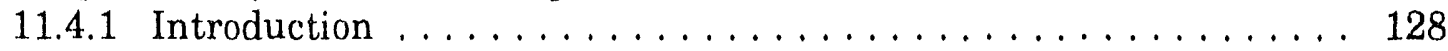

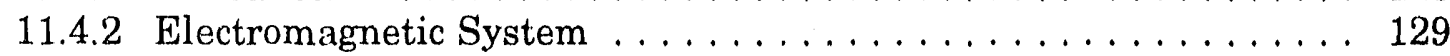

11.4 .3 Electrodynamic System . . . . . . . . . . . . . . . . . . . . 129

11.4.4 Analysis of a System with a Dashpot . . . . . . . . . . . . . 132

11.5 Communications . . . . . . . . . . . . . . . . . . . . 137

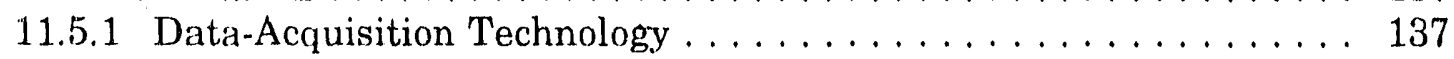

11.5 .2 Cost . . . . . . . . . . . . . . . . . . . . . . . . 139

11.6 Research and Development Opportunities . . . . . . . . . . . . . . 139

11.6.1 Modeling Study . . . . . . . . . . . . . . . . . . . . 139

11.6 .2 Suspension Stability Study . . . . . . . . . . . . . . . 140 


\section{CONTENTS (Cont'd)}

11.6.3 Adaptive Control Algorithm . . . . . . . . . . . . . . . 140

11.6.4 Study of Discrete Control Systems . . . . . . . . . . . . . . . 141

11.6.5 All-Ground Propulsion-Con rol Design . . . . . . . . . . . . 141

11.6.6 Simulation of the Control Systems . . . . . . . . . . . . . . 142

11.6.7 Development of New Measuring Systems . . . . . . . . . . . 142

11.7 References for Chapter $11 \ldots \ldots \ldots \ldots \ldots \ldots \ldots \ldots$

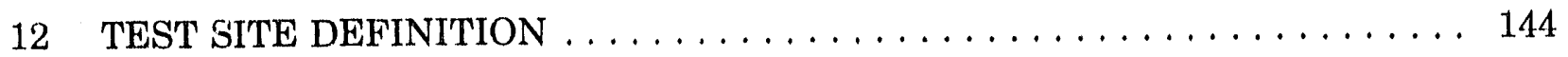

12.1 Objectives and Requirements $\ldots \ldots \ldots \ldots \ldots \ldots \ldots \ldots \ldots \ldots \ldots \ldots$

12.2 Facility Structure . . . . . . . . . . . . . . . . . . . . . 147

12.2.1 Maintenance Garage . . . . . . . . . . . . . . . . . . . 148

12.2.2 Electrical Power Station . . . . . . . . . . . . . . . . . 149

12.2.3 Control Station . . . . . . . . . . . . . . . . . . 150

12.2 .4 Water Supply . . . . . . . . . . . . . . . . . . . . 151

12.2 .5 Waste Treatment . . . . . . . . . . . . . . . . . . 153

12.2 .6 Fences . . . . . . . . . . . . . . . . . . . . . 153

12.2 .7 Roads/Parking Lots . . . . . . . . . . . . . . . . . . . . 153

12.3 Organization and Administration of the Site $\ldots \ldots \ldots \ldots \ldots \ldots \ldots$

12.4 Site Selection Considerations . . . . . . . . . . . . . . . . 154

12.4.1 Climate ........................... 154

12.4.2 Soil Physical and Engineering Properties/Soil Limitations . . . . . 155

12.4 .3 Vegetation and Wildlife $\ldots \ldots \ldots \ldots \ldots \ldots \ldots \ldots \ldots \ldots$

12.4.4 Availability of Natural Resources, Water, and

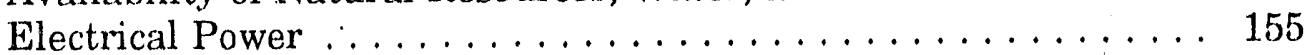

12.4 .5 Topological Requirements . . . . . . . . . . . . . 156

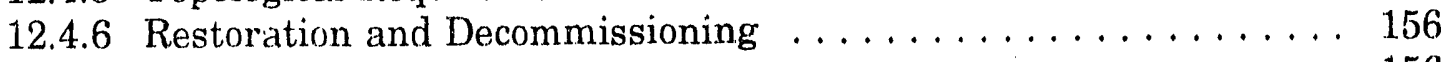

12.5 Remarks ............................ 156

13 SIMULATION OF MAGLEV MOTION $\ldots \ldots \ldots \ldots \ldots \ldots \ldots$

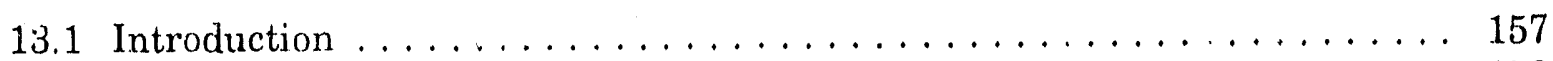

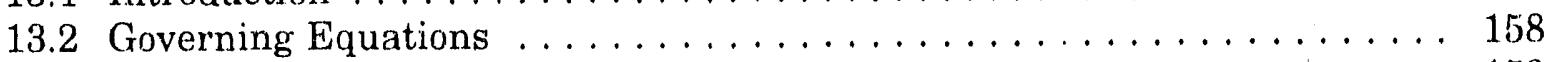

13.3 Program Sequence $\ldots \ldots \ldots \ldots \ldots \ldots \ldots \ldots \ldots \ldots \ldots \ldots$

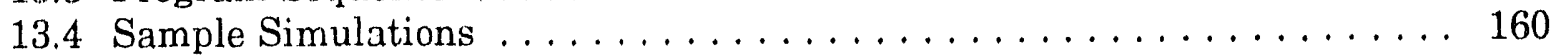

13.4.1 Shaped Guideway . . . . . . . . . . . . . . . . . 160

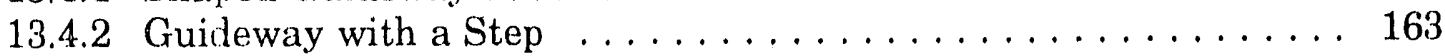

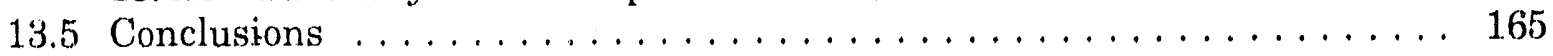

APPENDIX: Summary of Illinois Maglev Design Conference, Held at

Argonne National Laboratory, November 28-29, 1990 . . . . . . . . . 169 


\section{FIGURES}

1.1 Partial View of the Proposed Test Guideway and Test Vehicle, Electrodynamic Suspension System with Sidewall-Mounted Coils and a Linear Synchronous Motor $\ldots \ldots \ldots \ldots \ldots \ldots \ldots$

2.1 Cross-Sectional View, German Transrapid Maglev System . . . . . . . . . . . . 10

2.2 Side View, German Transrapid Maglev System . . . . . . . . . . . . . . . . . 10

2.3 Cross-Sectional View, Japanese MLU-002 Maglev System . . . . . . . . . . . . 13

2.4 Cutaway View, Japanese MLU-002 Maglev System . . . . . . . . . . . . . . 13

6.1 Artist's Conception of the Maglev Test Vehicle on the Guideway . . . . . . . . . 42

6.2 Major Components of the Maglev Test Vehicle . . . . . . . . . . . . . . . . 42

6.3 Cutaway View of the Front End of the Maglev Test Vehicle . . . . . . . . . . . 43

6.4 Vehicle Dimensions . . . . . . . . . . . . . . . . . . . . . 44

6.5 Supporting Wheel and Suspension $\ldots \ldots \ldots \ldots \ldots \ldots \ldots \ldots \ldots \ldots \ldots$

6.6 Wheel with Solid Tire and Brake $\ldots \ldots \ldots \ldots \ldots \ldots$

6.7 Carbon Brake . . . . . . . . . . . . . . . . . . . 49

6.8 Wheel Suspension and Hydraulic Control System . . . . . . . . . . . 50

6.9 Guiding Wheel and Aerodynamic Fairing $\ldots \ldots \ldots \ldots \ldots \ldots \ldots$

7.1 Conceptual View of the Long-Stator Linear Synchronous Motor . . . . . . . . 53

7.2 Current-Sheet Model for Long-Stator Air-Cored Linear Synchronous Motor ......................... 54

7.3 Efficiency as a Function of Current Angle, with Ratio $\Omega$ as a Parameter . . . . . 56

7.4 Power Factor of the Long-Stator Linear Synchronous Motor as a Function of Current Angle, with $\Omega$ as a Parameter . . . . . . . . . . . . . 59

7.5 Current-Sheet Model of the Long-Stator Iron-Cored

Linear Synchronous Motor . . . . . . . . . . . . . . . . . . . . 60

7.6 Front View of the Cylindrical Maglev System $\ldots \ldots \ldots \ldots \ldots \ldots$

7.7 Side View of the Integrated Propulsion, Levitation, and Guidance System for the Cylindrical Maglev System . . . . . . . . . . . . . . . . . . . . . 62 


\section{FIGURES (Cont'd)}

7.8 EDS Test Vehicle, Option \#1: Continuous-Sheet Suspension $\ldots \ldots \ldots \ldots 64$

7.9 EDS Test Vehicle, Option \#2: Loop-Shaped Coil Suspension $\ldots \ldots \ldots \ldots$. . . 64

7.10 EDS Test Vehicle, Option \#3: Null-Flux Figure-Eight-Shaped

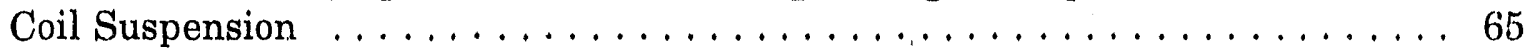

7.11 Normalized Force and Power for EDS Test Options as a Function of Speed ... 65

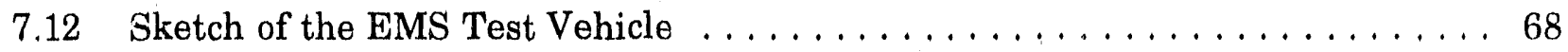

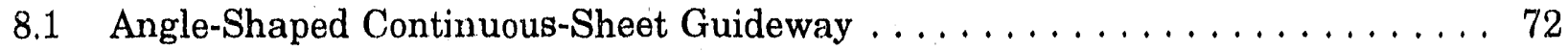

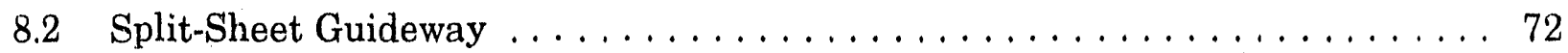

8.3 Variation in $\mathrm{dM} / \mathrm{dz}$ per Turn as a Function of Levitation Height, with Magnet Length as a Parameter . . . . . . . . . . . . . . . . 73

8.4 Magnetic Lift and Drag Forces Calculated by Using the Analytical Model and the Numerical Model $\ldots \ldots \ldots \ldots \ldots \ldots \ldots \ldots \ldots$

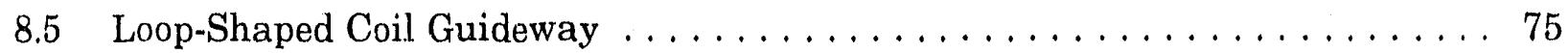

$8.6 \quad$ Figure-Eight-Shaped Coil Guideway $\ldots \ldots \ldots \ldots \ldots \ldots \ldots \ldots \ldots \ldots$

8.7 Lift, Drag, and Guidance Forces vs. Vertical Displacement . . . . . . . . . 80

8.8 Lift, Drag, and Horizontal Guidance Forces vs. Vehicle Speed . . . . . . . . . . 80

8.9 Force Pulsations in Null-Flux Coil Suspension System $\ldots \ldots \ldots \ldots \ldots$

9.1 Required Electrical Power per Motor Section as a Function of Vehicle Speed $\ldots \ldots \ldots \ldots \ldots \ldots \ldots \ldots \ldots \ldots \ldots \ldots \ldots \ldots$

9.2 Required Electrical Power per Motor Section as a Function of Guideway Length ............................ 84

9.3 Sketch of Power Supply and Distribution System for Maglev Test Facility . . . . . . . . . . . . . . . . . . . . . . . . . . . 85

10.1 Acceleration on Vehicle and Guideway $\ldots \ldots \ldots \ldots \ldots \ldots \ldots \ldots$

10.2 Vehicle/Guideway Dynamic Interactions $\ldots \ldots \ldots \ldots \ldots \ldots \ldots \ldots$

10.3 Two Possible Guideway Cross Sections $\ldots \ldots \ldots \ldots \ldots \ldots \ldots \ldots \ldots$

10.4 Detailed Guideway Cross Section $\ldots \ldots \ldots \ldots \ldots \ldots \ldots \ldots \ldots \ldots \ldots$ 


\section{FIGURES (Cont'd)}

10.5 Parapet Wall Details . . . . . . . . . . . . . . . . . . . . . . . . 102

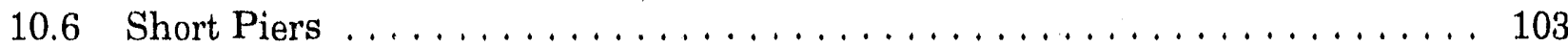

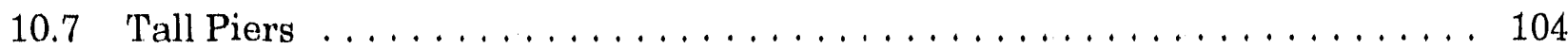

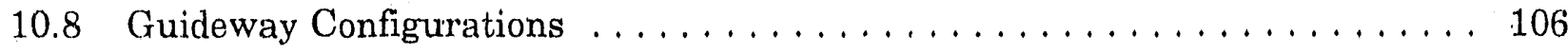

10.9 Location for Strain Gauges $\ldots \ldots \ldots \ldots \ldots \ldots \ldots \ldots \ldots \ldots \ldots \ldots \ldots$

11.1 Organization of Control Systems $\ldots \ldots \ldots \ldots \ldots \ldots \ldots \ldots \ldots \ldots \ldots$

11.2 Adaptive and Conventional Speed-Control Schemes $\ldots \ldots \ldots \ldots \ldots \ldots$

11.3 Block Diagram of TR-06 Drive-Control System $\ldots \ldots \ldots \ldots \ldots \ldots \ldots \ldots$

11.4 Block Diagram of MLU-001 Drive-Control System $\ldots \ldots \ldots \ldots \ldots \ldots \ldots 119$

11.5 Test Facility Propulsion-Control System $\ldots \ldots \ldots \ldots \ldots \ldots \ldots \ldots \ldots$

11.6 Adaptive Speed-Control System . . . . . . . . . . . . . . . . . . . . 122

11.7 Diagram of the Phase Synchronization Controller . . . . . . . . . . . . . 122

11.8 Diagram of the Speed Pattern Generator . . . . . . . . . . . . . . . . . . 123

11.9 Motor-Section Changeover Process . . . . . . . . . . . . . . . . . . . . . . . 124

11.10 Test Facility Wayside Protection Control System . . . . . . . . . . . . . 127

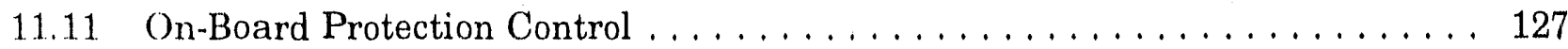

11.12 Fault-Tolerant Configuration $\ldots \ldots \ldots \ldots \ldots \ldots \ldots \ldots \ldots \ldots \ldots$

11.13 Simplified Model of Vehicle with Dashpot . . . . . . . . . . . . . . . . . 133

11.14 Power Spectral Density of Vertical Accelerations Experienced by Vehicle . . . . . . . . . . . . . . . . . . . . . . . . . . . . . . 134

11.15a Response due to a Guideway Step, A . . . . . . . . . . . . . . . 135

11.15h Response due to a Guideway Step, B . . . . . . . . . . . . . . . . 135

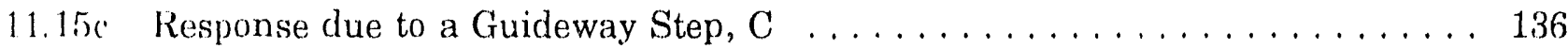

$11.15 d$ Response due to a Guideway Step, D . . . . . . . . . . . . . . . 136 


\section{FIGURES (Cont'd̉)}

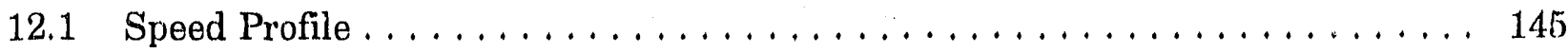

12.2 Artist's View of the Maglev Facility $\ldots \ldots \ldots \ldots \ldots \ldots \ldots \ldots \ldots \ldots$

12.3 Size Requirements for the Experimental Test Facility with

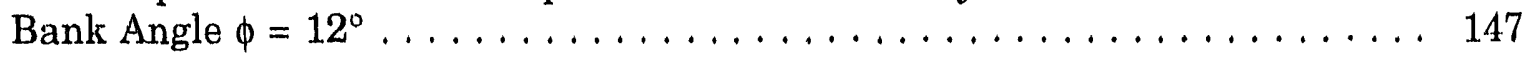

12.4 Size Requirements for the Experimental Test Facility with

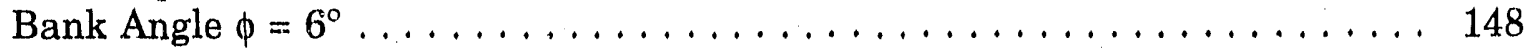

12.5 Cutaway View of Maglev Vehicle Maintenance Garage . . . . . . . . . . . . 149

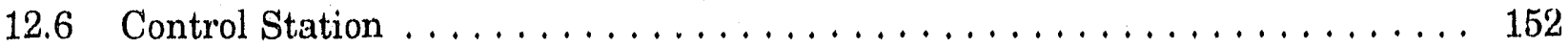

12.7 Organization Chart - Conceptual $\ldots \ldots \ldots \ldots \ldots \ldots \ldots \ldots \ldots \ldots \ldots$

13.1 Block Diagram of Program ANLMAGLEV . . . . . . . . . . . . . . . . 161

13.2 Block Diagram of Subroutine MAGF $\ldots \ldots \ldots \ldots \ldots \ldots \ldots \ldots \ldots \ldots$

13.3 Curved Guideway $\ldots \ldots \ldots \ldots \ldots \ldots \ldots \ldots \ldots \ldots \ldots \ldots \ldots \ldots \ldots$

13.4 Heave Motion with Hilly Guideway $\ldots \ldots \ldots \ldots \ldots \ldots \ldots \ldots \ldots \ldots$

13.5 Slip Motion with Curved Guideway $\ldots \ldots \ldots \ldots \ldots \ldots \ldots \ldots \ldots \ldots$

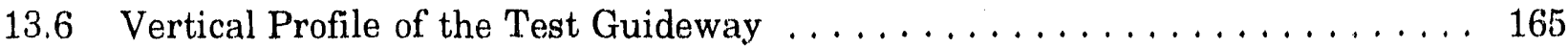

13.7 Simulated Vertical Acceleration of the Center of Mass $\ldots \ldots \ldots \ldots \ldots \ldots$

13.8 Simulated and Measured Heave Motion . . . . . . . . . . . . . . . . . . . 167

\section{TABLES}

2.1 Main Features of Transrapid TR-07 Maglev System $\ldots \ldots \ldots \ldots \ldots \ldots \ldots$

2.2 Main Features of Railway Technical Research Institute Maglev System MLU $-002 \ldots \ldots \ldots \ldots \ldots \ldots \ldots \ldots \ldots \ldots \ldots, \ldots \ldots$

4.1 Test Matrix: Progression of Test Facilities from Laboratory Scale

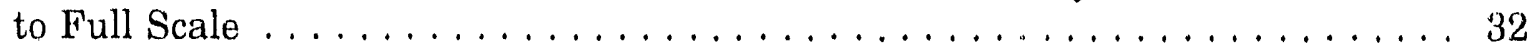

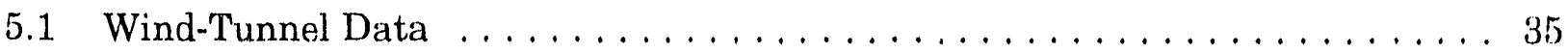

6.1 Major Vehicle Dimensions $\ldots \ldots \ldots \ldots \ldots \ldots \ldots \ldots \ldots \ldots \ldots \ldots \ldots$ 


\section{TABLES (Cont'd)}

6.2 Specifications for a Typical Battery $\ldots \ldots \ldots \ldots \ldots \ldots \ldots \ldots \ldots \ldots \ldots$

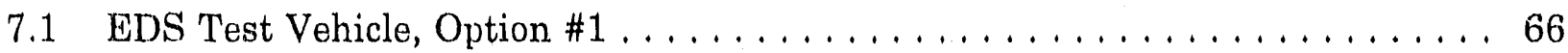

7.2 EDS Test Vehicle, Option \#2 $\ldots \ldots \ldots \ldots \ldots \ldots \ldots \ldots \ldots \ldots \ldots \ldots \ldots$

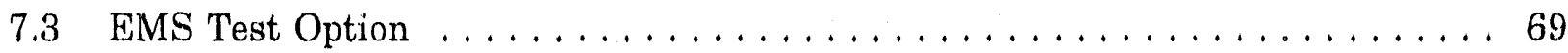

8.1 Null-Flux Suspension Test Option $\ldots \ldots \ldots \ldots \ldots \ldots \ldots \ldots \ldots$

9.1 Summary of the Power Supply and Distribution System Specifications . . . . . 86

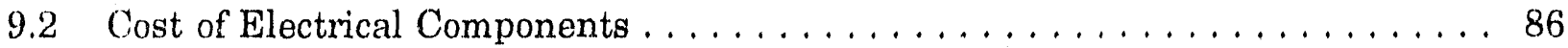

10.1 Guideway Materials and Properties $\ldots \ldots \ldots \ldots \ldots \ldots \ldots \ldots \ldots$

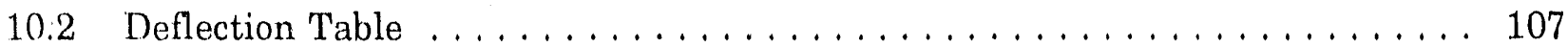

10.3 Stresses and Creep at Various Locations . . . . . . . . . . . . . . . . . . . . 108

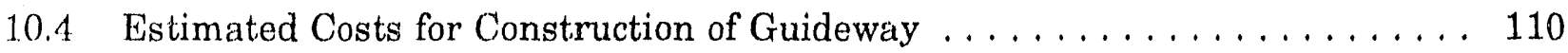

11.1 Specifications of the Linear Synchronous Motor $\ldots \ldots \ldots \ldots \ldots \ldots \ldots$

11.2 Specifications of the Propulsion-Control System $\ldots \ldots \ldots \ldots \ldots \ldots \ldots \ldots$

11.3 Options for Controlling Forces in the Electrodynamic System . . . . . . . . . 131

12.1 Specifications for Maintenance Garage $\ldots \ldots \ldots \ldots \ldots \ldots \ldots \ldots \ldots$

12.2 Electrical Power Supply Station Costs $\ldots \ldots \ldots \ldots \ldots \ldots \ldots \ldots$

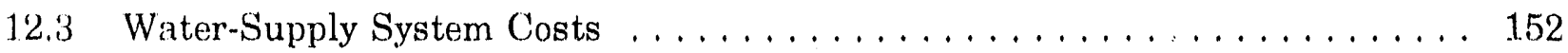

12.4 Cost Estimate for Infrastructure Demolition . . . . . . . . . . . . . . . . 156 


\section{ACKNOWLEDGMENTS}

The maglev (magnetic-levitation) development facility described in this report would be used by industrial and governmental organizations in evaluating maglev concepts prior to the design and construction of full-scale systems. To ensure that the facility is sufficiently versatile to evaluate most, or all, of the expected concepts, we proposed to develop the design in workshops with industrial, governmental, and academic participants. During a two-day workshop held at Argonne Natiunal Laboratory in November 1990, the expected characteristics of operational maglev systems were broadly defined. The authors benefited greatly from the contributions of the workshop's 40 participants and gratefully acknowledge their help. A list of those who contributed their time to this effort is given in the appendix.

To further assure a broad perspective, a Technical Advisory Committee was established to guide the technical design of the program. The authors are grateful to the following people whc agreed to serve on the committee:

$\begin{array}{ll}\text { David Gross } & \text { Illinois Governor's Science Advisory Committee } \\ \text { Gary McAllister } & \text { Bechtel National, Inc. } \\ \text { Glenn Salpaka } & \text { Electromotive Division, General Motors } \\ \text { Richard Gran } & \text { Grumman Aerospace Corporation } \\ \text { William Roper } & \text { U.S. Army Corps of Engineers } \\ \text { Merrill Travis } & \text { Illinois Department of Transportation } \\ \text { Robert Bauer } & \text { Illinois State Geological Survey } \\ \text { Dominick J. Cratto } & \text { Knight Architects, Engineers, Planners } \\ \text { Anthony Eastham } & \text { Queen's University, Ontario } \\ \text { Patrick J. Sutton } & \text { U.S. Department of Energy } \\ \text { Ronald Odegaard } & \text { Commonwealth Edison Company } \\ \text { Robert Klein-Schroder } & \text { Lockheed Missiles and Space Company }\end{array}$

The committee members or their alternates (with the exception of Anthony Eastham, who was unavailable at the time) met at the outset of the program, and informal discussions continued with many of the members throughout the course of the facility design effort. Their advice provided a valuable focus on the technical requirements of the facility. 
Early in the program, a solicitation for proposals issued by the National Maglev Initiative had the effect of placing potential participants in the design workshops and some members of the Technical Advisory Committee in competition, invalidating the workshop concept and making it necessary that the design be performed by Argonne National Laboratory and noncompeting consultants. This circumstance limited our utilization of the expertise that had so generously been offered.

Following completion of the design, a draft of this report was submitted to external reviewers. We have attempted to incorporate their numerous suggestions in thic report. Conflicting views among reviewers sometimes prevented us from incorporating all their comment $\approx$ as they were stated, so the report does not necessarily reflect the opinion of any individual reviewer. We are very grateful for the efforts of the following primary reviewers for detailed reviews and comments: Richard Gran, Robert Klein-Schroder, Stephen Kuznetsov (Power Silicon and Monolithic Technologies, Inc.), Gary McAllister, Ronald Odegaard, William Roper, Glenn Salpaka, Jack Stauffer (Transportation Test Center), and Patrick Sutton. In some cases, these primary reviewers passed the draft report to additional persons in their organizations for review. For their efforts in this regard, we thank John Loyd, Richard Armstrong, James Ballard, James Lever, William Croisant, Rick Suever, and Vincent Charito (U.S. Army Corps of Engineers); Michael Proise (Grumman Aerospace Corporation); Joseph Perkowski and Jane Blanchard (Bechtel National, Inc.); and unidentified reviewers at Commonwealth Edison Company. Any errors or omissions are the responsibility of the authors.

The authors have benefited from many discussions with Larry Johnson, Director of the Center for Transportation Research at Argonne National Laboratory, and with Norman Sather, Director of Argonne's Energy Systems Division; we thank them for their support and encouragemont throughout this program. Finally, the continued interest of David Gross (Governor's Science Advisory Committee), David Baker (Illinois Coaliticn), and John Straus, Jr. (Illinois Department of Commerce and Community Development), is gratefully acknowledged. 
AASHTO

$\mathrm{AC}$

$\mathrm{ACI}$

ANL

CR

DACA

DAS

DC

DOE

DOT

DSP

EDS

EMS

FRA

FY

GTO

HST

HVAC

ISO

$\mathrm{I} / \mathrm{O}$

JNR

KM

LIM

LSM

maglev

MBB

MPFL

MTBF

MUX

NASA

NMI

OSHA

PSC

PSD

RTRI

SCM

SCR

$\mathrm{S} \& \mathrm{H}$

SRI

SW

TACRV

TR

TVE

UTACV

VVVF
American Association of State Highway and Transportation Officials alternating current

American Concrete Institute

Argonne National Laboratory

switch controller

data acquisition and control adapter

data-acquisition system

direct current

U.S. Department of Energy

U.S. Department of Transportation

digital signal processor

electrodynamic suspension

electromagnetic suspension

Federal Railroad Administration

fiscal year

gate turn-off

high-speed train

heating, ventilating, and air-conditioning

International Standards Organization

input-output

Japanese National Railroads

Krauss-Maffei

linear induction motor

linear synchronous motor

magnetic levitation

Messerschmitt-Boelkow-Blohm

maximum possible fire loss

mean times between failures

multiplexer

National Aeronautics and Space Administration

National Maglev Initiative

Occupational Safety and Health Administration

phase synchronization controller

power spectral density

Railway Technical Research Institute

superconducting magnet

silicon-controlled rectifier

safety and health

Stanford Research Institute

switch gear

tracked air-cushion research vehicle

Transrapid

test vehicle site, Emsland, Germany

urban tracked air-cushion vehicle

variable voltage, variable frequency 


\title{
PRELIMINARY DESIGN FOR A MAGLEV DEVELOPMENT FACILITY
}

\author{
by
}

\author{
H.T. Coffey, J.L. He, S.L. Chang, J.X. Bouillard, \\ S.S. Chen, Y. Cai, L.O. Hoppie, S.A. Lottes, \\ D.M. Rote, Z.Y. Zhang, G. Myers,
}

A. Cvercko, and J.R. Williams

\begin{abstract}
A preliminary design was made of a national user facility for evaluating magnetic-levitation (maglev) technologies in sizes intermediate between laboratory experiments and full-scale systems. A technical advisory committee was established and a conference was held to obtain advice on the potential requirements of operational systems and how the facility might best be configured to test these requirements. The effort included studies of multiple concepts for levitating, guiding, and propelling maglev vehicles, as well as the controls, communications, and dataacquisition and -reduction equipment that would be required in operating the facility. Preliminary designs for versatile, dual 2-MVA power supplies capable of powering attractive or repulsive systems were developed. Facility site requirements were identified. Test vehicles would be about $7.4 \mathrm{~m}$ (25 ft) long, would weigh from 3 to 7 metric tons, and would operate at speeds up to $67 \mathrm{~m} / \mathrm{s}(150 \mathrm{mph})$ on a $3.3-\mathrm{km}(2.05-\mathrm{mi})$ elevated guideway. The facility would utilize modular vehicles and guideways, permitting the substitution of levitation, propulsion, and guideway components of different designs and materials for evaluation. The vehicle would provide a test cell in which individual suspension or propulsion compone is or subsystems could be tested under realistic conditions. The system would allow economical evaluation of integrated systems under varying weather conditions and in realistic geometries.
\end{abstract}

\section{INTRODUCTION}

The objective of the Illinois magnetic-levitation (maglev) program was to design and establish a national user facility for the development of high-speed maglev technologies for the ground transportation of passengers and time-sensitive freight. The facility must be versatile enough that many different maglev concepts can be evaluated, if the construction of multiple developmental facilities at different sites is to be avoided. This report describes the design study undertaken to assess the characteristics such a facility might have. Actual 
construction of the facility depends on the acceptance of the concept by the National Maglev Initiative, the Administration, and the Congress.

Maglev development began more than two decades ago in the United States, Germany, Japan, Canada, and England. By 1974, Ford Motor Company was developing a 300 -mph test sled for the evaluation of one maglev technology. In 1975, however, recognizing the capabilities of the (then) new wide-body jet aircraft and facing conflicting demands for federal funding to improve the railway system, the United States government withdrew funding for these studies. Efforts continued in Japan and Germany.

Today, Germany is in the final stages of evaluating the safety of one type of maglev system, a $13.5 \mathrm{-mi}(21.6 \mathrm{-km})$ demonstration of which will be operational in Orlando, Florida, by 1994. Japan is testing another type of system and expects to demonstrate it in Sapporo, Japan, around the same time. Each country has invested over $\$ 1$ billion in its respective technology. Although these systems are in the advanced deve opment stage, other means of magnetic levitation that have not yet been fully investigated are possible. The first system to be installed will have a significant advantage in terms of winning public support, so it is important that alternative systems be evaluated and the best sysiem be installed from the outset.

The stakes are bigh. A $\$ 5.2$-billion bid has been submitted to install a Germandeveloped system between. Las Vegas, Nevada, and Anaheim, California, at a cost of more than $\$ 19$ million per mile. Assuming a 2,000-mi $(3,200-\mathrm{km})$ network of maglev lines in the United States, the cost would be approximately $\$ 38$ billion if this technology were used. A 20,000-mi network throughout the United States is conceivable, at a cost of $\$ 380$ billion, in the 21st century. The export market, will also be significant. The Congress has taken note of these developments, and several maglev-related bills have been introduced. Twelve million dollars was appropriated for maglev studies in fiscal year (FY) 1991, and the budget for this purpose was approximately doubled in FY 1992. The Administration listed maglev in its FY 1991 budget as one of the top 10 projects "enhancing research and development."

A National Maglev Initiative (NMI), led by the Federal Railroad Administration and codirected by thr U.S. Department of Energy (DOE) and the U.S. Army Corps of Engineers ( $\mathrm{COE}$ ), has been formed to assess maglev technologies and recommend a course of action for the United States. The following options have been identified:

1. Install the German system,

2. Modify and codevelop either the German or Japanese system, or

3. Develop a new system.

Exercising the third option would require that new technologies for magnetic levitation be conceived and analyzed. A major part of this effort would be the development of analytical or computer models to predict the performance of new systems. These models must be validated by comparing their predictions with experimental data. It is desirable to 
obtain these data from experiments with small, economical systems before committing to the construction and testing of full-scale prototypes. Although the experimental systems must be capable of testing the appropriate analytical predictions, it is not necessary that the tests be performed on scrile models of operational systems. These verifications will be unusually important in the development of passenger-carrying maglev systems. Ultimately, it will be necessary to evaluate full-scale prototype systems to ensure the manufacturability, reliability, operation, safety, and economy of maglev systems in revenue service.

Laboratory facilities for the proof-of-concept efforts can be constructed relatively quickly, but facilities for the development of larger, more advanced systems require considerable advance planning. In this program, we sought to identify the requirements for operational systems and use that information to identify the requirements for a development facility. From this exercise, we have developed the preliminary design of an intermediate-size development facility. The facility could be used not only to develop new maglev systems for the United States, if that option is chosen, but also to continue evolutionary development of maglev systems based on foreign designs, if one of these is selected. A modular component approach was taken in designing the facility, allowing users to replace entire sections of the guileway and the complete suspension and propulsion systems (or any of their component, parts) on the vehicle for experimentation with alternative concepts.

It is intended that this design be reviewed by industrial participants in the development of magnetic-levitation systems and that their suggestions for modifying it be incorporated to make the facility as universally useful as possible. Industrial collaboration in this design through a series of workshops was planned for this program, but a request for proposals for maglev system concept definitions, issued by the National Maglev Initiative during the time planned for the workshops, precluded industrial participation.

This study began with a review of existing and proposed systems, followed by a twoday conference with industrial and governmental personnel who defined, broadly, the characteristics expected of operational maglev systems. Subsequently, considerable effort was devoted to reviewing maglev technologies. These studies and the output of the conference were used to define the range of parameters the experimental facility would be called upon to) uvaluate.

Parallel with these efforts, the development of a computer program was begun to assess the dynamic motions of vehicles levitated and propelled with any form of magnetic suspension and propulsion over guideways having arbitrary perturbations, surface roughnesses, flexibilities, and curvatures.

\subsection{SYSTEM DESCRIPTION}

The development facility would require a triangular-shaped site $2.2 \mathrm{mi}(3.5 \mathrm{~km})$ long and $1.2 \mathrm{mi}(1.9 \mathrm{~km})$ wide. Other uses of parts of the site could be permitted, reducing the repuirements for land acquisition. The facility would include elevated test guideways; one (1) more fully instrumented test vehicles; data-acquisition, transmission, and reduction 
facilities; power and power-conditioning equipment; operational controls; a control and office building; and a maintenance garage. 'The location of the site is currently unspecified, but it would have to be located in a region with varied climatic conditions to test the all-wenther operational capabilities of items or systems under development.

The main guideway would be $2.05 \mathrm{mi}(3.3 \mathrm{~km})$ long, straight, and level; provisions would be made for the addition of a curved, banked, and graded guideway with fixed or functional switches, as required by the users. The main guideway is designed in three sections, the first and last of which would be used for accelerating and stopping the vehicle. These sections would be constructed of reinforced concrete piers and spans, with modular attachments for testing different maglev systems. The basic guideway would be a two-meterwide, pier-supported, flat concrete structure onto which sidewalls or other structures and a variety of propulsion systems could be mounted. Most experiments would be performed on the central $1-\mathrm{km}(0.6-\mathrm{mi})$ portion of the guideway, which is designed to be altered to meet the requirements of specific tests. This section (an be modified and instrumented in any way the user desires for evaluating the performance of the guideway while interacting with passing vehicles. Alternative structures or materials of construction would be evaluated in this section. To facilitate the rapid evaluation of different concepts, it has been suggested that two parallel guideways be constructed, one being modified for testing while the second is in experimental use. This approach would permit the basic site, power, power-conditioning, control, instrumentation, and data-acquisition, -transmission, and -reduction equipment to be used for both guideways, at a 15 to $20 \%$ increase in cost, and would more fully utilize the overall facility.

The proposed vehicle is designed to be a test bed for different maglev susponsion, guidance, and propulsion technologies. The vehicle comprises two parts. The uppor part has an aerodynamically shaped body with a flat chassis on which batteries, power-conditioning equipment, diagnostic and operational instrumentation, and controls and communications equipment would be mounted. The bottom part is designed to permit installation and removal of any magnetic levitation, guidance, or propulsion systems the user might wish to evaluate. Since wheels must be provided for electrodynamic levitation systems, the vehicle can be used for routine transportation of equipment on the guideway by using these wheels when no maglev system is installed. A test cell, or bay, is also provided in the vehicle for evaluating single levitation or propulsion systems, active or passive damping systems, ctc. while the vehicle is operated at realistic speeds and under realistic conditions by using either the wheels or a levitation system. Use of the test cell would permit the development of these elements while avoiding the unnecessary risks entailed in levitating the vehicle with new and untested systems. Vehicles having total levitated weights of three to seven metric tons could be tested at speeds up to $150 \mathrm{mph}(67 \mathrm{~m} / \mathrm{s})$. An artist's concept of the test vehicle and guideway is shown in Figure 1.1.

At the proposed speeds, aerodynamic forces would be small compared with those on revenue vehicles, so the dominant power requirement would be that required for accelerating the vehicle to $150 \mathrm{mph}$. Two variable-voltage, variable-frequency 2-MVA power supplies are adequate for this purpose. The two supplies would power successive blocks of the motor in 


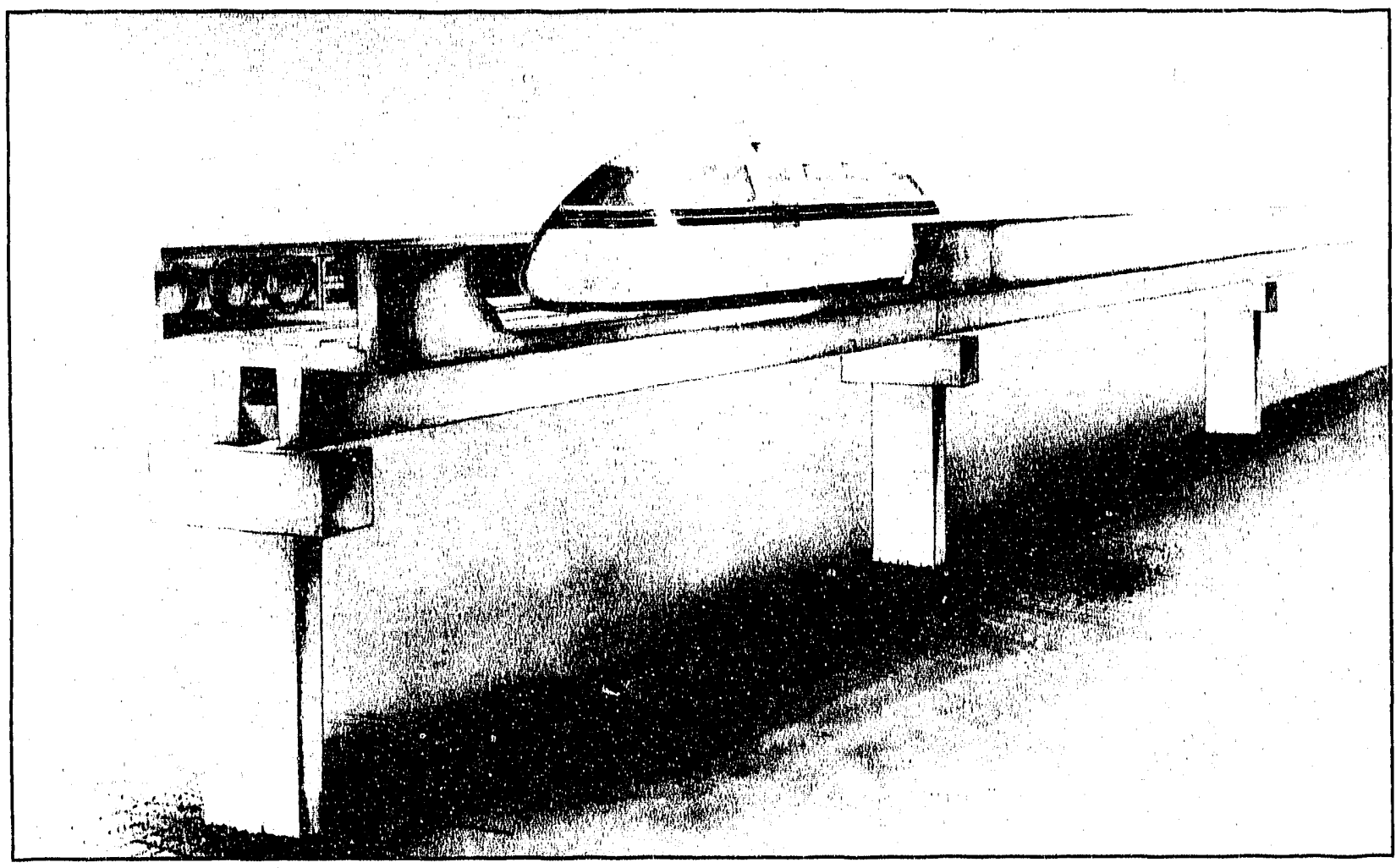

FIGURE 1.1 Partial View of the Proposed Test Guideway and Test Vehicle, Electrodynamic Suspension System with Sidewall-Mounted Coils and a Linear Synchronous Motor

the guideway, and power and phase synchronization equipment would be provided for this purpose. Since the pole pitch of linear synchronous motors used in electromagnetic suspension systems is shorter than that of those used in electrodynamic suspension systems, a higher frequency is required for the electromagnetic systems to achieve the same speed. The power supplies would provide adequate frequency ranges for either application. Controls for the power supplies will be programmable for testing of different systems or strategies. If a linear induction motor is proposed for evaluation, a catenary for high-speed power pickup can be installed beneath or above the guideway.

Communication with the vehicle is expected to be either by a telemetry system or by a "leaky coax" extending the length of the guideway. The telemetry system is more direct, but the leaky coax (or a modification of it) is useful in areas obscured from the transmitter by hills or tunuels. Since operational systems will be controlled from a central facility, continuous, reliable communications with the vehicle are critical and will likely be a subject of developmental testing. Data from the vehicle and guideway sensors would be transmitted to a central control and data-collection/processing facility. Moderate data-processing facilities, such as personal microcomputers and a workstation minicomputer, would be installed in the control-communication building. This facility would also contain offices for on-site personnel. 
A maintenance garage would be provided for maintaining the vehicles, installing and removing test items, and storing equipment and supplies.

\subsection{OPERATION AND USES}

The facility would be operated as a national user facility, available to all U.S. governmental, industrial, and academic developers of maglev systems. Use of the facility in the "public interest" would be permitted at no cost. Developers evaluating proprietary systems would be charged the full-recovery cost of operating the facility. Use of the facility would be scheduled by a users' committee established for this purpose by the agencies funding the design, construction, and operation of the facility.

Devices or systems brought to the facility for evaluation would have undergone preliminary evaluation by the developers of the equipment, who would provide a schedule of experiments in advance. Such preparations should assist in detecting variations from expected performance and should expedite testing after the experiments begin. Routine modifications of the equipment for developmental purposes would be made as part of the ordinary operation and testing plan. If excessive delays were incurred, a second test vehicle might be required, although much of the same diagnostic and communication equipment might be transferable. The levitation systems could also be removed from the test vehicle and the wheels installed for testing individual components or subsystems by other developers while awaiting modification of the primary test item. Modifications of the vehicle for different maglev configurations should require no more than one to three weeks. Removal and replacement of parts of the modular guideway should proceed quite rapidly with the use of one or more cranes, with extra shifts being used if required to perform these tasks expeditiously. Linear motors are expected to be constructed in modular form for installation and removal from the guideway. This might be the most time-consuming task in a reconfiguration effort, depending on the complexity of the motor and the sensors required to operate it. Overall, reconfiguration of the facility for testing a different maglev configuration should be accomplished in about four to six weeks.

At the highest speeds, the vehicle would transit the entire guideway in less than $1.5 \mathrm{~min}$. Returning the vehicle to the starting point (on its wheels or levitated) should require no more than $10 \mathrm{~min}$. Consequently, data output from the facility will occur at a very high rate. A given developer should be able to complete a detailed series of tests in 8 to 10 weeks. 


\section{BACKGROUND}

The development of magnetically levitated vehicles has proceeded along two paths, one using attractive magnetic forces and the other using repulsive forces. These approaches are commonly referred to as the electromagnetic suspension (EMS) and the electrodynamic suspension (EDS) systems, respectively. The basic principles of levitating and guiding vohicles by using both technologies have been recognized for decades, but the absence of the requisite technologies precluded their practical application until about 25 years ago. The EMS (attractive) system, which requires rapid control of substantial amounts of power, had to await the development of high-power solid-state devices capable of controlling this power. Permanent magnets can be used in EDS (repulsive) systems to levitate vehicles, but the levitation height is quite small. Therefore, most stuaies have concentrated on EDS systems that rely on very-high-current-density magnets carried aboard the vehicles - current densities that can only be supplied by supersonducting magnets.

By the mid-1960s, it was recognized that then-current technologies provided the possibility of implementing these systems in practical transportation applications, and development began in several countries. In the United States, the impetus for much of this work derived from the High-Speed Ground Transportation Act of 1965, which sought to develop new methods of surface transportation to supplement the growing demand for air iravel and to revitalize the railway system (which was falling into disuse in terms of passenger travel). These developments have been reviewed elsewhere; ${ }^{1}$ they are briefly summarized here to indicate the evolutionary development of these technologies.

\subsection{IDEVLOPMENT OF ELECTRODYNAMIC SYSTEMS}

J.R. Powell and G.T. Danby (Brookhaven National Laboratory) published the seminal paper. ${ }^{2}$ on the EDS system in 1967; they also patented their concept. ${ }^{3}$ In this system, superconducting magnets carried aboard the vehicle induce currents in passive coils in the guideway as the vehicle magnets pass overhead, producing levitation and guidance forces. Powell and Danby later invented the null-flux system, which has formed the basis of Jayamese efforts in maglev development, ${ }^{4}$ and incorporated linear synchronous motors (LSMs) into their guideway.

In 1967-68, SRI International ${ }^{5}$ and Atomics International ${ }^{6}$ evaluated the feasibility of using Powell and Danby's concept for the suspension and guidance of a Mach 10 rocket slocl. Puwer being of little concern in this application, S.L. Wipf (Atomics International) proposed using continuous sheets of aluminum in place of guideway coils, a concept that was axtended to high-speed ground transportation systems by H.T. Coffey and F.M. Chilton at SKR. In 1970, SRI constructed a 175-m-long maglev guideway, on which a 4.3-m-long, (5)() $\mathrm{k}_{\mathrm{g}}$ maglev test sled using this concept was evaluated with funding from the Federal Rarilroad Administration (FRA). ${ }^{8}$ Reitz, Davis, and Borcherts of Ford Motor Company began minlev studies in 1969, and in 1971, under contract with the FRA, they analyzed and eviluated continuous-sheet maglev systems using a rotating aluminum cylinder to simulate 
a moving guideway. Their work culminated in a baseline revenue-producing vehicle design." In 1974 , they were awarded a contract to develop a $300-\mathrm{mph}(500-\mathrm{km} / \mathrm{h})$ magnotically levitated test sled; after all federal funding for maglev studies was withdrawn in 1975 , however, construction of the sled was canceled.

In 1970, H.H. Kolm and R.D. Thornton (Massachusetts Institute of Technology) conceived a novel form of maglev, in which saddle-shaped superconducting magnets wero placed along the bottom of the vehicle and levitated over a semicircular guideway containing both a continuous sheet for suspension and a three-phase meander winding coil for propulsion. ${ }^{10}$ This system, called the "MAGNEPLANE," provided levitation, guidance, and propulsion and had the unique capability of rotating about its longitudinal axis in a curve to provide coordinated turns, as in an airplane. A small-scale model was constructed and levitated to demonstrate the concept.

J.K. Dukowicz, L.O. Hoppie, and T.C. Wang (General Motors) in'vented and patented a maglev configuration called "MAGPAC" that combined levitation, propulsion, and guidance of a vehicle over a guideway consisting of metallic loops excited by direct current and individually controlled by silicon-controlled rectifiers (SCRs). ${ }^{11}$ This system, which does not require three-phase excitation, would avoid the magnetic drag force.

Several Canadian universities began studies of maglev in the early 1970s, analyzing systems using superconducting magnets with continuous sheets or null-flux configurations in conjunction with continuous sheets. The Canadian investigators also included LSMs in their designs. Atherton, Eastham, and Hayes have been prominent in these efforts.

AEG, Brown-Boveri \& Cie, and Siemens, in Germany, began similar efforts in 1972. In 1974, they levitated a 17-metric-ton, 12-m-long vehicle with four superconducting magnets on a circular guideway having a continuous aluminum sheet.

The most sustained efforts in developing the EDS system have been made in Japan. Under the leadership of Y. Kyotani and H. Tanaka, a series of test and developmental vehicles has been constructed, first under the sponsorship of Japanese National Railroads (JNR) and later with that of the Railway Technical Research Institute (RTRI). A test sled (levitated with superconducting magnets and propelled by a linear motor) and a larger vehicle called the ML-100 were first tested in 1972. The latest vehicle, the MLU-002, is $22 \mathrm{~m}$ long; weighs 17 metric tons, and carries 44 passengers. A $47-\mathrm{km}$-long test site for evaluating fullsized vehicles is now under construction.

\subsection{DEVELOPMENT OF ELEC'TROMAGNETIC SYSTEMS}

The development of electromagnetic suspension systems can be traced back at least to 1969, when Krauss-Maffei (KM) and Messerschmitt-Boelkow-Blohm (MBB) began development of two systems, MBB's using separate levitation and guidance magnets and KM's using a combined levitation/guidance system. Krauss-Maffei's first test sled, including a single-sided, short-stator, iron-cored linear induction motor (LIM), was levitated in 1969. 
This was followed in 1971 by a 10.7 -metric-ton vehicle with eight seats, propelled by a double-sided short-stator LIM. In the same year, MBB levitated a 5.8-metric-ton vehicle by using the same iype of propulsion system. In 1974, Transrapid EMS was formed to combine these efforts in developing EMS maglev systems.

In the United States, the Rohr Corporation began developing its ROMAG system in 1970 and constructed both a top-suspended vehicle for six passenger's and a bottom-supported system for 20 passungers. Both vehicles used short-stator LIMs for propulsion. In 1978, the Boeing Company acquired the rights to the ROMAG technology and continued development of the propulsion system. Boeing's technology was licensed to Carnegie-Melion University in 1986 .

Transrapid (TR) has now developed seven test vehicles. The latest of these, a prototype revenue vehicle, is $50 \mathrm{~m}$ long, weighs 92 metric tons, and scats 198 passengors in two coupled cars. It is being developed on a $31.5 \mathrm{~km}-$ long elevated guideway in Emsland, Germany.

\subsection{STATE OF THE ART OF MAGLEV SYSTEMS}

The two most highly developed maglev systems at this time are the Transrapid EMS system in Germany and the MLU-002 EDS system in Japan. The two systems differ radically, but both are, or will be, capable of transporting passengers at speeds of $500 \mathrm{~km} / \mathrm{h}$ $(300 \mathrm{mph})$.

The Transrapid system is levitated, guided, and propelled by magnetic fields generated in iron-cored magnets and LSMs, as shown in Figures 2.1 and 2.2. The main features of the system are summarized in Table 2.1. The levitation magnets, arranged al'ung the length of the vahicle, lift it toward the iron (steel) in the long-stator armature windings. In order to achieve good ride quality and to minimize dynamic energy losses, each magnet is mounted to a bogie with a spring-shock absorber. The cabin is supported on the bogies by pnoumatic springs and shock absorbers. The control of the system is fully automated.

With constant currents in the levitation magnets, the velicle is unstable; either the manots are attracted to the steel guideway and clamp onto it, or else they fall away from the guideway. Stabilization is achieved by continuously monitoring the distance between the unideway and the magnets and decreasing or increasing the currents in them as the vehicle moves toward or away from the guideway. The power for these magnets is supplied by an on-board bank of batteries and by a linear generator, which picks up power from the guideway while in transit. In the event of a failure of the stabilizing system, the vehicle descends onto the slide rail (shown in Figure 2.1) and skids to a stop. The guidance system is analogous to the levitation system and maintains the vehicle in a central position.

Propulsion and primary braking are achieved by means of an LSM installed in the guilleway. The three-phase armature (stator) windings of this motor, comprising laminated iron cures with slots for the electrical windings, generate a traveling magnetic wave along the 


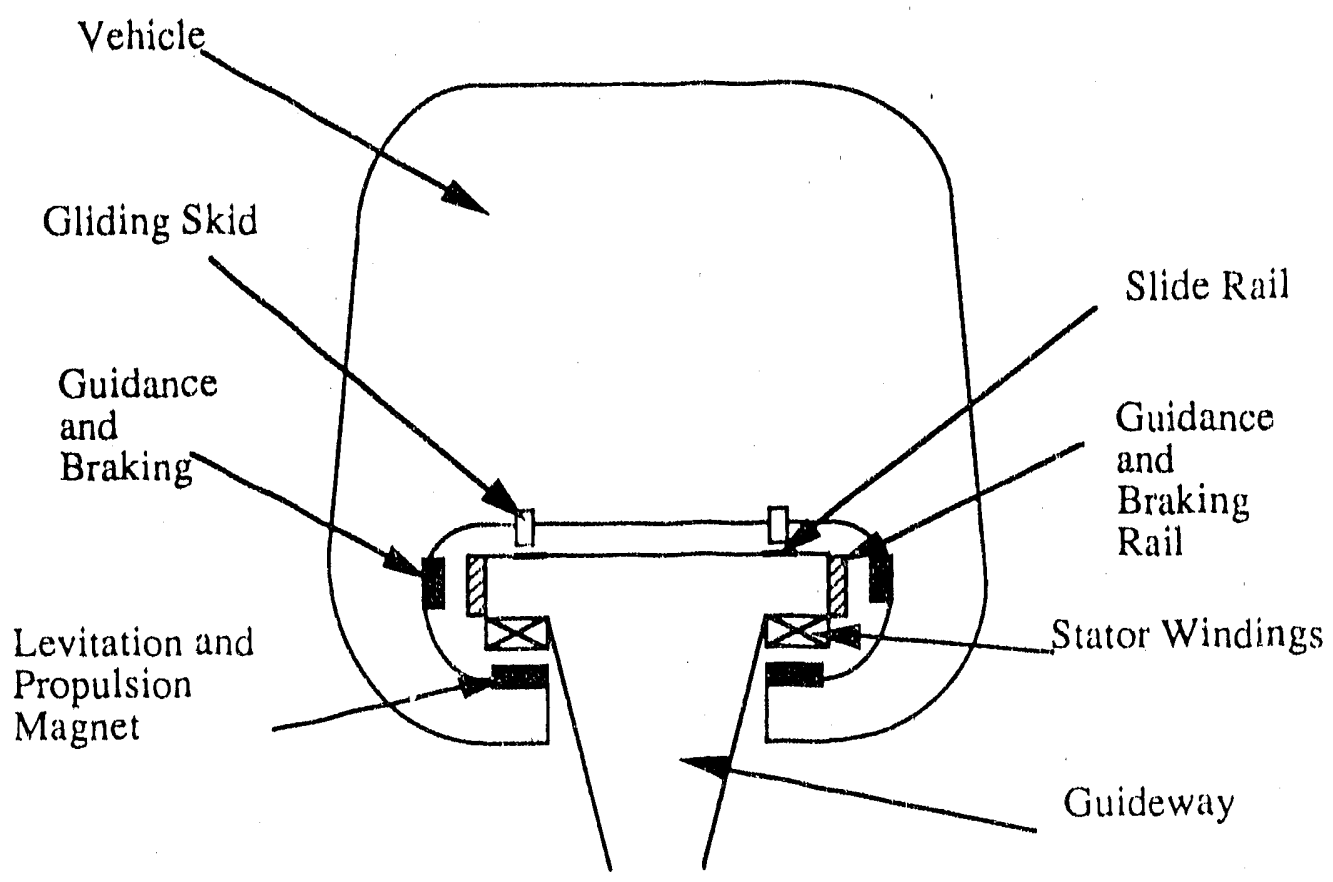

FIGURE 2.1 Cross-Sectional View, German Transrapid Maglev System
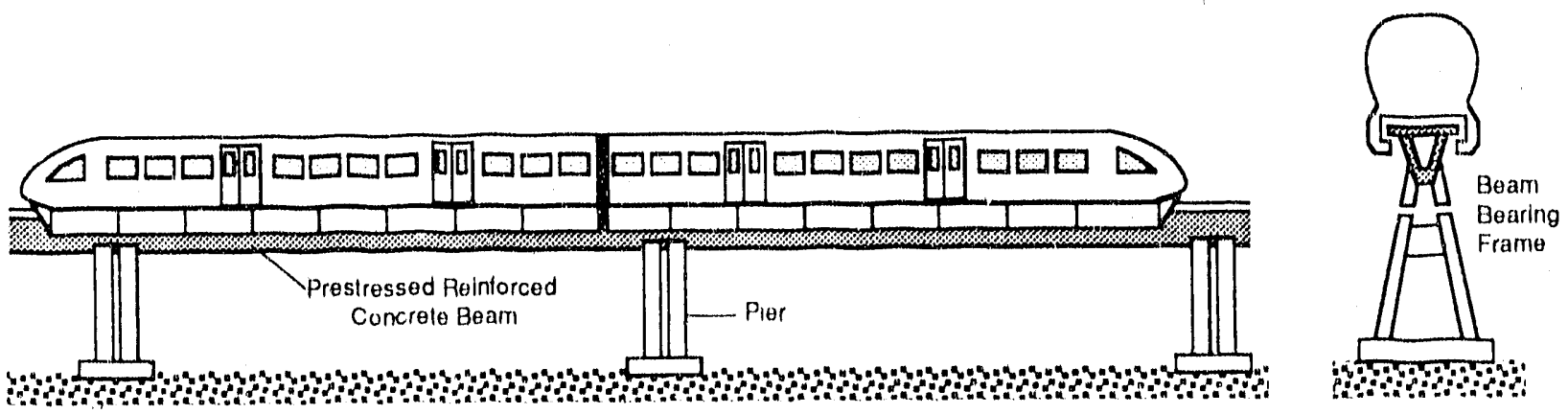

FIGURE 2.2 Side View, German Transrapid Maglev System

length of the guideway. This wave interacts with the vehicle-mounted magnets to propel or brake the vehicle synchronously with the moving magnetic wave. Secondary braking is achieved by means of eddy currents induced in the guidance rail of the guideway. The power for the motor is supplied by a variable-voltage, variable-frequency (VVVF), pulse-widthmodulated power supply at the side of the guideway. To increase the power utilization and efficiency of the system, the long-stator armature windings on the guideway are divided into separate motor sections that vary in length from 300 to $2,000 \mathrm{~m}$.

Since the magnetic field in the air gap between the iron poles of an electromagnetic system decreases rapidly as the gap is lengthened, the power required to maintain the magnetic fields of the on-board magnets increases rapidly as the magnets move away from 
TABLE 2.1 Main Features of Transrapid TR-07 Maglev System

\begin{tabular}{|c|c|c|}
\hline Component & Item & Value/Explanation \\
\hline \multirow[t]{8}{*}{ Vehicle } & Luength/car $(\mathrm{m})^{\mathrm{a}}$ & 25.6 \\
\hline & Width $(\mathrm{m})$ & 3.7 \\
\hline & Height (m) & 3.95 \\
\hline & $\begin{array}{l}\text { Weight/car, loaded } \\
\text { (metric tons) }\end{array}$ & 53 \\
\hline & Passengers/car & 100 \\
\hline & Design speed $(\mathrm{km} / \mathrm{h})$ & 500 \\
\hline & Acceleration $\left(g^{\prime} s^{b}\right)$ & 0.087 max., 0.060 mean (TR-06) \\
\hline & On-board power $(\mathrm{kW})^{\mathrm{c}}$ & 400 \\
\hline \multirow[t]{11}{*}{ Guideway } & Type & 5-11 m, elevated, piers and beams \\
\hline & Materials & \\
\hline & Piers & Cast-in-place crncrete \\
\hline & Beams & Prestressed concrete/steel \\
\hline & Width (m) & 2.8 \\
\hline & Bank angle, max, (degrees) & 12 \\
\hline & Radii, $500 \mathrm{~km} / \mathrm{h}$ & \\
\hline & Horizontal (m) & 6,530 \\
\hline & Vertical (km) & $+38.58,-19.29$ \\
\hline & Gradient (\%) & 10 (max.) \\
\hline & Switching & By bending steel guideway \\
\hline \multirow[t]{8}{*}{ Suspension } & Type & \\
\hline & Primary & Electromagnetic $(7 \mathrm{~Hz})$ \\
\hline & Secondary & Pneumatic $(0.8 \mathrm{~Hz})$ \\
\hline & Weight (metric tons) & 32 \\
\hline & Power (kW/metric ton) & 1.5 \\
\hline & Gap $(\mathrm{mm})$ & \\
\hline & Levitation & 8 \\
\hline & Guidance & 10 \\
\hline \multirow[t]{6}{*}{ Propulsion } & Type & Long-stator, iron-cored LSM \\
\hline & Force $(k N)$ & 100 \\
\hline & Motor length $(\mathrm{m})^{\mathrm{d}}$ & $300-2,000$ \\
\hline & Pole pitch (m) & 0.258 \\
\hline & Current/phase (A) & 1,200 \\
\hline & Voltage/phase (V) & 4,250 \\
\hline \multirow[t]{3}{*}{ Power System } & Type & Variable voltage, variable frequency \\
\hline & Converters & Gate-turnoff (GTO) thyristors \\
\hline & Frequency $(\mathrm{Hz})$ & $0-215$ \\
\hline \multicolumn{3}{|l|}{ "Two cars. } \\
\hline \multicolumn{3}{|c|}{ 1. Acceleration due to gravity, g, equals $9.8 \mathrm{~m} / \mathrm{s}^{2}\left(32 \mathrm{ft} / \mathrm{s}^{2}\right)$. } \\
\hline \multicolumn{3}{|c|}{ "Batteries and induced power from LSM. } \\
\hline 'Per block. & . & \\
\hline
\end{tabular}


the armature. For this reason, the air gap is regulated to remain within about $8-10 \mathrm{~mm}$ (0.33-0.40 in.).

The elevated guideway used at the Emsland test site (TVE) for the evaluation of this system was constructed of reinforced-concrete and steel piers and beams. The beams are typically $25 \mathrm{~m}$ long, with concrete beams as long as $37 \mathrm{~m}$ being used in special cases. The guideways are premanufactured to assure the close tolerances required to avoid contact between the electrical structures mounted on them and the vehicle magnets. The guideway is also quite stiff, so that it will not undergo flexing as the vehicle passes; such flexing could also result in contact of the vehicle magnets with the guideway structure. The maximum cant (bank angle) of the guideway was selected to be $12^{\circ}$. Switching of vehicles is accomplished by bending a 150 -m-long steel section of the guideway by using electromechanical actuators.

The EDS system in Japan uses superconducting magnets on the vehicle, which react against conventional coils in the guideway to achieve levitation, guidance, and propulsion. In early tests, the superconducting magnets were placed in a horizontal position and reacted against horizontal coils on the bottom of the guideway. The superconducting magnets were later redesigned in the MLU-002 vehicle and located vertically, reacting with horizontal coils on the guideway for levitation and vertical coils located on the sidewalls of the guideway for guidance. The guidance coils are connected in a null-flux configuration to reduce the electromagnetic drag. Linear synchronous propulsion coils are also located on the sidewalls, but since they are symmetrically located with respect to the null-flux coils, they do not interact with them (see Figures 2.3 and 2.4). The magnets are provided with passive, mechanical secondary suspensions to achieve greater ride comfort as they pass over the discrete coils in the guideway (see Chapter 8), and passive damping plates are used for additional damping and electromagnetic shielding of the magnets (see Chapter 10). The MLU-002 was tested on the test guideway at Miyazaki at $380 \mathrm{~km} / \mathrm{h}$ in December 1988. Major characteristics of the MLU-002 system are given in Table 2.2.

Currently, plans are being made to construct a 43-km-long test facility in the Yamanashi Prefecture of Japan that will become a part of a revenue-producing system operating between Tokyo and Osaka. The revenue vehicle will have superconducting magnets located on bogies with secondary suspensions at the junctions between cars in the train. This configuration will keep the magnets at a greater distance from the passengers and reduce their exposure to magnetic fields; however, it will also make it necessary to strengthen the vehicle, since the magnetic support will not be distributed along the body of the vehicle. Another significant innovation in this system is the removal of the horizontal coils from the bottom of the guideway. Levitation will be achieved by interaction with coils located on the sidewalls of the guideway. 


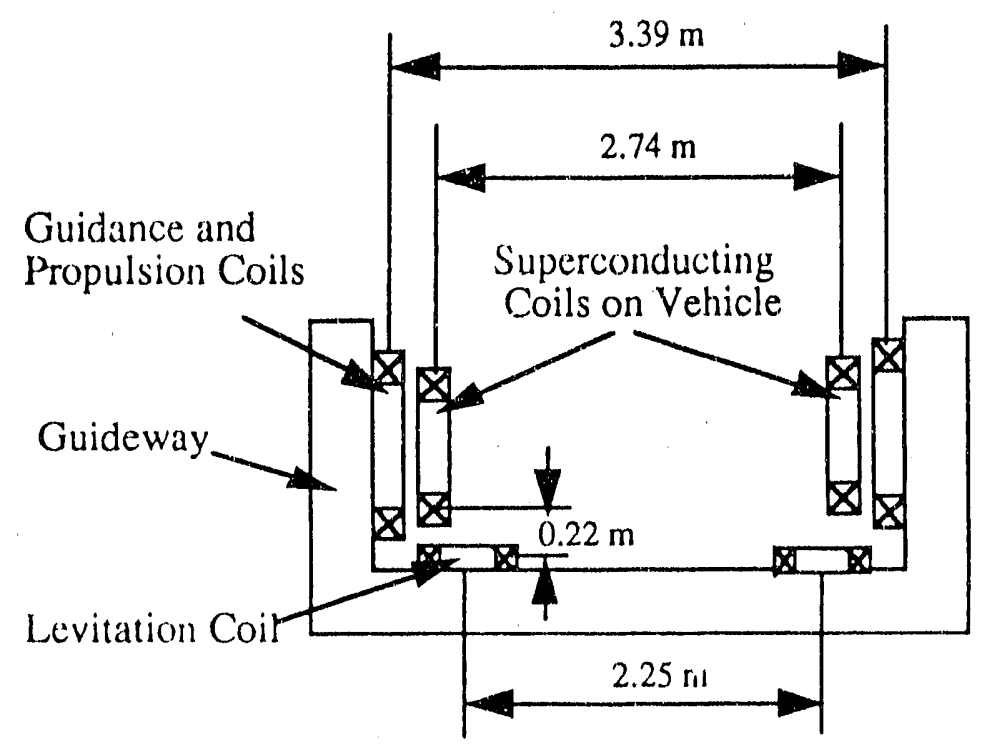

FIGURE 2.3 Cross-Sectional View, Japanese MLU-002 Maglev System

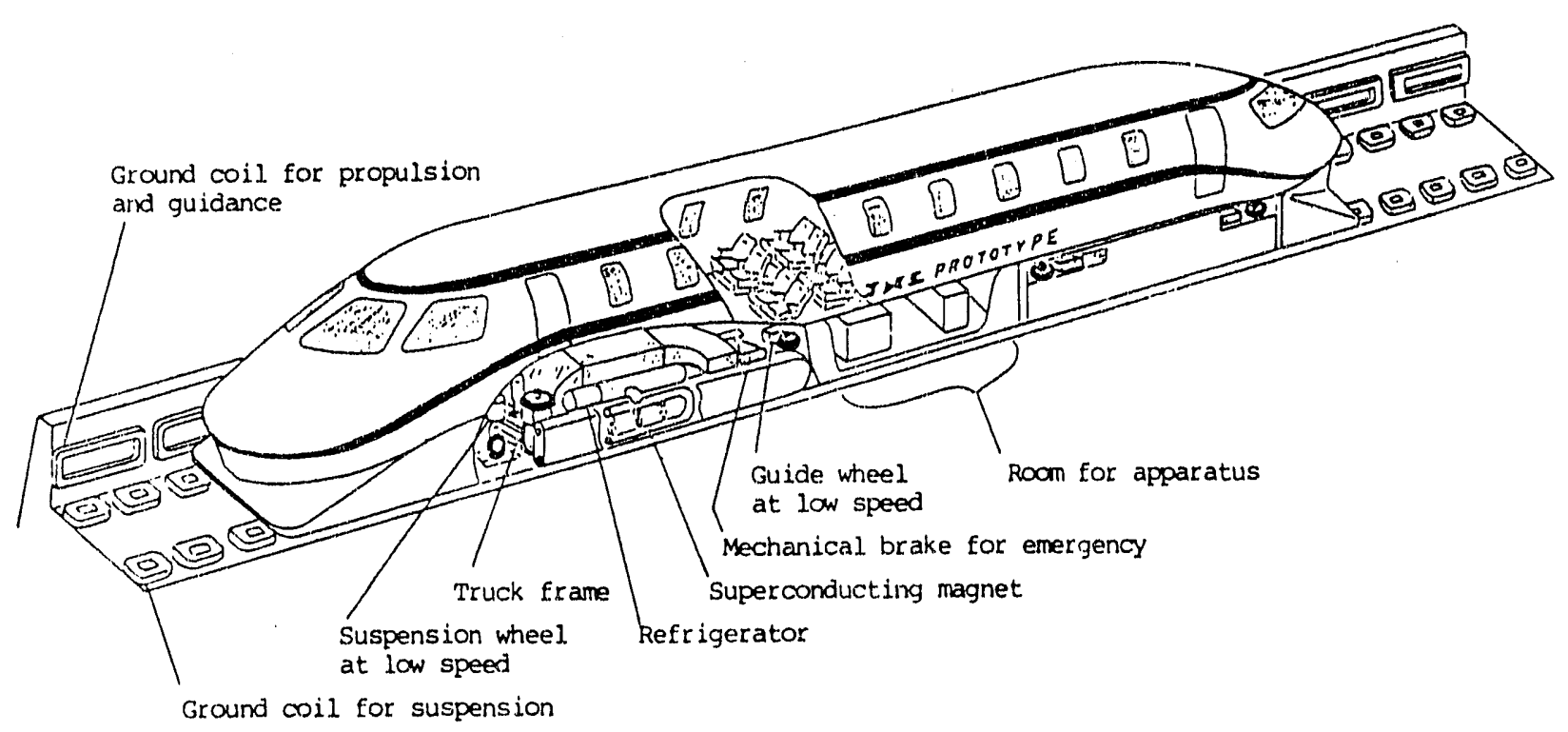

FIGURE 2.4 Cutaway View, Japanese MLU-002 Maglev System 
TABLE 2.2 Main Features of Railway Technical Research Institute Maglev System MLU-002

\begin{tabular}{|c|c|c|}
\hline Component & Item & Value/Explanation \\
\hline Vehicle & $\begin{array}{l}\text { Length }(\mathrm{m}) \\
\text { Width }(\mathrm{m}) \\
\text { Height }(\mathrm{m}) \\
\text { Weight (metric tons) } \\
\text { Passengers } \\
\text { Design speed }(\mathrm{km} / \mathrm{h}) \\
\text { On-board power }\end{array}$ & $\begin{array}{l}22 \\
3.0 \\
3.7 \\
17 \\
44 \\
500 \\
\text { Inverter, 3-phase, 200 VAC, DC/DC } \\
\text { converter, 24-V battery bank }\end{array}$ \\
\hline Guideway & $\begin{array}{l}\text { Type } \\
\text { Materials } \\
\text { Piers } \\
\text { Beams }\end{array}$ & $\begin{array}{l}\text { Elevated, piers and beams } \\
\text { Cast-in-place concrete } \\
\text { Concrete, low magnetic rebars }\end{array}$ \\
\hline Suspension & $\begin{array}{l}\text { Type } \\
\text { Primary } \\
\text { Secondary } \\
\text { Effective gap (cm) } \\
\text { Magnets } \\
\text { Ampere-turns per } \\
\text { magnet (kA turns) } \\
\text { Magnet length (m) }\end{array}$ & $\begin{array}{l}\text { Electrodynamic } \\
\text { Mechanical } \\
11 \\
3 \text { per bogie, two bogies } \\
700 \\
1.7\end{array}$ \\
\hline Guidance & $\begin{array}{l}\text { Type } \\
\text { Force }(\mathrm{kN})^{\mathrm{a}} \\
\text { Gap }(\mathrm{cm})\end{array}$ & $\begin{array}{l}\text { Null-flux } \\
83.3 \\
15\end{array}$ \\
\hline Propulsion & $\begin{array}{l}\text { Type } \\
\text { Force }(\mathrm{kN}) \\
\text { Pole pitch (m) } \\
\text { Current/phase (A) } \\
\text { Voltage/phase (V) } \\
\text { Frequency }(\mathrm{Hz})\end{array}$ & $\begin{array}{l}\text { Long-stator, air-cored LSM } \\
79.4 \\
2.1 \\
900 \\
5,800 \\
0-28\end{array}$ \\
\hline $\begin{array}{l}\text { Power } \\
\text { System }\end{array}$ & $\begin{array}{l}\text { Type } \\
\text { Converters } \\
\text { Frequency }(\mathrm{Hz})\end{array}$ & $\begin{array}{l}\text { Variable voltage, variable frequency } \\
\text { Cycloconverter, } \\
60-120 \mathrm{~Hz} \text { motor-generator } \\
0-28\end{array}$ \\
\hline Brakes & Types & Aerodynamic, electrical, mechanical \\
\hline
\end{tabular}

a 5 -cm displacement. 


\subsection{REFERENCES FOR CHAPTER 2}

1. Johnson, L.R., et al., Maglev Vehicles and Superconductor Technology: Integration of High-Speed Ground Transportation into the Air Travel System, Argonne National Liahoratory Report ANI/CNSV-67 (April 1989).

2. Powell, J.R., and G.T. Danby, High-Speed Transport by Magnetically Suspended Trains, American Society of Mechanical Engineers paper 66-RR-5, Winter Annual Meeting of ASME, New York (1966).

3. Powell, J.R., and G.T. Danby, U.S. Patent 3,470,828 (1968).

4. Powell, J.R., and G.T. Danby, Dynamically Stable Cryogenic Magnetic Suspensions for Vehicles in Very High Velocity Transport Systems, in Recent Advances in Engineering Science, Vol. 3, Gordon and Breach, New York (1968).

5. Barbee, T'R., et al., The Hypervelocity Rocket Sled - A Design Analysis, Stanford Research Institute Final Report, Project PMU-7014, Stanford, Calif. (1968).

6. Guderjahn, C.A., et al., Magnetic Suspension and Guidance for High-Speed Rockets by Superconducting Magnets, J. Applied Physics, 40:2133 (1969).

7. Colfey, H.T., and F.M. Chilton, Suspension and Guidance of Vehicles by Superconducting Magnets, J. Applied Physics, 40:2161 (1969).

8. Coffey, H.T., Magnetic Suspensions for High Speed Vehicles, Advances in Cryogenic Engrineering, 19, Plenum Press, New York (1974).

9. Philco-Ford Corporation, Conceptual Design and Analysis of the Tracked Magnetically Levitated Vehicle Technology Program (TMLV): Repulsion Scheme, Vols. 1 and 2, available from National 'Technical Information Service, PB-247-931 and PB-247-247-9312 (1975).

10. Kolm, H.H., and R.D. Thornton, The Magneplane, Guided Electromagnetic Flight, Proc. 1972 Applied Superconductivity Conf., Institute of Electronics and Electrical Engineers Pub. No. 72CH0682-5-TABSC (1972).

11. Dukowicz, J.K., L.O. Hoppie, and T.C. Wang, DC Magnetic Propulsion and Levitation System for High Speed. Vehicles, U.S. Patent 3,815,511 (1974). 


\section{APPROACH}

\subsection{INTRODUCTION}

A facility for evaluating maglev systems and components must be capable of testing the range of characteristics that operational systems might encounter. To assess the uses to which revenue-producing maglev systems will be applied, more than 40 experts in transportation and magle $v$ technologies discussed their views of the utilization of maglev systems at the two-day Illinois Maglev Conference held at Argonne National Laboratory (ANL) in November 1990. This conference built on a previous set of system specifications developed by the U.S. Army Corps of Engineers in an earlier conference at ANL. A summary of the discussions from the Illinois Maglev Conference is given in the appendix. Some of the implications of the discussions (and other information available in the literature) related to operational systems are presented here. In Section 3.2, the known capabilities of maglev systems and some of their implications for transportation systems are discussed. Following that is a discussion of some of the requirements that will be placed on maglev systems if they are to be incorporated into our transportation infrastructure. The requirements placed on the test facility by these considerations are discussed in the next chapter.

\subsection{TRANSPORTATION CAPABILITIES AND IMPLICATIONS OF MAGLEV SYSTEMS}

Operational speeds of $250-300 \mathrm{mph}(417-500 \mathrm{~km} / \mathrm{h})$ are realistically achievable with either EDS or EMS vehicles or trains, providing travel times that are competitive with those of aircraft over distances up to $600 \mathrm{mi}(1,000 \mathrm{~km})$. Some investigators believe these systems will be advantageous at speeds under $150 \mathrm{mph}(250 \mathrm{~km} / \mathrm{h})$, even though trains operating at these speeds are now available.

Aerodynamic noise from air flowing around the vehicles will be the primary source of noise from maglev systems. This noise will be low while approaching or leaving populated metropolitan areas at reduced speeds, thus permitting unobtrusive operation in these areas. Maglev transportation will be possible in weather conditions that would halt airport operations and slow or stop most other modes of travel. EDS systems are expected to offer greater advantages than EMS systems in this respect.

Maglev vehicles can be operated at $300 \mathrm{mph}$ with headways ${ }^{*}$ of about $1 \mathrm{~min}$ and $15 \mathrm{~s}$. (In the appendix, an unnecessarily restrictive warning time of $15 \mathrm{~s}$ is used in emergencies. A five-second warning is assumed here.) With 150 passengers per vehicle, the throughput will be 7,200 passengers per hour, the equivalent of about 18 fully loaded Boeing 747 s per hour in each direction. By operating the system at lower speeds, the safe headways can be reduced and the throughput can be increased. At $150 \mathrm{mph}(250 \mathrm{~km} / \mathrm{h})$, the capacity of the system increases to 13,800 passengers per hour. Operating at this speed near major

\footnotetext{
${ }^{*}$ Time intervals between vehicles or trains.
} 
motropolitan areas and at $300 \mathrm{mph}(500 \mathrm{~km} / \mathrm{h})$ elsewhere would allow 6,600 commuter passengers to board separate vehicles on the same guideway. Connecting two vehicles together will double the capacity, and the introduction of trains will expand the capacity beyond that which will probably be utilizable for the foreseeable future. Such high-speed, high-capacity operations will permit airports to be interconnected to alleviate delays associated with weather conditions or to cope with temporary demands for additional capacity.

Maglev systems have a significant capacity to transport high-value, time-sensitive freight, either concurrently with passenger transportation or during off-peak periods. This capacity could provide a significant new capability for the U.S. transportation system, with implications that have not been thoroughly explored.

Land use for maglev systems is minimal compared with some forms of transportation. A 100 - $\mathrm{ft}$-wide (30-m-wide) right-of-way (the nominal minimum necessary) would require only 12 acres $\left(4.9 \times 10^{4} \mathrm{~m}^{2}\right)$ of land per mile of two-way guideway. The guideway would be elevated to avoid grade crossings and to avoid the collection of debris. 'The lanl under or near elevated guideways could be used for other purposes. Existing rightsof'-wily might be usable in some cases. Land costs, while they are a major consideration in highly populated areas, are not significant in rural areas.

The maglev systems will be automated. An electrically powered linear synchronous motor offers the potential for precise control of vehicle speeds and locations, permitting operations with relatively short headways and frequent departures. Adequate electrical power is available in regions of the country where the first systems are expected to be installed. Effects on the existing power grid are expected to be minimal.

The energy required per passenger mile is about one-third that of a commercial jet airplane and can be produced by any electrical energy source, thereby reducing our reliance on petroleum. Powering the system electrically assures that pollutants will be generated only by the power-generating plants, where they can be well controlled.

Capital costs of maglev systems are expected to be high, but operational and maintenance costs are expected to be low because the energy usage is low, few operating personnel will be required, and the vehicles make no contact with the guideway. EDS systems are expected to use guideways that are less rigid and have looser dimensional tolerances than EMS systems. Since the major cost of either system will be the guideway, the development of vehicles that can be operated on less expensive guideways is a high priority.

\subsection{TRANSPORTATION REQUIREMENTS FOR MAGLEV SYSTEMS}

Maglev systems offer unique characteristics that can be useful in our transportation infiastructure. The existing infrastructure is complex, howover, and modifying it to include maris transportation will be difficult. Perhaps the greatest problem facing the designer of 
a maglev system is to determine the function it is to perform in the context of existing systems.

To be accepted, a maglev system must provide capabilities in transportation that do not currently exist and that cannot be achieved by other means at a lower cost. It will be necessary to determine how many passengers will be transported, when, where, and how fist, and what fare they will pay for this transportation. None of these questions has been answered at this time; at best, the answers will be estimated by future studies, some of which are under way at this time. ${ }^{*}$ The technology to be used need not be specified in order to answer these questions. The answers do, however, affect the technical design of the equipment to be used. Some of these topics were addressed in the November 1990 conference (see appendix) and provide a basis for proceeding. Other factors, such as safety, are not subject to debate. The factors judged to be most important in such a system are discussed below.

The question of safety of ground transportation systems operating at speeds of 150-300 mph must be addressed in each component of the system - that is, the vehicle, motor, control system, braking, guideway, terminals, and amenities. If headways were short to achieve the maximum utilization of the system (which might be an econornic necessity), passengers might be required to wear seat belts to avoid falls during acceleration and deceleration. Access to the vehicle at terminals must provide for handicapped persons, and it must be safe to enter and exit in the time allowed. The vehicle must be designed to suffer no damage from (or be protected from) objects on the guideway and from airborne objects in its path, including birds. All failure modes must be assessed and provisions made to assure safety in the event of the particular failure. These modes include failures of components, magnets, motors, power supplies, controls, brakes, and guideway switches, as well as damage to the guideway. The effects of unexpected wind gusts must be considered. The gravity of a failure of any of these components or systems must be assessed and the design of the system altered appropriately.

To provide a realistic improvement in the existing transportation system, and to justify the expense of installing and operating maglev systems, the vehicles must operate at speeds that are unusual for ground travel. Currently, the minimum speed recommended is $150 \mathrm{mph}(250 \mathrm{~km} / \mathrm{h})$, and the most frequently mentioned maximum speed is $300 \mathrm{mph}$ $(500 \mathrm{~km} / \mathrm{h})$.

The capacity of the maglev system must be sufficient to provide a significant improvement in the transportation system in the United States. As already mentioned, the capacity is expected to exceed requirements. Maglev systems should supplement the airlines, afford planners additional planning options, and alleviate some of the pressure on the highway system. Maglev, however, should not be thought of strictly in terms of these present modes, since it provides transportation capabilities generally associated with air travel. A

\footnotetext{
"Studies have been made of the use of maglev systems between Las Vegas, Nevada, and Anaheim, California.
} 
maglev system operating at $300 \mathrm{mph}$ with 150 passonger vehicles and two-minute headways has a citpacity of 4,500 passengers per hour, but it provides 1,350,000 passenger-miles of' transportation in an hour. In comparison, a single highway lane designed for 70-mph $(112 \mathrm{~km} / \mathrm{h})$ travel and having traffic moving at $60 \mathrm{mph}(97 \mathrm{~km} / \mathrm{h})$ or greater accommodates 700 cars per hour, ${ }^{1, *}$ with a capacity of about 2,800 passengers per hour, but it provides only 168,000 passenger-miles of transportation in an hour. Maglev systems are primarily passenger-oriented, but they will undoubteciry carry high-valued and time-sensitive freight; vehicles and terminals must include provisions for this likely option. The required capacity of the system is undetermined at this time, but it appears to be satisfied by individual vehicles.

The ride quality of the system must be adequate to attract the patronage of the riding public. Essentially any desired quality of ride can be achieved with a maglev aystem, but the costs increase with the ride-quality requirements, and overemphasizing this factor could have the effect of making the system too costly for passengors to afford. Ride quality is a subjective function of many variables, including not only the accelerations felt by the passengers, but also the duration of the trip, the temperature and humidity in the vehicles, the noise level, and the amonities provided. All these latter factors can be controlled relatively easily and at much less expense than can the roughness or routing of the guideway, which are major sources of accelerations on the passengers. The dosign of the vehicle's suspension and damping systems can also provide a smoother ride over rougher guideways. The quality of the ride is increased by banking the guideway to provide coordinated turns, in which the forces on the passenger are felt as a normal force only, rather than a lateral force. At high speeds, and in sharp turns, the bank angle can become significant, but relatively sharp turns are desired to allow routing the guideway arouid obstacles or silluctures and to avoid tunneling. This is an important but imperfectly understood area of concern that must be resolved to provide an economical design for the system.

A major factor in the design and acceptability of a system is its cost. The guideway and the motor incorporated into it is the most expensive part of the system. It is necessary (1) develop a maglev system with good ride quality that uses low-cost and easily installed muicleway sections, possibly along existing rights-of-way. These designs must be economical nonugh for operation in a competitive transportation environment. The issue of how the system will be financed remains to be resolved. Independent of the means of financing, huwever, the system should be designed to be as cost-effective as is consistent with safety and the intended uses of the system.

The maglev system must effectively interface with existing and future modes of lransportation. Since it will serve as an intercity transportation system, passengers can be expected to have luggage that must be moved between modes in a convenient and timely mimmer. The location of terminals is expected to result in redistributions of businesses and pupulations, as has occurred upon the introduction of other transportation systems, with signiticant economic implications.

\footnotetext{
'This rapacity increases to 2,000 cars per hour at $30 \mathrm{mph}(48 \mathrm{~km} / \mathrm{h})$.
} 
If service is to be provided by separate vehicles, arrivals and departures can be expected to be frequent. Therefore, few passengers will accumulate at terminals, and tho torminals can be smuller than they would be if there were long queues. Also, with more froquent operations, more intermediate destinations can be served; however, more switching operations will be needed for these destinations, and the control system must be designed to handle this capacity.

If trains are used, switching will be less frequent than with single vehicles, but the guideway will be subjected to different loads and induced vibrations, and more installerl power will be required. In the absence of possible requirements for emergency stopping, passengers would be permitted to sit without seat belts and to wander about the train during operation. Off-peak loads would entail removing some of the cars from the train, operating a complete train with a reduced load of passengers, or operating with a full load on a still less frequent schedule. If commuter as well as intercity service is to be provided, the control of the system will differ, and additional switches and terminals will be required. The guideways might be designed for two levels of vehicles, one over and one under the guideway, with transfer's occurring at the terminals.

Finally, the system must be relatively benign in terms of its envircumental impacts. This tends to be a strong point of maglev systems, ${ }^{2}$ but it must not be overlooked in the design process.

\subsection{REFERENCES FOR CHAPTER 3}

1. Highway Capacity Manual, Special Report 209, Transportation Research Board, National Research Council, Washington, D.C. (1985).

2. Lynch, T., in Benefits of Magnetically Levitated High-Speed. Transportation for the United States, Vol. 1, prepared by the Maglev Technology Advisory Committee, reporting to the U.S. Senate Committee on Environment and Public Works, published by Grumman Corporation, Bethpage, N.Y. (June 1989). 


\section{RESEARCH OPPORTUNITIES, 'TEST REQUIREMENTS, AND PROPOSED FACILITY CHARAC'TERISTICS}

\subsection{INTRODUCTION}

Opportunitios for research and development exist in every feature of a maglev system, from the operation of the system to the component parts of subsystems. Once innovations are identified, it will be necessary to reduce them to practice. In this chapter, major areas in which innovations might be expected are discussed and related to the calpabilitios recuired of the proposed experimental facility.

The facilities required at each level of research and development differ and are idcotified. No attempt is made to prejudge or prejudice any design concept. The objective is to ontertain as many options as reasonably feasible for testing using the facility. Somo systems might be found that cannot be evaluated and would require separate facilities if they prove to bo moritorious in smaller-scale tests.

The test facility is not intended to evaluate full-scale systems, but to test integrated and discrete systems and components in sufficient sizes and under sufficiently realistic conditions that they can be extrapolated to operational configurations and speeds by using analytical models. The development and validation of these models are priority tasks. To achiove these goals, the test system must be capable of evaluating the predictions of these analytical models.

In order to recognize research and development opportunities in a new maglev system, a thorough understanding is required of the system's intended uses. Some of these considerations were discussed in the previous chapter and in the appendix; they will be mentioned here only to maintain a focus on the objectivos.

Many important features have been incorporated into the Japanese and German maglev systems, giving them an advantage in developing a commercial system. This advantage, however, can be overemphasized. A new resign can capitalize on their experience and mistakes. Unique technologies developed by them might be used under licenses from them. If their systems prove to be the "best" systems for their applications, they would not nocensitrily be the best systems in the United States. Discussions on this topic frequently highlight the differences in distances between citses in the United States and in Japan and Europe. The system requirements will differ in these settings. The Transrapid system, for aximple, has only a small clearance between the motor and the guideway, requiring that the gruideway be very rigid and installed and maintained to close tolerances. Will it operate in icing conditions in the northern parts of the United States? And the Japanese, who have rolitivaly expensive electrical power, have invosted a great deal in reducing the power dissiplation in the guidoway, athough this power represents only $20 \%$ or less of the total power at 300-mph operating speeds. The balanes is unavoidably required to overcome the arerofynamic drag. How much should be invested in the guideway to reduce this eledromannetic drag? 'l'he maximum energy savings depend on the operational speed profile 
of the system, and these savings can be determined only after the operational requiremonts are established. Of course, this information will be needed to establish the operational requirements, so practical options should be determined at an early date.

The natural reluctance to redesign a system that works also favors a new design. For example, high-definition television is clearly superior to existing technologies, but to implement it might require extensive and costly revisions to the system in which so much has been invested. Transrapid, and to a lesser extent the Japanese developers, will be faced with this problem if a better approach is found, while the United States would begin with a new design.

\subsection{SYSTEM OPPORTUNITIES}

A maglev system comprises many parts that must function interactively to provide a safe, comfortable, and economical system. The major components are the vehicle, guideway, motor, power supply, and the control and communications system. The size of the vehicle or train is determined mainly by its operational requirements, as well as by technical limitations imposed by its suspension and propulsion systems, the dynamic requirements placed on it by safety and ride comfort, and aerodynamic factors. The guideway, in turn, is required to support the vehicle and motor with the same restrictions. In addition, it must be fabricated, installed, and maintained as economically as possible within the limitations of safety and ride comfort and ecological considerations. It must be aesthetically acceptable, and it might be required to be installed on existing interstate highway structures or to operate in railroad rights-of-way. In most current concepts, the motor is installed on the guideway and powered by facilities at the wayside. It is an expensive component affecting the structure of the guideway and the ride quality of the vehicle. The control systems control the operation of all electromechanical parts of the system. Each of these component parts of a maglev system differs in different designs, and each presents opportunities for devoloping a new maglev system.

\subsubsection{Vehicle/Train Opportunities and Test Requirements}

The speed and capacity of a vehicle or train for use in a maglev system are not yet specified, but they can le assumed to be about $300 \mathrm{mph}(500 \mathrm{~km} / \mathrm{h})$ maximum and $100-150$ passengers per vehicle, or car of a train. The propulsion and suspension systerns, and the motor and controls used in conjunction with these vehicles, will differ depending on the system used. The vehicle will interact with the guideway, responding to its curvature, irregularities, and flexibility to provide varying degrees of ride quality, and it will interact with the propulsion system, which will also induce vibrations in the vehicle.

It will be necessary to quantify the motion-dependent magnetic forces caused by the motion of the vehicle and the oscillations of the guideway. With these furres quantified, the dynamic stability of the vehicle, including vehocle/guideway interactions, can be analyzed, and the results can be compared with results form the test facility. It will also be necessary to 
develop, modify, or improve computer codes for the dynamic simulations of the vehicleguideway interaction. Ideally, these codes should be capable of accommodating multiple vehicles and vehicle elasticities, secondary suspensions, guideway dynamics, aerodynamic forces, magnetic forces, guideway irregularities, and feedback control.

It is important that the vehicle incorporate all available technologies to allow it to operate with less expensive guideways and motors, since these components are so expensive and extensive. The size, weight, and aerodynamic shape of the vehicle are the major determinants of the power requiremeits (and thus the size of the motor) at high operational speeds. In addition, the aerodynamic forces can be destabilizing and affect the safety of the vohicle. The aerodynamics of high-speed vehicles operating in tunnels is a relatively new topic for investigation. Buffeting and noise in and around the vehicle and between prassing vehicles will be of considerable interest. The dynamic flexure of the vehicle will affect the ride quality of the vehicle. This consideration, though important, is expected to be primarily the responsibility of system developers who will build on the resuls olutained through the use of the test facility. Ultimately, all these factors must be evaluated in full-scale prototypo vohiclos. Some of the identifiable vehicle testing capabilities desirecd in the test facility are discussorl below.

The facility must be capable of evaluating single and coupled test vehicles at realistic spreds. While it might be necessary to understand the dynamic motions of multiple vehicles, it will be necessary to understand the motions of single vehicles before coupled vehicles can be analyzed. Some believe that this understanding will be sufficient to permit a preliminary analysis of the behavior of coupled vehicles with a high degree of confidence. The preliminary facility :lesign permits both single and coupled vehicles to be tested, but onler angle vehicles are proposed to be tested initially.

'The vehicles must be of such size and tested at such speeds that the results can be rusunably extrepolated to operational sizes and speeds. The proposed maximum test speed is $67 \mathrm{~m} / \mathrm{s}(150 \mathrm{mph})$, which provides an aerodynamic force approximately $25 \%$ as great as that of the same vehicle operating at $134 \mathrm{~m} / \mathrm{s}(300 \mathrm{mph})$. This is believed to be sufficient to permit a preliminary assessment of the aerodynamic interaction of the vehicle with differing guideway structures. Crosswinds will add to this force and will be evaluated. The vehicle is clesigned for a minimum weight of 3 to 4 metric tons and a maximum weight of 6 to 7 metric tons, so the aerodynamic forces are 5 to $10 \%$ of the vehicle weight. These forces are univoriable in the test vehicle and must be characterized to separate aerodynamic effects from the performance data on the other components of the system. In particular, the performance of the levitation and guidance systems when the vehicle is subjected to wind gusts will be of considerable interest.

Mechanical vibrations induced by guideway imperfoctions affect the suspension systens and therehy the ride quality of the vehicle. Since the maximum test speed will bo ort-half that of a full-scale system, the frequencies of these vibrations will be one-half the fremponey of a system uperating at $300 \mathrm{mph}(50) \mathrm{km} / \mathrm{h})$. The guideway will be constructed 1. provide periodic perturbations from piers at time intervals comparable with those of an 
operational system. Ride quality assessments made with this facility and doscribed by analytic models of the ride quality can be extrapolated realistically to thon of full-scale vehicles. The vehicle will be accelerated at $0.2 \mathrm{~g}$ 's, the approximate accoleration of a f fullscale system, thereby providing realistic assessments of the propulsion, power, and control systems.

Evaluating the dynamics and ride quality of the vehicle over guideways of varying construction, irregularities, curvatures, and flexibilities will be a high-priority task. 'The vehicle and guideway will be fully instrumented to measure the accelerations and displacements of the vehicle in all degrees of freedom with any suspension, propulsion, or damping system used. By using a common test bed, the comparative merits of alternative systems can be assessed directly. A computer program to analyze the motions of the vehicle (assumed to be a rigid body) is in advanced development.

The vehicle must be capable of assessing the performance of a wide variety of primary and secondary suspension systems and active or passive damping systems used with them. The upper portion of the test vehicle will contain diagnostic instrumentation, control and communication, and power facilities common to all systems tested. The underside of the vehicle is designed as a flat surface to which any suspension system can be attached interchangeably. $\mathrm{Up}_{\mathrm{p}}$ to $45 \mathrm{~kW}$ of on-board DC power will be made available for EMS systems. The test facility provides for the storage and handling of cryogens, as well as the use of cryogens in the vehicle.

It would be an unnecessary risk to levitate an expensive test vehicle with a collection of untried suspension systems. The vehicle is designed to use noninflated, high-speed wheels for support and guidance of the vehicle during takeoff and landing with EDS suspension systems. This configuration provides the opportunity to significantly expand the utility of the vehicle and the test facility. A test bay approximately $1.0 \mathrm{~m}$ wide and $1.5 \mathrm{~m} 1 \mathrm{hng}$ is provided in the center of the vehicle for evaluating a wide range of subsystems and components while operating the vehicle at relatively high speeds with these wheels. Single suspension, guidance, propulsion, power pickup, braking, or other systems of new designs can be safely tested against the appropriate reaction component in the guideway while varying the suspension height, lateral position, guideway characteristics, vehicle speed, etc. Similarly, active or passive damping systems or secondary suspensions can be evaluated realistically and economically at very low risk with the test vehicle. Ample on-board dataacquisition, recording, and telemetry instrumentation will be provided for the evaluation of test items.

The exposure of passengers to magnetic fields is of concern. The test vehicle body is expected to be constructed of aluminum, both to minimize its weight and to avoid masking the diagnostic measurement of magnetic fields from the propulsion and suspension system. A fiber-reinforced polymer body could also be used for this purpose.

\footnotetext{
${ }^{*}$ Acceleration due to gravity, g, equals $9.8 \mathrm{~m} / \mathrm{s}^{2}\left(32 \mathrm{ft} / \mathrm{s}^{2}\right)$.
} 


\subsubsection{Guideway Opportunities and Test Requirements}

The guideway is singled out for special attention because it presents unusual opportunities for cost savings. The Transrapid spans are designed and constructed to have a maximum deflection of about 1 part in 4,000 of the span length, and EDS systems are expected to tolerate considerably larger deflections. 'This rigidity requirement can be a major' factor in the cost of the guideway spans, and the spans can dominate the capital cost of the guideway.

The propulsion motor, mounted on the guideway, moves with the guideway and causes interactions with the vehicle (in addition to those caused by the motion of the roactive portions of the suspension and guidance system). These complex nonlinear interactions of the vohicle, guideway, and motor will require considerable analysis in the development of new magley systems. There is a possibility that the motor might be controlled or' inclependontly suspended to smooth the ride of the vehicle, as suggested by others previously and cliscussed below under "controls" and in Chapter 11.

Intentional camber of the guideway beams can improve ride comfort under specific conclitions. Further study is needed to determine its effectiveness under various operating conditions, and practical methods of controlling the magnitude of camber need to be developed.

Independent and cooperative control methods using feedback control to suppress rigid bocly motions and structural vibrations need to be studied with the objective of relaxing the tolerances and reducing the cost of the guideway. An optimized design incorporating the best fortures of guideway dynamics and control techniques might result in a more economical. system.

Existing ride-quality criteria need to be reviewed and new criteria developed. Vortical and lateral acceleration levels have frequently been used as criteria for ride comfort. The influence of guideway surface roughness and alignment, as well as the parameters of the vehicle suspension, should bo analyzed in detail to relate all the system parameters to ride comfort. New or modified criteria for ride comfort might be needed for high-speed systems.

The test facility in general, and the guideway in particular, must be capable of evaluating alternative maglev systems. For this purpose, the guideway is designed to have a flat surface with two, integrated "I" beams underneath. This structure alone is capable of supporting the maximum vehicle weight anticipated with a deflection of less than 1 part in 1,000 of the span. EMS systems can be tested in the Transrapid configuration by mourting the LSM to the underside of the guideway. Penetrations through the guideway are provided at 50 -cm intervals for $2.5-\mathrm{cm}\left(1-\mathrm{in}_{1}\right)$ diameter bolts for mounting this or other structures. For (.he El) configuration, parapet walls are provided for forming a " $U$ " channel. These walls are mounted with the same bolts and bolt spacings and increase the rigidity of the structure considerably, as discussed in Chapter 10. Other configurations would be mounterl on the flat surfice of the guideway. Tho spans are $13.5 \mathrm{~m}$ long and the wall segments are $4.5 \mathrm{~m}$ long, each having eye bolts for ease of installation and removal using a crane. The walls, like the 
guideway, are provided with many penetrations for mountingr bolts. Power cables will be rung beneath the guideway between the "I" beams. Large penetrations are made at each end of each span to permit the power cables to be connected to motor sections.

As noted in the vehicle discussion above, the vehicle and guideway will be usable for evaluating discrete maglev subsystems and components by mounting the appropriate components on the guideway.

The guideway must be sufficiently long to permit the performance of velicle tests at speeds up to $67 \mathrm{~m} / \mathrm{s}(150 \mathrm{mph})$. The proposed guideway is approximately $3.3 \mathrm{~km}(2.05 \mathrm{mi})$ long, which, with accelerations and decelerations of $0.2 \mathrm{~g}$ s, provides a $15-\mathrm{s}$ period $(1-\mathrm{km}$ distance) for experimental $i$ its at full speed, and longer periods at lower speeds. The central $1-\mathrm{km}$ section of the guideway would be used for most experiments. Provisions are made for stopping the vehicle, nondestructively, if all braking measures fail.

The guideway must be suitable for evaluating ride comfort. The initial and final 1.15-km-long sections of the guideway will have static deflections of 1 part in 1,000 of the span length or less. EMS vehicles are expected to traverse these relatively flexible sections with reduced ride quality. In the experimental section, however, provisions will be made to remove and replace guideway sections with other experimental sections having different rigidities, structural designs, structural tolerances, or materials. These sections will be instrumented, as required by the user, to determine their response to single or coupled vehicles, wind, temperature excursions, or other variables. Provisions are made for jacking the spans at each pier to introduce vertical or lateral offsets, such as those that would occur because of settling of the footings or earthquakes. Such offsets provide an excellent means for assessing the response of the vehicle when different suspension and damping systems are used.

Various means of obstacle detection will be capable of evaluation with the test system. Initially, TV monitoring of the entire guideway will be used. Pattern recognition techniques can be employed at a later date to detect changes if desirable. Individual users of the system are expected to devise other, additional schemes for accomplishing this task.

The initial guideway is proposed to be linear and level. Provisions are made in the site design to incorporate a spiral inio a curve and inclined sections of the guideway at a later date. A switch or a fixed curve can be incorporated in the guideway at that time if desired. It has been suggested that two parallel guideways be installed to expedite the evaluation of different concepts. Each guideway would use the common power, control, communication, data-acquisition, and data-processing facilities available at the site.

\subsubsection{Propulsion System Opportunities, Requirements, and Characteristics}

The propulsion system is another expensive component of a maglev system. Current systems employ linear synchronous motors for propulsion, thereby avoiding the environmental liabilities of fossil-fueled propulsion systems. The Japanese system uses an 
air-cored LSM with a relatively long pole pitch and large air gap, while Transrapid uses an iron-cored LSM having a relatively short pole pitch and small air gap. The larger air gap in EDS systems appears to be a significant advantage, but these systems require superconducting magnets with high magnetic fields from which the passengers must be shielded. The superconducting magnets also require the use of cryogenics aboard the vehicle. Alternative designs should be explored.

The weight of the iron-cored LSM in the EMS guideway is considerable; means of reducing this weight should be investigated.

Weathering effects on the propulsion systems should be explored. The proposed facility is ideal for these evaluations.

The motors of both systems are expected to generate harmonics of their fundamental operating frequencies, and these induce vibrations in the suspension systems. Means of avoiding, reducing, or attenuating these vibrations need to be explored.

The length of the motor sections is closely related to the design of the motor if the efficiency and power factor of the electrical system are to be maintained within reasonable limits. With shorter motor sections, more power facilities will be required at the side of the guideway, increasing the cost. These factors can be explored in detail with the test facility.

Propulsion systems will operate at frequencies comparable with their full-scale counterparts, since the pole pitches of the systems evaluated will be comparable with or about one-half that of full-scale systems. The test facility is ideal for the evaluation of these systems.

With the test facility, innovative strategies for controlling the propulsion system can be cvaluated directly, under conditions in which both the vehicle-guideway dynamics and wind gusts affect and interact with the rnotor.

The preliminary design of the guideway provides for the replacement of the propulsion system in part (for the evaluation of variations in particular motor designs) or in its entirety (for the evaluation of alternative maglev systems). In conjunction with the modifiable design of the vehicle, a wide range of propulsion concepts can be developed with the test facility. The power supply and control systems, discussed below, provide great experimental flexibility in motor development.

\subsubsection{Control System Opportunities and Requirements}

Control systems are used in many parts of the system, from the suspension and active damping controls to the control and synchronization of the propulsion power applied to secjuential sections of the motor.

Suspension control systems will be aboard some types of maglev vehicles and will play a major role in providing ride comfort to the passengers when traversing guideway 
sections that are irregular or when the vehicle is operating in gusty winds. These controls can assist the suspension system in achieving a high-quality ride over less-expensive guideways.

Propulsion controls are required to reliably regulate the acceleration, speed, spacing and braking of the vehicles. The propulsion system moves with the guideway and intoracts with the suspension system, resulting in the complex effect on the ride quality of the vehicle mentioned above. It might be possible to incorporate some aspects of controlling the ride comfort into the pror ulsion system. Most guideway disturbances will occur at fixed locations and will not change with time. 'Thus, the potential exists for the suspension's control system to "learn" about such disturbances and anticipate them to improve ride comfort.

The operations control system monitors and directs all other components of the system. It is responsible for interacting with all elements of the system to assure that vehicles are in their assigned positions in the system and operating at their proper speeds. The design of a successful control system depends largely on the model that is adopted. A good mathematical model is determined not only by how closely it corresponds to the real system, but also by its use of practical rather than ideal control strategies. A reasonable yet simple model might lead to : powerful, economically feasible control system.

The LSM and vehicle models are essentially nonlinear and time-varying, with unpredictable factors due to the effects of variations in the payload, guideway deflections, electromagnetic parameters, and aerodynamic drag. Linear and nonlinear control models of the LSM and vehicle need to be explored that use time-varying parameters, which may be either deterministic or stochastic.

Analyses of suspension dynamics are complicated in the EMS system because of its nonlinear electromagnetic properties. An exact solution would enable a feedback control system to be designed with the maximum stability margin. The large air gap in EDS systoms suggests that an active suspension-control system might be possible in which the air-gap measurement is used by the propulsion system to decrease the fluctuation error in the air gap.

Since the dominant excitation force to the suspension system results from guideway irregularities, which can be represented by a stationary stochastic signal, a stochastic stability analysis and control design could be beneficial, perhaps permitting the application of a Kalman filter to the suspension control to improve the ride quality over a rough guideway.

Numerous control methodologies could be exploited, but efforts should be made to develop an adaptive control design that detects changes in the parameters and self-adjusts the parameters of the controller. Although the effects of small changes on the dynamic characteristics are attenuated in a feedback control system, if changes in the system parameters and environment are unpredictable and significant, a satisfactory system must have the ability to adapt. Although such adaptive controls are desirable, the algorithms required might be too slow for processing the inputs. These algorithms will be a subject of study. 
Unquestionably, a new maglev design will stress the use of digital technology in the control and communication systems. A sampled system behaves like a continuous-time system if the sampling period is sufficiently small. However, the discrete time intervals would change important system properties, such as the stability region, controllability, and observability. Discrete sampling time designs present engineering and theoretical problems, and research is needed in modeling these controls as input-output models, difference models, or state-space models. The application of digital control strategies, such as dead-beat control and self-turning controls, needs to be explored with the development of discrete algorithms for sampling, holding, and control policy. The test facility will be useful for evaluating each of these.

A control system in which all measurements are ground-based would result in increased reliability and would permit hard-wire data transmission, which would reduce the polential for errors and reduce the equipment aboard the vehicle. The key to the solution is to devolop a set of formulas that describe the interactive relations between the motor sections and the vehicle via a time-varying air gap and to develop a set of on-line estimation algorithms. Because of the flexible expansion capability and the tremendous speed of digital technology, the future of this approach is very promising.

Computer simulation is an indispensable tool for the research and development of control systems. The simulation of dynamic control systems is conventional for vehicle design, but the simulation of the operation control system is a new topic. The facility can he used to develop an expert system and a database for accumulating test results.

Vehicle position and levitation air-gap signals are vitally important to the propulsion and suspension control systems. In the Transrapid TR-06 system, three different measuring systems for position detection were installed and none of them were completely satisfactory. On the other hand, the levitation sensors are the most troublesome devices, according to reported operation experiences, and a redundant design has been used to improve the reliability of the sensors. The development of new air-gap and position measuring systems could directly increase the reliability of the system and the control stability.

Control and communications response times in the test facility will vary depending on the particular control considered, but they will not be less than one-half those of operational systems.

\subsubsection{Power Supply Opportunities and Requirements}

Power supplies for maglev systems regulate substantial amounts of power. The svstems used in the Transrapid and Japanese systems have substantially different frequency requirements as a result of the difference in the pole pitches of their motors. Cycloconverters and motor'generator sets have been used to convert frequencies. The most direct approach appears to be the use of gate-turn-off thyristors (GTOs) for controlling the power. The G'TOs refuired must have powar ratings that might not be available in the United States and might providi: a manufacturing opportunity for U.S. industries. The test facility will use these 
devices to convert power to the wide range of frequencies required for the EMS and EloS system for which test provisions are being made. Novel systems would be expected to have frequency and power requirements within the range provided by the test facility.

\subsubsection{All-Weather Research Opportunities}

Maglev systems are expected to be the superior method of transportation in adverse weather conditions. This expectation arises from the fact that the vehicle does not necessarily rely on frictional contact with the guideway for propulsion and braking, but floats at some height above (or below) tho physical surface of the guideway. The development facility will be capable of full operation in adverse weather, permitting users to evaluate the safety, ride quality, standard and emergency braking, ingress and egress, cold-weather effects on controls, communications and instrumentation, and hazard detection and warning systems under conditions of heavy winds, snow and ice accumulations, fog, and heavy rain. The facility will be located in a seasonally cold climate to evaluate the effects of these elements and temperatures. Artificial snow- and ice-making capabilities will be added if necessary to permit more reliable winter-testing capabilities.

The facility will permit the evaluation of snowdrift patterns around guideways and piers, as well as the snow and rain collection and ice accretion characteristics of alternative guideway geometries, either on the operational guideway or on a separate test section. Mitigation measures, such as snow and ice removal methods, low-adhesion coatings, wind breaks, etc., can be tested. A meteorological station, including instruments for measuring wind speed and direction, air temperature, humidity, rain and snow flux, and solar radiation, will be installed to facilitate these evaluations, and a clear fetch will be provided along the direction of the prevailing wind to permit realistic analyses of wind and snowdrifting effects.

\subsection{SUBSYSTEM AND COMPONEN'T DEVELOPMENT}

Not all parts of a development program require the use of the test facility. 'T'he practicality and applicability of new ideas to maglev systems must be evaluated in many ways, beginning with thorough analyses, or computer simulations, and followed by breadboard-type experimentation to establish that no major factor has been overlooked. If these tests prove successful, then the subsystem or component can be constructed in a larger size and evaluated individually or with other components or subsystems if possible. Some tests of this type can be performed economically in the laboratory or in facilities smaller than the one proposed here. Ultimately, however, these packages must be integrated as functional parts of more complex systems to evaluate their potential for full-scale development, a role assumed by the test facility. As noted, the test vehicle and guideway provide for the testing. of systems and components that are larger than laboratory-scale in a realistic setting. In considering site requirements, we have included space for a possible 300-m-long test facility for similar testing purposes. 
As indicated in Table 4.1, testing of new concepts will begin with exporiments on rotalting wheels simulating the guideway, or other laboratory-scale facilities, and culminate in testing of full-scale prototype systems. As test items and their accompanying analyses are proven in these sizes, they will be subjected to testing either on small linear test tracks or in the test bay of the proposed vehicle to determine their performance in a linear system. Since each of these components or subsystems must inevitably be used cooperatively with other systems, it will be necessary to determine that other systems combined with them perform as expected; otherwise, the subsystems must be modified and developed further. For example, the suspension, guidance, and propulsion systems, in conjunction with their respective controls and communications, must function together on a guideway with some degree of flexibility to provide the desired ride quality. These interactions can only be olserved in a test facility large enough to incorporate each of these systems in realistic sizes. 
TABLE 4.1 Test Matrix: Progression of Test Facilities from Laboratory Scale to Full Scale

\begin{tabular}{|c|c|c|c|c|c|}
\hline $\begin{array}{l}\text { System Components } \\
\text { and Characteristics }\end{array}$ & $\begin{array}{c}\text { Rotating } \\
\text { Wheel }\end{array}$ & $\begin{array}{c}\text { Other Lab } \\
\text { Tests }\end{array}$ & $\begin{array}{l}300-111 \\
\text { Track }\end{array}$ & $\begin{array}{l}3,000 \mathrm{~mm} \\
\text { Track } \\
\end{array}$ & $\begin{array}{c}\text { Tull-kicalo } \\
\text { Track }\end{array}$ \\
\hline New Concepts & $\mathrm{X}$ & $\mathrm{X}$ & $\mathrm{X}$ & $\mathrm{X}$ & $\mathrm{X}$ \\
\hline $\begin{array}{l}\text { Vehicles } \\
\text { Suspensions } \\
\text { Superconducting } \\
\text { Conventional } \\
\text { Secondary } \\
\text { Damping } \\
\text { Dynamics'Ride } \\
\text { Aerodynamics }\end{array}$ & $\frac{-}{x}-$ & $\frac{x}{-}$ & $\begin{array}{l}\mathrm{X} \\
\mathrm{X} \\
- \\
- \\
-\end{array}$ & $\begin{array}{l}\mathrm{X} \\
\mathrm{X} \\
\mathrm{X} \\
\mathrm{X} \\
\mathrm{X} \\
\mathrm{X}\end{array}$ & $\begin{array}{l}X \\
X \\
X \\
X \\
X \\
X\end{array}$ \\
\hline $\begin{array}{l}\text { Guideways } \\
\text { Dynamic } \\
\text { Materials } \\
\text { Switching }\end{array}$ & - & $\bar{x}$ & - & $\begin{array}{l}X \\
X \\
X\end{array}$ & $\begin{array}{l}X \\
X \\
X\end{array}$ \\
\hline $\begin{array}{l}\text { Propulsion } \\
\text { LSM } \\
\text { LIM } \\
\text { Regeneration }\end{array}$ & $\begin{array}{l}? \\
? \\
-\end{array}$ & - & $\begin{array}{l}X \\
X \\
-\end{array}$ & $\begin{array}{l}X \\
X \\
X\end{array}$ & $\begin{array}{l}X \\
X \\
X\end{array}$ \\
\hline $\begin{array}{l}\text { Control } \\
\text { Suspension } \\
\text { Propulsion } \\
\text { Operations }\end{array}$ & - & - & $\begin{array}{l}X \\
- \\
-\end{array}$ & $\begin{array}{l}X \\
X \\
X\end{array}$ & $\begin{array}{l}X \\
X \\
X\end{array}$ \\
\hline $\begin{array}{l}\text { Vehicle/Cuideway/Propulsion/ } \\
\text { Control Interactions }\end{array}$ & - & - & - & $\mathrm{x}$ & $\mathrm{X}$ \\
\hline Aerodynamics & - & $\mathrm{X}$ & - & $x$ & $X$ \\
\hline Braking & - & - & - & $\mathrm{X}$ & $\mathrm{X}$ \\
\hline Safety & - & - & - & $X$ & $X$ \\
\hline Adverse Weather & - & $\mathrm{X}$ & - & $\mathrm{X}$ & $x$ \\
\hline
\end{tabular}

"An "X" indicates that the component/characteristic is tested at tho scale shown; a "-" indicates that the component/characteristic is not tested at that scale, while a "?" indicates uncertainty. 


\section{AERODYNAMIC CONSIDERATIONS}

A maglev vehicle operating at 67 to $134 \mathrm{~m} / \mathrm{s}$ ( 150 to $300 \mathrm{mph}$ ) will be significantly affected by aerodynamic forces. At high speeds, these forces are the major source of drag on (and therefore the major requirement for propulsion power for) the vehicle, and at high and low speeds, they can affect its stability, ride quality, and noise levels. The forces generated depend on the configuration of the vehicle and guideway, whether the vehicle is traveling in open air or in a tunnel, and whether a side wind is incident on the vehicle. These forces must be thoroughly understood in the final design of a maglev system. They will have similar but reduced effects in the development facility.

\subsection{AERODYNAMIC DRAG}

The aerodynamic drag arises from two sources, the form drag, determined by the shape of the nose and tail and independent of the length of the vehicle, and the skin friction, which is proportional to the surface area. given by: ${ }^{1,2}$

The aerodynamic drag, $\mathrm{F}_{\mathrm{d}}$, acting on a vehicle traveling at a speed $\mathrm{V}$ in open air is

$$
F_{d}=0.5 \rho C_{D_{o}} A V^{2}+0.5 \rho P L C_{f_{o}} V^{2}
$$

where $p$ is the density of the air, $\mathrm{A}$ is the cross-sectional area of the vehicle, $C_{D_{0}}$ is the pressure drag coefficient, $\mathrm{P}$ is the vehicle perimeter, $\mathrm{L}$ is the vehicle length, and $C_{f_{0}}$ is the skin friction coefficient. The terms of this expression can be combined as follows:

$$
F_{d}=0.5 \rho A C_{D} V^{2}
$$

If the vchicle moves at a horizontal angle, $\Psi$, to the wind (yaw angle), the drag is given by:

$$
F_{d}=0.5 \rho A C_{D} V^{2}(1+k \Psi)
$$

where $\mathrm{k}$ is the yaw correction factor.

The force acting on a vehicle body due to the air flow is the surface integral of all normal and shearing stresses acting on it. The component of the resulting force parallel to the undisturbed initial velocity is referred to as the drag, $\mathrm{D}$. If the dynamic head, $0 \mathrm{~V}^{2} / 2$, is selccted for reference, the dimensionless coefficient for drag becomes:

$$
C_{d}=\frac{2 D}{\rho V^{2} A}
$$


in which $\rho$ is the fluid density, $V$ is the vehicle velocity, and $A$ is the frontal area expresed to the flow direction by the body. A dimensional analysis shows that for geometrically similar vehicles, the dimensionless drag coefficient is a function of one variable only, namely, the Reynolds number. The Reynolds number, which is a dimensionless combination of' characteristic velocity, V (vehicle), characteristic length, L (mean vehicle width), and kinematic viscosity of the fluid, $v$, is defined as:

$$
\operatorname{Re}=\frac{V L}{v}
$$

Drag coefficients can be theoretically derived for some bodies with simple geometries; for more complex cases, drag coefficients can be riumerically computed or experimentally oltained. For laminar flow, the drag coefficient decreases with increasing Reynolds number (e.g., the drag coefficient of a sphere is about 30 for $R \Theta=1$ and 0.5 for $R \theta=10^{5}$ ). The drag coefficient is generally much larger for turbulent flow than for laminar flow (e.g., at $R e=2 \times 10^{5}$, the laminar drag coefficient for a flat plate is 0.0015 and the turbulent coefficient is 0.005 ). At a speed of $240 \mathrm{~km} / \mathrm{h}$, the air flow around the maglev vehicle is cloarly turbulent, because the Reynolds number becomes $9 \times 10^{6}$, which is larger than the critical Reynolds number for a plate $\left(3.5 \times 10^{5}\right)$.

Drag coefficients for objects having a complex geometry (such as vehicles) are commonly determined by conducting wind tunnel experiments. The drag coefficient of an automobile ranges from 0.6 for a flat-nosed car to 0.2 for a streamlined car. On the basis of boundary layer theory, the thickness of the boundary layer in which the velocity gradient is high greatly affects shearing stresses acting on the vehicle. In addition, flow separation thickens the wake and increases the pressure drag contribution to total drag. 'The incidence of separation is often rather sensitive to small changes in the shape of the solid budy, especially when the pressure distribution is strongly affected by this change in shape. The drag coefficient depends strongly on vehicle shape, size, and velocity and can be significantly improved if the vehicle shape copes well with the flow field.

The turbulent boundary layer thickness, $\delta$, is also correlated with the Reynolds number:

$$
\frac{\delta}{L}=0.37(R e)^{-0.2}
$$

Without flow separation, the boundary layer thickness near the rear of the test maglev vehicle moving at $240 \mathrm{~km} / \mathrm{h}$ would be about $0.1 \mathrm{~m}$.

In the case of compressible fluids, when elastic forces are important compared with the inertial and friction forces, the dimensional Mach number $M=V / c$ ( $c$ is the speed of sound) needs to be includeu. Up to $M=0.3$ (or a velocity of less than $100 \mathrm{~m} / \mathrm{s}$ in standard air), the influence of the Mach number is negligible. Therefore, the compressibility effect of 
air un the tost maglev vehicle is not important, but will need to be considered for a full-scale maglesv vehicle when the vehicle velocity exceeds $100 \mathrm{~m} / \mathrm{s}$ (or $360 \mathrm{~km} / \mathrm{h})$.

The skin friction drag of a smooth, flat plate with a boundary layer turbulent from the leading edge is given by the Prandtl-Schlichting relation:

$$
C_{f_{o}}=0.455 /\left(\log _{10} R e\right)^{0.258}
$$

The above equation underestimates the skin friction drag of scaled trains, according to Brockie and Baker, ${ }^{2}$ who used the following similar expression:

$$
C_{f_{0}}=\alpha_{1} /\left(\log _{10} R e\right)^{\alpha_{2}}
$$

where $\alpha_{1}$ is 0.128 and $\alpha_{2}$ is 1.814 , based on data for the $1 / 76$ th- and $1 / 40$ th-scale models of British Rail high-speed trains (HSTs).

'The drag coefficients (including $\mathrm{C}_{\mathrm{D}}, \mathrm{C}_{\mathrm{D}_{0}}$, and $\mathrm{C}_{\mathrm{f}_{0}}$ ) are normally measured by using scile models in wind tunnels. Some of the data are given in Table 5.1. An aerodynamic drag force of $20 \mathrm{kN}$ was predicted at $300 \mathrm{~km} / \mathrm{h}$ for $\mathrm{TR}-06$, based on a $1 / 10$ th-scale model in a wind tunnel. ${ }^{3}$ In 1984, a total drag of $28 \mathrm{kN}$ was observed at top speed.

The drag coefficient $\mathrm{C}_{\mathrm{D}}$ can be as low as 0.2 for slender vehicles designed to carry about 100 passengers. However, the doors, windows, and various minor protuberances make it very unlikely that a drag coefficient of less than 0.3 could be achieved in practice for maglov. ${ }^{4}$ For example, the drag coefficient for the proposed designs for streamlined vehicles by Philco-Ford Corporation varies from 0.188 to 0.303 , depending on the seat arrangement and passenger capacity. 5

\begin{tabular}{|c|c|c|c|c|c|}
\hline \multirow[b]{2}{*}{ Authors } & \multirow[b]{2}{*}{$R \theta$} & \multicolumn{3}{|c|}{ Drag Coefficients } & \multirow[b]{2}{*}{ Model Type } \\
\hline & & $\mathrm{C}_{\mathrm{D}}$ & $\mathrm{C}_{\mathrm{tn},}$ & $\mathrm{C}_{\mathrm{f}_{10}}$ & \\
\hline Brockie and Baker & $\begin{array}{c}2.54 \times 106 \\
7 \times 10^{6} \\
-\end{array}$ & $\begin{array}{c}1.85 \\
1.84 \\
1.41-1.56\end{array}$ & $\frac{1.1}{-}$ & $\begin{array}{c}0.0044 \\
0.0039 \\
0.002-0.004\end{array}$ & $\begin{array}{l}\text { 1/76th-scale model } \\
1 / 40 \text { th-scale model } \\
\text { British Rail, HST }\end{array}$ \\
\hline Matsinuma et al. & - & - & 0.15 & 0.004 & $\begin{array}{l}\text { Shinkansen } \\
\text { Series } 100 \mathrm{~N}\end{array}$ \\
\hline
\end{tabular}

\section{TABLE 5.1 Wind-Tunnel Data}


In a tunnel, the interaction of the air stream with the tunnel must be considered. The drag force in this case can be represented by: ${ }^{1}$

$F_{d}=0.5 \rho\left[\frac{A\left(C_{D_{0}}+R\right)(u-V)^{2}}{(1-R)^{2}}-\frac{P^{\prime} L C_{f_{0}} R(u-R V)|u-R V|}{(1-R)^{2}}+\frac{P L C_{f_{0}}(u-V)^{2}}{(1-R)^{3}}\right]$

where:

$$
\begin{aligned}
& u=V R-\frac{\left[V(1-R) R\left(b_{1}-b_{2}\right)\right]}{\left.(1-R) b_{1}+R^{2}+\left[b_{1} b_{2}+P^{\prime} L C_{f_{o}}^{\prime}\left|b_{1}-b_{2}\right| / A^{\prime}\right)\right]^{0.5}} \\
& b_{1}=\left[P^{\prime} C_{f_{o}}{ }^{\prime}\left(L^{\prime}-L\right) \mid A^{\prime}+C_{0}\right](1-R) \\
& b_{2}=\left[(1-R)\left(C_{D_{0}}+R\right)+P L C_{f_{o}} \mid A\right] / R \\
& R=A \mid A^{\prime}
\end{aligned}
$$

In these expressions, $U$ is the velocity of the air flow induced by the train running in the tunnel. The parameters associated with the tunnel are $\mathrm{A}^{\prime}$, the cross-sectional area; $\mathrm{L}^{\prime}$, the length; $\mathrm{P}^{\prime}$, the perimeter; $\mathrm{C}_{\mathrm{f}_{0}}{ }^{\prime}$, the skin friction coefficient; and $\mathrm{C}_{0}$, the pressureloss coefficient at the entrance and exit of the tunnel.

The determination of drag coefficients presents the following difficulties: (1) the skin friction drag dejends on the Reynolds numbers, which must be established; (2) the vehicle boundary layer is generally strongly three-dimensional; and (3) the vehicle may operate close to a fixed ground plane, which imposes certain conditions on aerodynamics.

The aerodynamics for maglev vehicles are generally understood. The aerodynamic forces for a specific maglev system can be measured by wind tunnel tests, but because of the difficulty of simulating practical conditions, measurements on full-scale models are needed.

The dominant aerodynamic factor in high-speed trains and maglev systems is the aerodynamic drag. Since the major source of drag is skin friction, which is proportional to the vehicle surface, it is advantageous to make larger vehicles and tunnels instead of longer vehicles. However, for a single maglev vehicle, long, slender shapes are preferred for a fixed payload volume. ${ }^{5}$ The aerodynamics problems for maglev have some unique features. Although a basic understanding of these problems is available, precise predictions of the aerodynamic effects remain difficult because of the lack of extensive aerodynamic data for these systems. 


\subsection{CROSSWIND EFFECTS}

Because maglev vehicles are lightweight, they might be subject to wind-induced accidents. Therefore, aerodynamic forces and moments acting on vehicles in crosswinds need to be understood. In general, a model of a vohicle positioned statically on a ground board in a wind tunnel is used in measuring the aerodynamic forces and moments. In this case, the relative motion between the ground and the vehicle is not considered. Robinson and Baker have attempted to use a model vehicle propelled across a wind tunnel. ${ }^{6}$ It is difficult, however, to simulate an atmospheric boundary layer in a wind tunnel, because the aerodynamic forces and moments are strongly affected by the length scale and intensity of the turbulence.

The aerodynamic side and lift force coefficients $\left(C_{s}\right.$ and $\left.C_{L}\right)$ and yawing and pitching moment coefficients $\left(C_{Y}\right.$ and $\left.C_{P}\right)$ are calculated as follows:

$$
\begin{aligned}
C_{s}=\frac{F_{s}}{0.5 p V^{2} A} & C_{L}=\frac{F_{L}}{0.5 p V^{2} A} \\
C_{Y}=\frac{F_{Y}}{0.5 p V^{2} A h} & C_{P}=\frac{F_{P}}{0.5 p V^{2} A h}
\end{aligned}
$$

where $F_{s}, F_{L}, F_{Y}$, and $F_{P}$ are the side force, lift force, yawing moment, and pitching mornent, respectively; $A$ is a reference side area; and $h$ is the reference height of the vehicle.

The variation of these force coefficients with yaw angle for different turbulence conditions was obtained by Robinson and Baker. ${ }^{6}$ The forces were found to be either reasonably constant or to be linear functions of pitch and yaw for small angles, typically less than 0.2 rad yaw. Since $0.2 \mathrm{rad}$ corresponds to a crosswind of $27 \mathrm{~m} / \mathrm{s}$ when the vehicle speed is $135 \mathrm{~m} / \mathrm{s}$, it will only be reached, in practice, during exceptionally stormy conditions. ${ }^{4}$

Assuming a side wind velocity of $10 \mathrm{~m} / \mathrm{s}$, a vehicle velocity of $67 \mathrm{~m} / \mathrm{s}$, a drag coefficient of 0.3 , and an air density of $1.2 \mathrm{~kg} / \mathrm{m}^{3}$, the drag on the vehicle described in (hapter 6 is $3.1 \mathrm{kN}$. A power of $0.21 \mathrm{MW}$ is required to overcome this drag force under these conditions, and it is linearly dependent on the drag coefficient.

\subsection{MICROPRESSURE WAVE}

When a high-speed vehicle enters a tunnel, a compression wave is generated in front of the vehicle, a pressure decrease occurs belsind it, and some of the air flows around the volicle. When the compression wave exits at the end of the tumnel, a boom caused by the relense of the pressure pulse can be heard. In the low-frequency range, the magnitude of the hoom is proportional to the pressure gradient of the compression wave arriving at the tunnel 
exit. ${ }^{1}$ 'The severity of the effect depends on the portion of the tunnol cross-sectional area thut is blocked by the vohiclo.?

T'o reduce the pressure gradient of the compression wave, which is proportional to the third power of the vehicle speed, either a hood with openings can be provided at the entrance of the tunnel or the nose of the vehicle can be streamlined. $\Lambda$ hood with oponings also reduces the aerodynamic force acting on the vehicle when it enters a tunnel. Insido a tunnel, bypasses or side branches can be used to decrease the pressure gradient. Furtherm re, sound-absorbing materials can be used on the tunnel walls. Some of these methods have been applied on the Sanyo-Shinkansen, as well as on the maglev systems in Japan. ${ }^{1}$

\subsection{AERODYNAMIC NOISE}

Aerodynamic noise due to the turbulent boundary layer over a high-speed vehicle can be very significant; the noise level is approximately proportional to the sixth power of the vehicle's speed. In some cases, however, the dominant sources of noise are associated with the gaps between vehicles and with specific regions, such as the vehicle nose. It is important, to recognize and correct the sources of noise in maglev systems at an early stage in their development.

In Japan, a method and a program called ACOUSI'; have been developed on the basis of a series of assumptions to predict the sound field. ${ }^{1}$ A remarkable noise reduction was accomplished by smoothing the uneven surfaces of the ground coils for the MLUJ-001. and MLUJ-002 vehicles. Furthermore, the front profile of the vehicle, one of the possible noise sources, was streamlined for MLU-002, resulting in a reduction of aerodynamic noise compared with MLU-001. Thus, when uneven surfaces of the car body and the guideway are smoothed and soundproof walls are effectively set up, noise can be reduced considerably. ${ }^{8}$

In Germany, the acoustic noise was measured by using a microphone array in conjunction with flow visualization during wind-tunnel testis, and the results of these measurements were used to optimize the vehicle design to reduce aerodynamic noise." Ono of the general requirements for T'R-06 is that the external noise be less than 84 dB peak value at $2,5 \mathrm{~m}$ to the side of the track.

In the United States, the FRA specified the total vehicle noise limit to be 73 dB at $15 \mathrm{~m}$ from the vehicle centerline. This level was set as a goal, but the noise lovel was expected to be much higher." The aerodynamic noise may be reduced by using soundabsorbing materials on the lower surface of the vehicle and/or the guideway, as well as by making the vehicle's surfaco smooth. 


\subsection{AERODYNAMIC BRAKES}

The cruising speed of maglev vehicles is oxpected to be higher than the landing spoes of modorn jets. At these speeds, aerodynamic drag can be used as a brake. In general, aerodynamic brakes will bo used as a backup. For safety, the maximum deceleration should be limited to $-0.2 \mathrm{~g}$ 's. Several considerations apply to the design of an aerodynamic brake:

- The aerodynamic brake should be tested in a wind tunoel to select the appropriate parameters.

- The vehicle's response should be checked on a full-scale model or by computer simulations.

- The vehicle should not be allowed to displace more than an acceptable amount of air in both the lateral and vertical directions.

A 1/25th-scale model was tested in a wind tumnel, and a full-scale model was used by Japun in testing the MLU.001. ${ }^{10}$

\subsection{RLFERENCES FOR CHAPTER 5}

1. Matsunuma, S., et al., A Study on the Characieristics of the Aerodynamics of the Magrietically Levitated. Transportation System (MAGLEV), Proc. Eleventh International Conf. on Magnetically Levitated Systems and Linear Drives (Maglev '89), Yokohama, Japan, July 7-11, 1989, pp. 275-280 (1989).

2. Brockie, N.J.W., and C.J. Baker, The Aerodynamic Drag of High Speed Trains, J. Wind Engineering and Industrial Aerodynamics, 34:273-290 (1990).

3. Ciande, P.J., The Vehicle Transrapid 06, Specification and Experiences under Practical ('inditions, Proc. International Conf, on Maglev 'Transport '85, pp. 115-121 (1985).

1. Rhodes, R.G., and B.E. Mulhall, Magnetic Levitation for Rail Transport, Clarendon Press Oxford, New York (1981).

5. Philco-Ford Corporation, Conceptual Design and Analysis of the Tracked Magnetically Leuitated. Vehicle Technology Program, Repulsion Scheme, Vol. I: Technical Studies, Roport DOT-FT-40024, Task 1 (1975).

6. Robinson, C.G., and C.J. Baker, The Effect of A tmospheric T'urbulence on Trains, J. Wind Engineering and Industrial Aerodynamics, 34:251..272 (1990).

7. Hammitt, A.G., Special Aerodynamic Problems of High Speed Ciround Tramsportation. Systrms, High Speed Ground Transportation J., 8(2):93-100 i1974). 
8. Fujie, J., Current Status of EDS System in Japan, Proc. Eleventh International Conf. on Magnetically Levitated Systems and Linear Drives (Maglev '89), Yokohama, Japan, July 7-11, 1989, pp. 81-83 (1989).

9. Alscher, H., Aero-Acoustic Investigations of the Magnetic Train Transrapid 06, l'roc. Eleventh International Conf. on Magnetically Levitated Systems and Luear Drives (Maglev '89), Yokohama, Japan, July 7-11, 1989, pp. 269-274 (1989).

10. Oda, K., M. Azakami, and M. Yoshimura, Development of Aerodynamic Brake of Maglev Vehicle for Emergency Use, Proc. Eleventh International Conf. on Magnetically Levitated Systems and Linear Drives (Maglev '89), Yokohama, Japan, July 7-11, 1989, pp. 281-286 (1989). 


\section{MAGLEV VEHICLE DESIGN}

Many different EMS and EDS suspension and motor designs can be tested in the test vehicle at speeds up to $67 \mathrm{~m} / \mathrm{s}(150 \mathrm{mph})$. To reduce costs and achieve this speed in a short distance, the vehicle must be small and light. An aluminum alloy is used for the vehicle structure to reduce weight, and a streamlined vehicle body is used to minimize the aerodynamic drag. The use of the aluminum alloy also minimizes the interference with the magnetic fields of the propulsion and levitation systems. Figure 6.1 shows an artist's conception of the vehicle on the guideway. The vehicle is divided into two compartments: a lower propulsion and suspension compartment and an upper test equipment and passenger compartment. For EDS applications, the major components in the vehicle include superconducting magnets, cryogenic systems, auxiliary supporting wheels and their suspension, auxiliary guiding wheels, a control panel, test equipment, and a passenger seat. Some of the major components of the vehicle are shown in Figures 6.2 and 6.3. Figure 6.2 shows the seat and control panel. Figure 6.3, a transparent view of a test vehicle, shows the general locations of motors, supporting wheels, and the floor separating the two compartments. Current plans do not include the carrying of passengers during levitated operation, although provision is made for possible passenger use in the future.

General design concepts of the rehicle are discussed in this chapter. The chapter is organized into five main sections: vehicle configuration, structure and components, wheel and brake systems, accessories and instrumentation, and vehicle specifications and testing.

\subsection{VEHICLE CONFIGURATION, SHAPE, AND DIMENSIONS}

The rehicle's dimensions are determined by the size of the guideway, the size of major components, and the ability of the vehicle to accommodate a variety of experimental components. Aerodynamic drag and acoustic noise are primarily dependent on the vehicle shape, size, and velocity. An understanding and analytical description of these effects are especially important for comparing the test results with the analytical models of the system.

The overall configuration of the test vehicle is shown in Figure 6.4. The 7.4-m-long, 1.8-m-wide, and 1.8-m-high vehicle has a streamlined shape to minimize aerodynamic drag and noise. The body is divided longitudinally into three sections: a $1.75-\mathrm{m}$ nose section, a 3.90-m midsection, and a $1.75-\mathrm{m}$ tail section. As shown in Figure 6.4a, the curves in both the nose and tail sections are smooth. The nose and tail streamlines consist of circular arcs and inclined straight lines. The circular arc starts from the bottom of the vehicle, where the slope of the arc is vertical to the vehicle half-height point $\left(\mathrm{H}_{1}=0.9 \mathrm{~m}\right)$, at which the slope of the arc matches that of a line inclined at 35 degrees with respect to the horizontal line. A small circular arc connecting the inclined line and the top horizontal line smooths the tratisition. The front view of the vehicle (as shown in Figure 6.4c) has a semicircular top portion $(0.9 \mathrm{~m}$ in radius) and a rectangular bottom portion $(0.9 \mathrm{~m}$ in height and $1.8 \mathrm{~m}$ in width). To 


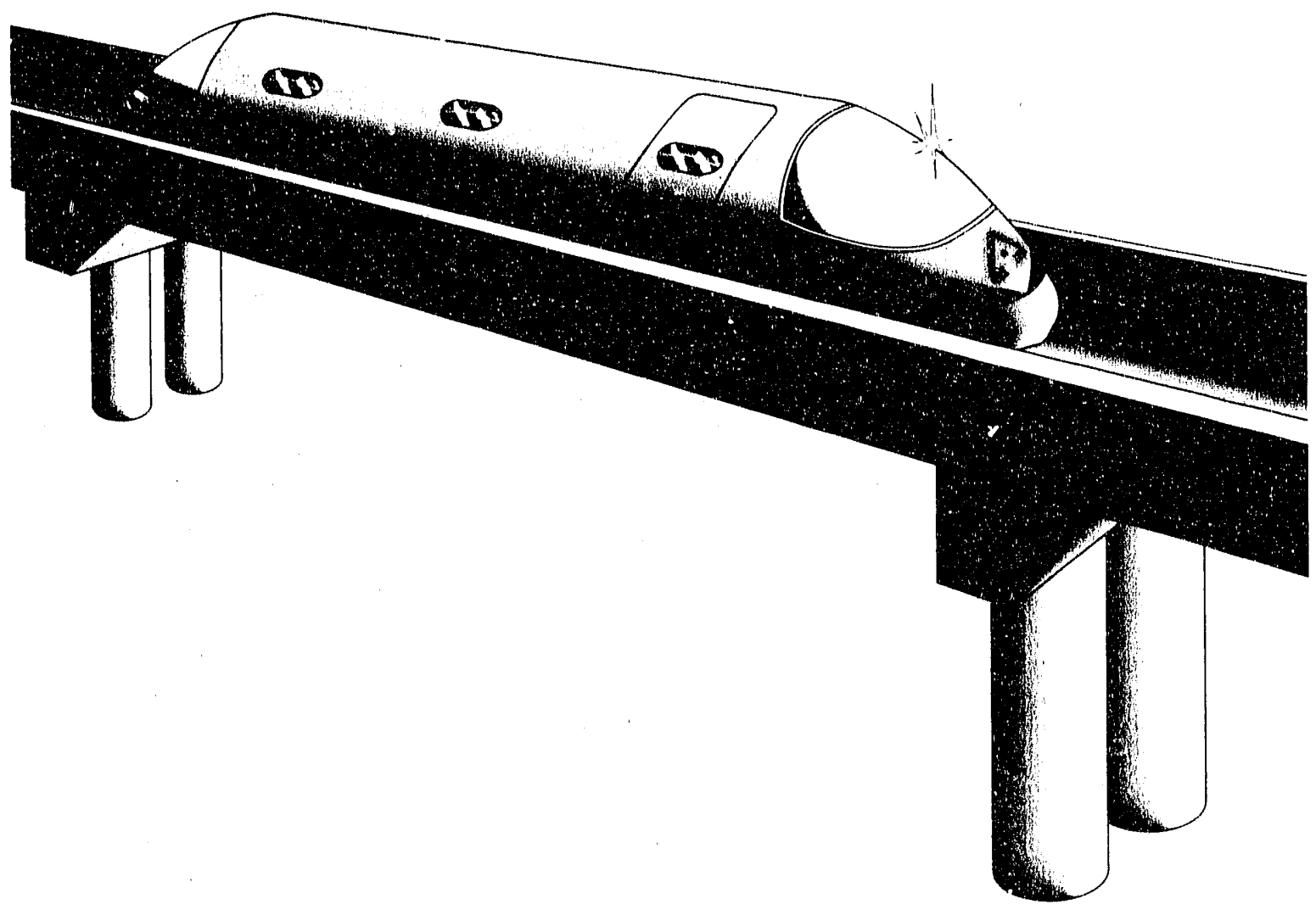

FIGURE 6.1 Artist's Conception of the Maglev Test Vehicle on the Guideway

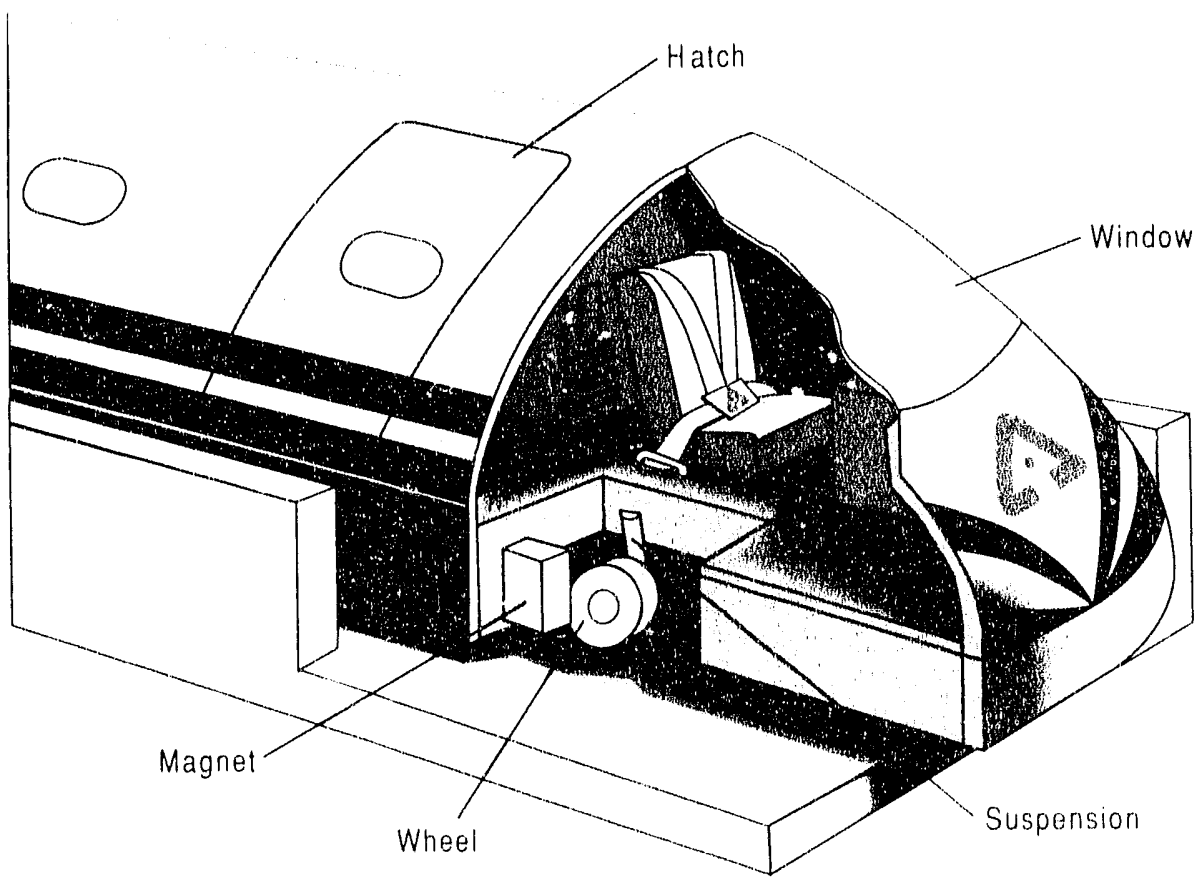

FIGURE 6.2 Major Components of the Maglev Test Vehicle 


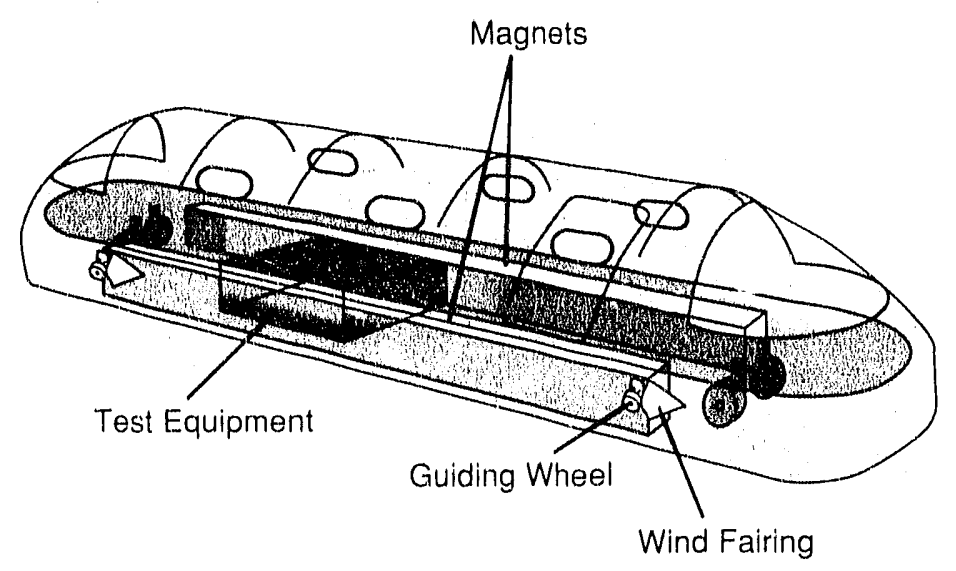

FIGURE 6.3 Cutaway View of the Front End of the Maglev Test Vehicle

facilitate testing of different vehicle designs, the vehicle is divided vertically into two compartments: a test compartment (top) and a propulsion and suspension compartment (bottom). The test compartment ( $1.1 \mathrm{~m}$ in height) is common for all test vehicles and consists of windows, a door, a passenger seat, a control pavel, test equipment, and batteries. The propulsion and suspension compartment $(0.7 \mathrm{~m}$ in height), which can be different for different motor designs, contains levitation anr propulsion magnet systems, cryogenic devices, auxiliary supporting and guiding wheels, and secondary suspension systems. Space in the midsection of the propulsion and suspension compartment can be used for testing various secondary suspension or propulsion systems. The space is $1.5 \mathrm{~m}$ in length, $1 \mathrm{~m}$ in width, and $0.7 \mathrm{~m}$ in height. The primary dimensions of the vehicle are summarized in Table 6.1.

The surface areas of the vehicle that are needed to determine the vehicle weight, aerodynamic drag, and structural strength are computed as follows. The projected areas of the vehicle computed from Figures $6.4 \mathrm{a}, 6.4 \mathrm{~b}$, and $6.4 \mathrm{c}$ are $10.56 \mathrm{~m}^{2}$ for the side area, $13.14 \mathrm{~m}^{2}$ for the top (or bottom) area, and $2.89 \mathrm{~m}^{2}$ for the frontal area. The exterior surface area, excluding the bottom area (or top view projected area), is about $35 \mathrm{~m}^{2}$. The floor area between the test and motor compartments is $12.31 \mathrm{~m}^{2}$.

\subsection{STRUCTURE AND COMPONENTS}

\subsubsection{Layout of Components}

The test compartment of the vehicle contains windows, a sliding door, a passenger seat, a vehicle control panel, test equipment, and an on-board power supply. Curved safety glass is used in all the windows. Inside the door (which is attached to the body frame) is a seat, which faces the vehicle control panel. Test equipment or test equipment instrumentation and controls are installed next to the seat, and on-board power is installed behind the seat. 


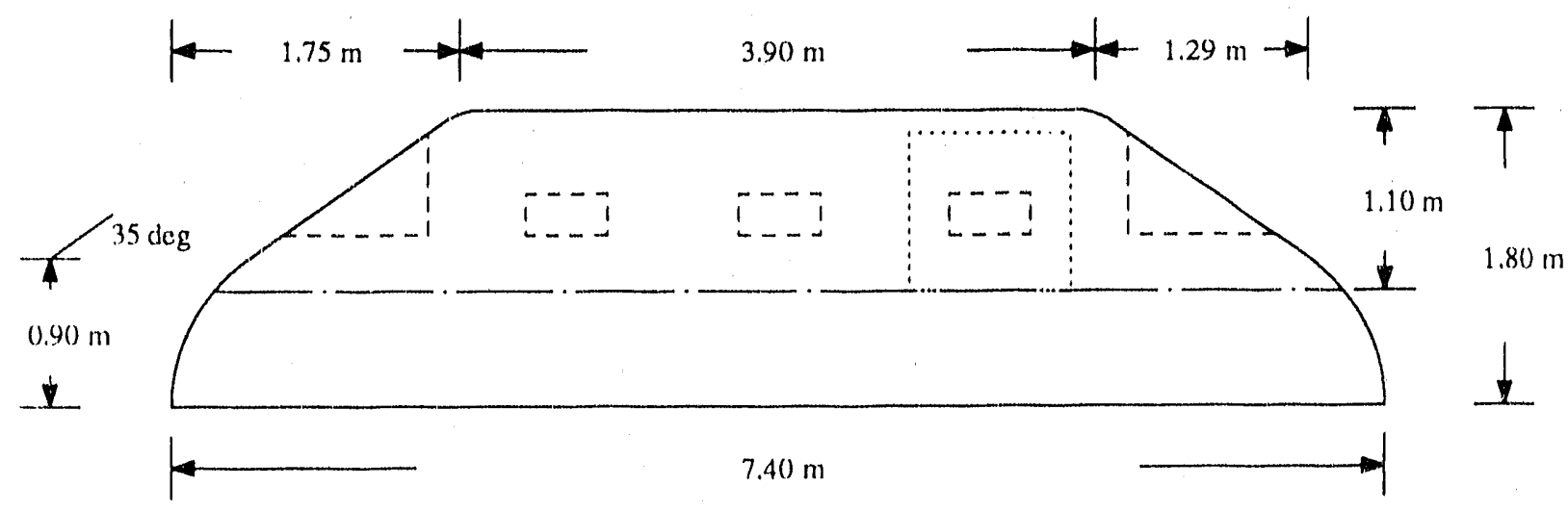

(a) Side View

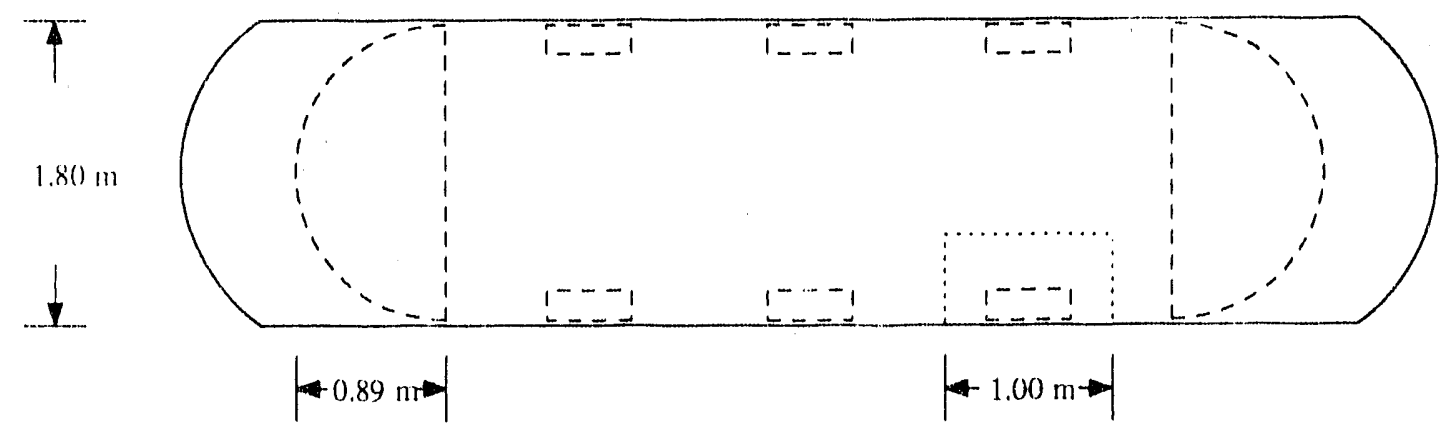

(b) Top Vicw

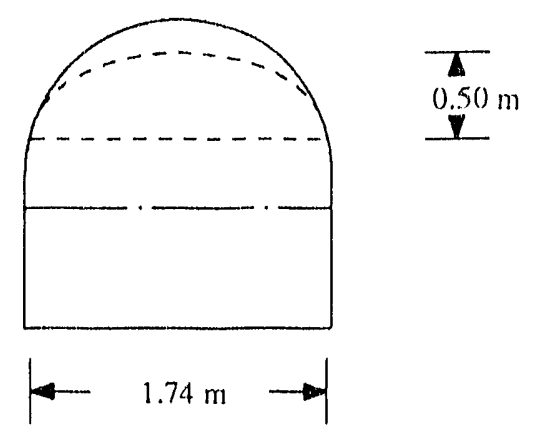

Door

(c) Front Vicw

FIGURE 6.4 Vehicle Dimensions 
The propulsion and suspension compartment contains the levitation and propulsion system, cryogenic devices, auxilian'y supporting and guiding wheels, and a secondary suspension system. The magnetic suspension system is installed along the two sides of the vehicle in the midsection. Two pair's of auxiliary supporting wheels are installed, one pair of wheels in the nose section and the other pair in the tail section. 'T'wo pairs of auxiliary guiding wheels are installed above the supporting wheels. The cryogenic devices are placed between the matgnets in the midsection. The midsection also contains a test equipment compartment, approximately $1.0 \mathrm{~m}$ in width and $1.5 \mathrm{~m}$ in

TABLE 6.1 Major Vehicle Dimensions

\begin{tabular}{lc}
\multicolumn{1}{c}{ Parameter } & Value \\
\hline Dimensions (m) & \\
Length & 7.40 \\
Width & 1.80 \\
Height & 1.80 \\
& \\
Nose Incline Angle (degrees) & 35 \\
Areas $\left(\mathrm{m}^{2}\right)$ & \\
Exterior Surface & 35 \\
Side Surface & 35 \\
Front & 2.89 \\
Bottom & 13.14 \\
Floor & 12.31 \\
\hline
\end{tabular}
length, which can be used for evaluating individual primary and secondary suspensions, propulsion systems, and components.

\subsubsection{Materials for Vehicle Body}

A 3003 aluminum-manganese alloy will be used for the vehicle body to minimize weight and avoid interference with the magnetic fields of the propulsion and levitation systems. This alloy has a high tensile strength and is capable of accepting a considerable amount of cold working. Pre- and posttreatments are not required for welding and brazing. Inert gis-shielded arc welding gives the best results. This alloy is about three times lighter than steel and has about one third the strength of steel.

\subsubsection{Weight and Strength of Vehicle Body and Frame Structure}

$\Lambda$ frame constructed with 25.4-mm-square, $3.18-\mathrm{mm}$-thick aluminum tubes clad in two-layer, 1.6-mm-thick aluminum panels will be used for the body of the vehicle. Fiber glass or styrofoam, having a specific weight of $4.4 \mathrm{~kg} / \mathrm{m}^{2}$, will be installed between the panels. The two-layer panels will weigh $308 \mathrm{~kg}$. The cross-sectional area of the square-tube body frame is $282 \mathrm{~mm}^{2}$, resulting in a specific weight of $0.77 \mathrm{~kg} / \mathrm{m}$. The frame tubes will be spaced $0.5 \mathrm{~m}$ apart, resulting in a total tubing length of $120 \mathrm{~m}$ and a frame weight of $92 \mathrm{~kg}$. The allowable stress of the body frame will be $67 \mathrm{MPa}$, with a safety factor of two. The body frame can carry a load of more than two metric tons.

'The floor plate and chassis aluminum frame are constructed with 50.8-mm-square, 6.35-mm-thick tubes clad in a layer of $2.3-\mathrm{mm}$-thick aluminum panels. The specific weight of the panel is $6.28 \mathrm{~kg} / \mathrm{m}^{2}$. The floor and bottom areas are 12.31 and $13.14 \mathrm{~m}^{2}$, respectively, a11. weigh a total of $160 \mathrm{~kg}$. The cross-sectional area of the square tube used for the lower cumpurtment frame is $1.129 \mathrm{~mm}^{2}$ and has a specific weight of $3.08 \mathrm{~kg} / \mathrm{m}$. Trusses, formed 
from framing material, are proposed for each side of the lower compartment framo and provide the strength to support the magnets, motor compartment equipment, and the vehicle floor, without the bulk and weight of beams of equivalent strength. With framo cross nembers spaced at $0.5 \mathrm{~m}$, the total length of the lower compartment framing tube is alout $150 \mathrm{~m}$, and the frame weighs $460 \mathrm{~kg}$. The floor frame can carry a load of more than eight metric tons. The total weight of the panels and frame is approximately $1,020 \mathrm{~kg}$.

Accessories and test equipment in the upper or test compartment, including the seat, control panel, accessory batteries, and test equipment, are estimated to weigh 0.5 metric tons. The magnets are estimated to weigh less than 1.5 metric tons, and auxiliary equipment for the magnets, such as the cryogenic system, is estimated to weigh 0.5 metric tons. The total estimated mass of the EDS vehicle, with magnets, accessories, and test equipment, is 3.5 metric tons or less.

The center of mass of the vehicle must be low enough to ensure that the vehicle will be stable, especially under the emergency condition of loss of power to the magnets during high-speed operation. Under these conditions, the auxiliary dolly wheels keep the vehich: from contacting the guideway sidewalls. For stable operation under these conditions, at a minimum, the dolly wheels must be located above the vertical center of mass. The vehicle is assumed to be approximately symmetrical from side to side, and therefore, the horizontal mass center is assumed to be located at approximately the vehicle centerline.

On the basis of mass per unit length and the vertical position of the body and frame elements, excluding the nose and tail sections, the weight of the body and frame is about $108 \mathrm{~kg} / \mathrm{m}$, and the vertical position of the center of mass of the body and frame is at $0.52 \mathrm{~m}$. Assuming the equipment weight to be $75 \mathrm{~kg} / \mathrm{m}$ with a vertical mass center at $1.0 \mathrm{~m}$ and magnets at $250 \mathrm{~kg} / \mathrm{m}$ with vertical mass center at $0.30 \mathrm{~m}$, a vertical center of mass cian be calculated to be about $0.48 \mathrm{~m}$. This position is close to but below the position of the dolly wheels $(0.60 \mathrm{~m})$. Additional weight in the lower or motor compartment would improve (lower) the vertical center of mass. Additional weight in the upper compartment, above tho estimates made here, would raise the vertical mass center and require checking to unsure? that the vehicle remains stable.

The maximum deflection for a simple beam with a uniform loarl is:

$$
8=\frac{5 q L^{4}}{384 E I}
$$

where $\delta$ is the maximum deflection, $q$ is the load per unit length, $L$ is the support spacing, $\mathrm{E}$ is the elasticity modulus, and $\mathrm{I}$ is the moment of inertia of the beam. For a square tube having an outside width "a" and inside width " $b$ ":

$$
I=\frac{a^{4}-b^{4}}{12}
$$


For a floor frame tube having outside and inside widths of $50.8 \mathrm{~mm}$ and $38.1 \mathrm{~mm}$, respectively, the moment of inertia is $3.8 \times 10^{-7} \mathrm{~m}^{4}$. If the load of the magnet on the frame does not exceed 0.5 metric ton $/ \mathrm{m}$ and the frame spacing is $0.5 \mathrm{~m}$, the maximum deflection of the floor frame between posts will be less than $0.15 \mathrm{~mm}$.

\subsection{WHEEL AND BRAKE SYS'TEMS}

Supporting and guiding wheels are required in an EDS maglev vehicle. The supporting wheel system consists of tires, brakes, and suspension. Mechanical brakes offer in alternative for stopping the vehicle when regenerative braking by the magnet system fails. During emergency stopping, the wheel suspension absorbs the impact of the vehicle when the tirn contact the guideway.

\subsubsection{Supporting Wheels and Brakes}

Figure 6.5 shows the preliminary design of a supporting wheel and its suspension systom. Either airless or pneumatic tires can be used in this design. Airless tires run smoothly without the risk of deflating, a critical factor in a maglev vehicle because the clearance between the vehicle and guideway is small. These tires are new, however, and their availability in the required size is still uncertain. They consist of metal wheels bonded to rubber treads by an elastomer cast in a polyurethane web-and-spoke design. A crosssectional view of a solid tire wheel and brake is shown is Figure 6.6. Goodyear pneumatic
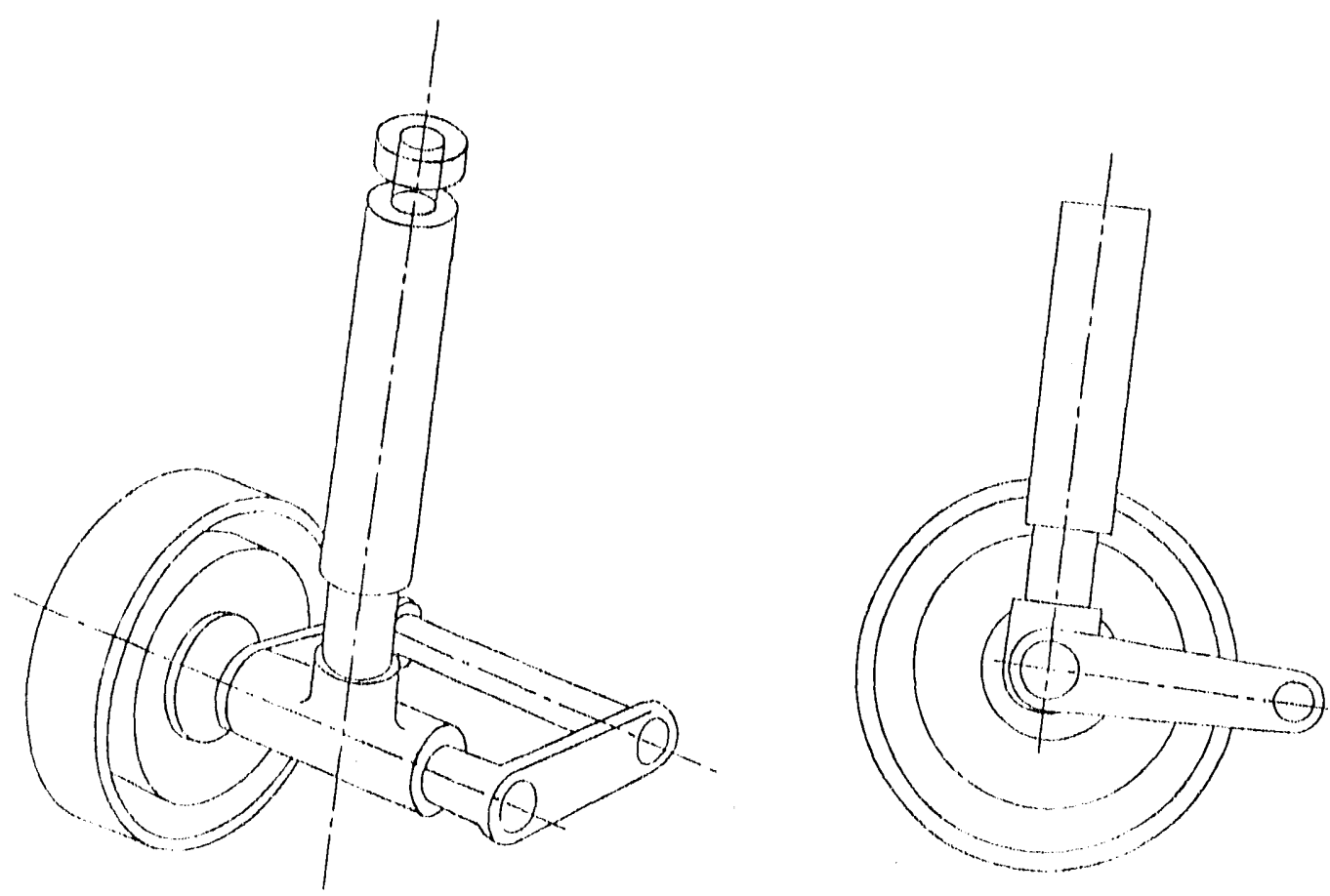

FIGURE 6.5 Supporting Wheel and Śuspension 
aircraft $18 \times 5.75-8$ tires can be used if airless tires are not available. These tires are $45 \mathrm{~cm}$ in diameter and $14.6 \mathrm{~cm}$ wide and have maximum speed and load ratings of $300 \mathrm{~km} / \mathrm{h}$ and 1.4 metric tons, respectively.

The suspension is attached to both the floor plate and the chassis to prevent the vehicle from hitting the guideway during emergency braking. Carbon brakes are recommended, because they will have little effect on the magnetic field and carbon dust from the brake pads will not cause shorting problems in the coils on the guideway. These brakes, as shown in Figure 6.7, would be able to stop a 4-metric-ton vehicle moving at $240 \mathrm{~km} / \mathrm{h}$ in less than $1 \mathrm{~km}$. Carbon brakes would be modified for us: with solid tires if that option were chosen. Four supporting wheels will be used, as shown in Figure 6.8 , to adjust the height of the wheels in relation to the vehicle frame. Two wheels will be in the nose section, and the other two will be: in the tail section. An EMS vehicle will have skids instead of supporting wheels. Skids having a coefficient of friction of 0.3 or more will stop a 9 -metric-ton vehicle traveling at $67 \mathrm{~m} / \mathrm{s}$ in less

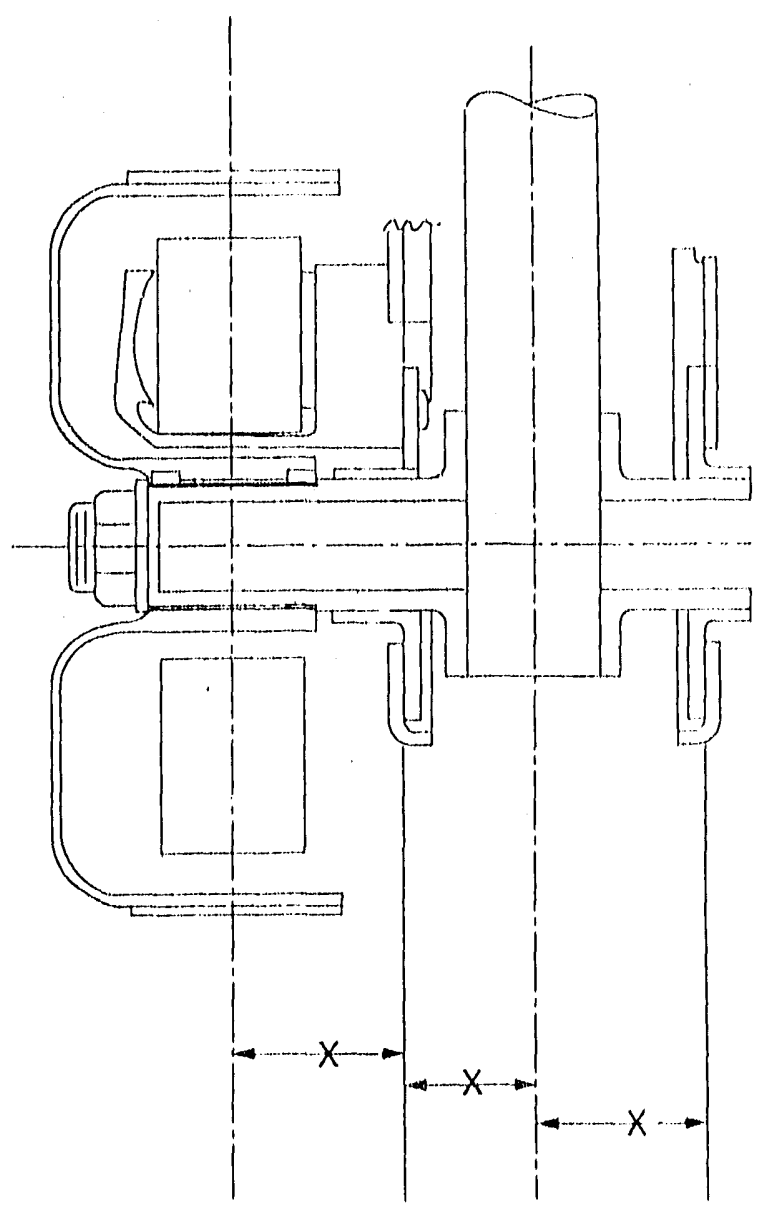

FIGURE 6.6 Whool with Solid Tire and Brake than $1 \mathrm{~km}$.

\section{3,2 Guiding Wheels}

Four dolly wheels (Figure 6.9) will be used to guide the vehicle when magnetic guidance is not available. One pair will be in the nose section and another pair will be in the tail saction. They will be installed about $60 \mathrm{~cm}$ from the bottom of the vehicle to avoid damage to wiring in the guideway siciewalls. An aerodynamic fairing will be used with each wheel to reduce noise and aerodynamic drag. Each wheel will be $10 \mathrm{~cm}$ in diameter and will be installed at a 45-degroe angle with respoct to the vertical line.

\subsubsection{Emergency Stopping System}

To prevent an EDS vehicle from running off the end of the guideway, a safity net and other emergency stopping devices will be installed before the end of the guideway. For a worst-case scenario, the vehicle (4 metric tons and $67 \mathrm{~m} / \mathrm{s}$ ) has to be stopped in $25 \mathrm{~m}$ by the safety net. The rate of deceleration is about $90 \mathrm{~m} / \mathrm{s}^{2}$, and 36 metric tons of stopping force are 
required. Assuming a safety factor of 5 , eight cables ure required for connecting the net. Each 2-cm-diameter steel wire cable provides a strength of 22.5 metric tons. The same system can be used for a 9-metric-ton EMS vehicle with a safety factor of 2 , or additional cables can be added to increase the load factor birck to 5 .

\subsection{ACGESGORIES AND INS'I'RUMEN'TA'TION}

\subsection{1 (An-Board Power}

Forty-five kilowatts of on-board power will be provided by standard leadracid $12-\mathrm{V}$ batterics for powering the magnets, test upuipment, and accessories of an EMS system. The specifications for a typical 70.A.h aulomobile battery are given in Table 6.2. 'This battery can supply $3.5 \mathrm{~A}$ for $20 \mathrm{~h}$ with a steady voltage. The efficiency, however,

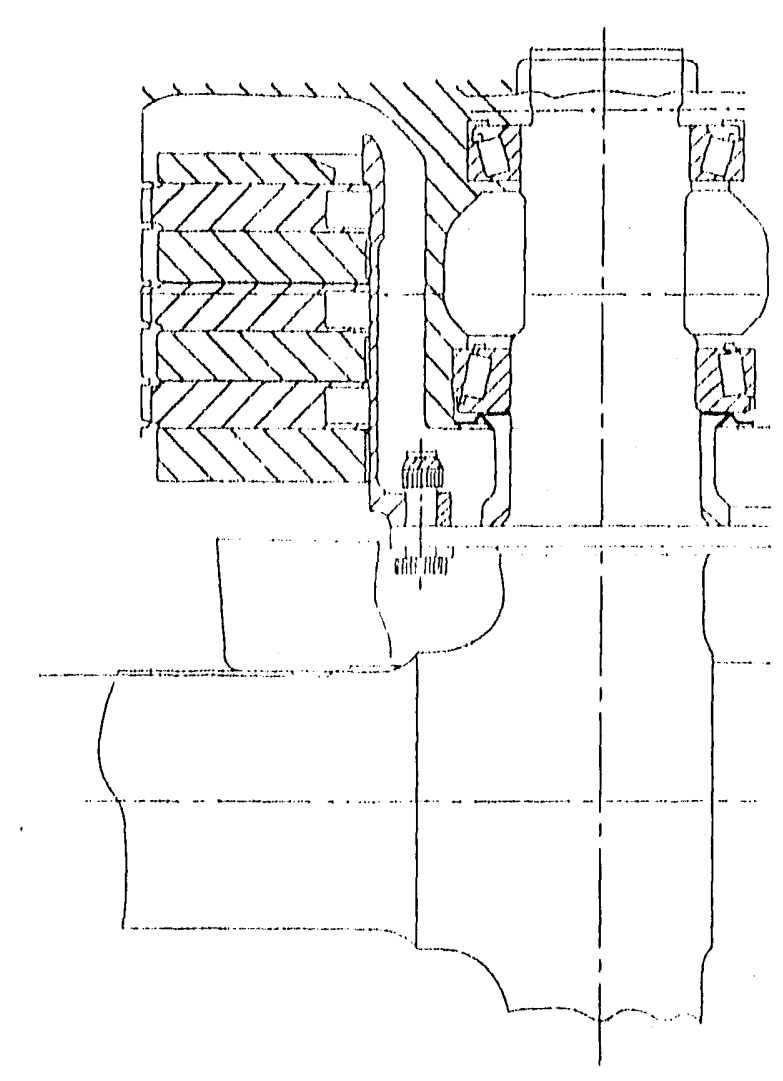

FIGURE 6.7 Curbon Brake depencls strongly on the discharge rate and tomperature. At a discharge rate of $150 \mathrm{~A}$ and a temperature of $80^{\circ} \mathrm{F}$, the battery can maintian a steady $9.3 \mathrm{~V}$ for $16 \mathrm{~min}$. At a temperature of $0^{\circ} \mathrm{F}$, however, the operating time decroases to $10 \mathrm{~min}$. More than 32 100-A h batteries, weighing 0.7 metric tons, will be recpuired. A separate ventilation system is necessary for this number of batteries. Since test runs will be of short duration, and the vehicle can be heated in the garage prior to a test, the lomprorature factor will be only a minor inconvenience.

\subsubsection{Accessories}

Since testing of the vehicle is anticipated in all weather conditions, some accessory rfuipment is required, both for the workers and for the equipment aboard the vehicle. An (lectrically heated windshield of triplex safety glass will be used and will be supplied with windshicld wipers. Safety glass will be used for other windows. A flow-through ventilation systrm will permit air to flow through the vehicle interior, entering in the standard way from the front of the vehicle and exhausting through vents in the tail. A separate ventilation system will be used for the area containing the batteries. A propane heater with a $2(0-1 \mathrm{~b}$ (1) k kis) tank will be installed that can heat the vehicle for several days in cold weather. 'Towing ryes will be provided at the front and roas of the vehiclo, and lifting sockets will bo: installed on the vehicle. Headlamps will he provided in the front amd rear of the vehicle. 


\subsection{VEHICLE INSPICCTION AND 'TESTING}

Quality and configuration nıanagomont and control procedures will be developed and implemented during the construction of the vehicle and its component parts. After construction, it will be necessary to inspect and test the vehicle in detail prior to operating it for ins intended purposes. Detailed acceptance-test procedures will be developed to ensure that all parts of the vehicle have been constructed as designed and that the design is in fact adequate for the vehicle.

Checklists similar to those used in aircrift operations will be developed and used to ensure that the vehicle is in operational condition prior to dally exporiments and during the day if functional parts of the vehicle have been modified during the day.

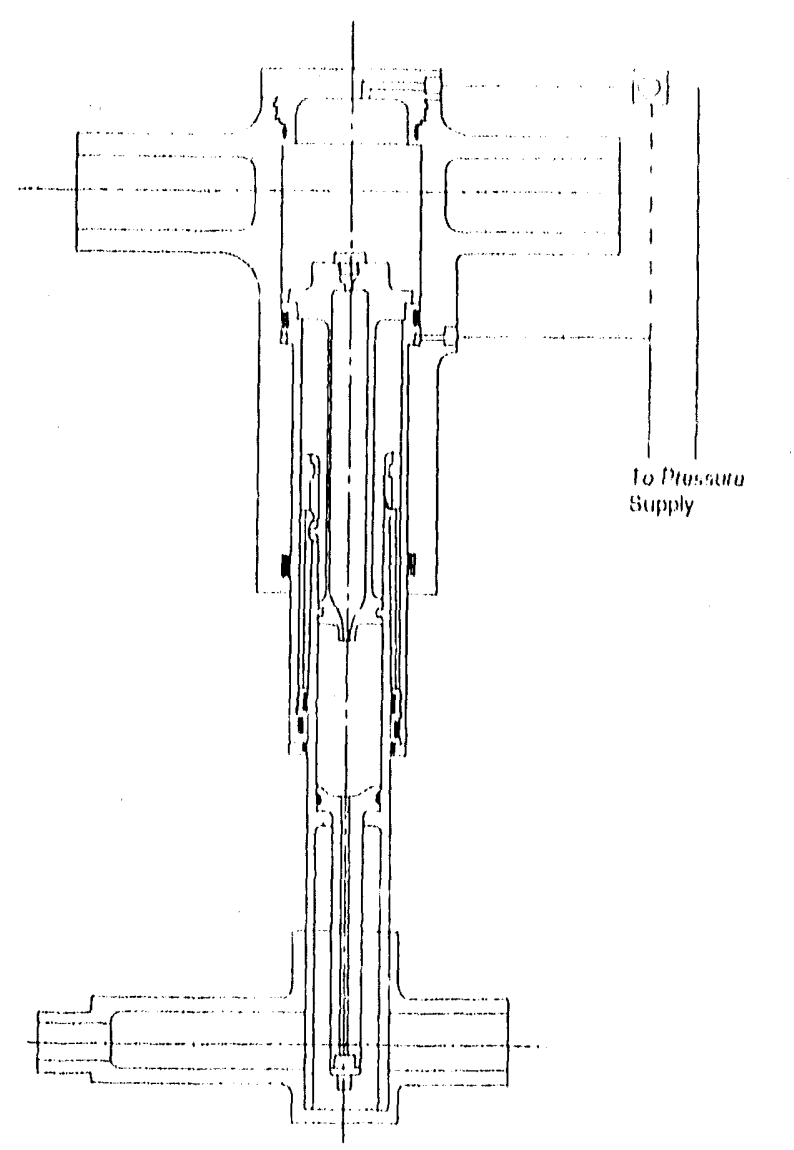

FIGURE 6.8 Wheel Suspension and Hydraulic Control System 
TABI 6.2 Specifications for a Typical Battery

\begin{tabular}{|c|c|}
\hline Parameter & Value \\
\hline Numinal voltage (V) & 12 \\
\hline l)imensions & \\
\hline Longth (mm) & 2,60 \\
\hline Width (mm) & 173 \\
\hline Height (mm) & $2: 26$ \\
\hline Volume (L) & 1.0 .1 \\
\hline Weight (kg) & 21.5 \\
\hline 20-h rating capacity $(A \cdot h)$ & 70 \\
\hline 0 fis discharge time (min) & 6.0 \\
\hline Vultage at $5 \mathrm{~s}$ at $150 \mathrm{~A}(\mathrm{~V})$ & 9.3 \\
\hline$\Lambda$ h $/ \mathrm{L}$ at 20 -h rate & 6.9 \\
\hline $\mathrm{A} \cdot \mathrm{h} / \mathrm{L}$ at $0^{\circ} \mathrm{F}$ at $150 \mathrm{~A}$ & 1.48 \\
\hline ('harge current (A) & 5.25 \\
\hline
\end{tabular}

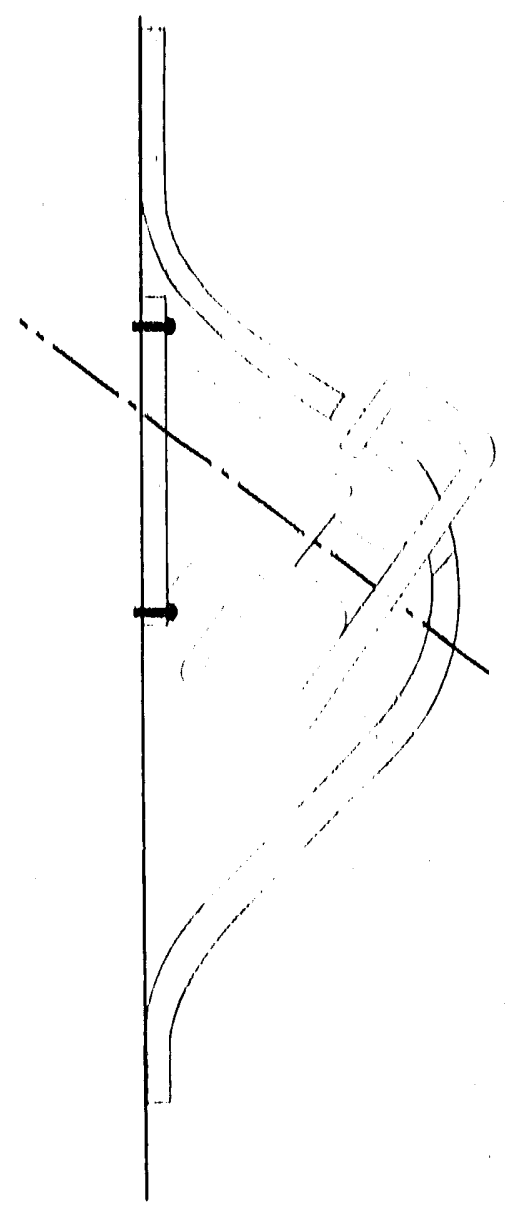

FIGURE 6.9 Guiding (Dolly) Whool and Aorodynamic Fairing 


\section{PROPULSION GYSTEMS}

Currently, both the Japanese and Cerman maglov designe incorporate linenr Hynchronous motors for propulsion. In this chapter, preliminary analyses are made of such motors for use with a variety of EDS and LMS systems. These designs are used in later chapters to determine the power and control requirements for the experimental facility. 'lho designs are general enough that they should be representative of propulaion systems that, user's of the development facility might propose to study. More detailed analyses will be required befure construction.

\subsection{LONG*STATOR AIR-CORED LINEAR SYNCHIRONOUS MO'TOR}

Air-cored linear synchronous motors (LSMs) have become vory popular in migley applications because they have many advantages over iron-cored LSMa. The unique feat ures of air-cored LSMs include the following: (1) they can propel 11 maglev vehicle at 4 large clearance, because air-cored LSMs are excited by high-current superconducting magnots (SCMs) aboard the vehicle; (2) the guideway is less costly, because the laminated iron coro on the guideway is eliminated (see the power supply chapter for the cost); and (3) because the required on-board power is reduced substantially and the iron-cored on-board magnots are eliminated, the vehicle bscomes much lighter in weight and the system can have a high payload efficiency.

'The preliminary design of long-stator air-cored LSMs can be made on the basis of a current-shest model that has been widely used in the desigr of conventional eloctrical machines. The design and analysis of linear machines using this approach havo hoon discussed previously. ${ }^{1-7}$ In this chapter, we review the current-sheet model and dovelop a group of simplified closed-form formulas for the long-stator airucored LSM. These simplified formulas relate motor performance directly to system parameters, such as the required SCM currents, the enorgized motor section length, and other system dimonsions. Soveral EDs test. options are evaluated on the basis of tho model.

\subsubsection{Current-Sheot Model}

The current-sheot model represents the field currents aboard tho vehicle and the armalure currents in the guideway by two current sheets. Because both the stator windinge and the SCMs consist of either stranded conductors or many series-connected turns, the current distributions in the coils may be considered uniform. The actual current distributions in the superconducting coils and in the stator windings may be reduced to surface-current sheots by letting the thickness of the conductor vanish while letting the curront donsity, $f\left(\mathrm{~A} / \mathrm{m}^{2}\right)$, go to infinity. If it is assumed that both current shoets are in a traveling.wave for'm, the propulsion force of the LSM is produced from the interaction betwoon the two waves. Figure 7.1 shows a conceptual viow of the linear synchronous motor. In tho 


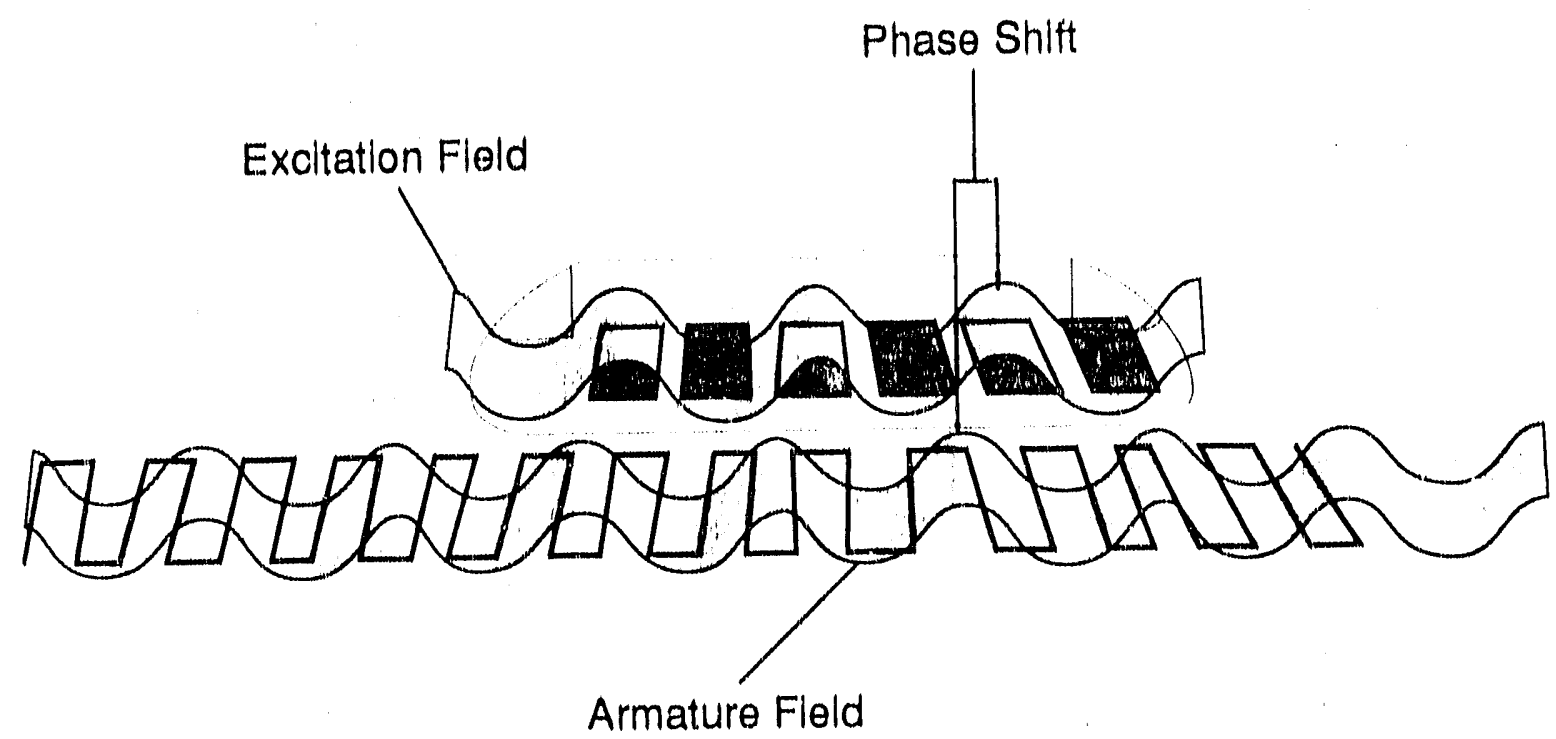

FIGURE 7.1 Conceptual View of the Long-Stator Linear Synchronous Motor

long-stator propulsion system, it is particularly importint to considor the maglev performance under 4 situation in which the energized stator length (or motor-section length), $\mathrm{L}_{H}$, is much longer than that of the on-board magnet system, $L_{y}$. One arrives at the model shown in Figure 7.2, in which the vehicle magnet current sheet, $\mathrm{K}_{\mathrm{v}}$, and stator winding current sheet, $\mathrm{K}_{s}$, are separated by an equivalent air gap, $\mathrm{z}_{0}$, The y-directed current sheets in phasor notation are:

$$
\begin{gathered}
\vec{K}_{v}=K_{v} \\
\vec{K}_{s}=K_{s} e^{j \varphi}
\end{gathered}
$$

where $p$ is the angle between the two currents.

\subsubsection{Forces and Efficiency}

It can be shown that the magnetic vector potential, $\overrightarrow{\mathbf{A}}$, generated by both $\vec{K}_{\mathrm{s}}$ and $\overrightarrow{\mathrm{K}}_{\mathrm{v}}$ satisfies the equation:

$$
\frac{\partial^{2} \vec{A}}{\partial z^{2}}-\beta^{2} \vec{A}=0
$$




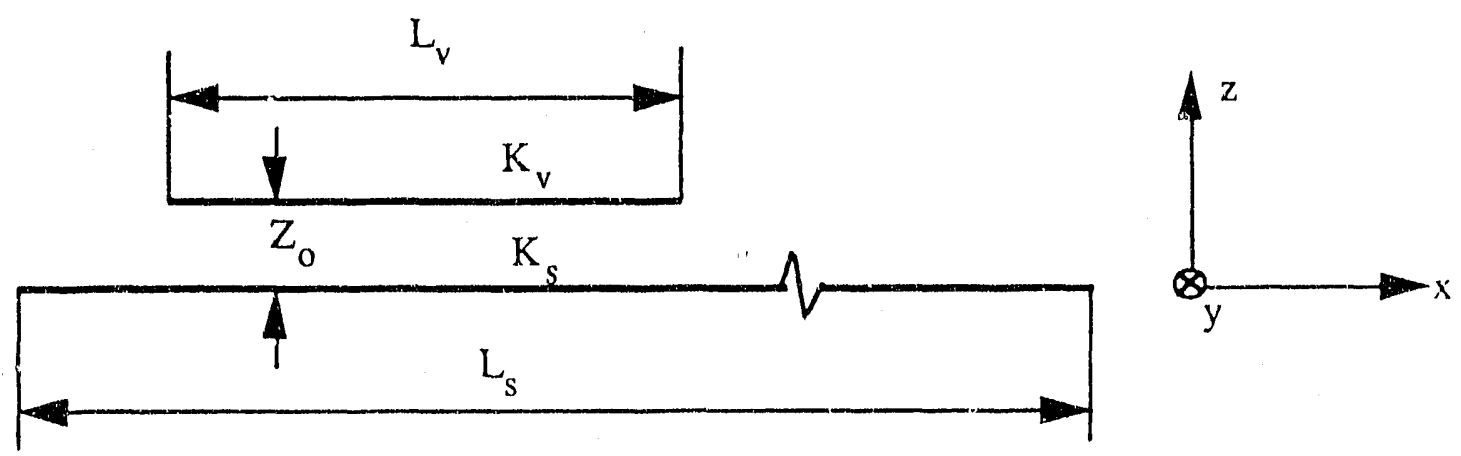

\section{FIGURE 7.2 Current-Sheet Model for Long-Stator Air-Cored Linear Synchronous Motor}

where $\beta=\pi / \tau$ is tile wave number, and $\tau$ is the pole pitch. By solving Equation 7.3, the flux densities, $\overrightarrow{\mathbf{B}}_{\mathbf{z}}$ and $\overrightarrow{\mathbf{B}}_{\mathbf{x}}$, produced by the stator current at $\mathbf{z}=\mathrm{z}_{0}$ are found to be:

$$
\begin{aligned}
& \vec{B}_{z}=j \beta \vec{A}=j \frac{\mu_{0}}{2} K_{s} e^{-\beta z_{0}} e^{j \varphi} \\
& \vec{B}_{x}=\beta \vec{A}=\frac{\mu_{0}}{2} K_{s} e^{-\beta z_{0}} e^{j \varphi}
\end{aligned}
$$

The forces per unit surface $\left(\mathrm{N} / \mathrm{m}^{2}\right)$ acting on the vehicle magnet system located at $\mathrm{z}=\mathrm{z}_{11}$ are then:

$$
F_{x}=\frac{1}{2} R_{e}\left\{K_{v}^{*} \vec{B}_{z}\right\}=\frac{1}{4} \mu_{0} K_{s} K_{v} e^{-\beta z_{0}} \sin \varphi
$$

and

$$
F_{z}=\frac{1}{2} R_{e}\left\{K_{s}^{*} \vec{B}_{x}\right\}=\frac{1}{4} \mu_{0} K_{s} K_{v} e^{-\beta z_{0}} \cos \varphi
$$

If $\mathrm{W}$ and $\mathrm{p}_{\mathrm{v}}=\mathrm{L}_{\mathrm{v}} / 2 \tau$ are the width and the number of pole-pairs of the magnet system, respectively, the total propulsion and levitation forces can be obtained by multiplying Equations 7.6 and 7.7 by the area of the magnet system, $2 \tau p_{v} W$. If the vehicle runs at a synchronous speed $\mathrm{v}$, the total converted power is then:

$$
P_{\text {conv }}=v F_{y} 2 p_{\nu} \tau W
$$


The total power dissipated in the $L_{s}=2 p_{s} \tau$ long-stator windings is:

$$
p_{\text {lass }}=\frac{K_{s}^{2}}{2 \sigma a_{s}} 2 p_{s} \tau W
$$

where $a_{s}$ and $\sigma$ are the equivalent thickness and conductivity of the statior conductors, respectively. From Equations 7.8 and 7.9, we obtain the efficiency of a long-stator LSM:

$$
\eta=\frac{P_{\text {conv }}}{P_{\text {conv }}+P_{\text {loss }}}=\frac{e^{-\beta \varepsilon_{0}} \sin \varphi}{e^{-\beta z_{0}} \sin \varphi+\frac{L_{s}}{L_{v}} \frac{K_{s}}{K_{v}} \frac{v_{c}}{v}}
$$

where $v_{c}=2 /\left(\mu_{0} \sigma a_{s}\right)$ may be defined as a characteristic speed, depending on the thickness and material properties of the stator conductors. It is seen from Equation 7.10 that the efficiency of a long-stator LSM depends on the product of ratios $\mathrm{L}_{\mathrm{s}} / \mathrm{L}_{\mathrm{v}}, \mathrm{K}_{\mathrm{s}} / \mathrm{K}_{\mathrm{v}}$, and $\mathrm{v}_{\mathrm{c}} / \mathrm{v}$ for a given pole pitch $\tau$, levitation gap $z_{0}$, and current angle $\phi$. A long block length, or motor section, may be achicved by either increasing the on-board magnet current or the vehicle speed, because high speed and large excitation current can compensate the inductive reaction power in the remainder of the guideway. For given $\mathrm{K}_{\mathrm{v}}$ and $\mathrm{K}_{\mathrm{s}}$, it seems necessary to have a short block length at low speeds and a longer block length at high speeds. For example, if the following values are assumed:

$$
\begin{aligned}
\mathrm{Z}_{0} & =0.25 \mathrm{~m}, \\
\tau & =1 \mathrm{~m}, \\
\phi & =120 \\
\mathrm{~L}_{\mathrm{s}} & =2000 \mathrm{~m}, \\
\mathrm{~L}_{\mathrm{v}} & =20 \mathrm{~m}, \\
\mathrm{~K}_{\mathrm{s}} / \mathrm{K}_{\mathrm{v}} & =0.01, \text { and } \\
\mathrm{v}_{\mathrm{c}} / \mathrm{v} & =0.1,
\end{aligned}
$$

then the efficiency is about $79 \%$. The efficiency considered in Equation 7.10 represents an ideal case. In practice, side-bar conductors reduce the system efficiency, as discussed in Section 7.1.3. 
By introducing a nondimensional parameter, $\Omega$ :

$$
\Omega=\frac{L_{s}}{L_{v}} \frac{K_{s}}{K_{v}}=\frac{\text { Equivalemi ampere turns of stator windings }}{\text { Equivalent ampere turns of field windings }}
$$

one obtains from Equation 7.10:

$$
\eta=\frac{e^{-\beta z_{0}} \sin \varphi}{e^{-\beta \varepsilon_{0}} \sin \varphi+\Omega \frac{v_{c}}{v}}
$$

where $\Omega$ is an important design parameter that relates the surface current densities, the length of the magnet system, and the length of the motor section directly to the motor efficiency.

Figure 7.3 shows the dependence of the LSM efficiency on current angle $\varphi$, with $₫ 2$ as a parameter. It is seen from Figure 7.3 that $\Omega$ should be kept smaller than unity in order to have a relatively high efficiency, and the efficiency does not change significantly as the current angle changes from $45^{\circ}$ to $135^{\circ}$.

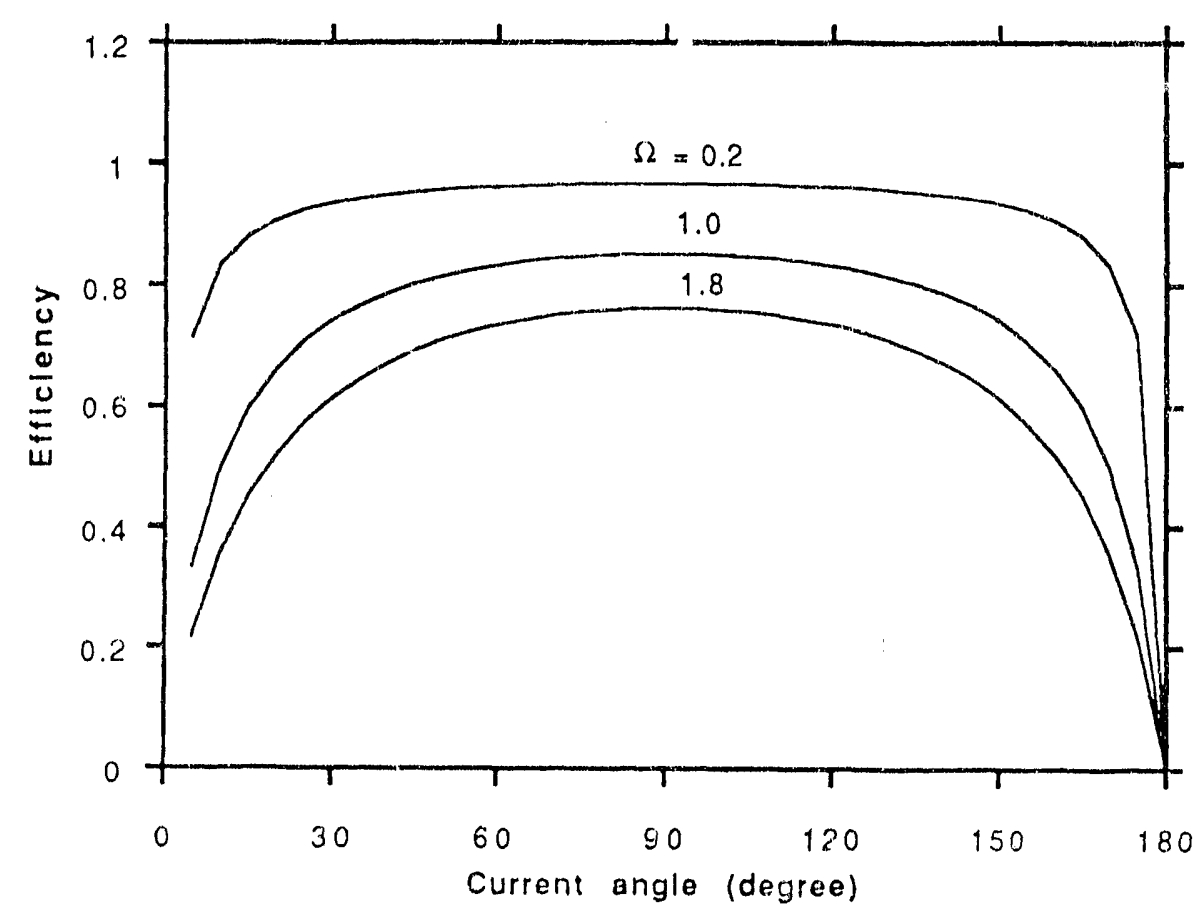

FIGURE 7.3 Efficiency as a Function of Current Angle, with Ratio $\Omega$ as a Parameter $\left(Z_{o}=0.25 \mathrm{~m}, \tau=1.0 \mathrm{~m}, \mathrm{v}_{\mathrm{c}}=5.3 \mathrm{~m} / \mathrm{s}\right.$, and $\mathrm{v}=67 \mathrm{~m} / \mathrm{s}$ ) 


\subsubsection{Voltage, Current, and Power Factor}

The voltage of the stator windings consists of two parts: the voltage corresponding to the magnet system and the voltage corresponding to the remaining motor section. Assuming that the stator windings are connected in series in each phase, the terminal voltage per phase is obtained by adding the two voltages. The electric field associated with the magnet system is:

$$
\vec{E}_{v}=v \vec{B}_{z}=j \frac{\mu_{0} \nu}{2}\left[K_{s} e^{j \varphi}+K_{v} e^{-\beta z_{0}}\right]
$$

and the electric field associated with the remaining motor sections is:

$$
\vec{E}_{s}=j \frac{\mu_{0} v}{2} K_{s} e^{j \varphi}
$$

By letting $\mathrm{N}_{\mathrm{s}}$ be the effective number of turms per coil per pole-pair in the stator windings, the phase voltage across the $p_{\mathrm{s}}$ pole-pair series-connected stator windings is:

$$
\vec{V}_{p h}=\frac{2 W N_{s}}{\sqrt{2}}\left\{P_{v} \vec{E}_{\nu}+\left(P_{s}-P_{\nu}\right) \vec{E}_{s}\right\}=j \frac{\mu_{0} \nu W N_{s}}{\sqrt{2}}\left\{p_{v} K_{v} e^{-\beta_{\nu_{0}}}+p_{s} K_{s} e^{\nu \varphi}\right\}
$$

By introducing the relation between the phase current, $I_{p h}$, and the sheet current, $K_{\mathrm{s}}$,

$$
\vec{K}_{s}=\frac{3 \sqrt{2} \vec{I}_{p h} 2 N_{s}}{2 \tau}=\frac{2 \sqrt{2} \vec{I}_{p h} N_{s}}{\tau}
$$

a terminal impedance per phase is obtained:

$$
Z_{p h}=\frac{\vec{V}_{p h}}{\vec{I}_{p h}}=\frac{3 \mu_{0} \nu W N_{s}^{2} L_{s}}{2 \tau^{2}}\left\{\frac{e^{-\beta z_{0}} \sin \varphi}{\Omega}+j\left[1+\frac{e^{-\beta z_{0}} \cos \varphi}{\Omega}\right]\right\}
$$

The relations $\mathrm{p}_{v}=\mathrm{L}_{\mathrm{v}} / 2 \tau, \mathrm{p}_{\mathrm{s}}=\mathrm{L}_{\mathrm{s}} / 2 \tau$, and Equation 7.11 have been used to obtain Equation 7.17. The power factor of the LSM from Equation 7.17 is written as follows:

$$
P F=\frac{1}{\sqrt{1+\left[\frac{\cos \varphi}{\sin \varphi}+\Omega \frac{\rho^{\beta z_{0}}}{\sin \varphi}\right]^{2}}}
$$


For $\phi=90^{\circ}$, at which the propulsion force is maximum, the power factor is:

$$
P F=\frac{1}{\sqrt{1+\Omega^{2} e^{2 \beta z_{0}}}}
$$

Equations 7.18 and 7.19 relate the power factor directly to the dimensions of the motor, such as the pole pitch $\tau$, the air gap $z_{0}$, the length of motor section $L_{s}$, and the length of the on-board magnet system $\mathrm{L}_{\mathrm{v}}$, as well as the ratio of the surface current densities $\mathrm{K}_{\mathrm{s}} / \mathrm{K}_{\mathrm{v}}$. For a power factor greater than $70 \%$, the following relationship should hold:

$$
\Omega \leq e^{-\beta z_{0}}
$$

For the previous example, $\tau=1 \mathrm{~m}, \mathrm{z}_{0}=0.25 \mathrm{~m}$, and $\Omega<0.456$; then,

$$
\frac{L_{s}}{L_{v}} \leq 0.456 \frac{K_{v}}{K_{s}}
$$

Equation 7.21 shows a simple relation between the length ratio and the surface current density ratio. If the length of a vehicle magnet system is $20 \mathrm{~m}$, and the surface current density ratio is 100 , the length of the energized motor section should be shorter than $912 \mathrm{~m}$ in order to have a power factor greater than 70\%. Figure 7.4 shows the dependence of the power factor on the current angle, with $\$ 2$ as a parameter. It can be seen from Figure 7.4 that the power factor peaks as the current angle varies from $0^{\circ}$ to $180^{\circ}$ and decreases as $\Omega$ increases. Again, $\Omega$ should be smaller than unity in order to have a reasonable power factor.

So far, the analysis has been based on the ideal current-sheet model without consideration of the leakage inductance of the side-bar conductor. To complete the preliminary design formulas, the side-bar inductance can be added in the following manner: ${ }^{4}$

$$
L_{s h}=\frac{\mu_{0}}{6 \pi} N_{s}^{2} L_{s} \ln \left[\frac{W}{D}+\sqrt{\left(\frac{W}{D}\right)^{2}+1}\right]
$$

and the phase resistance of the stator windings can be rewritten as follows:

$$
R_{s}=\frac{4 L_{s} N_{s}(W / \tau+1)}{\pi \tau D^{2}}
$$

where $\mathrm{D}$ is the diameter of the armature conductor. The equivalent circuit can then be formed from Equations 7.17, 7.22, and 7.23 to determine the major parameters of the longstator air-cored I.SM. 


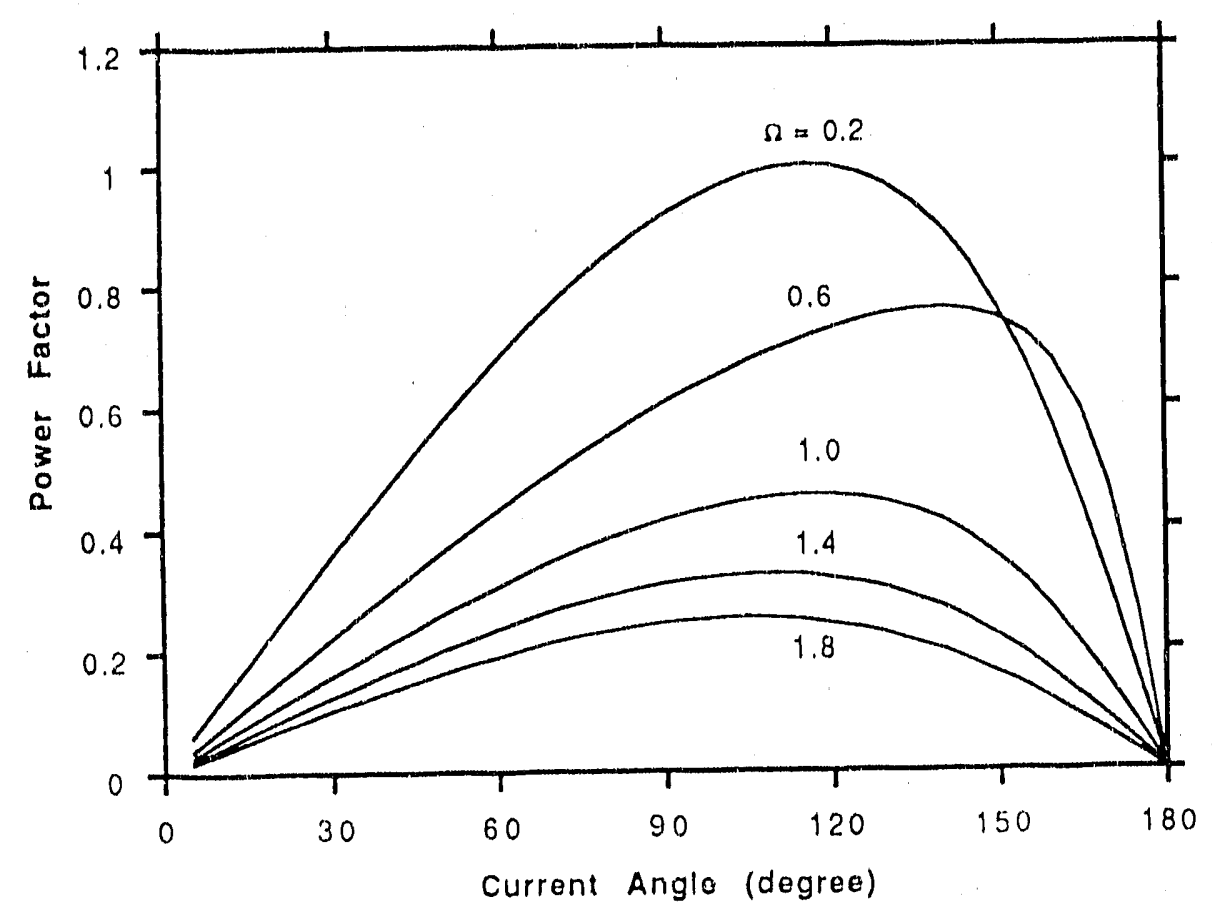

FIGURE 7.4 Power Factor of the Long-Stator Linear Synchronous Motor as a Function of Current Angle, with $\Omega$ as a Parameter $\left(\mathrm{z}_{\mathrm{o}}=0.25 \mathrm{~m}\right.$ and $\left.\tau=1 \mathrm{~m}\right)$

\subsection{LONG-STATOR IRON-CORED LINEAR SYNCHRONOUS MOTOR}

An approach similar to that used in the air-cored LSM design is now used for the preliminary design of the long-stator iron-cored LSM. A current-sheet model for the long." stator iron-cored LSM is shown in Figure 7.5, in which the iron-cored LSM is approximated by two surface-current sheets backed by laminated iron. The length of the energized motor section is $L_{s}$, the length of the DC magnet system aboard the vehicle is $L_{v}$, and $K_{s}$ and $K_{v}$ are the current sheets given by Equations 7.1 and 7.2. The air gap is $\mathrm{Z}_{0}$.

The flux density in the air gap can be determined from Ampere's law: $:^{2,7}$

$$
\vec{B}=j \frac{\mu_{0} \tau}{\pi z_{0}}\left(\vec{K}_{s}+\vec{K}_{\nu}\right)
$$

Thus, the thrust produced per unit surface of the air gap is:

$$
F_{x}=\frac{1}{2} R_{e}\left\{\vec{K}_{v}^{*} \vec{B}\right\}=\frac{\mu_{0} \tau}{2 \pi Z_{0}} K_{s} K_{v} \sin \varphi
$$




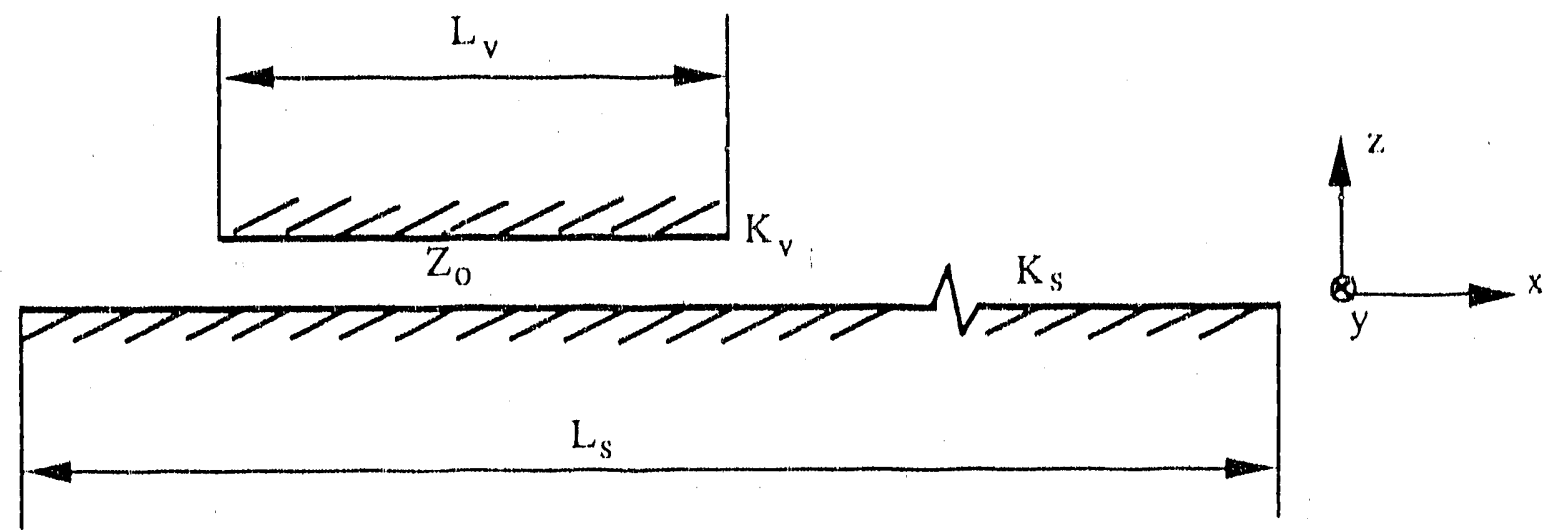

\section{FIGURE 7.5 Current-Sheet Model of the Long-Stator Iron-Cored Linear Synchronous Motor}

Similarly, the lift force acting on a magnet system per unit surface can be obtained from tho following equation: $:^{4,7}$

$$
F_{z}=\frac{\mu_{0}}{4}\left\{\frac{1}{\left(\beta z_{0}\right)^{2}}\left[K_{v}^{2}+2 K_{v} K_{s} \cos \varphi+K_{v}^{2}\right]-K_{v}^{2}\right\}
$$

The total propulsion and lift force acting on the magnet system can be obtained by multiplying Equations 7.25 and 7.26 by $\mathrm{L}_{v} \mathrm{~W}$ or $2 \tau \mathrm{p}_{\mathrm{v}} \mathrm{W}$. The power dissipated in the stator windings, $P_{d i s s, s}$, and in the excitation windings, $P_{\text {diss,v }}$, is given by:

$$
P_{d k s, s}=\frac{K_{s}^{2}}{2 \sigma a_{s}} L_{s} W
$$

and

$$
P_{d t s, v}=\frac{K_{v}^{2}}{2 \sigma a_{v}} L_{v} W
$$

where $a_{s}$ and $a_{v}$ stand for the equivalent thicknesses of the stator winding conductors and field windings conductor, respectively. The efficiency, $\eta$, of a long-stator iron-cored ISM is then:

$$
\eta+\frac{P_{c o m v}}{P_{c o n v}+P_{d l s s, s}+P_{d i s s, v}}=\frac{\sin \varphi}{\sin \varphi+\frac{\beta z_{0} \nu_{c}}{2 v}\left[\Omega+\frac{J_{v}}{J_{s}}\right]}
$$


where $\mathrm{J}_{\mathrm{v}}=\mathrm{K}_{\mathrm{v}} / \mathrm{a}_{\mathrm{v}}$ and $\mathrm{J}_{\mathrm{s}}=\mathrm{K}_{\mathrm{s}} / \mathrm{a}_{\mathrm{s}}$ are the current densities of the field winding and stator winding, respectively. In most cases, $J_{v}$ is approximately equal to $J_{y}$, and Efuation 7.29 becomes:

$$
\eta=\frac{\sin \varphi}{\sin \varphi+\frac{\beta z_{0} v_{c}}{2 \nu}[\Omega+1]}
$$

In Equation 7.30, $\mathrm{z}_{0}$ for an iron-cored LSM is typically about 10 to $20 \mathrm{~mm}$. Thus, the parameter range of $\Omega$ for an iron-cored LSM differs from that for an air-cored LSM.

\subsection{ANALYSIS OF A CYLINDRICAL MAGLEV SYSTEM}

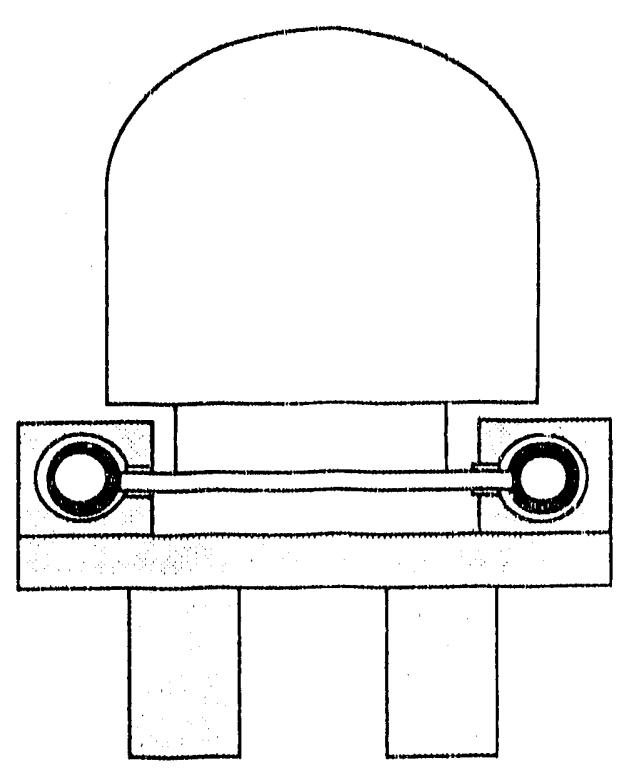

FIGURE 7.6 Front View of the Cylindrical Maglov System

Figure 7.6 shows the basic configuration

of a cylindrical type of maglev system proposed by H. Coffey. The guideway of the system consists of two arrays of solenoid coils energized by a three-phase power source, generating traveling waves along both sides of the guideway. 'Two arrays of superconducting magnets aboard the vehicle interact with the traveling waves to produce propulsion, levitation, and guidance forces. Since the configuration is similar to that of the electromagnetic launcher discussed in the literature, ${ }^{8}$ a cylindrical current-sheet model used for the analysis and design of the electromagnetic launcher is applied to the cylindrical type of maglev system.

Because the superconducting coils aboard the vehicle have constant and uniformly distributed currents, we can represent these currents by a cylindrical current sheet $K_{v}$ located at an average radius $r_{v}$, as shown in Figure 7.7. Similarly, we may represent the currents either in the stator windings or in the aluminum tube by a cylindrical current sheet $\mathrm{K}_{\mathrm{s}}$ located at an equivalent radius $\mathrm{r}_{\mathrm{s}^{\prime}}$. Both $\mathrm{K}_{\mathrm{v}}$ and $\mathrm{K}_{\mathrm{s}}$ are the azimuthal components raveling in the $\mathrm{z}$ direction and have the same phasor notation as given in Equations 7.1 and 7.2 .

In the following analysis, the aluminum tubes are ignored, and the vehicle and stator windings are assumed to be concentric and to have the same pole pitch. The azimuthal compronent of the vector potential A satisfies the following equation:

$$
\frac{\partial^{2} \vec{A}}{\partial r^{2}}+\frac{1}{r} \frac{\partial \vec{A}}{\partial r}-\left(\beta^{2}+\frac{1}{r^{2}}\right) \vec{A}=0
$$




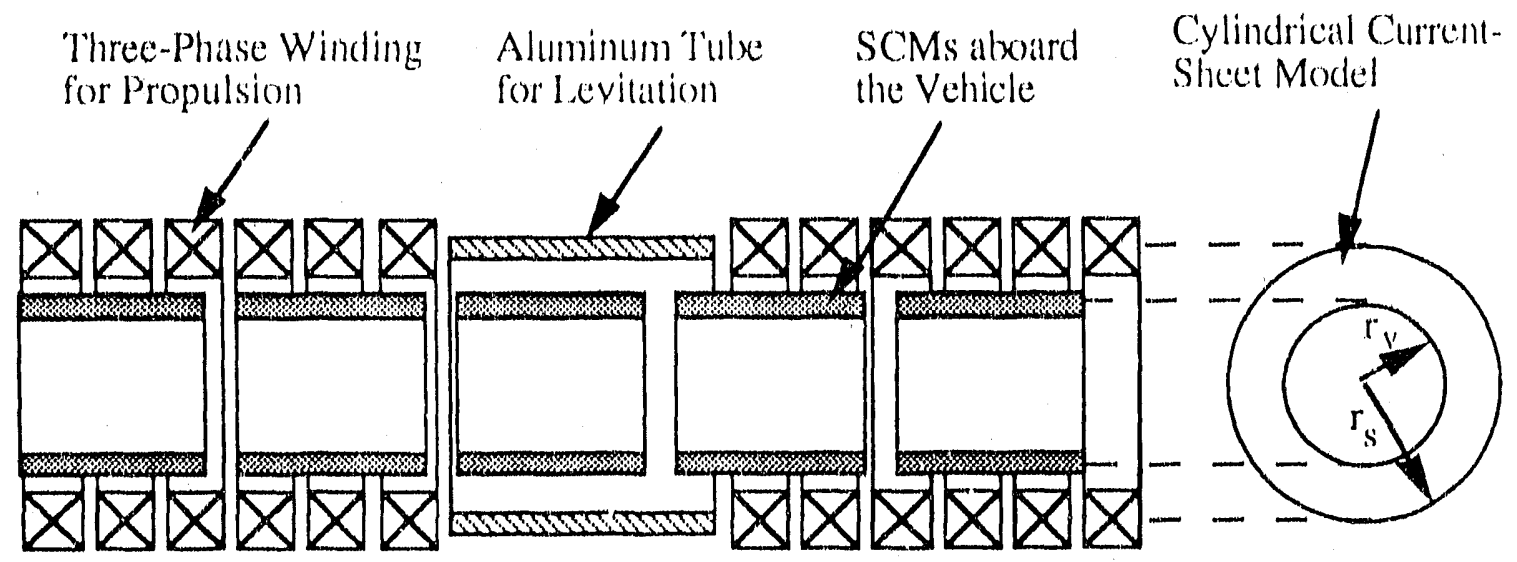

FIGURE 7.7 Side View of the Integrated Propulsion, Levitation, and Guidance System for the Cylindrical Maglev System (transition to current-sheet model)

with the following boundary conditions:

$$
\begin{gathered}
\vec{H}_{z}\left(r_{t}^{+}\right) \cdot \vec{H}_{z}\left(r_{t}^{-}\right)=\vec{K}_{t} \\
\vec{B}_{r}\left(r_{t}^{+}\right)=\vec{B}_{r}\left(r_{t}^{-}\right) \\
\vec{A}(\infty)=0 \text { and } \vec{A}^{\vec{A}}(0) \text { is finite }
\end{gathered}
$$

where subscript $\mathrm{i}$ stands for either $\mathrm{v}$ or $\mathrm{s}, \mathrm{H}=\mathrm{B} / \mu_{0}$, and $\mathrm{B}=\nabla \times \mathrm{A}$.

The solution of Equation 7.31 for a current source, $\mathrm{K}_{\mathrm{s}}$, is:

$$
\vec{A}= \begin{cases}\mu_{0} \vec{K}_{s} r_{s}\left(\beta r_{s}\right) K_{1}(\beta r) & r_{s} \leq r<\infty \\ \mu_{0} \vec{K}_{s} r_{s} K_{1}\left(\beta r_{s}\right) I_{1}(\beta r) & 0 \leq r \leq r_{s}\end{cases}
$$

where $I_{1}$ and $K_{1}$ are modified Bessel functions. Similarly, one can also obtain the magnetic vector potential, $A$, due to the SCMs aboard the vehicle by using the following:

$$
\vec{A}= \begin{cases}\mu_{0} \vec{K}_{v} r_{v} I_{1}\left(\beta r_{v}\right) K_{1}(\beta r) & r_{v} \leq r<\infty \\ \mu_{0} \vec{K}_{v} r_{v} K_{1}\left(\beta r_{v}\right) I_{1}(\beta r) & 0 \leq r \leq r_{v}\end{cases}
$$

The axial component of the flux density produced by $\mathrm{K}_{\mathrm{S}}$ at $\mathrm{r}=\mathrm{r}_{\mathrm{Y}}$ is:

$$
B_{z}=\frac{A_{s}}{r_{v}}+\frac{\partial A_{s}}{\partial r} \mid r=r_{v}=\mu_{0} K_{s} r_{s} \beta K_{1}\left(\beta r_{s}\right) I_{0}\left(\beta r_{\nu}\right)
$$

and the radial component is:

$$
B_{r}=j \beta A_{s}=j \mu_{0} \beta r_{s} K_{s} K_{1}\left(\beta r_{s}\right) I_{1}\left(\beta r_{v}\right)
$$


The propulsion force per unit surface of an SCM can be determined by using the following:

$$
F_{z}=\frac{1}{2} R_{d}\left(K_{v}^{*} B\right)=\frac{1}{2} \mu_{0} \beta r_{s} K_{v} K_{s} K_{1}\left(\beta r_{s}\right) I_{1}\left(\beta r_{v}\right) \sin \varphi \varphi
$$

The total propulsion force is then obtained by multiplying Equation 7.37 by the total magnet surface, $2 \pi r_{v} L_{v}$, where $L_{v}$ is the length of the magnet system,

The radial force per unit surface can be calculated from:

$$
F_{r}=\frac{1}{2} R_{e}\left\langle K_{v}^{*} B_{z}\right\rangle=-\frac{1}{2} \mu_{0} \beta r_{s} K_{v} K_{s} K_{1}\left(\beta r_{s}\right) I_{0}\left(\beta r_{v}\right) \cos \varphi
$$

This expression gives the compressive stress on the vehicle magnets, which should not be confused with the net lift "orce on the magnets. If the two sets of windings are concentric, there is no net lift force. A lift force is achieved when the magnets move away from the concentric position.

For large $\beta \mathrm{r}$, the Bessel functions can be simplified as:

$$
K_{1}(\beta r)=k_{0}(\beta r)=\sqrt{\frac{\pi}{2 \beta r}} e^{-\beta r} \quad \text { and } \quad I_{1}(\beta r)=I_{0}(\beta r)=\frac{e^{\beta r}}{\sqrt{2 \pi \beta r}}
$$

Thus, Equations 7.37 and 7.38 can be simplified as:

$$
F_{z}=\frac{1}{4} \mu_{0} K_{s} K_{v} \sqrt{\frac{r_{s}}{r_{v}}} e^{-\beta_{r_{0}} \sin \varphi}
$$

and

$$
F_{r}=\frac{1}{4} \mu_{0} K K_{v} K_{v} \sqrt{\frac{r_{s}}{r_{v}}} e^{-\beta \tau_{0}} \cos \varphi
$$

Equations 7.40 and 7.41 are similar to Equations 7.6 and 7.7, because at large $\beta$ r, the curvature of the conductors can be neglected so that the cylindrical current sheets become planar sheets. As before, this should not be interpreted as the net lift force. The effects of the aluminum tubes with respect, to the lift and drag forces produced can be analyzed in a similar manner. Additional studies need to be performed to determine the efficacy of this approach. 


\subsection{PROPULSION OP'TIONG FOR 'THE'T FACILIT'Y}

\subsubsection{LOS Tost Options}

Four differome liypos of Bus test options, shown in liguress 7.677.10, wore studiud. The cylindrical configuration shown in Figures 7.6 and 7.7 was discusesed in Section 7.3. In Figuro 7.8, the propulsion windings are horizontally arranged above the SCMs on both sides of the vehicle, and the vehicle is levitated above the angle-shapod aluminum shoet. Its levitation schome is discussed in the noxt chapter. One of tho advantages of the scheme is that the magnotic field in the cabin can lo reduced. Figure 7.9 shows an EOS option, in which the vohicle is levitated above the loop-shaped coil guideway

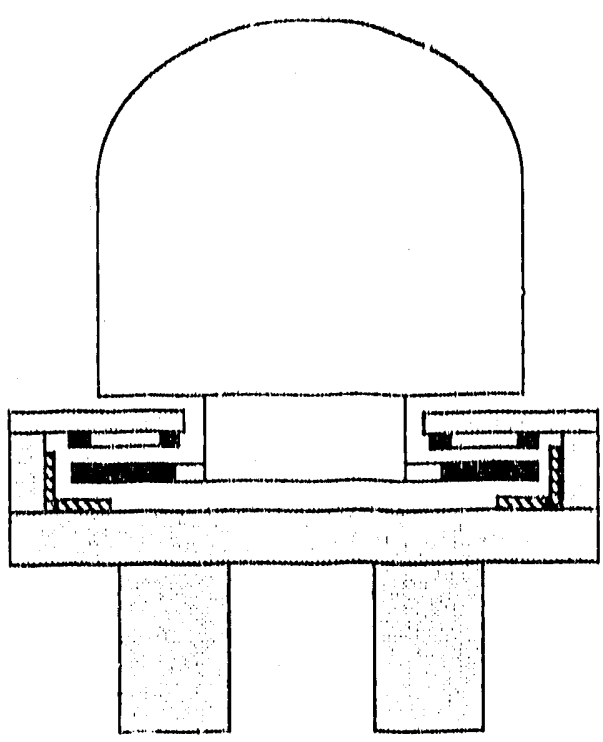

FIGURE 7.8 EDS 'Tant Vohiclo, Option \#1: ContinuousmShoot Suspension and propelled by the LSMA arranged vertically in both sides of the vehicle. 'The null-flux figure-eight-shaped coil suspension shown in Figure 7.10 has both propulsion windings and figure-eight coils mounted vertically on both sides of the guideway. Detailed discussions on suspensions are given in the noxl chapter.

The EDS tesst vehicle weighs about four metric tons ( see vehicle design for detailod dimensions). Assuming an acceleration of $0.2 \mathrm{~g}$ 's, we obtuin the totial propulsion force and powe! requirement, as shown in Figure 7.11. 'The air-cored LSM is alesigned to generate a total thrust of $1.1 \mathrm{kN}$. This force should be sulficient to overcomo acrodynamic and magnotic drags and to propol a 4-motric-ton vehicle at $67 \mathrm{~m} / \mathrm{s}$ with $0.2 \mathrm{~g}$ 's. However, it should be noted that $11 \mathrm{kN}$ is not enough to overcome the peak electromagnetic drag at about 3 to $5 \mathrm{~m} / \mathrm{s}$. Hydraulically actuated wheels are necessary to lift tho vohicle at low speed to avoid this poik. The detailed proliminary designs of LSMs for two bDS test options, a six-magnot vohicle and a fourmagnet vehicle, are listed in T'ables 7.1 and 7.2. In both cases, tha longth of the energized motor section is $320 \mathrm{~m}$, and the $3.2-\mathrm{km}-\mathrm{long}$ guideway is divided into 10 blocks.

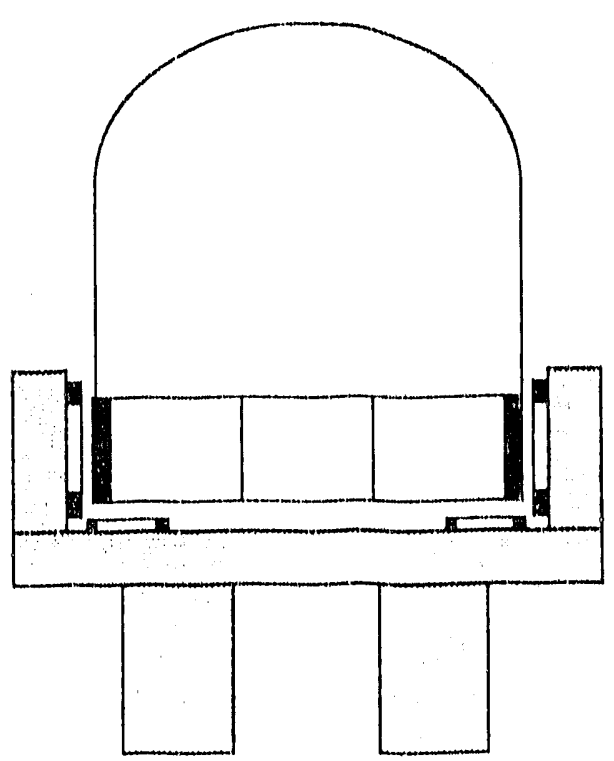

FIGURE 7.9 EDS Test Vehiclo, Option \#2: Loop-Shaped Coil Suspension 


\subsection{2 leMs T'est Options}

The Argonne test fucility also provides EMS test options that are similar to those for the Trunsrapid maglev systen (Figure 7.12), in which

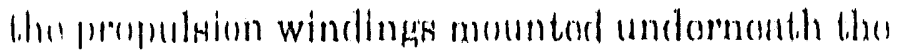
gruideway intexact with on-board DC magnets to produce propulsion and levitation forces. The guidano forco is produced by additional DC magnets mounted vertically on both sides of the guideway, Since the attractive levitation and guirlance forces are inhorontly unstablo, activo on-bourd control systems (see Chapter 11) are nocesany. Preliminary studies show that the minimum weight of the EMS test vehicle is about sovon metric tons. About 2 MW of power per motor section is needed to propel the vehicle up to $67 \mathrm{~m} / \mathrm{s}$ on the $3.2-\mathrm{km}$-long guideway with $0.2 \mathrm{~g} g$ accolaration. Detalled preliminary design parametor's for the EMS test option are given in 'Tinble 7.3 .

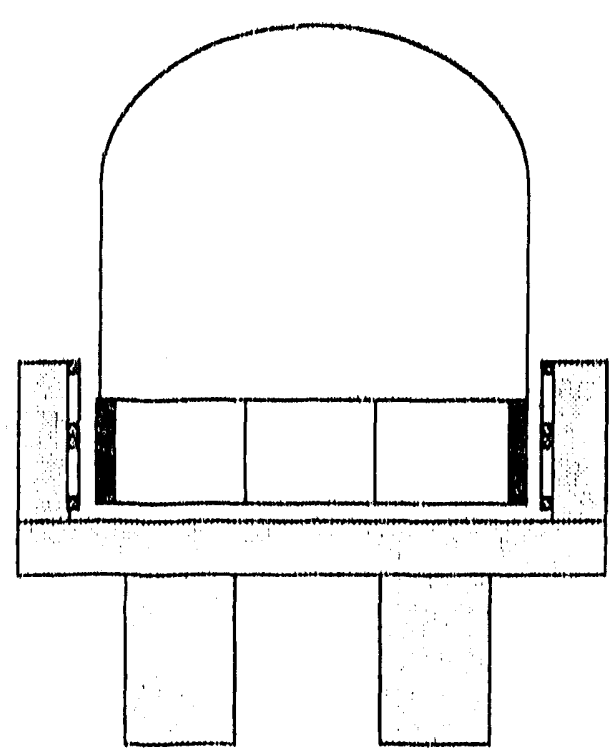

FIGURE 7.10 EDS Tost Vohiclo, Option \#3: Null. Flux Figure. Night-Shapod Coll Suspension

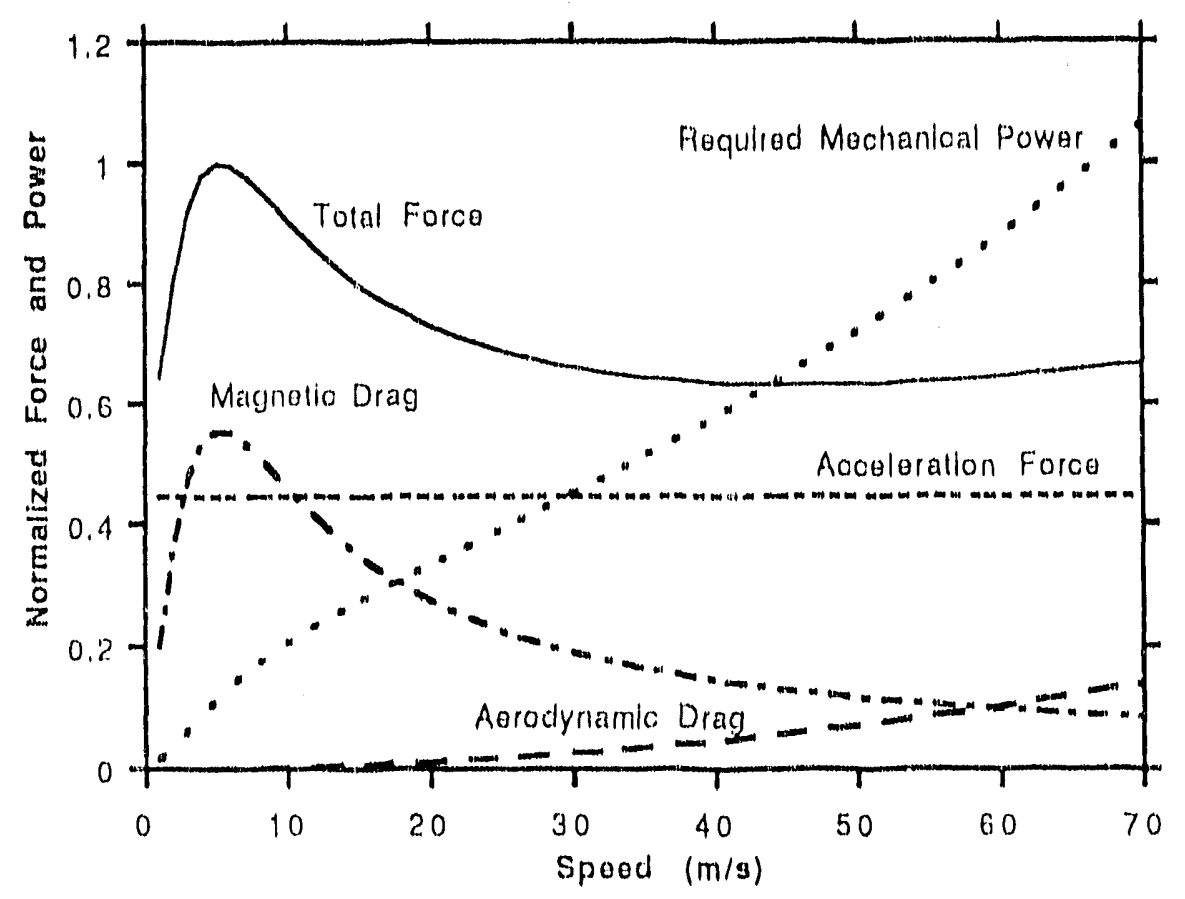

FIGURP 7.11 Normalized Force and Power for LDS 'Tost Options as a Function of Speed (Maximum force $17.6 \mathrm{kN}$ and maximum mechanical power $=0.8 \mathrm{MW}$; soe Chaptor 9 for the requilrod electrical powor) 
TABLE 7.1 ISOS I'ust Vohiolo, (option \#1 (six-magnot vohidelo)

\begin{tabular}{|c|c|c|}
\hline Itom & Paramotor & Valuo or Explanution \\
\hline Genurul & Maximum spood $(\mathrm{m} / \mathrm{s})$ & 663.7 \\
\hline \multirow{7}{*}{ information } & Guidowny longth (m) & 3,200 \\
\hline & Number of motor seotions & 10 \\
\hline & Lompllth of motor section (m) & 320 \\
\hline & 'Totr.l p,ronulstan force $(\mathrm{kN})$ & 0.11 \\
\hline & Poln pituh (m) & 1 \\
\hline & Optration frequenoy $\left(\mathrm{H}_{z_{1}}\right)$ & 0.34 \\
\hline & Luquivalent uir gap (cm) & 20 \\
\hline \multirow[t]{4}{*}{ Magnot systems } & Number of magnots & $\theta$ (in two rows) \\
\hline & Magnot current (kA-turn) & 350 \\
\hline & Width of magnet (m) & 0.4 \\
\hline & Longth of magnet (m) & 1 \\
\hline \multirow[t]{9}{*}{ Stator windings } & Muterial & Aluminum coils \\
\hline & Numbor of phases & \\
\hline & Coil width (m) & 0.4 \\
\hline & Coil length (m) & 0.83 (b/6 pole pitch) \\
\hline & Number of coils/phase & 6,400 \\
\hline & Number of turnss/coil & 10 \\
\hline & Diameter of conductor (mm) & $8.77^{\prime \prime}$ \\
\hline & $\begin{array}{l}\text { Operation angle (degrees } \\
\text { betweon SCM and stator } \\
\text { currentis) }\end{array}$ & 110 \\
\hline & Connection & $\begin{array}{l}2 \text { motors connocted in } \\
\text { serios in agch section }\end{array}$ \\
\hline \multirow[t]{5}{*}{ Porformance } & Current/phase $(A)$ & 121 \\
\hline & Voltage/phase (V) & 4,430 \\
\hline & Total input powor/soction (MVA) & $1.61^{\mathrm{l}}$ \\
\hline & Power factor $(\%)$ & 0.73 \\
\hline & Efficiency $(\%)$ & 0.73 \\
\hline
\end{tabular}


TABLE 7.2 EDS Test Vehicle, Option \#2 (four-magnet vohicle)

\begin{tabular}{|c|c|c|}
\hline Itern & Paramoter & Value or Ixplanation \\
\hline General & Maximum speed (m/s) & 66.7 \\
\hline \multirow{7}{*}{ information } & Guddeway length (m) & 3,200 \\
\hline & Number of motor sestions & 10 \\
\hline & Length of motur section (m) & 320 \\
\hline & Total propulsion force $(\mathrm{kN})$ & 11 \\
\hline & Pole pitch $(\mathrm{m})$ & 1 \\
\hline & Operation frequency (Hz) & 0.34 \\
\hline & Equivalent air gap (cm) & 20 \\
\hline \multirow[t]{4}{*}{ Mugnet systems } & Number of magnets & 4 (in two rows) \\
\hline & Magnet current (kA-turn) & 400 \\
\hline & Width of magnet (m) & 0.5 \\
\hline & Length of magnet (m) & 1.25 \\
\hline \multirow[t]{9}{*}{ Stator windings } & Material & Aluminum coils \\
\hline & Number of phases & 3 \\
\hline & Coil width $(\mathrm{m})$ & 0.5 \\
\hline & coil length (m) & 0.83 (5/6 pole pitch) \\
\hline & Number of coils/phase & 5,120 \\
\hline & Number of turns/coil & 10 \\
\hline & Diameter of conductor $(\mathrm{mm})^{\mathfrak{a}}$ & 9.44 \\
\hline & $\begin{array}{l}\text { Operation angle (degrees } \\
\text { between SCMs and stator } \\
\text { currents) }\end{array}$ & 110 \\
\hline & Connection & $\begin{array}{l}2 \text { motors connected in } \\
\text { series in each section }\end{array}$ \\
\hline \multirow[t]{5}{*}{ Performance } & Current/phase (A) & 140 \\
\hline & Voltage/phase (V) & 4,132 \\
\hline & $\begin{array}{l}\text { Total input power/section } \\
\text { (MVA) }\end{array}$ & 1.74 \\
\hline & Power factor $(\%)$ & 0.73 \\
\hline & Efficiency $(\%)$ & 0.63 \\
\hline
\end{tabular}




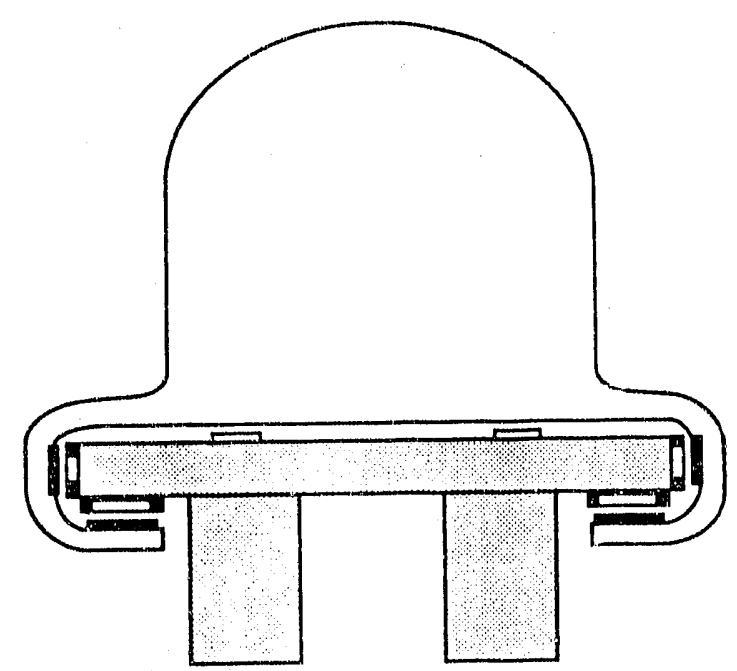

FIGURE 7.12 Sketch of the EMS

Test Vehicle

\subsubsection{Linear Liduction Motor Test Option}

Current designs for maglev systems use LSMs. Earlier designs, however, considered linear induction motors (LIM) with high-speed power pick-up from the waycide and with a catenary and pantograph. Such designs greatly simplify the design of the guideway's installed equipment. Since the motor is aboard the vehicle, however, the vehicle weight increases. Also, the wear on the catenary and pantograph at high speeds is a technical matter that has not been solved. If such a system were to be built, a catenary could be installed either on the underside of the guideway or on an overhead structure (the latter would require additional construction).

\subsection{KEFERENCES FOR CHAPTER 7}

1. Nasar, S.A., and I. Boldea, Linear Electric Motors: Theory, Design, and Practical Applications, Prentice-Hall, Inc., Englewood Cliffs, N.J. (1987).

2. Levi, E., and M. Panzer, Electrical Power Conversion, McGraw-Hill, New York (1966).

3. Levi, E., Polyphase Motor - A Direct Approuch to Their Design, John Wiley and Sons, New York (1984).

4. Laithwaite, E.R., Transport without Wheels, Eleek Science, London, U.K. (1977).

5. Laithwaite, E.R., A History of Linear Electric Motors, Macrnillan Education Ltd., London, U.r. (1987).

6. Skalski, C.A., The Air-Core Linear Synchronous Motor - An Assessment of Current Development, MITliE Corp., Alexandria, Va. (Sept. 1975). 
TABLE 7.3 EMS Test Option

\begin{tabular}{|c|c|c|}
\hline Item & Parameter & Value or Explanation \\
\hline $\begin{array}{l}\text { General } \\
\text { information }\end{array}$ & $\begin{array}{l}\text { Guideway length }(\mathrm{m}) \\
\text { Length of motor section (m) } \\
\text { Number of motor sections } \\
\text { Total required power (MVA) } \\
\text { Thrust (kN) } \\
\text { Maximum speed (mph) } \\
\text { Frequency }(\mathrm{Hz})\end{array}$ & $\begin{array}{l}3,200 \\
320 \\
10 \\
4 \\
0-16 \\
150 \\
0-133\end{array}$ \\
\hline $\begin{array}{l}\text { Propulsion and } \\
\text { levitation magnets }\end{array}$ & $\begin{array}{l}\text { Length of magnet system } / \text { side }(\mathrm{m}) \\
\text { Number of magnets/side } \\
\text { Number of poles/marnet } \\
\text { Pole pitch }(\mathrm{m}) \\
\text { Current density of inagnet } \\
\text { system }(\mathrm{kA} / \mathrm{m}) \\
\text { Ampere-turn/magnet } \\
\text { Width of magnet system }(\mathrm{m}) \\
\text { Height of magnet }(\mathrm{m})\end{array}$ & $\begin{array}{l}5 \\
5 \\
4 \\
0.25 \\
130 \\
\\
8,125 \\
0.3 \\
0.21\end{array}$ \\
\hline Stator windings & $\begin{array}{l}\text { Length of motor ssction }(\mathrm{m}) \\
\text { Winding material } \\
\text { Number of phases } \\
\text { Width of coil }(\mathrm{m}) \\
\text { Length of coil (m) } \\
\text { No. turns/coil per pole pair } \\
\text { Conductor cross section }\left(\mathrm{cm}^{2}\right)^{a} \\
\text { Connection }\end{array}$ & $\begin{array}{l}320 \\
\text { Aluminum } \\
3 \\
0.3 \\
0.21 \text { (5/6 pole pitch) } \\
4 \\
0.76 \\
2 \text { motors connected in } \\
\text { series in each section }\end{array}$ \\
\hline On-hoard power & $\begin{array}{l}\text { Propulsion and levitation }(\mathrm{kW}) \\
\text { Guidance }(\mathrm{kW}) \\
\text { Overload capability and other } \\
(\mathrm{kW})\end{array}$ & $\begin{array}{l}14 \\
14 \\
12\end{array}$ \\
\hline LSM performance & $\begin{array}{l}\text { Voltage/phase (V) } \\
\text { Current/phase (A) } \\
\text { Power factor (\%) } \\
\text { Efficiency }(\%)\end{array}$ & $\begin{array}{l}3,000 \\
230 \\
67 \\
76\end{array}$ \\
\hline $\begin{array}{l}\text { Weight of the EMS } \\
\text { vehicle }\end{array}$ & $\begin{array}{l}\text { Vehicle and measurement devices } \\
(\mathrm{kg}) \\
\text { Propulsion and levitation magnets } \\
(\mathrm{kg}) \\
\text { Guidance magnets }(\mathrm{kg}) \\
\text { Battery, } 5 \text { min at } 100 \mathrm{~A}(\mathrm{~kg}) \\
\text { Total }(\mathrm{kg})\end{array}$ & $\begin{array}{l}2,000 \text { (see vehicle design) } \\
2,644 \\
1,128 \\
800 \\
6,572 \\
\end{array}$ \\
\hline
\end{tabular}

a $J=3 \times 10^{6} \mathrm{~A} / \mathrm{m}^{2}$. 
7. Levi, E., Linear Syrichronous Motors for High-Speed Ground Transportation, Institute of Electrical and Electronics Engineers Transactions on Magnetics, (Mag-9)3:242-248 (Sept. 1973).

8. He, J.L., et al., Analysis of Induction Coilgun Performance based on Cylindrical Current-Sheet Model, Institute of Electrical and Electronics Engineers Transactions (In Magnetics, 27(1):579-584 (Jan. 1991). 


\section{SUSPENSION SYSTEMS}

The two most commonly used magnetic suspension systems for high-speed ground transportation are the electromagnetic suspension (EMS) and the electrodynamic suspension (EDS) systems. The EMS maglev system, which uses ferromagnetic material to produce both attractive levitation and guidance forces, is inherently unstable and requires an active control system. The suspension air-gap for the EMS system is typically about 1 to $2 \mathrm{~cm}$. The repulsive suspension force in the EDS maglev system is produced by the interaction between eddy currents induced in the guideway conductors and superconducting magnets aboard the vehicle. The EDS system is inherently stable and does not need a complicated fcedback-control system. Because of its stability, the EDS system can provide a much larger levitation air-gap, typically 5 to $10 \mathrm{~cm}$. Among the existing maglev systems, the German Transrapid and M-Bahn, Japanese HSST, and British Birmingham are of the EMS type, while the Japanese MLU and Canadian maglev (conceptual design) are of the EDS type.

The Argonr? maglev test facility will provide a wide range of capabilities for testing various suspension systems. Several types of EDS guideways (discussed below) are expected to be evaluated with the test facility.

\subsection{COIVTINUOUS-SHEET SUSPENSION}

The continuous-sheet guideway (see Figures 8.1 and 8.2) employs one of the basic levitation methods for EDS maglev systems. The repulsive levitation (suspension) force is generated by the interaction between the superconducting magnets (SCMs) aboard the vehicle and the eddy currents induced in the conducting sheet. The computation of lift and drag forces for the continuous sheet guideway is discussed in the literature. ${ }^{1-4}$ In particular, the combining of the Fourier transformation method with a numerical approach seems to be a powerful method. A computer code called MAGFORCE, written on the basis of the Fourier transform method, ${ }^{2-3}$ appears very useful for computing sheet guideway forces. The program's reliability was verified by experiments performed at Argonne.

Simple, approximately analytical expressions of lift $\mathrm{F}_{1}$ and drag $\mathrm{F}_{\mathrm{d}}$ forces are given by Equations 8.1 and $8.2 .^{4}$

$$
\begin{gathered}
F_{1}=F_{1}\left[1-\frac{1}{\left(1+v^{2} / v_{c}^{2}\right)^{n}}\right] \\
F_{d}=\frac{v_{c}}{v} F_{1}
\end{gathered}
$$




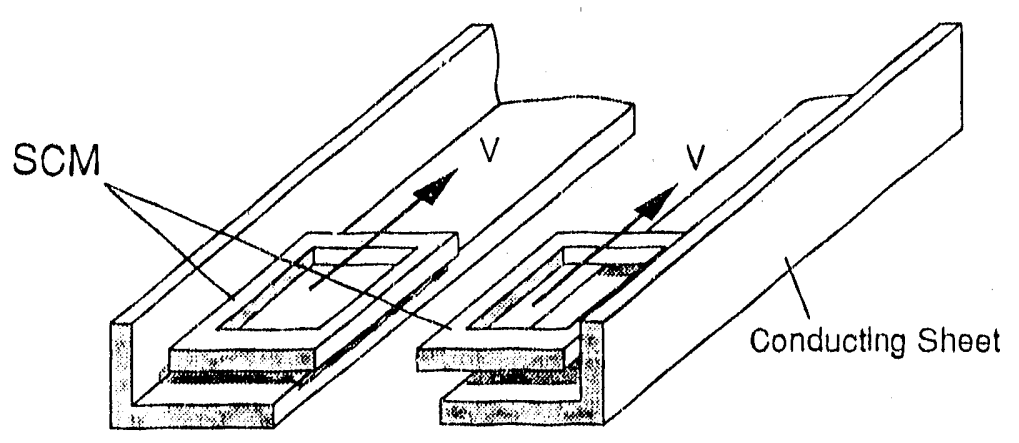

FIGURE 8.1 Angle-Shaped Continuous-Sheet Guideway

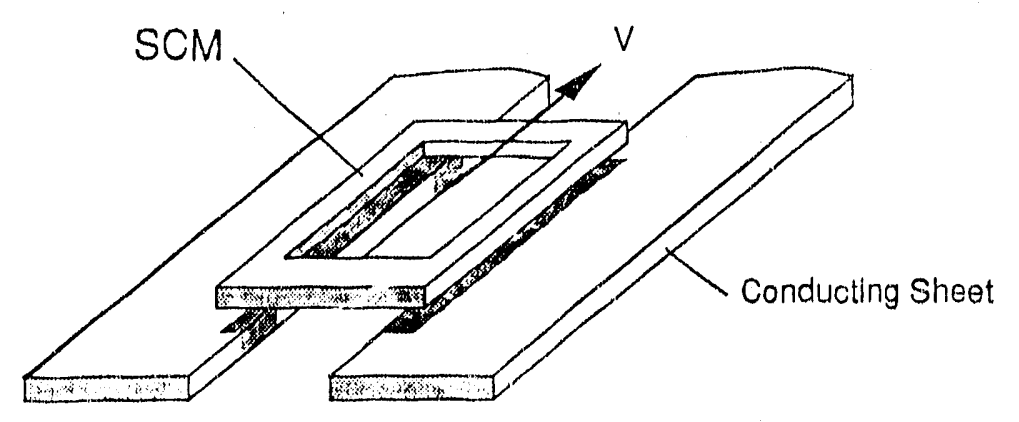

\section{FIGURE 8.2 Split-Sheet Guideway}

where $v$ is the speed of the vehicle; $v_{c}=2 /\left(\sigma \mu_{0} h\right)$ is the critical speed at which the magnetic $\mathrm{drag}$ is a maximum; $\sigma$ and $\mathrm{h}$ are the conductivity and the thickness of the conducting sheet, respectively; $\mathrm{n}$ varies from 0.2 to 0.3 , depending on the magnet coil geometry; and $\mathrm{F}_{\mathrm{i}}$ is the image force at the high speed limit:

$$
F_{t}=I_{s}^{2}\left|\frac{d M}{d z}\right|_{z=2 z_{0}}
$$

In Equation 8.3, $\mathrm{I}_{\mathrm{s}}$ is the total ampere-turns of the SCM, and $\mathrm{M}$ is the mutual inductance between the vehicle coil and image coil. The absolute value of $\mathrm{dM} / \mathrm{dz}$ as a function of the suspension height $\mathrm{z}$ (using the magnet length as a parameter) is indicated in Figure 8.3. One can determine the lift and drag forces of the continuous-sheet guideway on the basis of Equations 8.1-8.3 and the data in Figure 8.3. For example, consider an aluminum sheet guideway with the following measurements: thickness, $1.5 \mathrm{~cm}$; levitation height, $25 \mathrm{~cm}$; and magnet size, $0.5 \mathrm{~m}$ by $1 \mathrm{~m}$. Assuming that $\sigma=3 \times 10^{7} / \mathrm{mW}, \mathrm{n}=0.3, \mathrm{v}=67 \mathrm{~m} / \mathrm{s}(150 \mathrm{mph})$, and $I_{\mathrm{s}}=300 \mathrm{kA} \cdot \mathrm{T}$, we calculate that $\mathrm{v}_{\mathrm{c}}=3.54 \mathrm{~m} / \mathrm{s}$, the image force is about $39 \mathrm{kN} / \mathrm{magnet}$, the lift force is about $32 \mathrm{kN} /$ magnet, and the magnetic drag is about $1.7 \mathrm{kN} / \mathrm{magnet}$. Good agreement between the analytical model (Equations 8.1-8.3) and a calculation using the MAGFORCE program is shown in Figure 8.4. 


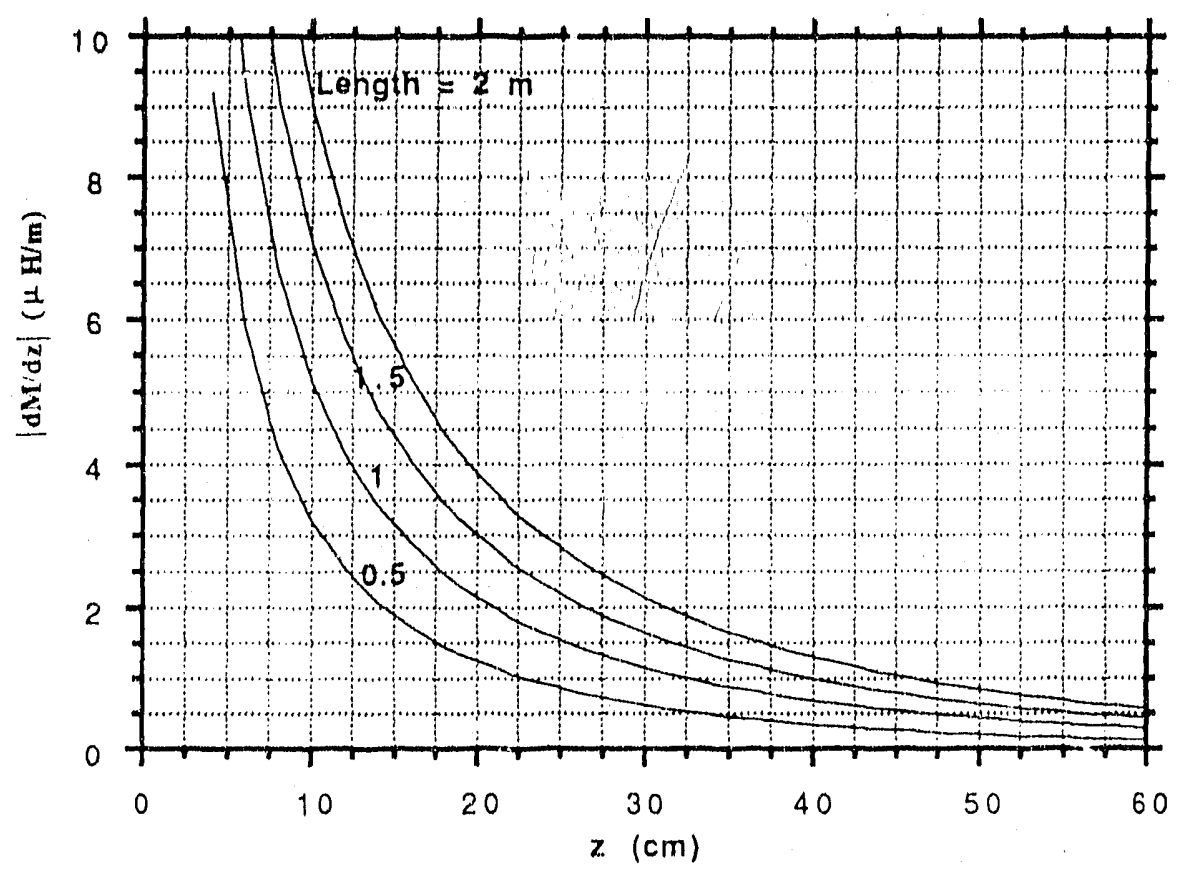

FIGURE 8.3 Variation in $\mathbf{d M} / \mathrm{dz}$ per Turn as a Function of Levitation Height, with Magnet Length as a Parameter (magnet width is assumed to be $0.5 \mathrm{~m}$ )

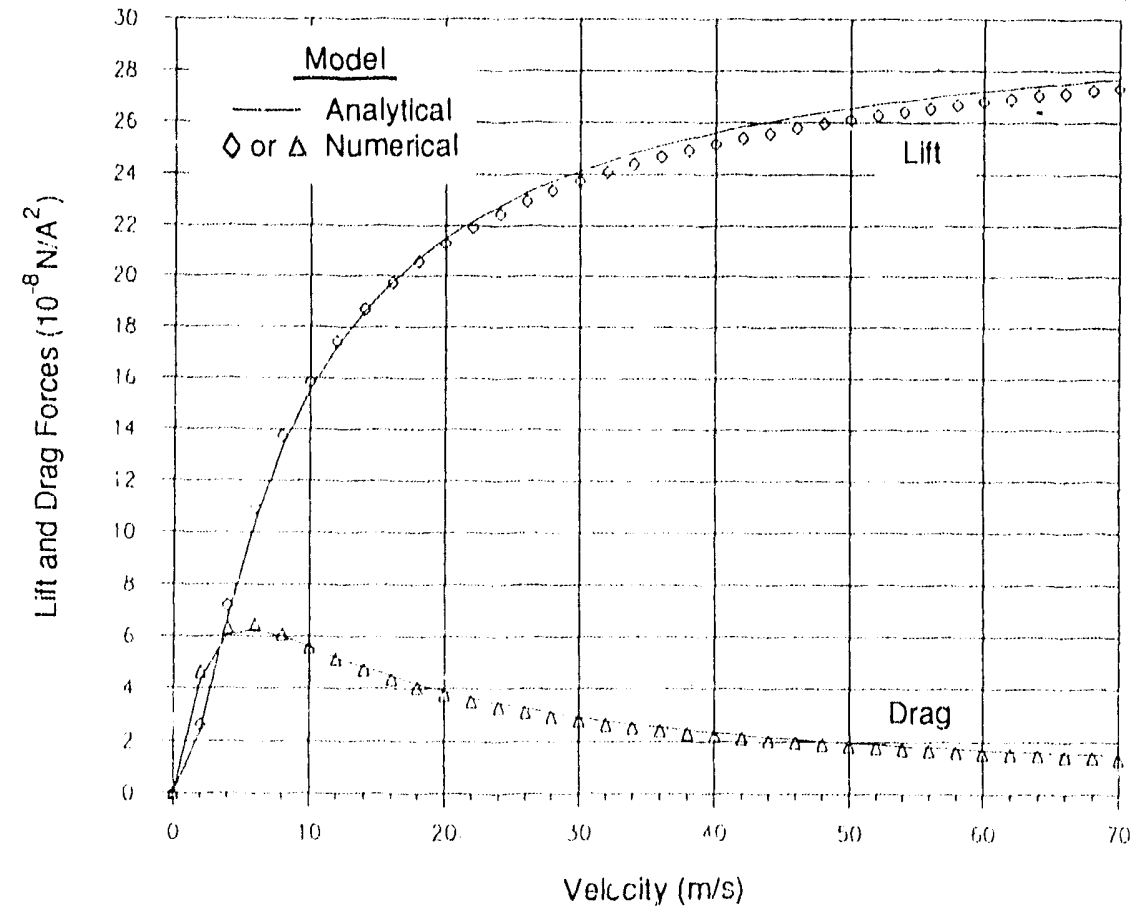

FIGURE 8.4 Magnetic Lift and Drag Forces Calculated by Using the Analytical Model (Equations 8.1-8.3) and the Numerical Model (MACFORCE: length, 1.0 m.; width, $0.5 \mathrm{~m}$ ) 
In the EDS test option shown in Figure 7.8, the SCMs are sandwiched between the propulsion windings on the top and the aluminum sheet underneath. Two vertical aluminum sheets provide the guidance force. In this arrangement, the interaction between tho propulsion and suspension systems is very important. As mentioned in Chapter 7, the best power factor and efficiency of the LSM can be achieved for a given motor-section length when a high current is used in the superconducting magnets. However, these high currents are not required to achieve the desired suspension forces. Thus, the width of the aluminum sheet can be reduced to about one-third to one-half of the magnet width. This guideway configuration is called an angle-shaped narrow-sheet guideway. The narrow-sheet guideway is similar to the split-sheet guideway shown in Figure 8.2, but the former provides additional guidance forcr. Preliminary studies show that the guidance force due only to the vertical aluminum sheet is about $4.6 \mathrm{kN} /$ magnet. A significant improvement in the guidance forces could be attained with this guideway.

If it is assumed that the guideway shown in Figure 8.1 has a thickness of $1.5 \mathrm{~cm}, \mathrm{a}$ width of $20 \mathrm{~cm}$, and a height of $30 \mathrm{~cm}, 129.6$ metric tons of aluminum sheet will be needed for a $3.2-\mathrm{km}-$ long guideway. If the price of aluminum sheet is $\$ 3.30 / \mathrm{kg}$, the aluminum will cost $\$ 428,000$.

\subsection{LOOP-SHAPED COIL, SUSPENSION}

Considerable attention has been given to suspension schemes in which the SCMs are levitated above loop-shaped coil guideways, as shown in Figure 8.5. The Japanese MLU system uses a coil guideway for levitation. It has been suggested that the coil guideway is superior to the sheet guideway because of the former's relatively low magnetic drag force. The loop-shaped coil guideway, however, produces force pulsations that do not arise in the continuous-sheet guideway. The amplitude of these force pulsations depends on the dimensions of the SCMs and the loop coils. A good steady-state analysis of coil guideways was performed by Hoppie et al., ${ }^{5}$ who employed the Fourier transiorm method in combination with steady-state circuit analysis.

An alternative approach for the analysis of the loop-shaped coil guideway is to use dynamic circuit theory. Let $I_{s}$ and $i_{j}$ be the currents in the SCM and the $j^{\text {th }}$ loop coil, respectively, and let $L_{s, j}$ be the mutual inductance between the SCM and the $j^{\text {th }}$ loop coil. We obtain the time-dependent lift force acting on a single SCM due to $n$ corresponding loop coils

$$
f_{z}=\sum_{j=1}^{n} I_{s j} i_{j} \frac{d L_{s j}}{d z}
$$

and the drag force:

$$
f_{x}=\sum_{j=1}^{n} I_{s} i_{j} \frac{d L_{s j}}{d x}
$$




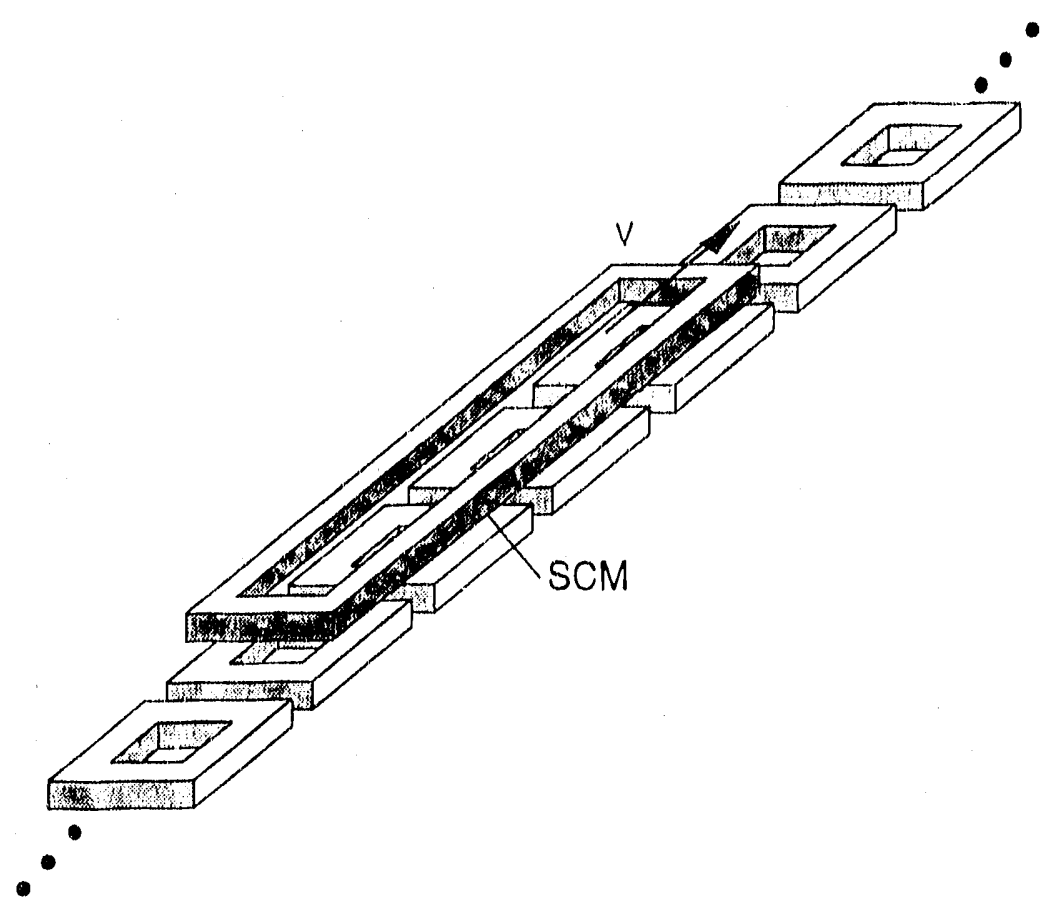

FIGURE 8.5 Loop-Shaped Coil Guideway

where $\mathrm{x}$ is in the direction of motion and $\mathrm{z}$ is in the vertical direction. In general, only those loop coils covered by the SCM need to be considered. If $\mathrm{l}_{\mathrm{m}}$ is the length of the SCM, a is the length of the loop coil, and $\mathrm{b}$ is the gap between the loop coils, then the number of loop coils covered by the SCM is $n=\ell_{n} /(a+b)$. Equations 8.4 and 8.5 are general expressions for both transient and steady-state analysis. The drag force in Equation 8.5 includes two parts: the drag due to dissipated energy and the drag due to stored magnetic energy.

In Equations 8.4 and 8.5, the loop currents $i_{j}(j=1, n)$ are the unknowns, which can be solved by using circuit analysis. When the space harmonics of the SCM are neglected (i.e., assuming a sine-wave distribution of the SCM field, which travels at speed v with pole pitch ८), simple approximate expressions of the lift and drag forces for the coil guideway can be obtained based only on the steady-state circuit analysis. The lift and drag forces for the ladder loop guideway are derived in Reference 4. The difference between the ladder loop guideway and the individual loop-shaped coil guideway lies in the definition of their respective circuit constants. Following Reference 4, we obtain the lift force for the coil guideway:

$$
F_{1} \approx \frac{v^{2}}{v^{2}+v_{c}^{2}} F_{i}
$$


and the drag force:

$$
F_{d s} \frac{\pi M}{|d M / d z| \ell} \frac{v_{c} \nu}{v^{2}+v_{c}^{2}} F_{i}
$$

where the image force $F_{1}$ is approximately given by Equation $8.3 ; M$ and $d M / d z$ are the mutual inductance and its derivative between the SCM and its image, respectively; and the critical speed $\mathrm{v}_{\mathrm{c}}$ is:

$$
v_{c}=\frac{R \ell}{\pi L_{e}}
$$

In Equation 8.8, $\mathrm{R}$ is the resistance of the individual loop coil, while $\mathrm{L}_{\mathrm{t}}$ is the equivalent inductance of the loop coil. $L_{\theta}$ equals its self-inductance for $n=2$.

Finally, the ratio of lift and drag forces for the coil guideway is as follows:

$$
\frac{F_{1}}{F_{d}}=\frac{\ell|d M / d z|}{\pi M} \frac{v}{v_{c}}
$$

\subsection{DESIGN AND COMPUTER SIMULATION OF NULL-FLUX COIL SUSPENSION}

The use of flat and folded figure-eight-shaped null-flux suspension and guidance coils (see Figure 8.6), invented by J. Powell and G. Danby in the late 1960s, has become a very important maglev concept that is widely recognized in the maglev community. In particular, the Japanese have succeeded in designing and testing several versions of EDS maglev systems based on the null-flux concept. Consequently, it is necessary that the Argonne maglev test facility provide a null-flux suspension test option (see Figure 7.10). In this test option, two arrays of null-flux ground coils are mounted vertically on both guideway sidewalls. Both vertical suspension and horizontal guidance forces are generated by the interaction between the on-board SCMs and the null-flux ground coils.

The design and analysis of null-flux coil suspension in this section are based on the dynamic circuit model. ${ }^{6,7}$ The model calls for the transient solution of the coupled circuit equations in matrix form. Thus, forces in three dimensions - the vertical suspension, the horizontal guidance, and the magnetic drag - are determined from the model. The basic matrix equation is as follows:

$$
[R][I]+\frac{d}{d t}\{[L][I]\}=0
$$




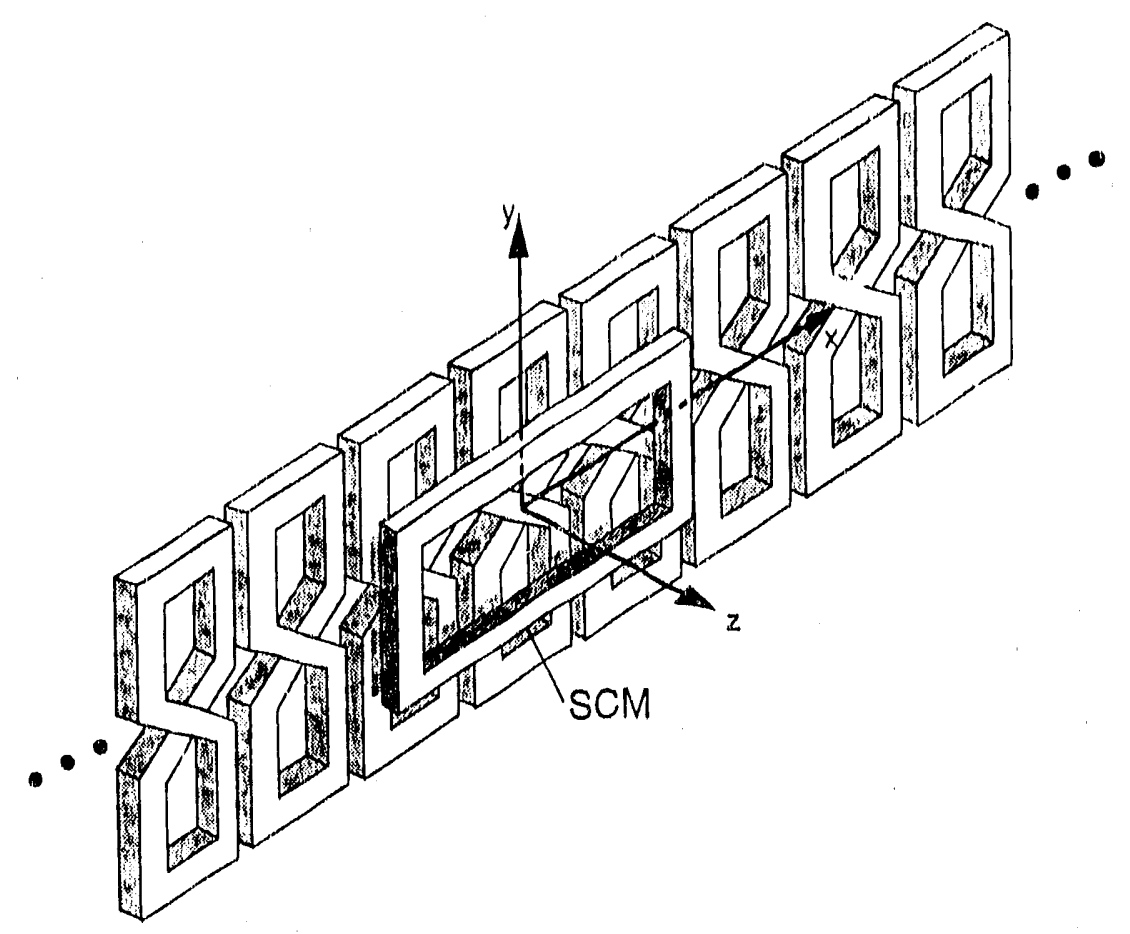

FIGURE 8.6 Figure-Eight-Shaped Coil Guideway

where $|\mathrm{I}|$ is a column matrix composed of $\mathrm{n}$ individual null-flux coil currents and $\mathrm{m}$ superconducting coil currents, respectively; $[R]$ is a diagonal matrix composed of $n$ individual null-flux coil resistances and $m$ diagonal zero elements for superconducting coils; and [L] is a square $(m+n) \times(m+n)$ matrix, each element of which represents either a mutual inductance between any two individual coils or the self-inductance of any null-flux coils. One can show that the three-dimensional forces acting on $m$ superconducting coils due to $n$ null-flux coils are:

$$
\begin{aligned}
& F_{x}=\sum_{i=1}^{n} \sum_{j=1}^{m} I_{i} I_{j}\left[\frac{\partial M_{i j}^{u}}{\partial x}-\frac{\partial M_{i j}^{\ell}}{\partial x}\right] \\
& F_{y}=\sum_{i=1}^{n} \sum_{j=1}^{m} I_{i} I_{j}\left[\frac{\partial M_{i j}^{u}}{\partial y}-\frac{\partial M_{i j}^{\ell}}{\partial y}\right] \\
& F_{z}=\sum_{i=1}^{n} \sum_{j=1}^{m} I_{i} I_{j}\left[\frac{\partial M_{i j}^{u}}{\partial z}-\frac{\partial M_{i j}^{\ell}}{\partial z}\right]
\end{aligned}
$$

where $M_{1 j}^{u}$ and $M_{j}^{\prime}$ are the mutual inductances between the $i^{\text {th }}$ null-flux coil and $j^{\text {th }}$ superconducting coil, and superscripts $u$ and $\ell$ stand for the upper and lower loops of the $i^{\text {th }}$ null-flux coil. A computer rode, developed in the collaborative program funded by the 
National Maglev Initintive and directed by D.M. Rote, was writion on the basis of this model. The code calculates both transient and steadyustate performances of the null-flux coil suspersion system.

The specifications and dimensions for the proposed null-flux test option for the tost fincility (Figure "7.10) are given in Table 8.1. Studios show that four magneds of atpongth $550 \mathrm{kA} \cdot \mathrm{T}$ ', two on each side, can lift an EDS test vehicle weighing 4 to 5 metric tons at $67 \mathrm{~m} / \mathrm{s}$ with an air gap of $20 \mathrm{~cm}$ and a vertical offset of $10 \mathrm{~cm}$. The lift, magnetic drag, and horizontal guidance forces per magnet, as a function of vertical displacement, are shown in Figure 8.7. It can be seen from this figure that, as expected, all forces disappear al the null-flux equilibrium point, and forces are symmetric about the axis $y=0$. Figure 8.8 shows the forces as a function of vehicle speed, from which one can see that the lift-to-drag ratio is about 20 at high speed, and a drag peak appears at $20 \mathrm{~m} / \mathrm{s}$. This implies that the resistance of the null-flux coil should be further reduced. Two options may be considered for the reduction of coil resistance: one is to increase the cross section of the aluminum coils, and the other is to use a copper conductor for the null-flux coil guideway.

Force fluctuations associated with the null-flux coil guideway are shown in Figure 8.9, which shows that all forces fluctuate around their average values. Typical fluctuations for the lift and the horizontal guidance forces are about $5 \%$. The frequency of the fluctuations seems to be determined by the vehicle speed divided by the average length of the ground coil. Thus, for $v=67 \mathrm{~m} / \mathrm{s}$ and a coil length of $0.5 \pm 0.05 \mathrm{~m}$, the frequency is $122 \mathrm{~Hz}$.

\subsection{REFERENCES FOR CHAPTLR 8}

1. Reitz, J.R., and L.C. Davis, Force on Rectangular Coil Moving above a Conducting Slab, J. Applied Physics, 43(4):1547-53 (April 1972).

2. Chilton, F., and H.T. Coffey, Magnetic Levitation, Tomorrow's Transportation, International Helium Society Symp, held in Washington, D.C., published by International Helium Society (1971).

3. Coffey, IIT., F. Chilton, and L.O. Hoppie, The Feasibility of Magnetically Levitating High Speed Ground Vehicles, prepared by Stanford Research Institute for U.S. Department, of Transportation, Federal Railroad Administration Report FRA-10001 (Feb, 1972).

4. Nasar, S.A., and I. Boldea, Linear Electric Motors: Theory, Design, and Pratical Applications, Prentice-Hall, Inc., Englewood Cliffs, N.J. (1987).

5. Hoppie, L.O, et al., Electromagnetic Lift and Drag Force on a Superconducting Masnet Propelled along a Guideway Composed of Metallic Loops, Proc. Applied Superconducting Conf., held May 1-3, 1972, Annapolis, Md., Institute of Electrical and Electronics Engineers Pub. No. 72CH0682-5-TABSC (1972). 
TABLE 8.1 Null-Flux Susponsion Test Option

\begin{tabular}{|c|c|}
\hline Item & $\begin{array}{c}\text { Valua/ } \\
\text { Explanation }\end{array}$ \\
\hline Test spesed (m/s) & 67 \\
\hline Null-flux lift per magnet" (kN) & 13.6 \\
\hline Horizontal guidanoa $(\mathrm{kN})$ & 12.6 \\
\hline Average air gap (m) & 0.2 \\
\hline Number of SCMs for 4- to Eumetric-tion vehicle & 4 \\
\hline Maximum magnetio drag por magnot (kN) & 1.5 \\
\hline Magnatic drag per magnet at $67 \mathrm{~m} / \mathrm{s}(\mathrm{kN})$ & 1 \\
\hline \multicolumn{2}{|l|}{ Superconducting coils } \\
\hline Length (nı) & 1.5 \\
\hline Width (m) & $0.5^{\prime}$ \\
\hline Strength $(\mathrm{kA} \cdot \mathrm{T})$ & 560 \\
\hline \multicolumn{2}{|l|}{ Null-flux coils } \\
\hline Length (m) & 0,5 \\
\hline Height per loop (m) & 0.35 \\
\hline Gap between loops $(\mathrm{m})$ & 0.05 \\
\hline Gap between null flux coils ( $\mathrm{m}$ ) & 0.05 \\
\hline Cross section $\left(\mathrm{cm}^{2}\right)$ & 9 \\
\hline Material & Aluminum \\
\hline Weight per coil (kg) & 8.3 \\
\hline Number of null-flux coils ${ }^{h}$ & 11,636 \\
\hline Material cost $\left(\$ 10^{3}\right)$ & 317 \\
\hline
\end{tabular}

a $11-\mathrm{cm}$ vertical offset,

b 96 metric tons for $3.2-\mathrm{km}$ length.

6. He, J.L., et al., Concerning the Design of Capacitively-Driven Induction Coil-Guns, Institute of Electrical and Electronics Engineers Transactions on Plasma Science, 17(3):429-438 (June 1989).

7. Atherton, D.L., et al., Electrodynamic Suspension and Linear Synchronous Motor Propulsion for High Speed Guided Ground Transportation, Final Report, prepared for Transport Canada Research and Development Centre, Report No. 77-1.3 (Sept. 1977).

8. Atherton, D.L., and A.R. Eastham, Limitation of Levitation by Iron-Cored Electromagnets, Institute of Electrical and Electronics Engineers Transactions on Magnetics, Mag-10 (Sept. 1974). 


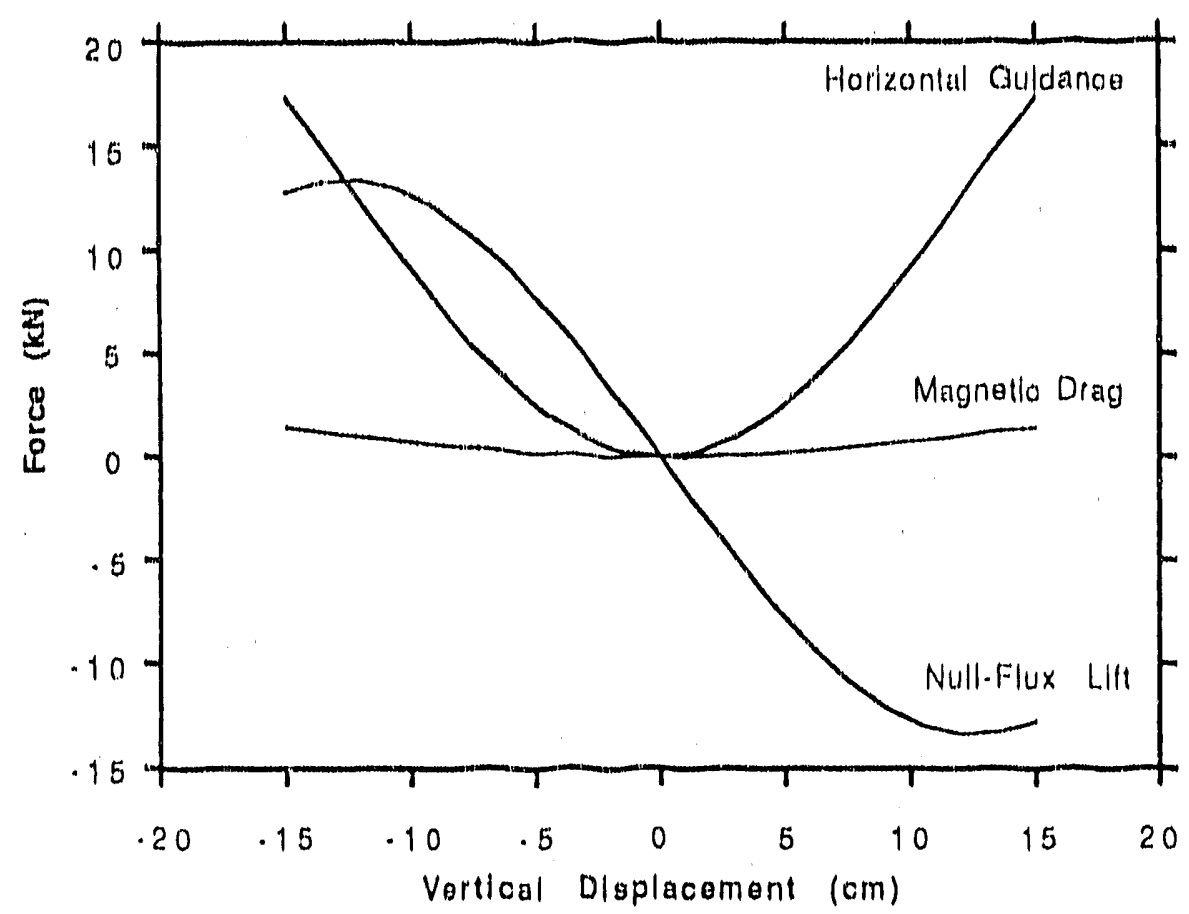

FIGURE 8.7 Lift, Drag, and Guidance Forces vs. Vertical Displacement

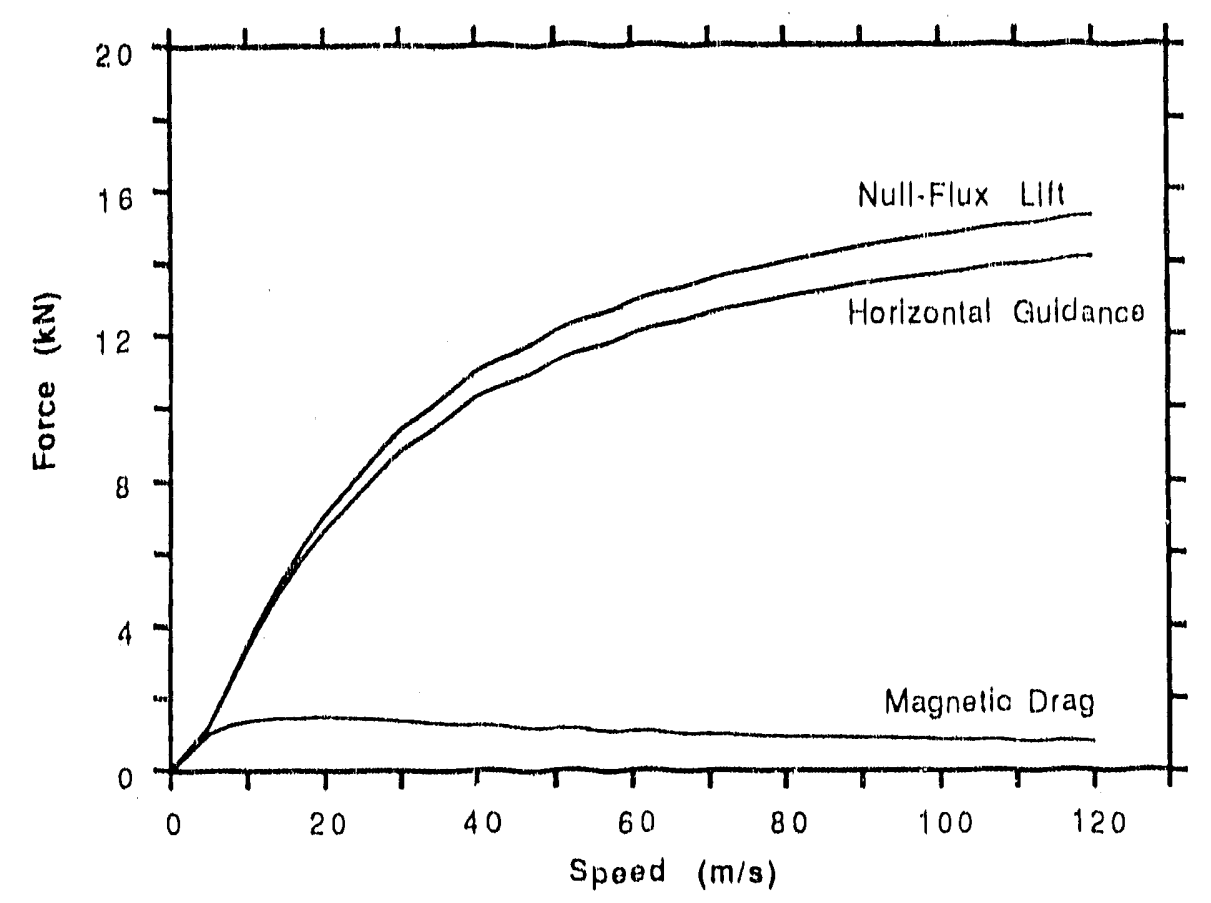

FIGURE 8.8 Lift, Drag, and Horizontal Guidance Forces vs. Vehicle Speed 


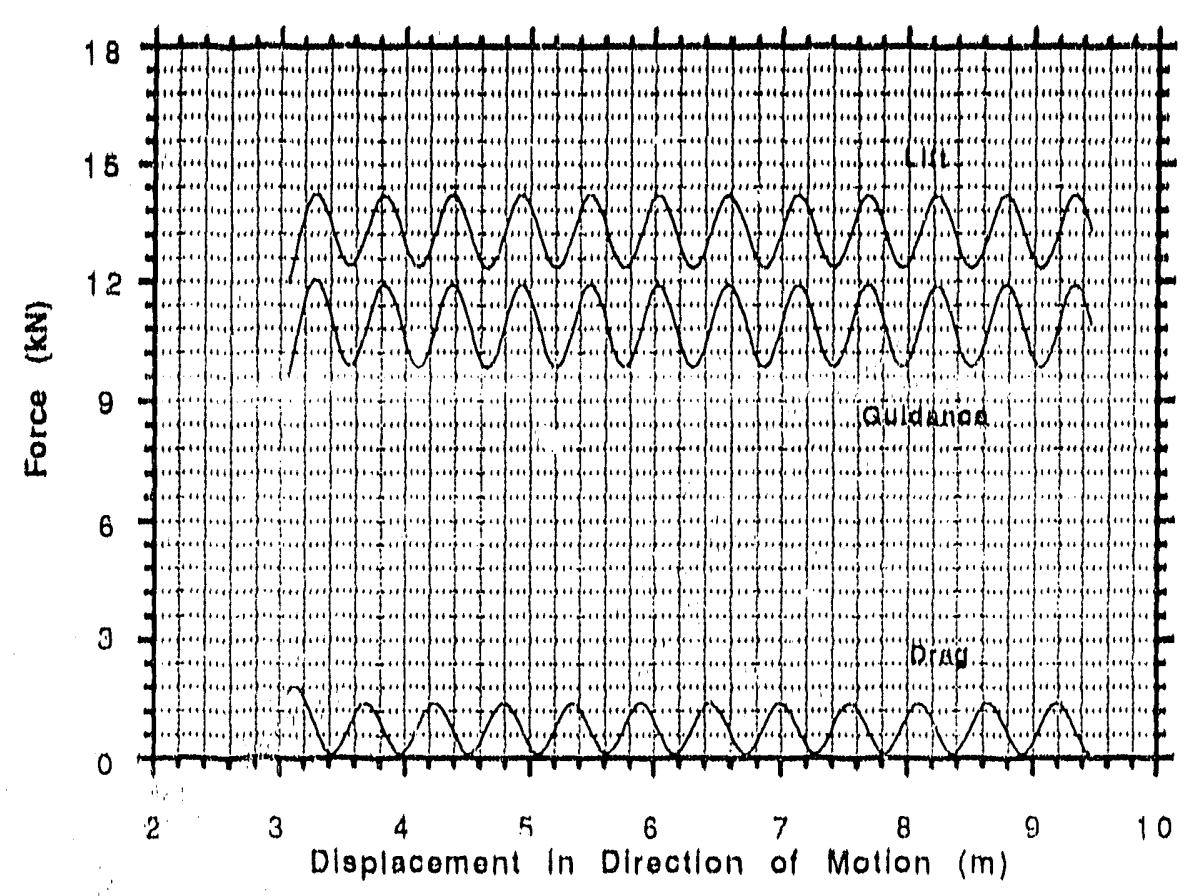

FIGURE 8.9 Force Pulsations in Null-Flux Coil Suspension Systera 


\section{POWER SUPPLY AND DISTRIBUTION SYSTEM}

\subsection{POWER REQUIREMENT}

The power requirement of the Argonne maglev test facility is determined according to the broadest test objectives likely to be established for the facility. Several important parameters determine the maximum power requirement. These parameters include maximum vehicle speed, acceleration, vehicle weight, length of the energized motor section, and the power factor, as well as the efficiency of the linear synchronous motor (LSM), etc.

The required mechanical power, or the power output from the motor $\left(\mathrm{P}_{\text {out }}\right)$, can be determined by the following equation:

$$
P_{\text {out }}=\frac{2 v_{c} v^{2}}{v_{c}^{2}+v^{2}} F_{m}+m a v+\frac{1}{2} c_{d} A \rho v^{3}
$$

where $\mathrm{v}$ is the vehicle speed, $\mathrm{v}_{\mathrm{c}}$ the critical speed at which the magnetic drag is maximum, $\mathrm{F}_{\mathrm{m}}$ the maximum magnetic drag, $\mathrm{m}$ the mass of the vehicle, a the acceleration, $A$ the cross-sectional area, $\rho$ the density of air, and $c_{d}$ the coefficient of aerodynamic drag (typically, $\left.c_{d}=0.3\right)$. In Equation 9.1, the first term represents the power required to overcome the magnetic drag of the EDS system. The magnetic drag of the EMS maglev system is expected to be smaller than that of the EDS system. The second term is the acceleration power, and the last term is the power required to overcome aerodynamic drag (see also Chapter 5 ). ${ }^{1}$ It should be noted that in most commercial systems, aerodynamic drag is the dominant term. In the test facility, however, the acceleration power (second term) will play the most important role because of the required constant acceleration and the limited length of the guideway.

The input electrical power of the LSM $\left(\mathrm{P}_{\text {in }}\right)$ depends on the power factor $(\mathrm{PF})$ and the efficieniy $(\eta)$ of the motor:

$$
\boldsymbol{P}_{\text {tn }}=\frac{\boldsymbol{P}_{\text {out }}}{\eta \cdot P F}
$$

As was discussed in a previous chapter, the power factor and efficiency of an LSM can vary within a large range, depending on the type of maglev system and its dimensions. For a commercial maglev system, both the power factor and the efficiency may be expected to exceed $80 \%$. The test facility, however, must be able to satisfy the broadest range of test objectives. Thus, a minimum power factor and an efficiency of about 70 to $75 \%$ are selected for the test facility.

The dependence of the required electrical power on vehicle speed, with vehicle weight as a parameter, is shown in Figure 9.1. According to the analysis in earlier sections, the 


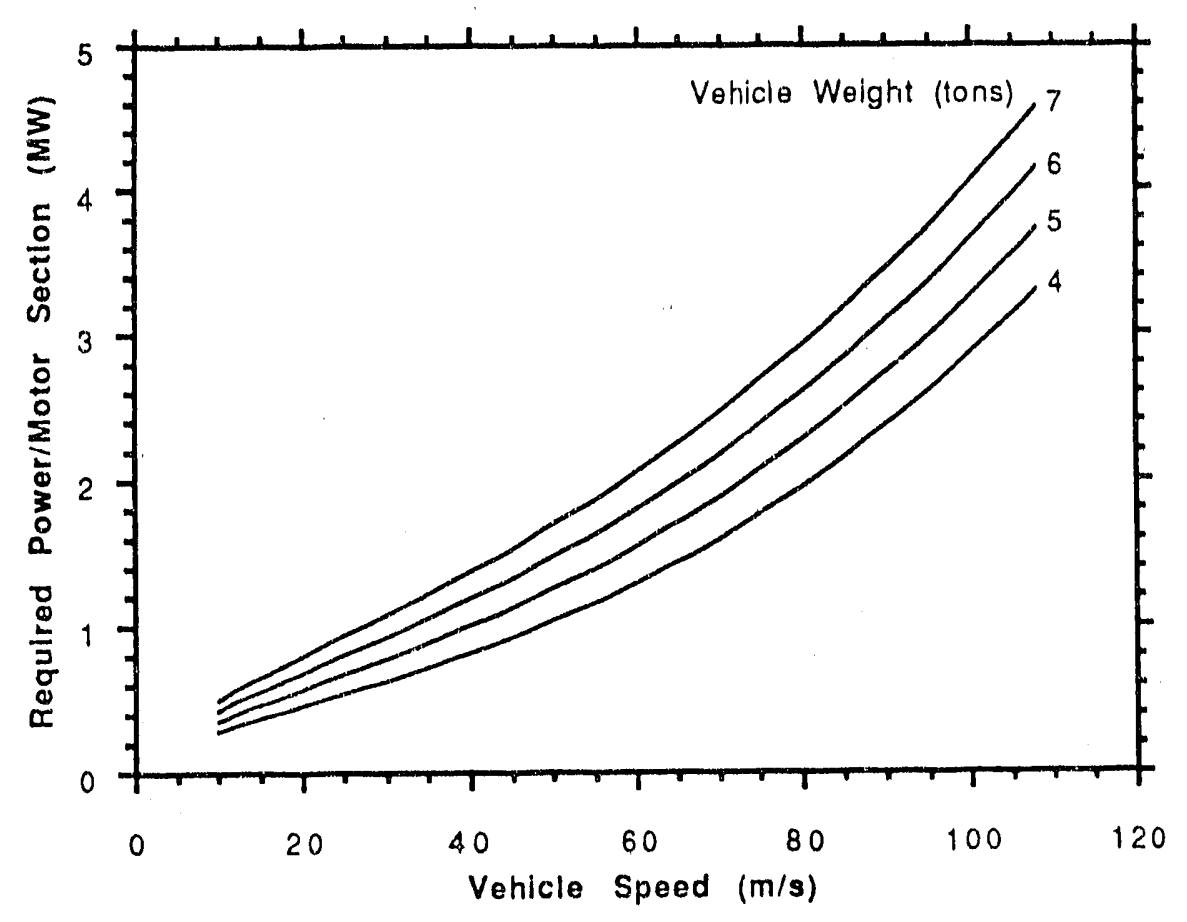

FIGURE 9.1 Required Electrical Power per Motor Section as a Function of Vehicle Speed (vehicle weight used as parameter; assume $v_{c}=5.3 \mathrm{~m} / \mathrm{s}, \mathrm{F}_{\mathrm{m}}=25 \%$ of the vehicle's weight, $\mathrm{c}_{\mathrm{d}}=0.3$, $\rho=1.2 \mathrm{~kg} / \mathrm{m}^{3}, \mathrm{a}=0.2 \mathrm{~g}^{3} \mathrm{~s}$ )

weight of test vehicles may vary from four to seven metric tons, depending on whether they are EDS or EMS vehicles. According to the figure, the required electrical power is about 1.5 MW per section for a four-metric-ton vehicle, and 2.3 MW per section for a seven-metricton vehicle, at a speed of $67 \mathrm{~m} / \mathrm{s}(150 \mathrm{mph})$. Although the guideway is energized section-by-section, two sections must be powered during the transition time in order to avoid any power interruption. Thus, the test facility is required to provide a total power of about 4 MVA to accommodate the wide range of test objectives.

The length of the guideway $\left(\mathrm{L}_{\mathrm{g}}\right)$ is determined by the required acceleration a, maximum speed $\mathrm{v}$, and the time $\mathrm{T}$ required to perform a constant-speed test:

$$
L_{8}=\frac{v^{2}}{a}+v T
$$

where the vehicle's acceleration and deceleration are assumed to be the same. For $\mathrm{v}=67 \mathrm{~m} / \mathrm{s}$ and $\mathrm{a}=0.2 \mathrm{~g}$ 's ( $\mathrm{g}$ is the acceleration due to gravity), the length of the guideway is $3,295 \mathrm{~m}$ for $\mathrm{T}=15 \mathrm{~s}$. For a given vehicle speed, we may obtain the required electrical power per motor section as a function of guideway length from Equations 9.1 and 9.3. Figure 9.2 shows that a guideway length of $3,200 \mathrm{~m}(2 \mathrm{mi})$ should be sufficient to test a 


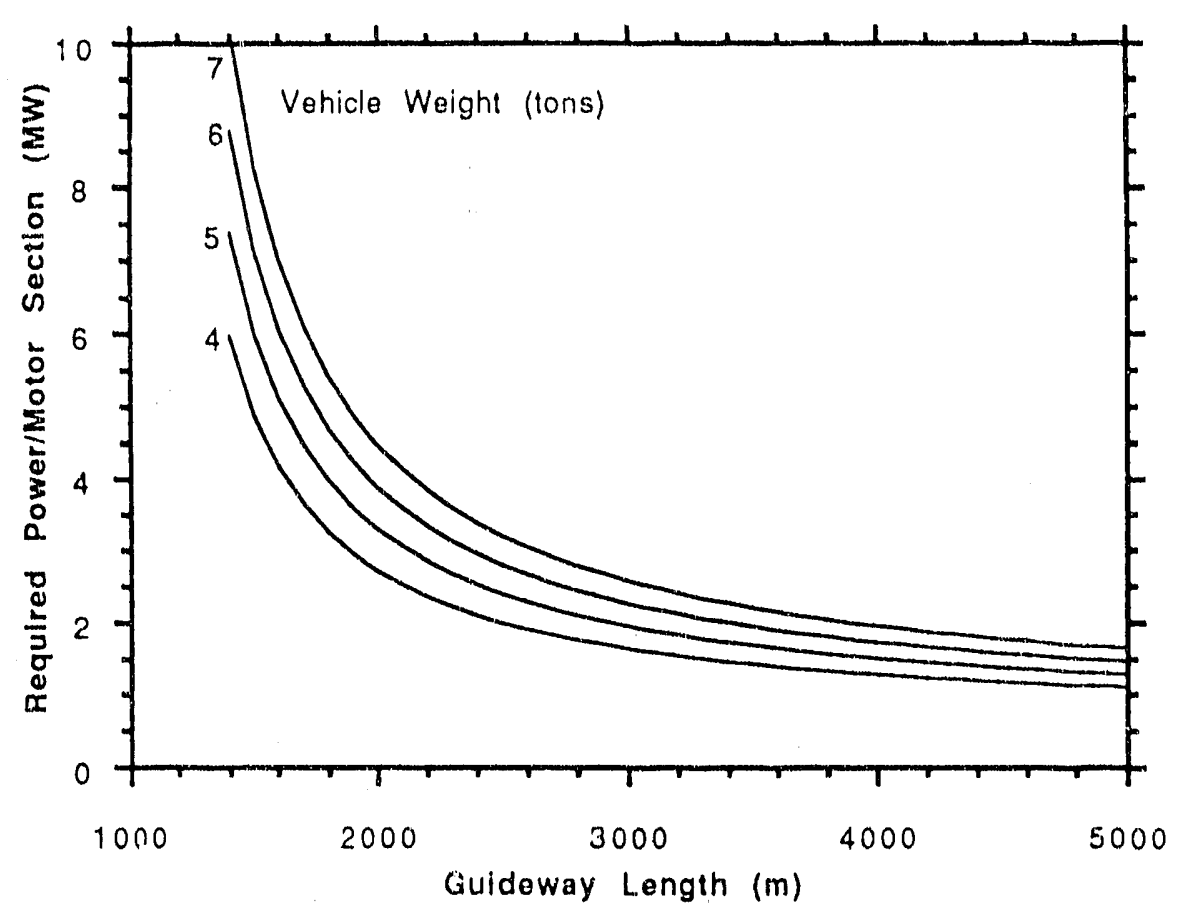

FIGURE 9.2 Required Electrical Power per Motor Section as a Function of Guideway Length (vehicle weight used as parameter; assume $v=67 \mathrm{~m} / \mathrm{s}$, time for constant-speed test is $15 \mathrm{~s}$, other parameters same as in Figure 9.1)

four- to five-metric-ton vehicie at $67 \mathrm{~m} / \mathrm{s}(150 \mathrm{mph})$ with two 2-MVA power supplies. The $3.2-\mathrm{km}$-long guideway with two 2-MVA power supplies is also sufficient to test a vehicle weighing six to seven metric tons at a maximum speed of $63 \mathrm{~m} / \mathrm{s}(142 \mathrm{mph})$.

\subsection{POWER SUPPLY AND DISTRIBUTION}

There are many options for the variable-voltage, variable-frequency (VVVF) power supply. One of the choices is the cycloconverter, which has been used by the Japanese for EDS maglev. The cycloconverter is a static frequency converter for transforming a higher frequency to a lower frequency without a direct-current (DC) link. Thirty-six thyristors are needed to build a three-phase system to generate a $30-\mathrm{Hz}$ output frequency from a $60-\mathrm{Hz}$ input frequency. The cycloconverter is well suited for most EDS maglev applications, since EDS maglev uses a long pole pitch ( 1 to $2 \mathrm{~m}$ or longer), corresponding to a low frequency. However, it is not appropriate to use a cycloconverter in the test facility, since a high-frequency option is needed for other maglev concepts. In particular, the pole pitch of the EMS system is expected to be about 0.2 to $0.5 \mathrm{~m}$, which would require a maximum frequency of about $200 \mathrm{~Hz}$ for a speed of $67 \mathrm{~m} / \mathrm{s}$. To satisfy both the EDS and EMS test requirements, rectifier inverters are required for the test facility. The output frequencies of the power supplies should be from 0 to $200 \mathrm{~Hz}$. Gate-turn-off (GTO) thyristors may oe used to build these power supplies. High-voltage (up to 4,500 V) and high-current (up to 
3,000 A) GTO thyristors are available in the commercial market. A control system is required to keep the power supplies in synchronized-phase operation (see Chapter 11).

The studies reported in previous chapters have indicated that a two-mile-long guideway divided into 10 motor sections would be suitable for both EDS and EMS test options. Thus, the length of each motor section is $320 \mathrm{~m}$. "Switching and position-detector systems will be installed along the guideway to detect the vehicle's position and to switch power from one section to another. A 10-motor-section guideway needs 10 three-phase power switches, with their corresponding protection circuits and triggering circuits.

A substation with a total capacity of 4 MVA is required for the test facility. The substation will transform power from high voltage (115-138 kV) to the level of a few kilovolts and also will house two VVVF power supplies. The substation will need one high-voltage transformer to step down the voltage from the standard power transmission line, two low-voltage input transformers, and two output transformers for the power supplies. The output transformer will also serve for isolation and step-up purposes. Figure 9.3 shows a sketch of the power distribution system in which the power switches along the guideway, motor section, and position-detector system are also included. The major specifications for the power supply and distribution system are listed in Table 9.1.

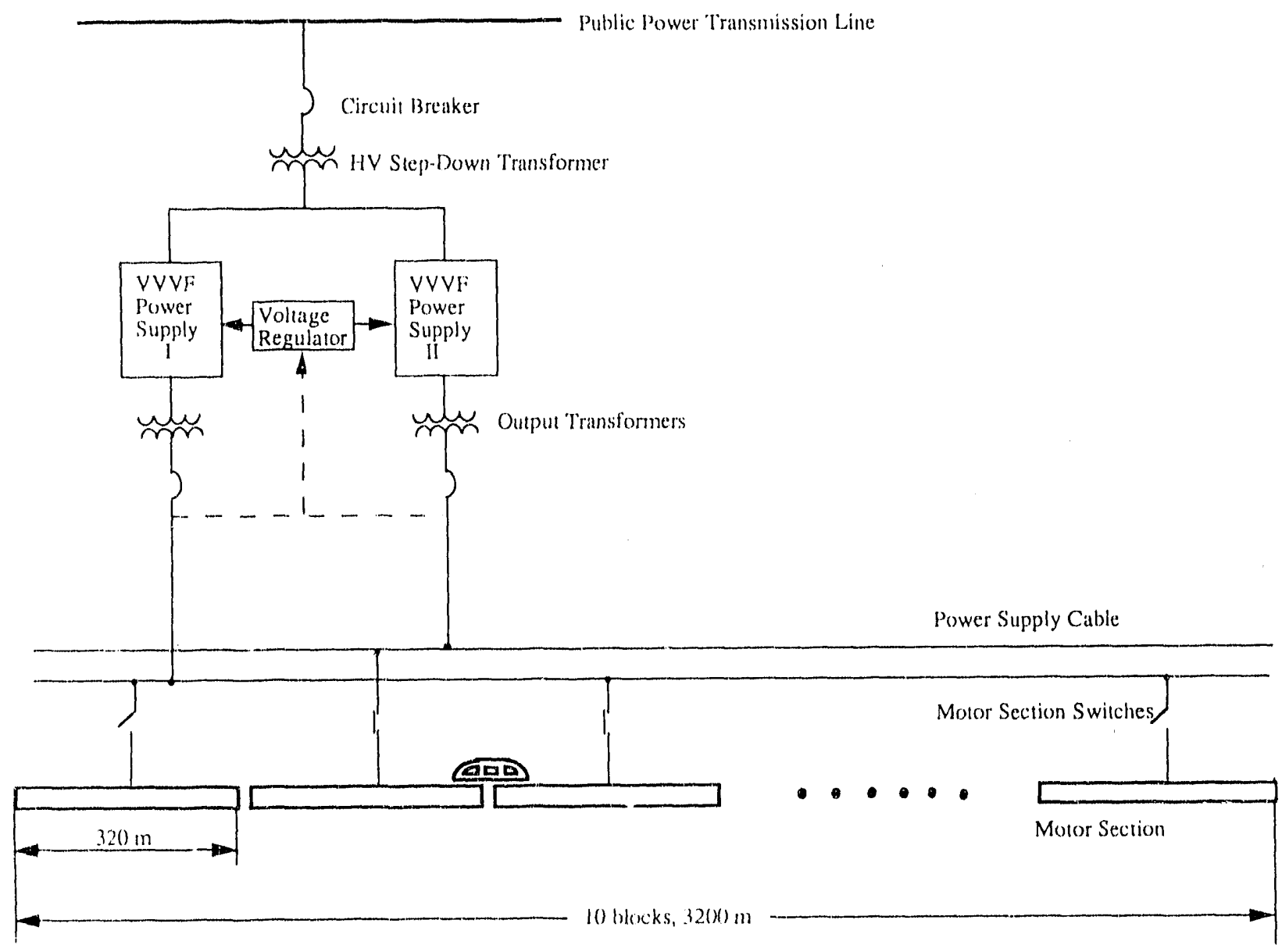

FI(iURE 9.3 Sketch of Power Supply and Distribution System for Maglev Test Facility 
Major substation components will also include:

- One high-voltage transformer (step down from 138 or $115 \mathrm{kV}$ ).

- Several low-voltage transformers (severalkilovolt level).

- Control and protection subsystems.

\subsection{COST OF MAJOR ELECTRICAL COMPONENTS}

The costs of major electrical components are estimated on the basis of the Means Electrical Cost Data. ${ }^{2,3}$ A historical cost index of 2.2 has been used to convert some information in Reference 4 . The cost comprises several parts, such as power supplies, substation components, LSM stator, and distribution (see Table 9.2). The two 2-MVA VVVF power supplies are estimated to cost about $\$ 1.2$ million, assuming a rate of $\$ 300 / \mathrm{kW}$. The air-cored stator windings are estimated to cost $\$ 180,000 / \mathrm{km}$, or $\$ 577,000$ for a 3,200-m-long guideway. For the EMS test option, the iron-cored stator will have a mass of $500 \mathrm{~kg} / \mathrm{m}$.
TABLE 9.1 Summary of the Power Supply and Distribution System Specifications

\begin{tabular}{lc}
\hline \multicolumn{1}{c}{ Item } & Value \\
\hline Substation capacity (MVA) & 4 \\
Number of VVVF units & 2 \\
Capacity per VVVF unit (MVA) & 2 \\
Frequency range (Hz) & $0-200$ \\
Maximum voltage (V) & 4,500 \\
Motor-section switches $^{\text {a }}$ & 10 \\
\hline a Three phases.
\end{tabular}

TABLE 9.2 Cost of Electrical Components

\begin{tabular}{ll}
\hline \multicolumn{1}{c}{ Item } & $\begin{array}{l}\text { Value } \\
\left(\$ 10^{6}\right)\end{array}$ \\
\hline LSM stator & \\
Air-cored & 0.58 \\
Iron-cored & 3.2 \\
VVVF power supplies & 1.2 \\
Aluminum sheet & 0.5 \\
Distribution and & 1.8 \\
substation & \\
Total & \\
EDS option & 4.08 \\
EMS option & 6.2 \\
\hline
\end{tabular}

The cost of the laminated steel sheet is about $\$ 1.50 / \mathrm{kg}$ without machining. Assuming $\$ 2.00 / \mathrm{kg}$ for the laminated core with slots and teeth, one obtains a cost of $\$ 3.2$ million for a 3,200-m-long guideway. The power substation and distribution system is estimated to cost $\$ 600,000 / \mathrm{km}$, or $\$ 1.8$ million for the $3,200-\mathrm{m}$ guideway. In addition, the $3,200-\mathrm{m}-\mathrm{long}$ continuous aluminum sheet for levitation and guidance in the EDS option is estimated to cost $\$ 500,000$.

In conclusion, the electrical components for the 3,200-m-long test facility are expected to cost $\$ 4.08$ million for the EDS test option and $\$ 6.2$ million for the EMS test option. This shows that the cost of the iron-cored LSM is about 50\% higher than that of the air-cored LSM. 


\subsection{REFERENCES FOR CHAPTER 9}

1. Matsunuma, S., Y. Nagayama, and S. Kobayashi, A Study on the Characteristics of the Magnetically Levitated Transportation System, Proc. Eleventh International Conf. on Magnetically Levitated Systems and Linear Drives (Maglev '89), Yokohama, Japan, July 7-11, 1989, pp. 275-280 (1989).

2. Means Electrical Cost Data, R.S. Means Co., Inc., Kingston, Mass. (1991).

3. Means Heavy Construction Cost Data, R.S. Means Co., Inc., Kingston, Mass. (1991).

4. Skalski, C.A., The Air-Core Linear Synchronous Motor - An Assessment of Current Tevelopment, MITRE Corp., Alexandria, Va. (Sept. 1975). 


\section{GUIDEWAY STRUCTURES}

\subsection{INTRODUCTION}

The guideway is the single most costly element of a maglev system. Associated with it are the power distribution, propulsion, and control and communication systems. It must provide for safe, comfortable support and propulsion of the vehicle and for safe egress from the vehicle in the event of an emergency; in addition, it should be aesthetically pleasing to the eye and nonintrusive with respect to the environment. As the most costly element, the guideway offers the greatest potential for cost savings in a new design. The many factors to be weighed in designing such a structure must be considered in conjunction with the other elements of the system. Evaluating these factors will be a major task for the development facility. These factors are discussed, and a preliminary design is presented, in this chapter.

\subsubsection{General Requirements}

The clearance between the guideway and the vehicle in EDS systems is substantially greater than that in EMS systems. This greater clearance permits EDS vehicles to pass over larger irregularities in the guideway structure, or larger objects on the guideway (without making contact with them), than can be tolerated with EMS vehicles: an EDS vehicle can pass over a $2-\mathrm{cm}$ vertical discontinuity without interference, while a similar discontinuity could have very bad effects on an EMS system. Similarly, deflections of the guideway as the vehicle passes over will have less effect on an EDS vehicle than on an EMS vehicle. Looser construction tolerances, greater safety from collision with debris, and reduced requirements to correct for settling appear to favor the EDS system.

These assumptions, however, are based primarily on the static loads placed on the guideway by vehicles passing over at their equilibrium suspension heights. Even if a suspension can be designed that will permit vehicles to pass over local depressions in the guideway while maintaining their equilibrium suspension heights (which is desired to avoid vertical accelerations on the passengers), the effact of the depression on the propulsion system must also be considered. In general, the propulsion force decreases as the spacing between the vehicle magnets and the stator increases. A momentary deceleration caused by passing over such a depression might be as uncomfortable to passengers as the vertical acceleration the suspension system is designed to avoid.

Substantial loads can be placed on the guideway by the vehicle as it passes by, inducing oscillations in the guideway that will interact back on the vehicle. If trains are used, the modes stimulated in the guideway are expected to be different, and the dynamic's of the individual cars in the train must be considered. Aerodynamic and seismic loads on the guideway must also be considered. 
With expected operating speeds of $300 \mathrm{mph}$, grade crossings cannot be allowed, and the guideway is expected to be elevated except at terminals. The guideway can comprise either continuous or discrete beams supported on piers; prefabrication of the support columns and guideway spans should be considered to make construction faster and less expensive. In electromagnetic maglev systems, any of the common construction materials can be used. (Both steel and concrete girders were used in the Emsland track.) Steel must be used judiciously in electrodynamic systems, since magnetic attraction and drag forces can be generated by the presence of this material.

Since maglev vehicles make no direct contact with the guideway, and the localized pressure is low compared with steel-wheel-on-steel-rail technology, the maintenance costs are expected to be minimal, and nonconventional structural materials might be usable in this long-lifetime structure. Active components of the guideway must be aligned with high tolerance in the EMS system, but they can be mounted and adjusted to the required tolerances on a basic guideway structure that is not subject to the same tolerances.

The limiting factor in determining the geometry of the guideway is the ride comfort achievible with a particular design. Because high-speed maglev vehicles do not depend on friction lor propulsion, they can climb steep gradients. Gradients as steep as 10\% have been suggested. The controllability of the guidance forces and the relatively low center of mass of these vehicles enable them to use more highly banked (and thus, relatively sharp) curves.

The design of the guideway is related to questions of passenger comfort, the construction tolerances, settling, and stiffness of the guideway, and the installation of functional components on it. It is generally expected that it will be most cost-effective to design a vehicle incorporating technological improvements in the suspension that will allow it to travel safely and comfortably over a guideway that is more flexible, has more irregularities in its construction, and requires less maintenance.

The curvatures of the guideway in both the lateral and vertical directions are important factors in its design. Allowing relatively sharp turns would permit the vehicle to avoid difficult terrain or costly structures, but this would result in accelerations on the vehicle and its passengers, and on the guideway, that must be considered. Figure 10.1 illustrates these considerations. For any vehicle velocity, there is a lateral curvature of the guideway and an angle at which the guideway can be banked to result in a coordinated turn (a turn in which the forces appear to the vehicle and its passengers to be only in the normal direction). Figure 10.1a shows the recessary bank angle for coordinated turns as a function of velocity and radius of curvature. Although quite steep coordinated turns can be made, concern has been expressed about the visual sensations associated with rolling into excessively steep turns.

Another consideration is the acceleration experienced by the passengers. Accelerations up to 1.1 times the force of gravity ( $1.1 \mathrm{~g}$ 's) are thought to be acceptable to passengers if imposed without excessive jerk (the rate of change of acceleration). This consideration limits the radius of curvature to $4,000 \mathrm{~m}$ at $300 \mathrm{mph}(134 \mathrm{~m} / \mathrm{s})$; see 
(a) ANGLE OF BANK

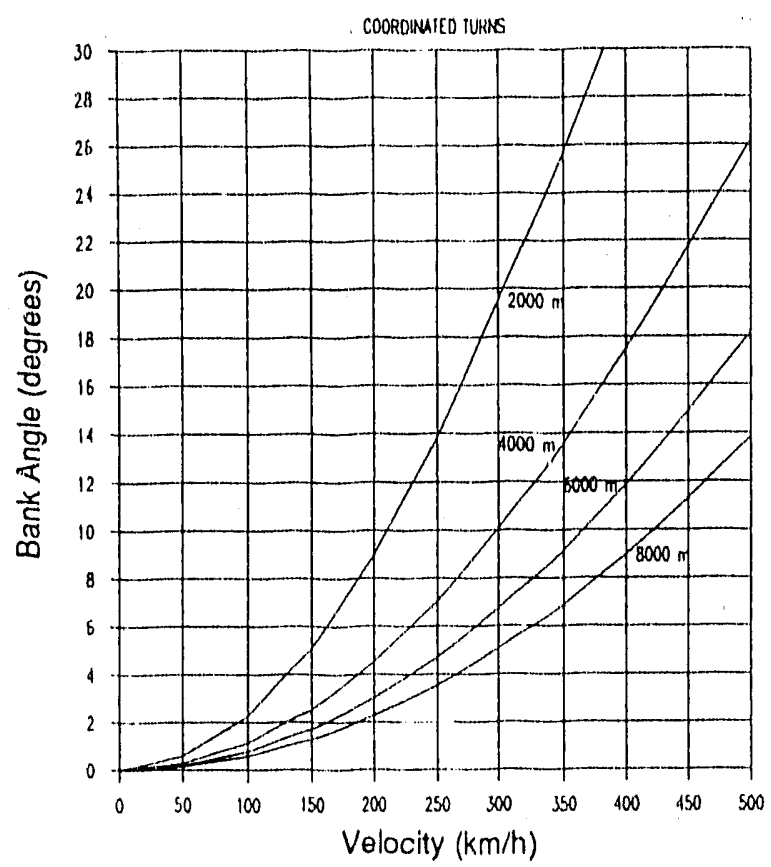

(c) LATERAL ACCELERATIONS, TURNS

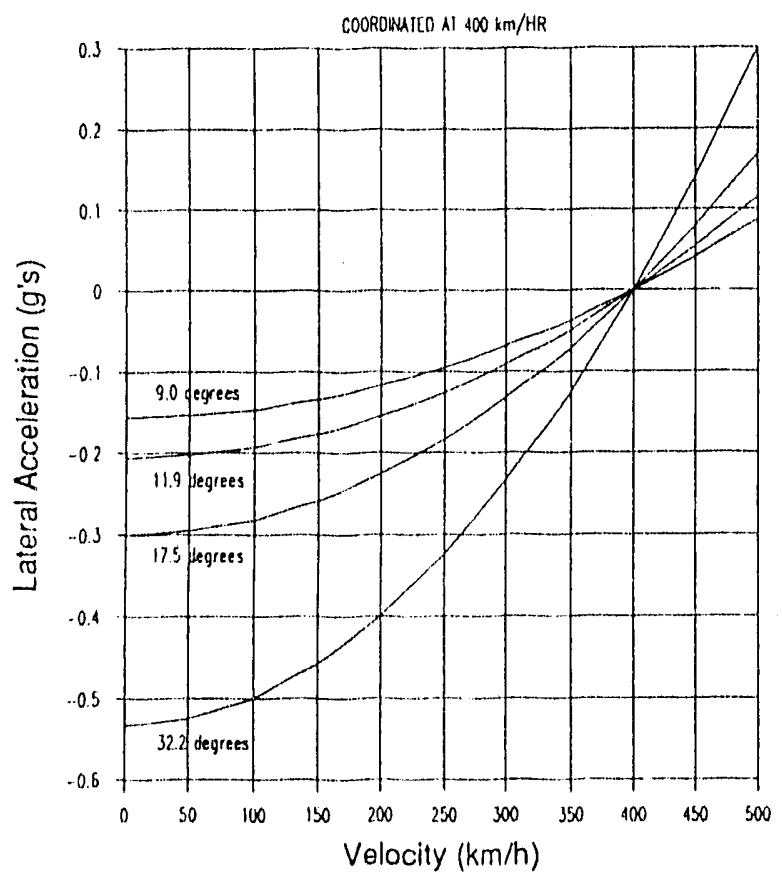

(b) NORMAL ACCELERATION

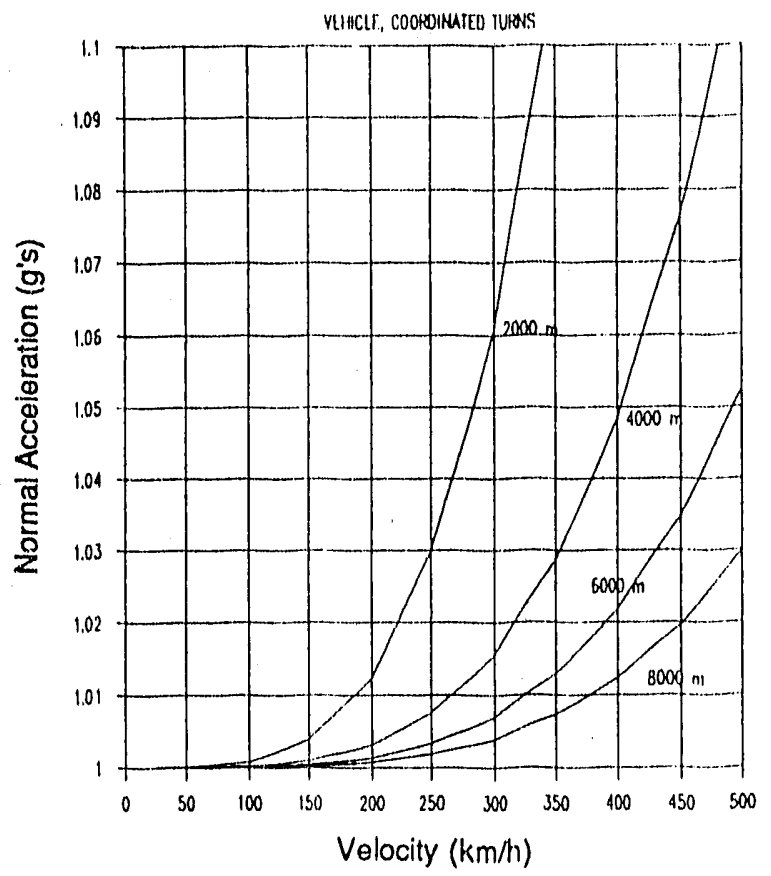

(d) LATERAL ACCEERATIONS ON

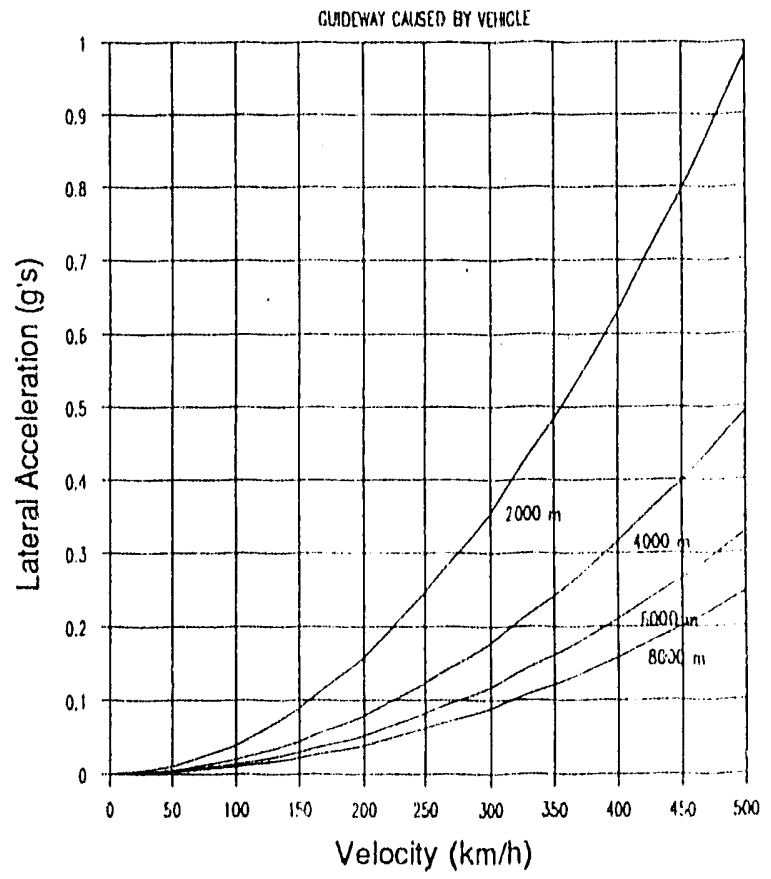

FrGURE 10.1 Acceleration on Vehicle and Guideway 
Figure 10.1b. Another concern is the effect of passing through such turns at velocities that are either above or below those that result in coordinated turns. 'This effect is illustrated in Figure $10.1 \mathrm{c}$, which shows the lateral acceleration caused by traversing a turn that is coordinated at $400 \mathrm{~km} / \mathrm{h}$ at greater or lesser speeds.

Although speeds above the coordinated-turn speed can easily be avoided, a propulsion failure could cause the vehicle to go through the turn at reduced speed or even to stop in midturn. Lateral accelerations are less comfortable than vertical accelerations and are frequently regarded as uncomfortable even when they amount to less than $0.1 \mathrm{~g}$ 's. A $9^{\circ}$ to $12^{\circ}$ angle of bank would permit operations at speeds that differ from the coordinated-turn speed by $100 \mathrm{~km} / \mathrm{h}$. If the vehicle were to stop in the turn, however, the lateral accelerations could be considerable; in the worst case, they would probably prevent many people who are not ordinarily considered disabled from being able to exit the vehicle. After exiting, moreover, they might not be able to walk on the banked guideway to reach an exit to ground level. Special "level" walkways in the center of the guideway might be provided for this purpose. Transrapid elected to limit the angle of bank to $12^{\circ}$. This angle, in the absence of special considerations or mitigating measures, appears prudent.

The radial load placed on the guideway by the vehicle is shown in Figure 10.1d. This load is independent of the angle of bank and can be substantial. A 100-metric-ton vehicle triveling at $500 \mathrm{~km} / \mathrm{h}$ would place a lateral load of 32 metric tons on the guideway if the radius of curvature were $6,000 \mathrm{~m}$.

In the following sections, the state of the art relative to maglev guideway designs is discussed, engineering requirements for a guideway design for the experimental facility are considered, and research needs are identified.

\subsubsection{Guideway Structures}

\section{Substructure}

The guideway substructure supports the guideway spans and distributes the loads on them. The relatively light weights of maglev vehicles and the large horizontal loadings at high speeds may lead to unusual behavior of the piers and footings due to the high overturning moments. Consequently, depending on the characteristics of the soil, the foundations for the piers might require pilings. The structure chosen by Transrapid uses four concrete piles, which are inclined to reduce the bending of the piles.

To minimize the cost of construction, a slender guideway with a large support spacing is desirable, but a large guideway with a small support spacing would be better able (1) Mrovide acceptable ride-comfort levels and/or accommodate constraints imposed by gruideway stresses. In general, to meet the ride-comfort specifications, guideway stiffness becomes the controlling factor. The guideway flexibility and the degree of irregularity that 
can be tolerated in maglev systems depend on the dynamics of the coupled vehicle/guideway system.

\section{Superstructure}

The guideway superstructure includes the equipment used to support, guide, propel, and control the vehicles. The spans of aerial structures can represent as much as $40 \%$ of the initial cost. ${ }^{1}$ Because the vertical loadings are relatively small, significant torsional stiffness is required for stability. A closed box girder was selected by Transrapid for their concrete spans and a triangular structure was used in the steel spans, as can be seen in Figure 2.2. In the Emsland test track, manufactured steel girders and precast, prestressed, posttensioned and reinforced concrete girders were used. These spans were relatively stiff $(1 / 4000$ th of the span) to keep the vertical deflection small.

\subsubsection{Static Loads}

Static loads on the guideway arise from several sources: the weight of the vehicle, centrifugal forces, aerodynamic forces on the guideway and vehicle, electrodynamic drag, propulsion and guidance forces, and impact forces during landing.

The weight per seat for maglev vehicles of either the ENS or the EMS type is lighter than that for their modern high-speed-train counter parts. The French TGV and the German Intercity Express (ICE) trains weigh 1.0 and 1.2 metric tons per seat, respectively, while the TR-07 weighs 0.45 metric tons empty ( 0.53 metric tons loaded) per seat and EDS vehicles weigh 0.21 to 0.45 metric tons per seat. The pressure exerted on the track by a maglev vehicle is about 0.1 to $0.01 \%$ of that exerted by a steel wheel on a steel rail.

The propulsive force exerted by th " 36 vehicle is $85 \mathrm{kN}$, to which there is a corresponding reaction by the guideway .... .e longitudinal direction. The TR-07 is expected to exert a $100-\mathrm{kN}$ propulsive force. Pr.jvisions must also be made for emergency braking of the vehicle. This requirement places a longitudinal load of $300 \mathrm{kN}$ on the guideway. The TR-07 vehicle weighs 106 metric tons loaded, resulting in a vertical force of $944 \mathrm{kN}$ or a pressure of $37 \mathrm{kN} / \mathrm{m}$ on the guideway; the lateral force is $10 \mathrm{kN} / \mathrm{m}$.

The Miyazaki test set consists of multiple cars, each weighing 10 metric tons and exerting a vertical force of $98 \mathrm{kN}$ (total) or a pressure of $10.2 \mathrm{kN} / \mathrm{m}$ on the guideway. This weight per meter is approximately half that for the TR-07 vehicle. The propulsive force, $51 \mathrm{kN} / \mathrm{car}$, and the lateral force, $49 \mathrm{kN} / \mathrm{car}$, exert forces of 5.3 and $5.1 \mathrm{kN} / \mathrm{m}$ in the longitudinal and lateral directions, respectively.

Side winds will increase the lateral loads on the vehicle, as discussed in Chapter 5 , and large impact loads may be generated when a maglev vehicle lands or when it runs over joints, misalignments, or irregularities in the guideway. 


\subsubsection{Dynamic Vehicle/Guideway Interaction}

Figure 10.2 shows the essential elements of an interaction model for vehicles and guideways. As the vehicle moves, it is acted upon by external forces, as well as by suspension, guidance, and control system forces. The vehicle will flex and the suspension control systems will respond to the motions of the rehicle and to the induced dynamic motions of the guideway, resulting in extremely complicated interactions.

In a simplified model only the vertical motions of a maglev vehicle are considered, on the assumption that this is the dominant motion and that other motions can be ignored. This model is applicable in a system in which passenger-compartment accelerations are limited to less than $0.05 \mathrm{~g}$ 's and the vehicle's unsprung mass inertia forces are small compired with the vehicle weight. ${ }^{2}$

Analytical methods of calculating dynamic vehicle/guideway interactions can be divided into three groups: lumped mass, direct numerical, and modal analysis methods. The lumped mass method is simple and can be used to account for nonuniform properties, while the direct numerical method is accurate but requires more computer time. The modal analysis method represents an efficient compromise between the lumped mass and direct numerical methods.

When the unsprung mass is less than about $5 \%$ of the vehicle mass and the acceleration of the vehicle is less than $0.05 \mathrm{~g}$ 's, a weak coupling exists between the vehicle and the guideway. ${ }^{2}$ In this case, the guideway deflection profile is computed assuming that the suspension forces are constant at their static values and move along the guideway at tho speed of the vehicle. The deflection is then used as a known displacement input into the suspension, and the vehicle's dynamic motions are determined by standard transfer function analysis.

When the unsprung mass is larger than $25 \%$ of the vehicle mass, as in an EMS vehicle, or when the vehicle accelerations are larger than $0.1 \mathrm{~g}$ 's, the guideway deflection may be significantly affected by the dynamic suspension forces; in such cases, a fully coupled anclysis of vehicle/guide"yay interactions is needed. In the attractive (EMS) system, the large accelerations of the primary suspension system mass that occur due to the roughness of the guideway cause significant excursions in the magnet reaction force, and the vehicle/grideway equations should not be decoupled. ${ }^{3}$

In order to evaluate a wide range of vehicle and guideway designs for a broad range of operating conditions, computer models are required to describe the response of the various parts of the system. Various computer codes have been developed to provide the necessary dynamic simulations.

MOTION was developed to study the dynamics of maglev systems. ${ }^{4-6}$ The program, which solves for a general rigid body undergoing large displacements in six degrees of frectum, was applied to the SRI maglev vehicle. 


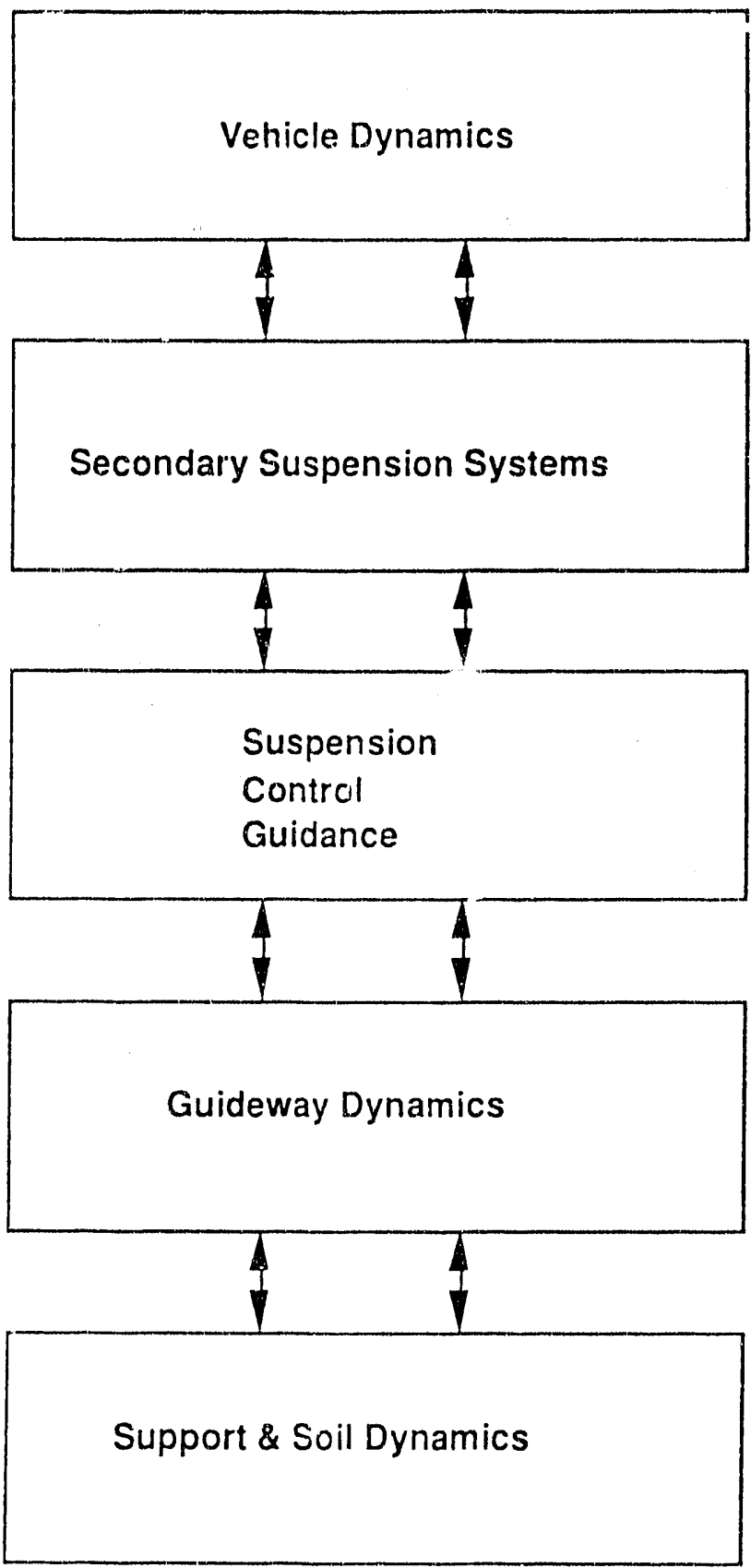

FIGURE 10.2 Vehicle/Guideway Dynamic Interactions 
ADAM was written for the purpose of analyzing mechanical systems undergoing large displacements; kinematic, static, quasistatic, and dynamic analyses are included. ${ }^{7}$ Systems are modeled at the basic level as groups of rigid mass parts connected by joints and forces that correspond directly to physical components. An extensive internal function library is available to permit the user to model complex mechanical phenomena for user-defined differential equations and forces.

MAGDYN is used to simulate vehicle and guideway dynamic responses for EDS systems. ${ }^{8}$ The model includes effects of the elastic deformation of the vehicle and guideway, vehicle suspension, multiple guideway spans, and aerodynamic loading:

- Rigid and flexible body vehicle motions are included.

- Four suspension and two propulsion forces are used for each vehicle.

- The guideway motion includes twisting and bending in two directions.

- Complete aerodynamic forces are modeled.

Nagai and Iguchi developed a program to analyze the vibration characteristics of a long train of EMS vehicles running over flexible guideways. ${ }^{9}$ Each vehicle is modeled as a four-degree-of-fresdom system, and the coupling between the vehicles and guideways is through distributed suspension forces. Some characteristics and limitations of the program are as follows:

- Only motions in the vertical plane are considered. Each vehicle is modeled with four degrees of freedom, heave and pitch of the vehicle and heave of two trucks.

- Multiple vehicles are analyzed, but the constraint in the vertical direction between adjacent vehicle bodies is neglected.

- The guideway is assumed to have single-span beams simply supported at both ends.

- An active feedback control loop is used to stabilize the levitation force.

Light guideways, especially steel ones, may be susceptible to dynamic instabilities and unacceptable vibrations, so a dynamic evaluation must be included in the structural analysis. Different dynamic responses of coupled vehicle/guideway systems may be observed; these include periodic oscillations, random vibrations, dynamic instabilities, chaotic motions, parametric resonances, combination resonances, and transient responses.

When the lift force varies sinusoidally with the guideway roughness, a maglev vehicle may experience both heaving and pitching oscillations. Analytical and experimental studies have been performed to understand this excitation mechanism. ${ }^{10}$ 
Parametric resonances of the guideway may occur if any external excitation causes large- amplitude oscillations. These external excitations include magnetic forces, wind forces, vehicle motion, and other sources. For example, in the Miyazaki Test Track, guideway oscillations at $300 \mathrm{~km} / \mathrm{h}$ are attributed to the coil pitch of the vehicle. ${ }^{11}$

Evenly spaced vehicles moving on a guideway at high speeds can cause the guideway to resonate with the passing of the vehicles. A simply supported beam has been considered. ${ }^{12}$ At a specific speed, large oscillations occurred, and methods were recommended to avoid resonances in such situations.

Guideway designs must be evaluated to ascertain their susceptibility to resonances, their coupling to the vehicle, and means of correcting them if they occur.

\subsubsection{Stabilization of Maglev Vehicles}

To assure a high level of ride comfort, a secondary suspension is used in EMS vehicles, and damping control or a secondary suspension is used in EDS vehicles. The suspension system should provide good guideway tracking and acceptable ride comfort. Good tracking in general demands small levitation clearances and stiffness of the support, while good ride comfort requires weak coupling between the passenger cabin and the guideway. Active or passive control of the suspension system can be developed to provide the required stiffness for vehicle support and the softness required for the passenger cabin.

The characteristics of the motion of a levitated vehicle when it is perturbed from steady motion have been analyzed by Wilkie. ${ }^{13}$ The magnetic forces for steady motion of a magnet over a conducting plane can be used to determine the perturbed motion. ${ }^{14}$ The motion resulting from a vertical perturbation is an essentially undamped vertical oscillation with a frequency of the order of $1 \mathrm{~Hz}$, and an exponentially growing motion results from a perturbation in the direction of motion if air drag is not included in the analysis. The small damping in the vertical motion can be either positive or negative, depending on the magnet geometry. The response to perturbations may be unacceptable in a passenger-carrying vehicle unless means of feedback control of the motion are used to obtain stability and suitable ride characteristics.

Several options can be used to stabilize a maglev system: passive electrodynamic primary suspension damping, active electrodynamic primary susperision damping, passive mechanical secondary suspension, and active mechanical secondary suspension. In Canada, an active secondary suspension system was recommended for the vertical suspension systern to achieve an acceptable ride quality without compromising the primary suspension system. ${ }^{15}$ It was found to be possible to achieve a suitable lateral dynamic response using both passive primary and secondary suspension systems. However, controlling the vehicle dynamics by the use of passive vertical suspension systems offers a higher degree of reliability, analogous to conventional automobile and railway suspension system designs. 


\subsection{PROPOSED GUIDEWAY}

\subsubsection{Objectives}

One of the principal goals of this program is to develop a preliminary guideway design for an experimental facility for less-than-full-scale maglev systems. The design must be compatible with the various constraints imposed by site, vehicle, and functional considerations. Since the functional and site constraints are unknown, an optimized design is impossible at this time. The guideway must provide for modifications to permit the evaluation of both EDS and EMS systems. Some of the objectives are as follows:

- Evaluate different maglev system concepts.

- Evaluate various maglev system components and parameters.

- Obtain experimental data for verification of computer codes for maglev systems.

\subsubsection{Approach}

As discussed in Chapter 3, the guideway for a commercial system is assumed to be elevated to avoid grade crossings, as well as for safety and other reasons, so the experimental guideway must be designed to evaluate parameters appropriate to this type of construction. These factors were considered in Chapter 4 . It must be capable of having installed on it various types of propulsion, and possibly power pick-up, equipment. To meet these requirements, the guideway is designed to be constructed of beams and piers. The beams will be constructed of precast, prestressed, posttensioned, and reinforced concrete girders.

'To realistically simulate operational systems, the potential for evaluating vehicles at speeds up to $67 \mathrm{~m} / \mathrm{s}$ (150 mph) was assumed to be necessary. At this speed, the aerodynamic forces are approximately one-fourth as ort. $t$ as those experienced by an operational vehicle. The length of the guideway was established on the basis of an assumed vehicle acceleration of $0.2 \mathrm{~g}$ 's, approximately that of commercial jet aircraft when taking off or landing. This assumption leads to guideway lengths of $1,145 \mathrm{~m}$ for acceleration and deceleration of the vehicle, or a total of $2,290 \mathrm{~m}$. A period of $15 \mathrm{~s}$ is allowed for testing of the vehicle at this peak speed, necessitating an additional guideway segment of $1,005 \mathrm{~m}$, for a total length of $3,295 \mathrm{~m}(2.05 \mathrm{mi})$. The 15 -s period will provide realistic acceleration power spectral density measurements to be made at frequencies of less than $0.1 \mathrm{~Hz}$. Frequencies approximating $0.5 \mathrm{~Hz}$ can cause motion sickness and are, therefore, of significance in determining the ride quality of passenger carrying systems. Although the developmental velicle will not necessarily be required to meet the ride quality specifications of a revenueproflucing vehicle, the vehicle will probably be used to evaluate controls in this frequency range. 
To minimize the restructuring of the guideway needed for various experimental configurations, the central $1,005-\mathrm{m}$ section will be regarded as the primary experimontal portion of the system. Piers and spans in this section will be removable to alter the physical and dynamic characteristics of the guideway. Permanent recesses will be installed on the pier caps for the placement of hydraulic jacks to be used for adjusting spans and for alignment of the spans for testing. In this way, spans with different llexibilities, structur's, surface tolerances, materials, etc. can be introduced at minimal cost for evaluation of the effects of these changes on the performance of the system. Mounting holes and penetrations through the guideway are liberally provided for attaching various propulsion, test, and power distribution equipment.

The acceleration and deceleration sections of the guideway will serve the purpose of achieving test speeds and stopping the vehicles. They will be constructed as inexpensively as possible, since they will not serve the primary function of system evaluation.

Operational systems will travel at peak speeds up to $134 \mathrm{~m} / \mathrm{s}$. Piers for the proposed operational systems are spaced on centers of about $25 \mathrm{~m}$ or greater, leading to periodic disturbances every $0.19 \mathrm{~s}$. For the experimental facility, with vehicles travelling at one-half the operational speed, a $13.5-\mathrm{m}$ pier-to-pier-spacing was chosen, resulting in periodic disturbances along the guideway every $0.20 \mathrm{~s}$. The proposed vehicle is approximately onehalf the length of the spans, but its effective length depends on the actual location of the magnets on the vehicle. This chuice results in spans with realistic experimental capabilities and reasonable sizes and weights; shorter or longer spans can be inserted in the experimental section of the guideway.

The static deflection of the spans in the Emsland test track for the EMS system is about 1:4,000; for EDS systems, the deflections are thought to be about 1:1,000. The latter value was tentatively selected, but it depends on the weight of the vehicle tested. The final decision awaits the judgment of industry as to its requirements. In the EDS configuration, to be discussed later, the actual rigidity of the guideway will, in fact, be closer to $1: 3,000$, while in the EMS configuration (the least i igid configuration) it will be about 1:1,000. Changing the rigidity from the values chosen here can be accomplished within reasonable limits by using somewhat larger prestressing strands in the direction of the guideway. The effects of steel bars or strands on the drag of the vehicle is a topic for evaluation. The use of these materials in the initial and final sections of the guideway might result in additional drag in these sections, but it need not affect operations in the experimental portion of the facility. Epoxy-coated reinforcing bars will be used to ensure that no closed electrical loops (which would result in the generation of undesirable forces) occur.

The initial guideway is proposed to be straight and level. Provisions have been made in the site design to accommodate a second, curved segment of guideway with a rise for evaluating the performance of systems under more realistic conditions. This curved guideway would branch from the main guideway about $510 \mathrm{~m}$ from the start, at which point the speed could be as great as $45 \mathrm{~m} / \mathrm{s}(100 \mathrm{mph})$, and additional acceleration could occur in the curved portion of the facility (see Chapter 12). A guideway switch can be used for this purpose, or a static structure can be employed. Such switches would be specific to the vehicle design and are not considered at this time, but they will be important topics for development. 
Evaluations of prototype maglev systems will, of course, be performed on other guideways elsewhere, at speeds that impose more demanding conditions.

Once a site is selected, the seismic status, local geological stability, and soil conditions will be determined to establish the requirements for the foundation and its stabilization. The foundations might require piles (such as four inclined concrete piles with a ground slab on the top) if the soil is soft, since the overturning moments on piers and footings may be large due to the horizontal loadings. For slender columns, A-frame-type piers might be used. The incline of the piers from the vertical on the tangent line might be from $12: 1$ to $4: 1$, while the underground piles could be inclined to about 1:4.

The route selected for the guideway will affect the vehicle dynamics, as well as the capital expenditures and operating costs. It will be necessary to establish the general geological profile along the project route and to identify lowland, upland, and wetlands and stormwater and drainage requirements, as discussed in the next chapter.

The basic guideway cross sections shown in Figure 10.3 can be constructed of prestressed concrete, with protrusinns minimized to reduce the cantilever hending moments due to the live load (these moments progressively increase with length, leading to a need for heavy structural member's). The positions of the 'fams must be precisely determined to ensure the accuracy of the three-dimensional carve and the transitions betwen the functional components on the beam joints. A computer-aided surveying technique can be used for this purpose. The beams would be roughly positioned and their positions recorded using a coordinate system; the necessary relative positioning of the beams in all degrees of freedom would then be determined by computer analysis.

\subsubsection{Detailed Design}

The basic tee beams shown in Figure 10.4 will be reinforced with epoxy-coated reinforcing bars, except in the case of the primary longitudinal reinforcement, which may be either epoxy-coated bars or prestressing strands. To minimize deflections, the concrete will have an ultimate strength of $34.5 \mathrm{MPa}(5,000 \mathrm{psi})$ at 28 days. Holes will be cast in the beam for the attachment of hardware and for the installation of cables. The beams will be supported on the piers by elastomeric bearing pads, and the elevation will be adjusted with steel plate shims. Materials and properties are shown in Table 10.1.

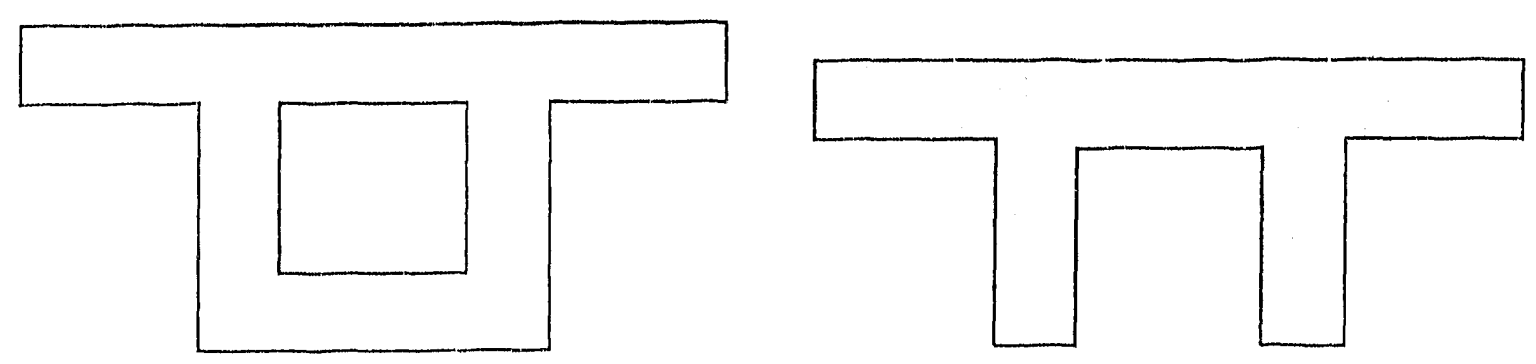

FIGURE 10.3 Two Possible Guideway Cl uss Sections 


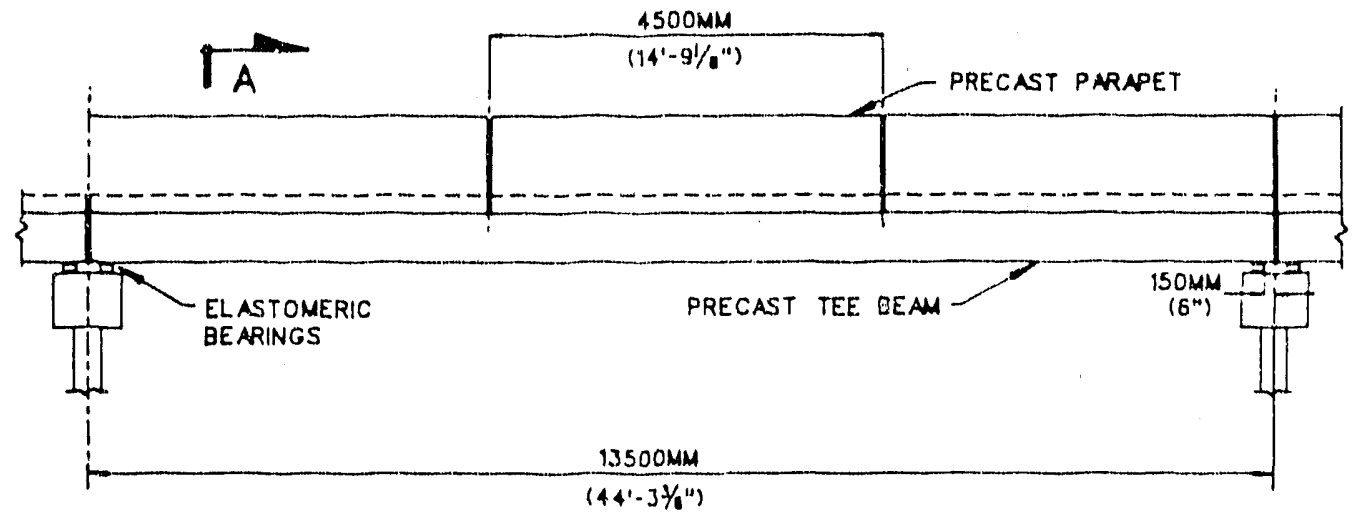

PARTIAL ELEVATION OF SUPERSTRUCTURE

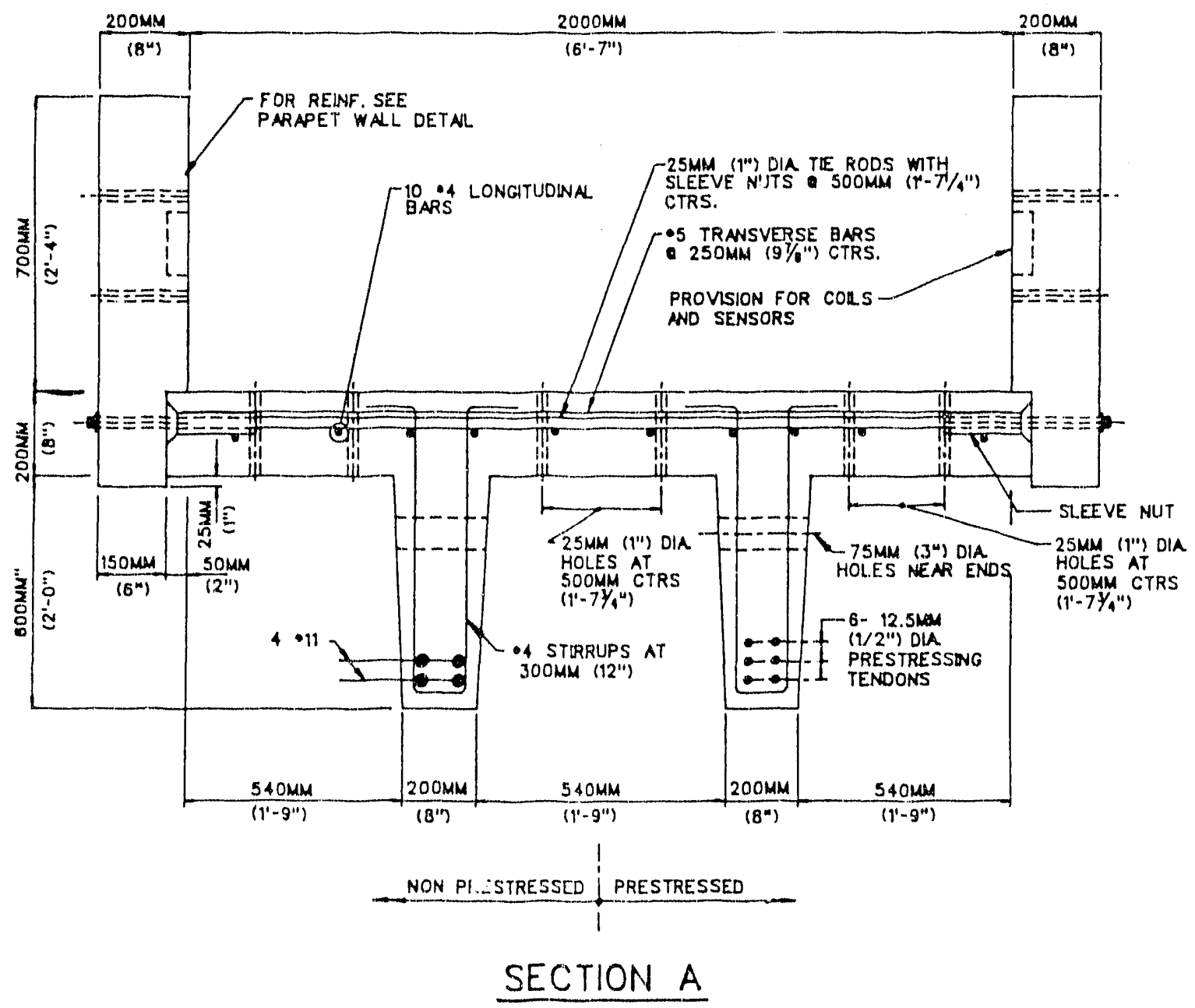

FIGURE 10.4 Detailed Guideway Cross Section 


\section{TABLE 10.1 Guideway Materials and Properties}

\begin{tabular}{|c|c|c|}
\hline Item & Material/Property & Value/Explanation \\
\hline \multirow{6}{*}{$\begin{array}{l}\text { Tee Beam and } \\
\text { Parapet Walls }\end{array}$} & Precast concrete & \\
\hline & Strength & $34.5 \mathrm{MPa}(5,000 \mathrm{psi})$ at 28 days \\
\hline & & a arram 0615 enoxy-roated \\
\hline & $\begin{array}{l}\text { Reinforcing bars } \\
\text { fy }\end{array}$ & $\begin{array}{l}\text { ASTM A61.5, epoxy-coated } \\
414 \mathrm{MPa}(60,000 \mathrm{psi})\end{array}$ \\
\hline & Es & $200,000 \mathrm{MPa}(20,000,000 \mathrm{psi})$ \\
\hline & $\begin{array}{l}\text { Prestressing strands } \\
\text { fy }\end{array}$ & $\begin{array}{l}\text { ASTM A416 } \\
1,860 \mathrm{MPa}(270,000 \mathrm{psi})\end{array}$ \\
\hline \multirow[t]{8}{*}{ Piers } & $\begin{array}{l}\text { Cast-in-place concrete } \\
\text { Strength }\end{array}$ & $27.6 \mathrm{MPa}(4,000$ psi $)$ at 28 days \\
\hline & $\begin{array}{l}\text { Assumed soil pressure } \\
\text { allowable }\end{array}$ & $0.2 \mathrm{MPa}(4,000 \mathrm{psf})$ \\
\hline & Piles & ASTM A36 \\
\hline & Size & HP $8 \times 36(20-\mathrm{cm}$ wide, $5 \mathrm{~kg} / \mathrm{m})$ \\
\hline & Maximum load & $534 \mathrm{kN}$ (55 metric tons) \\
\hline & $\begin{array}{l}\text { Elastomeric bearing } \\
\text { Allowable pressure }\end{array}$ & AASHTO M251 \\
\hline & $\begin{array}{l}\text { Allowable pressure } \\
\text { Maximum }\end{array}$ & $6.9 \mathrm{MPa}(1,000 \mathrm{psi})$ \\
\hline & Minimum & 1.4 MPa (200 psi) \\
\hline
\end{tabular}

As shown in Figure 10.4, the basic tee section can be modified to form a channel sh:ipe. The precast concrete parapet walls shown in Figure 10.5 are capable of supporting bolin horizontal (lateral) and vertical forces from the propulsion and levitation systems. The parapet walls will be connected to the basic tee beam with $2.54 \mathrm{~cm}$ (1-in.)-diametor bolts spaced at intervals of $0.5 \mathrm{~m}$ on center. The walls will be $4.5 \mathrm{~m}$ long to facilitate erection. The parapet walls will also have holes and recesses cast into them as required for the attichment of the hardware.

Depending upon the soil conditions at the site and the elevation of the test facility ahove the ground line, the piers may be supported on spread footings or steel piles. As shown in Figures 10.6 and 10.7, the geometry of the piers will be adapted to fit the site conditions.

The structure will be designed in accordance with the current requirements of the Amorican Concrete Institute (ACI) and/or Standard Specifications for Highway Bridges inlopted by the American Association of State Highway and Transportation Officials $(\triangle \Lambda$ sitT') $)$ Neither these criteria, nor those of the American Railway Engineering 


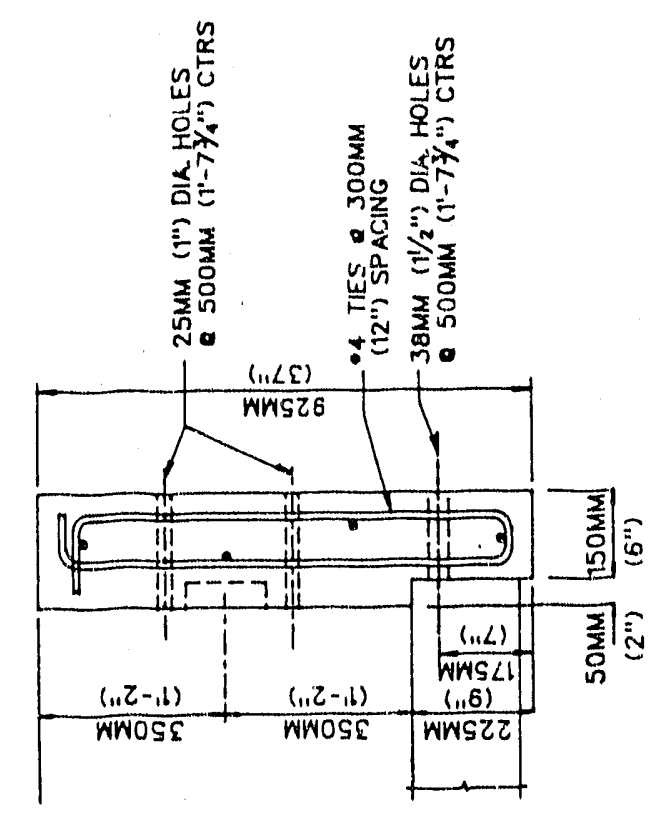

孞
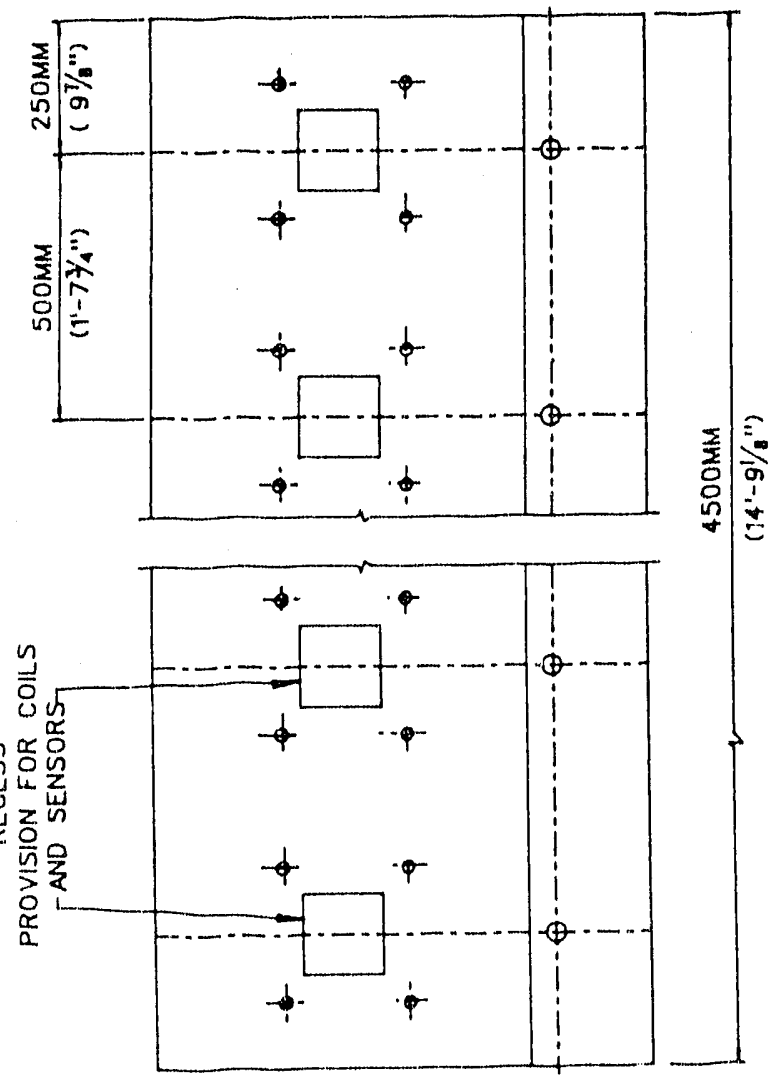

足 

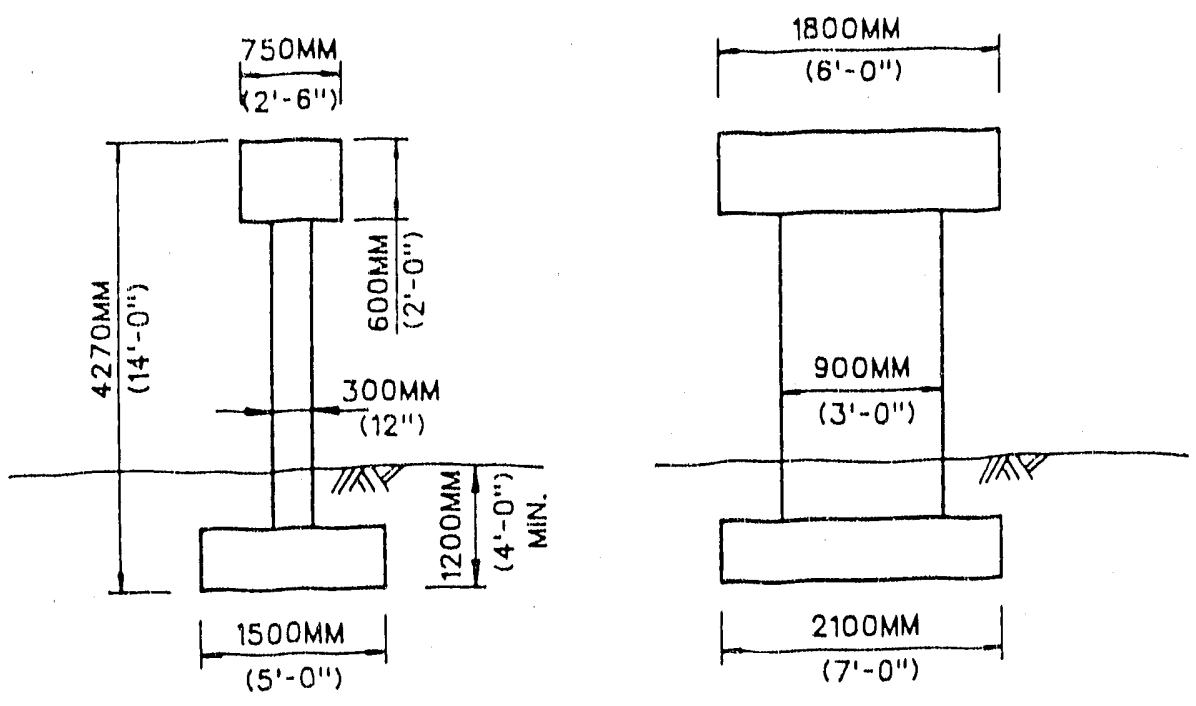

\section{PIERS ON SPREAD FOOTING}
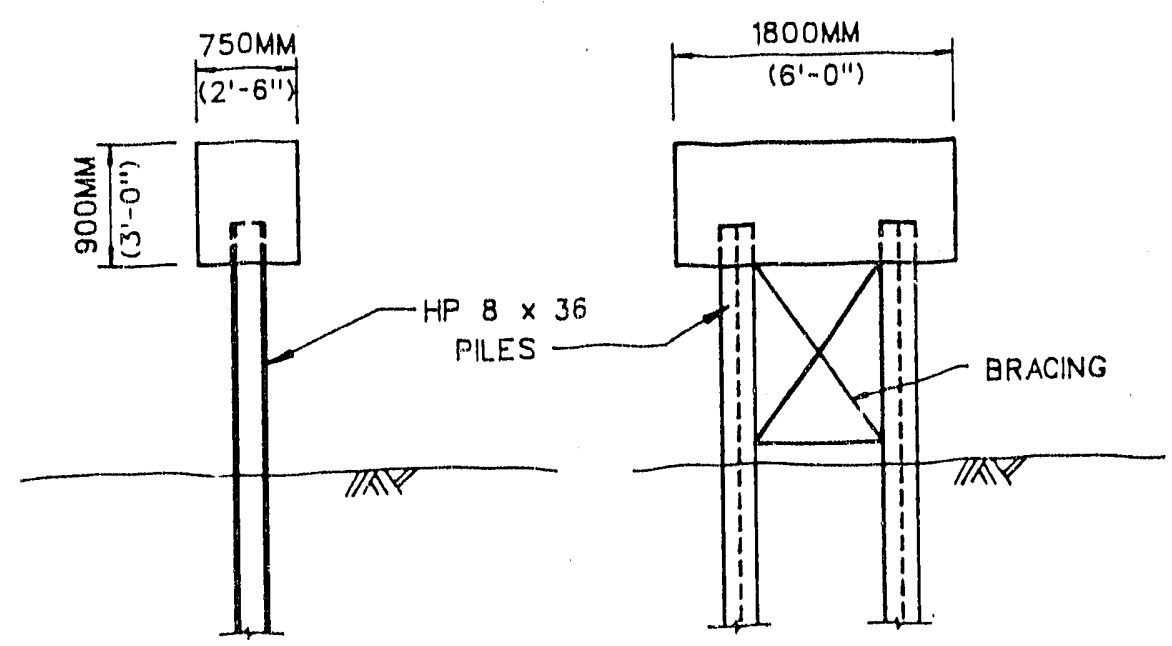

PILE BENT FOUNDATION

\section{FIGURE 10.6 Short Piers}



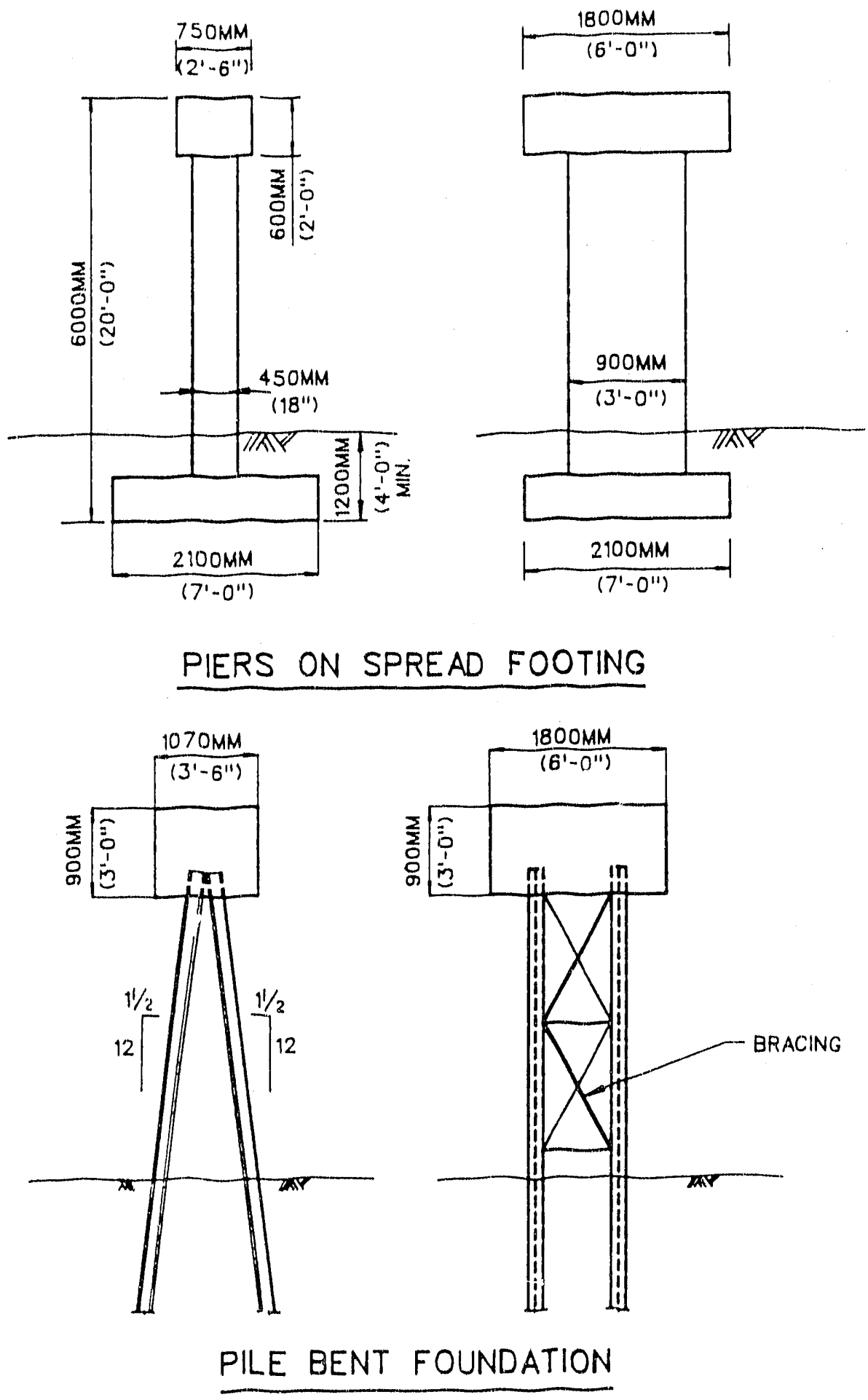

FIGURE 10.7 Tall Piers 
Association, specify equivalont static loading critoria to aceount for the dymamic offects of the magley vehicle on the guideway structure. Consequently, conservativo design values - an impract factor of $50 \%$ and a longitudinal foree of $20 \%$ of the test car lond - will be used. 'I'he assumod design loads of the three configurations studiod are shown in Figure 10.8. 'Tho: spandleflection ratio under live load plus impact will not bo less than 1,00).

\section{Deflections}

Deflections of concrete structures depend upon manv factors; the major ones are creep and shrinkage. Tablo 10.2 indicates the doflections based on the assumption that the tee heams will be approximately one year old beforo being londed. Aftor all hardware has been placed and adjusted, the structure will continue to creep (doflect). On the assumplion that the hardware for the first test will remain in place one yoar, tho creep over that poriod was estimated. The elastic deflection under full live load plus $50 \%$ impact was calculatod.

Although the contribution of the parapet walls to the load-carrying capacity was disregarded in determining the strength of the teo boam, the walls will act compositely with the tee beam to reduce deflection. The shear connecting capicity of the $2.54-\mathrm{cm}(1-\mathrm{in}$.) diamoter bolts connecting the walls to the toe beam was investigated and found to be quite: adecpuate. Therefore, the deflections due to live load and to creep of the parapet-wall doad loirl wore computed using the composite moment of inertia.

As shown, the live load deflections are well within the criteria, as is the live load plus creep for Configurations 1 and 2 (see Figure 10.8). The live load plus creep for Configuration 3 is just barely within the critoria, and the normal $\pm 20 \%$ variation would place it outside the limit $(89 .$. However, if Configuration 1 or 2 is tested first, the creep deflection under the second and later tests will be significantly reduced. In such a case, the live load plus creep for Configuration 3, oven with a possible $20 \%$ increase, would be $0.97 \mathrm{~cm}(0.38 \mathrm{in}$.) or a spandeflection ratio of 1,360 .

The horizontal deflection of the parapet wall under the lateral thrust of $10 \mathrm{kN}$ is $0.0063 \mathrm{~cm}(0.0025 \mathrm{in}$.$) . The vertical deflection of the elastomeric bearings under dead load$ is $0.076 \mathrm{~cm}(0.03 \mathrm{in}$.$) ; under live load plus impet of the 9$-metric-ton car, it is $0.05 \mathrm{~cm}$ (0.02 in.).

\section{Stresses at Critical Points}

The members are designed using the loat fatctor mothod and factors adopted by AASHTO to ensure an adequate safety factor. Stresses in the concrete and reinforcement under service loads at three critical sections are indicated in Tables 10.2 and 10.3.

The lack of adequate reference data to specify the requirements for the structural design of the support and guideway of a maglev system can lead to an overly conservative 


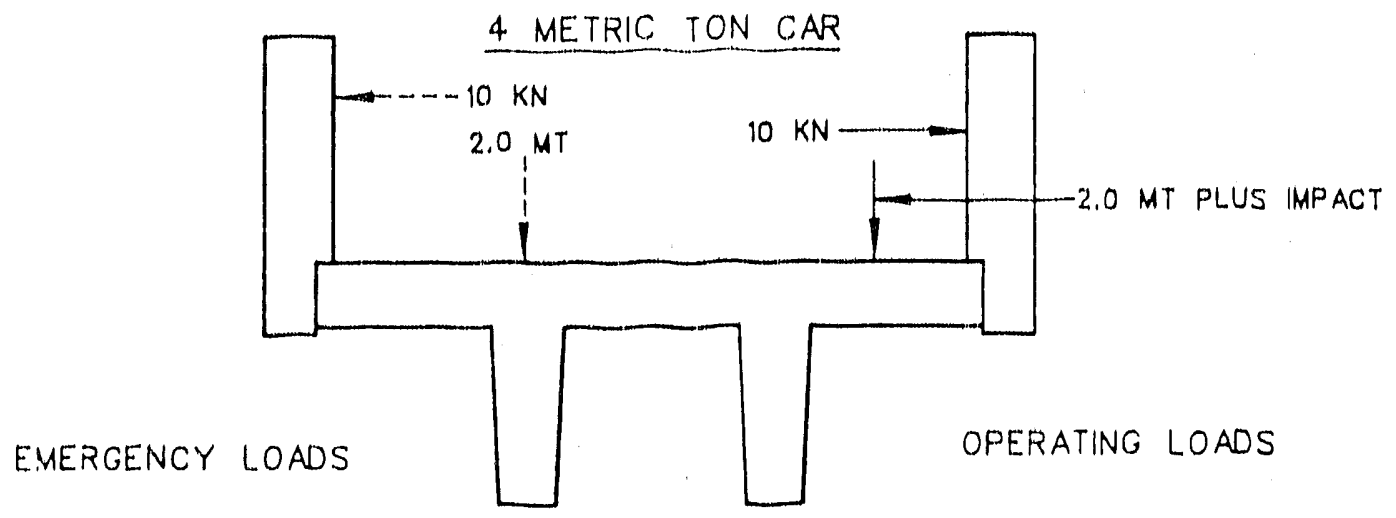

CONFIGURATION 1

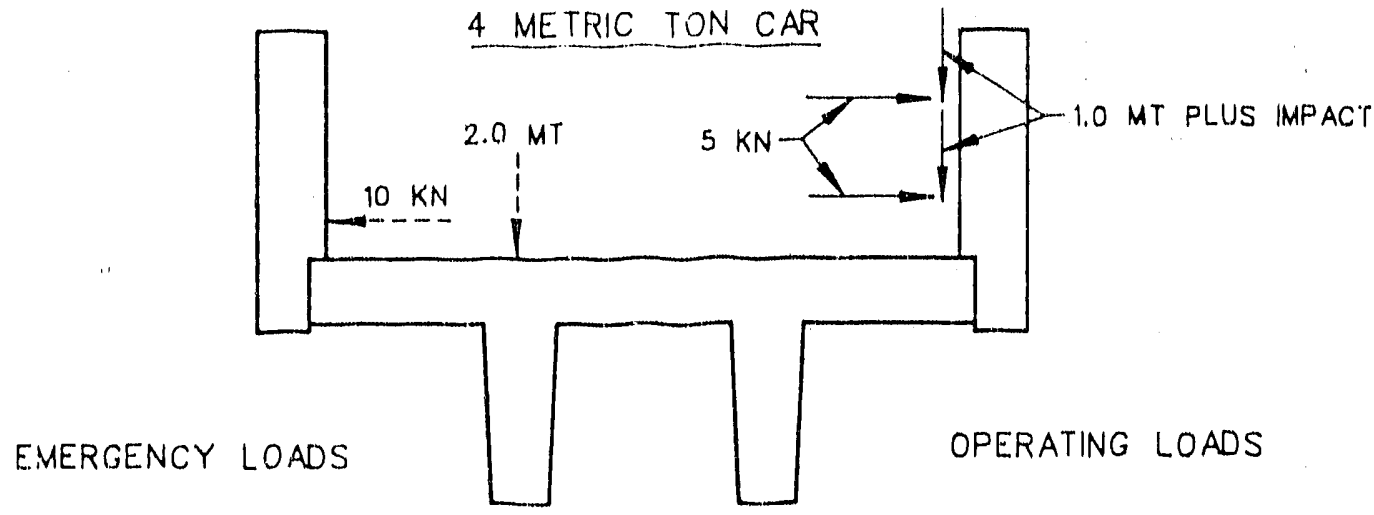

CONFIGURATION 2

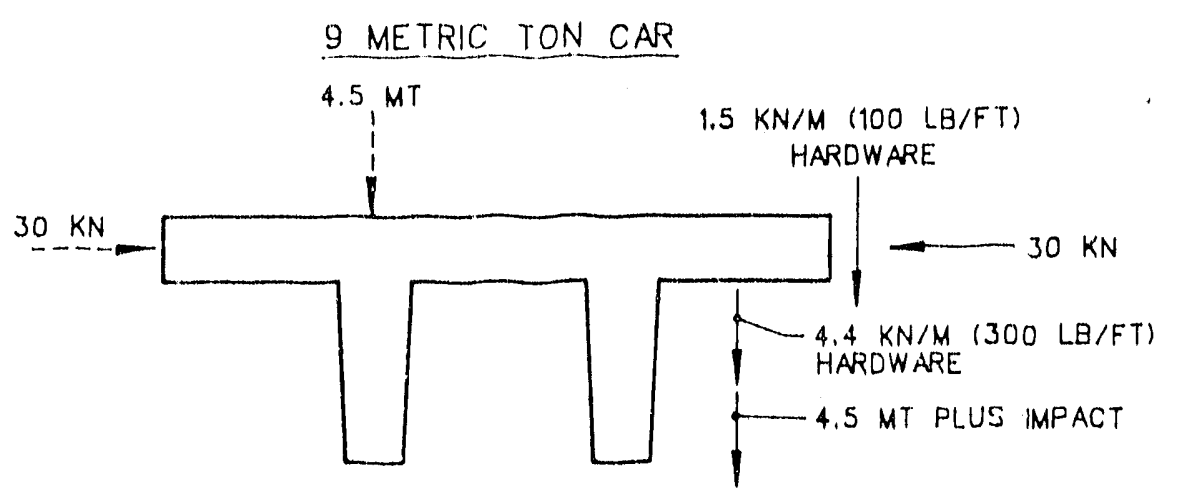

EMERGENCY LOADS

OPERATING LOADS

CONFIGURATION 3

FIGURE 10.8 Guideway Configurations 
TABLE 10.2 Deflection T'ablo

\begin{tabular}{|c|c|c|}
\hline Case & ltem & Value \\
\hline \multirow[t]{9}{*}{1.} & Lither Configuration 1 or 2 is Tested First & \\
\hline & Tee Boam - Filastic & $0.58 \mathrm{~cm}(0.23 \mathrm{in.})$ \\
\hline & Creep for One Year & $0.76 \mathrm{~cm}(0.30 \mathrm{in.})$ \\
\hline & Add Parapet Walls - Elastic & $0.33 \mathrm{~cm}(0.13 \mathrm{in.})$ \\
\hline & Creep for One Year (during test.) & $0.25 \mathrm{~cm}(0.10 \mathrm{in})$, \\
\hline & Total Dead Load & $1.93 \mathrm{~cm}(0.76 \mathrm{in.})$ \\
\hline & Live Load (4 metric tons) plus Impact - Elastic & $0.2 \mathrm{~cm}(0.08 \mathrm{in})$. \\
\hline & Live Load plus Creep after Adjustmont & $0.45 \mathrm{~cm}(0.18 \mathrm{in,})$ \\
\hline & Span/Deflection & 3,250 (dimensionless) \\
\hline \multirow[t]{9}{*}{2.} & Configuration 3 is Tested First & \\
\hline & Tee Beam - Elastic & $0.58 \mathrm{~cm}(0.23 \mathrm{in.})$ \\
\hline & Creep for One Year & $0.30 \mathrm{~cm}(0.30 \mathrm{in})$. \\
\hline & Add Hardware $(110 \mathrm{~kg} / \mathrm{m} ; 800 \mathrm{lb} / \mathrm{ft})$ - Elastic & $(0.13 \mathrm{~cm}(0.17 \mathrm{in.})$ \\
\hline & Creep for One Year (during test) & $0.71 \mathrm{~cm}(0.28 \mathrm{in.})$ \\
\hline & Total Dead Load & $2.49 \mathrm{~cm}(0.98 \mathrm{in.})$ \\
\hline & Live Load (9 metric tons) plus Impact - Elastic & $0.51 \mathrm{~cm}(0.20 \mathrm{in.})$ \\
\hline & Live Load plus Creep a "ter Adjustment & $1.22 \mathrm{~cm}(0.48 \mathrm{in.})$ \\
\hline & Span/Deflection & 1,080 (dimensionless) \\
\hline \multirow[t]{9}{*}{3.} & Configuration 3 is Tested Second or Third & \\
\hline & Additional Creep due to Doad Load & \\
\hline & Tee Beam for One Year & $0.109 \mathrm{~cm}(0.043 \mathrm{in.})$ \\
\hline & $83 \mathrm{~kg}(600 \mathrm{lb})$ Load for One Year & $0.058 \mathrm{~cm}(0.023 \mathrm{in.})$ \\
\hline & $28 \mathrm{~kg}(200 \mathrm{lb})$ for One Year $\mathrm{a}^{\mathrm{a}}$ & $0.137 \mathrm{~cm}(0.054 \mathrm{in})$, \\
\hline & Total Croep (during test) & $0.304 \mathrm{~cm}(0.120 \mathrm{in.})$ \\
\hline & Live Load plus Impact - Elastic & $0.508 \mathrm{~cm}(0.200 \mathrm{in.})$ \\
\hline & Live Load plus Creep after Adjustment & $0.81: 3 \mathrm{~cm}(0.320 \mathrm{in.})$ \\
\hline & Span/Deflection & 1,620 (dimonsionless) \\
\hline
\end{tabular}

" Hardware for Configuration 3 weighs $1,190 \mathrm{~kg} / \mathrm{m}(800 \mathrm{lb} / \mathrm{ft}$ ), while parapets weigh $890 \mathrm{~kg} / \mathrm{m}(600 \mathrm{lb} / \mathrm{ft})$. Creep for the $890-\mathrm{kg} / \mathrm{m}(600-1 \mathrm{~b} / \mathrm{ft})$ portion will be at a lesser rate than for the $300-\mathrm{kg} / \mathrm{m}(200)-\mathrm{hb} / \mathrm{h}$ ) portion. 
TABLE 10.3 Stresses and Creep at Various Locations

\begin{tabular}{|c|c|c|}
\hline Location & Configurations 1 and 2 & Configuration 3 \\
\hline \multicolumn{3}{|l|}{ At Center of Span } \\
\hline \multicolumn{3}{|c|}{ Flexure } \\
\hline Reinforcing & $164.0 \mathrm{MPa}(23.80 \mathrm{ksi})$ & $216.5 \mathrm{MPa}(31.40 \mathrm{ksi})$ \\
\hline Concrete & 0.8 MPa (0.99 ksi) & $9.0 \mathrm{MPa}(1.31 \mathrm{ksi})$ \\
\hline \multicolumn{3}{|l|}{ At Piers } \\
\hline \multicolumn{3}{|l|}{ Shear } \\
\hline Concrete & $0.68 \mathrm{MPa}(99 \mathrm{psi})$ & $0.94 \mathrm{MPa}(136 \mathrm{psi})$ \\
\hline $\begin{array}{l}\text { Allowable } \\
\text { (stirrups) }\end{array}$ & 2.1 MPa (305 psi) & $2.1 \mathrm{MPa}(305 \mathrm{psi})$ \\
\hline \multicolumn{3}{|l|}{ At Cantilever } \\
\hline \multicolumn{3}{|l|}{ Flexure } \\
\hline Concrete & $4.6 \mathrm{MPa}(0.66 \mathrm{ksi})$ & $3.2 \mathrm{MPa}(0.47 \mathrm{ksi})$ \\
\hline Reinforcing & $114.5 \mathrm{MPa}(16.6 \mathrm{ksi})$ & $82.7 \mathrm{MPa}(12.0 \mathrm{ksi})$ \\
\hline \multicolumn{3}{|l|}{ Shear } \\
\hline Concrete & $0.12 \mathrm{MPa}(17.4 \mathrm{psi})$ & $0.32 \mathrm{MPa}(46.5 \mathrm{psi})$ \\
\hline $\begin{array}{l}\text { Allowable } \\
\text { (no stirrups) }\end{array}$ & $0.83 \mathrm{MPa}(120 \mathrm{psi})$ & $0.83 \mathrm{MPa}(120 \mathrm{psi})$ \\
\hline
\end{tabular}

and uneconomical structural system. The present testing program will provide an ideal opportunity to improve our understanding of the behavior of this type of system. Therefore, it is recommended that instrumentation be installed on several of the elements of the structural system in order to make it possible to assess the magnitudes of the forces induced by the movement of a high-speed vehicle.

The necessary measurements can be accomplished by means of electronic strain gauges that are applied to the reinforcing bars within the superstruciure units and also to the pier systems. A possible arrangement of the gauges within the superstructure unit is shown in Figure 10.9. The gauges for the pier units would be applied in a vertical orientation at the tops and bottoms of the pier shafts.

Strain data can be recorded during any or all of the test configurations. These data can then be utilized to evaluate the range and magnitude of the maximum forces induced into the structural system. This will form the basis for estimating a realistic minimum loading criterion that will be appropriate for use in designing the structural support system for a maglev installation. 


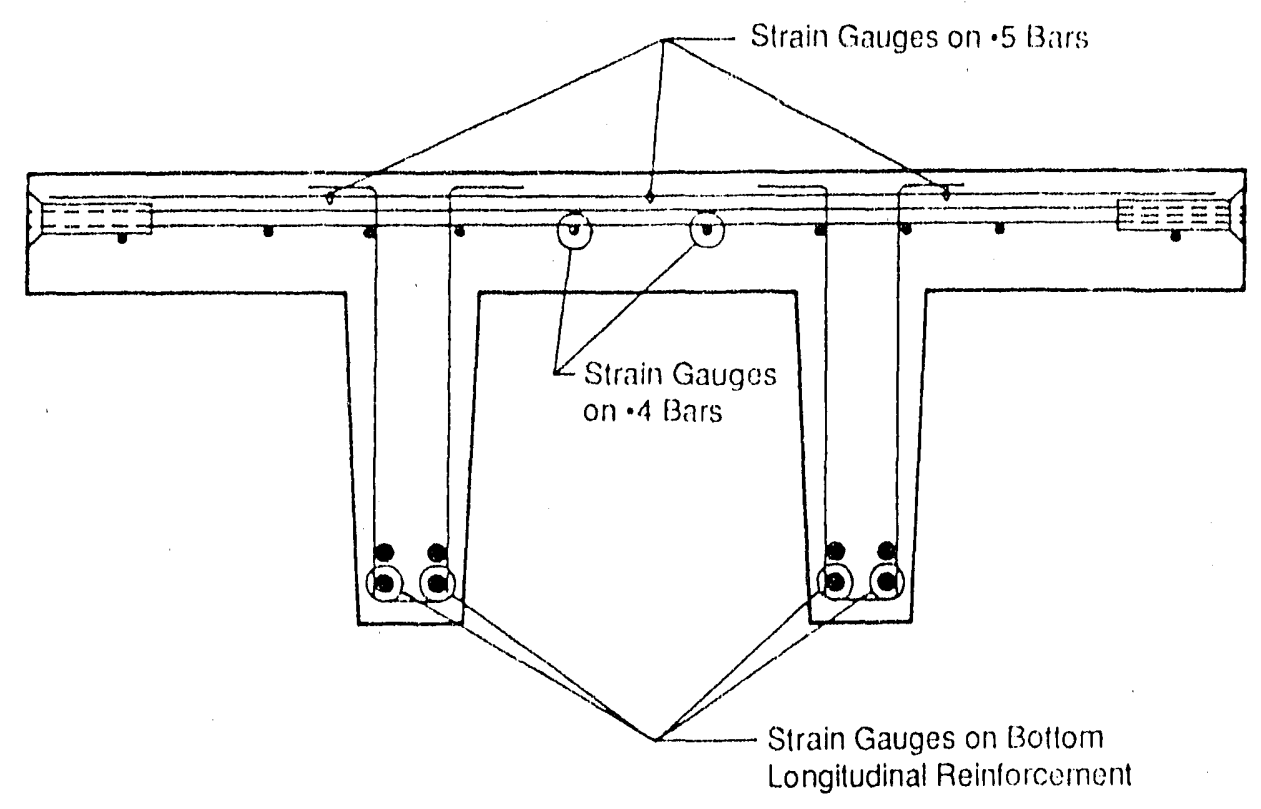

FIGURE 10.9 Location for Strain Gauges

\section{Cost Estimate}

A material take-off was made for the structure, and unit prices were selected from Means Construction Cost Data. ${ }^{16}$ The structure is an unusual one, and many assumptions have been made about the cost of the substructure that may be incorrect. Table 10.4 presents our best estimate of the construction cost.

\subsection{RIDE QUALITY}

Numerous attempts have been made to quantify the ride quality of vehicles to provide a basis for designing transportation systems. Without an understanding of this featurn, the system can be overdesigned at great and needless expense. A rigorous analysis, however, is very difficult, since it depends on subjective physiological and environmental factors. The major response of the body is in the 0.5 to $20 \mathrm{~Hz}$ frequency range in which urgans resonate. Ride quality criteria are frequently extended to 50 or even $80 \mathrm{~Hz}$, but a definitive range is not possible for all people. Comfort is also affected by other factors, such as noise, dust, humidity, and temperature, as well as by accelerations.

Two approaches have been taken to quantifying ride quality. The first is the fatigue time, which measures the time a passenger will willingly tolerate accelerations in different dircetions and at different but discrete frequencies. This approach fails to take into account the interactions between accelerations in different directions. These criteria have been rliscussed by Sinha ${ }^{17}$ and Garg and Dukkipati. ${ }^{18}$ 


\begin{tabular}{lr}
$\begin{array}{l}\text { TABLE 10.4 Estimated Costs for } \\
\text { Construction of Guideway }\end{array}$ \\
\hline \multicolumn{1}{c}{ Item } & Value (\$) \\
\hline 238 Tee Beams @ $\$ 4,400$ & $1,047,200$ \\
$6 \times 238$ Parapet Walls @ $\$ 600$ & 856,800 \\
49 Tall Piers @ $\$ 4,200$ & 205,800 \\
190 Short Piers @ $\$ 2,500$ & 475,000 \\
& $2,584,800$ \\
Contingencies, 20\% & 517,000 \\
Subtotal & $3,101,800$ \\
$\begin{array}{l}\text { Demolition: Remove and } \\
\text { dispose of piers and beams }\end{array}$ & 466,300 \\
Total & $3,568,100$ \\
\hline
\end{tabular}

The second approach is a ride index criterion, which attempts to combine various accelerations and other environmental factors. Currently, the second approach is favored. Peplar et al. ${ }^{19}$ have defined the following composite index, which incorporates features associated with buses, trains, and airplanes:

$$
W=1.0+0.5 \omega_{r}+0.1[d B(B)-65]+17 a_{t}+17 a_{v}
$$

where $\omega_{r}$ is the rms roll rate, $a_{t}$ is the rms transverse acceleration, and $\mathrm{dB}(\mathrm{B})$ is the ambient noise level. An index of 1 is regarded as very comfortable, and an index of 7 is regarded as very uncomfortable. Other indices have been proposed by Lee and Pradko and by Butkunas (see Reference 20), as well as by Sperling (see Reference 18).

\subsection{CONCLUSIONS}

On the basis of the state of the art of maglev guideway technology, it is possible to identify critical areas for future research. The proposed development facility would be instrumental in clarifying the following issues:

- The motion-dependent magnetic force components resulting from the motion of the vehicle and the oscillations of the guideway must be quantified. Knowing these force components, the dynamic stability of 
the vehicle, including vehicle/guideway interactions, can be analyzed and the results compared with those from the National Maglev User Facility.

- Computer codes for dynamic simulations of vehicle/guideway interactions need to be developed or further modified to prodict the performance of maglev systems, considering the coupled vehicle/guideway system. The code should include the capabilitie to accommodate multiple vehicles and vehicle olasticity, secondary suspension, guideway dynamics, aerodynamic forces, magnetic forces, guideway irregularities, and feedback control. Such codes can be validated with experimental data from the test facility.

- An analytical/experimental study of guideway dynamics needs to be performed with the objective of improving guidrway designs. For example, intentional camber of the guideway beams can improve ride comfort under specific conditions; further study is noeded to determine its effectiveness under various operating conditions and practical methods to control the magnitude of camber. Other structural designs, materials, and methods of construction can be realistically evaluated with the facility.

- Independent and cooperative control methods must be developed to suppress rigid body motions and structural vibrations. Using feedback control, the tolerances required for the guideway may be relaxed and the cost of the guideway reduced.

- Existing criteria for ride comfort need to be assessed and improved.

\subsection{REFERENCES FOR CHAPTER 10}

1. Zicha, J.H., Civil Aspects of Magleu Design, International Conf. on Maglev and Linear Drives, sponsored by Institute of Electrical and Electronics Engineers, Publication IEEE 86CH2276, pp. 69-87 (1986).

2. Richardson, H.H., and D.N. Wormley, Transportation Vehicle-Beam-Elevated Guideway Dynamic Interactions: A State-of-the-Art Roview, J. Dynamic Systems, Measurement, and Control, 96:169-179 (1974).

3. Katz, R.M., et al., Performance of Magnetic Suspensions for High Speed Vehicles Operating over Flexible Guidcuays, J. Dynamic Systems, Mcasurement, and Control, 96):204-212 (1974).

4. Coffey, H.T., F. Chilton, and L.O. Hoppie, The Feasibility of Magnetically Levitating High Speed Ground Vohicles, Stanford Research Institute Report FRA-10001 (NTIS Pli210505) (1972). 
5. Coffey, H.T., d.1). Colton, and K.D. Mahrer, Study of a Magnetically Levitated Velicule, Stanford Research lnstitute Report FRA-RT-73-24 (N'TIS PB221696) (1973).

6. Coffey, H.T., at al., An Eualuation of the Dynamies of a Magnetically Levitated Vehicle, Stanford Research Institute Report, FRA-ORD\&D-74-41 (N'TIS PB236671/4GA)(1974).

7. Elliott, A.S., and J.B. McConville, Analyzing Rotor Dynamics with a General-Purpose Code, Mechanical Engineering, pp. 21-25 (Dec. 1990).

8. Cherchas, D.B., A Dynamics Simulation for a High Speed Magnetically Levitated Guided Ground Vehicle, J. Dynamic Systems, Measurement, and Control, 101:223-229 (1979).

9. Nagai, M., and M. Iguchi, Dynamic (haracteristics of a Long Train of EML Vehicles over Elevated Flexible Guideuays, Bulletin of the JSME, 23(184):1663-1669 (1980).

10. Yabuno, H., and Y. Takabayashi, Bouncing and Pitching Oscillations of a Magnetically Levitated Vehicle Caused by Guideway Roughness, Proc. Eleventh International Conf. on Magnetically Levitated Systems and Linear Drives (Maglev '89), Yokohama, Japan, July 7-11, 1989, pp. 405-410 (1989).

11. Sato, Y., A. Matsuura, and Y. Satoh, Development of Guideway for Maglev, Proc. International Conf. on Maglev Transport '85, pp. 243-250 (1985).

12. Iguchi, M., and H. Hara, A Resonance-Eliminated Design of Simply Supported Beam for a. Guideway of a High Speed Maglev System, Proc. International Conf. on Maglev Transport '85, pp. 217-224 (1985).

13. Wilkie, D.F., Dynamics, Control and Ride Quality of a Magnetically Levitated High Speed Ground Vehicle, Transportation Research, 6:343-369 (1972).

14. Reitz, J.R., Forces on Moving Magnets due to Eddy Currents, J. Applied Physics, 41:2067-2071 (1970).

15. Kotb, M., T.S. Sankar, and M. Samaha, Suspension Bounce Response of Canctian Magleu Vehicle under Guideway Excitations, Part I: Deierministic Analysis, J. Vibration, Acoustics, Stress, and Reliability in Design, 105:104-111 (1983).

16. Means Construction Cost Data, R.S. Means Company, Inc., Kingston, Mass. (1991).

17. Sinha, P.K., Electromagnetic: S'uspension, Dynamics and Control, Peter Peregrinus Ltel., London, U.K. (1987).

18. Carg, V.J., and R.V. Dukkipati, Dynamics of Railway Vehicle Systems, Academic Press (1.984). 
19. Peplar, R.D., et al., Development of Terhmigues and Data for Lualuating Ride Quality, Vol. 1: Summary, Dunlap and Associates, Inc., Report No. DO'T-TSC-RSPD-77-1, I (1978).

20. Simith, C.C., D.Y. Mcethee, and A.J. Healey, The Prediction of Pessisenger Riding Comfort from Acceleration Data, J. Dynamic Systems, Measurement, and Control, Transactions American Society of Mechanical Engineers, 10():31-11 (1978). 


\section{CONTROL AND COMMUNICATIONS}

\subsection{IN'TRODUCTION}

The proposed test facility will be the first such facility to provide a means of intensively testing and ovaluating both EMS and EDS maglev systems. To meet this goal, the control systems will be required to have unusual capabilities. In addition, the high-speed and contactless characteristics require that the control systems play a much more important role than those for conventional train systems.

In general, the control systems to be designed for the test facility encompass three parts: the propulsion control system, the suspension control system, and the operation control system. Each part may be divided into several subsystems. A hierarchical diagram is shown in Figure 11.1.

The propulsion control system provides the drive control for the vehicle (position, speed, acceleration) according to a preset running pattern issued by the control center. The suspension control maintains the vehicle in a stable levitation and guidance attitude against various disturbances and perturbations. Meanwhile, the operations control system performs the commands sent from the control center, protection control, data transmission and management, peripherals, and operation supervision in the test facility.

Of all the design requirements of the control systems, safoty, reliability, and ride comfort are of primary importance. 'T'o meet these requirements, the features described below will need to be implemented.

\subsubsection{Control Response Time}

Since the vehicles will run at high speeds, the motor current and synchronization controls must respond quickly to ensure smooth vehicle propulsion. The suspension control for an EMS system must also respond quickly to small airgap errors. A sampling interval of about $1 \mathrm{~ms}$ is noeded to fulfill most of the drive control tasks, ${ }^{1}$ but the suspension control for an EMS system repuires a sampling time of about $0.5 \mathrm{~ms}$ to overcome the effects of high-frequency perturbations.

\subsubsection{Control Accuracy}

In order to meet ride-puality specifications, the levitation gap, vehicle speed, and acceleralion will have to be controlled within narrow limits. This requires that the suspension control system be able to provide very fine adjustments, even under severely disturbed riding environments. In the propulsion control system, the synchronous speed control will require that the sensors function with high accuracy to avoid strong jerks or 


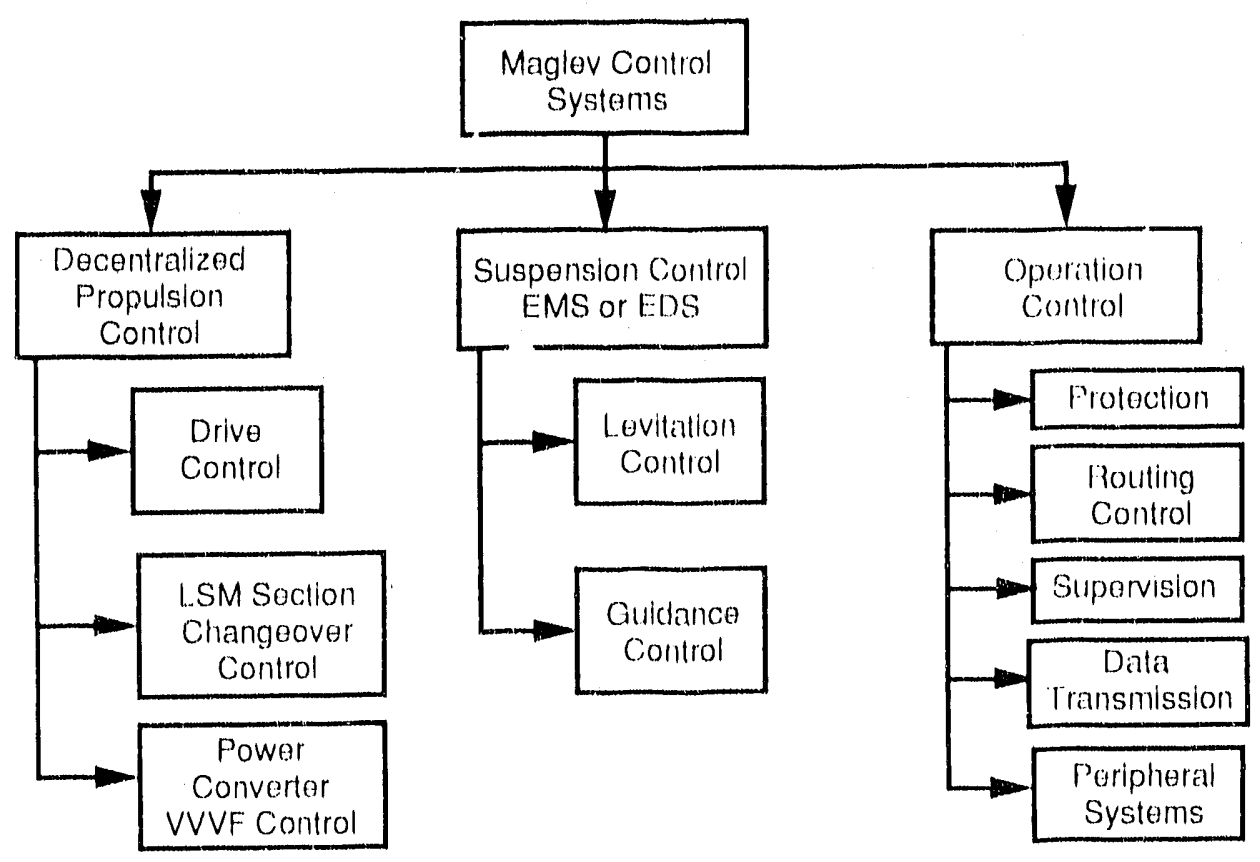

FIGURE 11.1 Organization of Control Systems

oscillations. ${ }^{2,3}$ To ensure the requisite accuracy, digital control tochnology should be applied, and high-porformance sensors should be used in the levitation, position, and accoleration control systems.

\subsubsection{Adaptive Control}

The vehicle will be subject to undesired effects from the variation of electromagnetic parameters, payload, guideway roughness, and aorodynamic drag. Therefore, the parameters of the LSM model and of the vehicle model vary with time. With adaptive control, real-time estimations of the time-varying parameters aro ohtained in terms of measurable input and output information of the plant. The parameters of the controller are updated using these astimates. Figure 11.2 shows the basic principle of an adaptive propulsion-control system as compared with a conventional control system.

\subsubsection{Fully Automatic Functions}

Functions performed by the control systems include not only vehicle spoed and suspension control, but also take-off control, brake control, solf-inspection, fail-safety, protection, data transmission, and supervision. These functions are interactive, and a hirrarchical decision scheme is needed to coordinale them. 4,5 


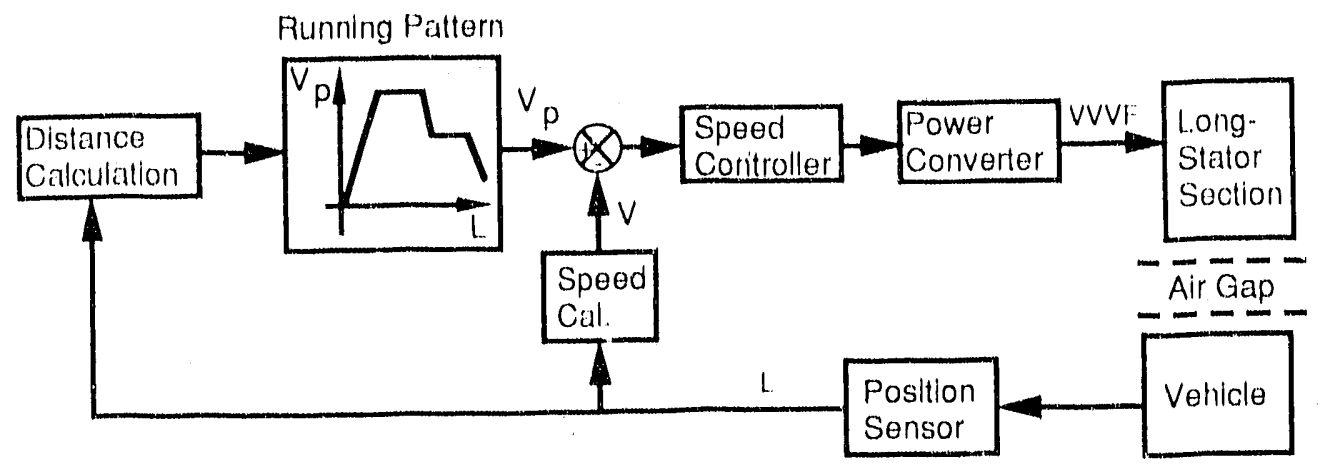

A conventional speed-control scheme

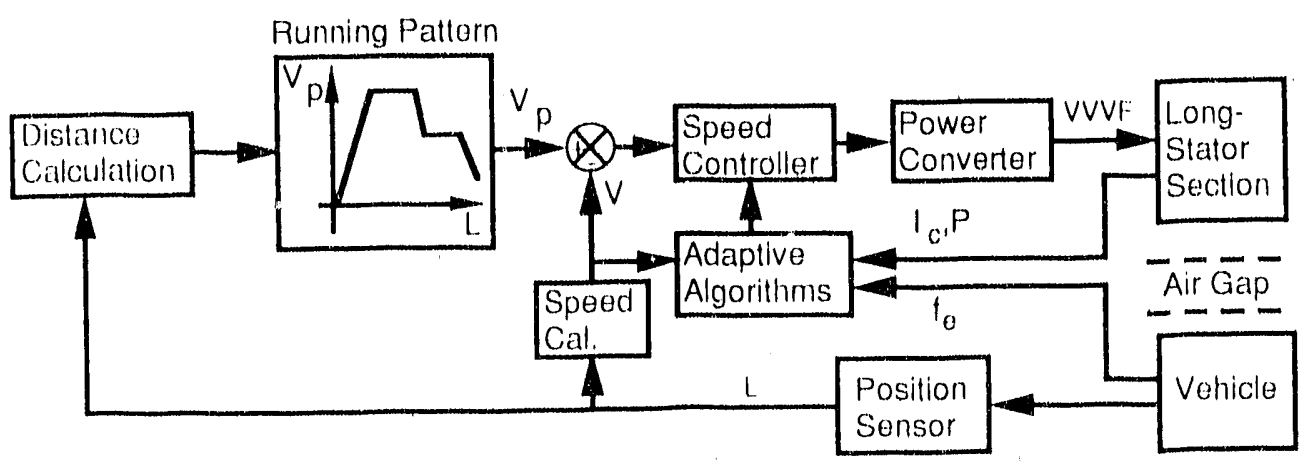

An adaptive speed-contrul scheme

\section{FIGURE 11.2 Adaptive and Conventional Speed-Control Schemes}

\subsubsection{Optimization}

Optimization technology will be widely applied in the control systems of the test facility. In the propulsion and suspension controls, the use of optimization criteria might improve the control processes to save time and minimize energy losses to achieve ride comfort and safety requirements. The use of optimization technology will assist in determining the length of the motor sections and will also be employed in the operation system design (e.g., in the routing design and protection control system resign).

\subsubsection{Decentralixed Control and Data Processing}

Since the propulsion and operation control facilities are distributed along the guideway, control signals and data transmission are needed between the control center, the power controller, motor sections, peripherals, and the vehicle. Therefore, decentralized controls and data processing, using microprocessor network technologies, are used for switching control, vehicle control, and motor section changeover control, and for supervision of the system. 


\subsubsection{Redundant Control Strategy}

To ensure the acceptance of a high-speed maglev system, the control system must be failure-tolerant. Consequently, system components like switches, contactors, and sonsors must have high mean-times-between-failures (M'TBF), and critical circuits and components must be made sufficiently redundant to ensure their reliability. One highly roliable redundant scheme, a 2 vs. 3 voting decision unit based on microprocessors, has beon developed and is discussed later. ${ }^{1,4}$

\subsection{PROPULAION.CONTROI. SYSTEMS}

\subsubsection{Foreign Propulsion-Control Systems}

Since Germany and Japan now lead in maglev technologios, the designs of their noil-commercial prototypes, the TR06-07 and MLJ-002, will be reviewed prior to the discussion of the system proposed for the test faccility.

\section{Transrapid TR-06 and TR-07}

The Transrapid (TR-06) is driven by an iron-cored, long-stator, linear synchronous motor that has been used to propel a 108 -metric ton vehicle to a speed of $412.6 \mathrm{~km} / \mathrm{h}$ (sec) References 3 and 6 ). The design of the drive controls (Figure 11.3) is based on the operational speed profile, the kinematic characteristics of the vehicle, and the requirements for dynamic behavior and passenger comfort (acceleration $\leq 1.5 \mathrm{~m} / \mathrm{s}^{2}$ and jerk $\leq 0.5 \mathrm{~m} / \mathrm{s}^{3}$ ). ${ }^{7}$

Two current controllers issue control signals to the two assigned variablo-voltagevariable-frequency (VVVF) inverter groups. The propulsion control circuits are partly analog and partly digital. The position and speed signals are both analog. The microcomputers have a slow cycle time of $60-100$ ms.

The superimposed computer controls and monitors the subsystems and performs test routinns. The speed controller calculates the setpoints for the control of the stator current on the hasis of the speed setpoint received from the supervisory control lovel.

Vehicle position detectors determino tho relative position of the exciter with respect. to the stator; for better accuracy, three different measuring systems, which are partially redundiant, are used: two on the ground and ono on the vehicle. 'The coordinating computer' and track systems controls porform the motor soction changenver fl. ation.

In the nower TR-()7, the propulsion control system was fully digitized. Sampling timos as low as $1 \mathrm{~ms}$ are used for most of the control tasks. 'The high motor frequencies of 


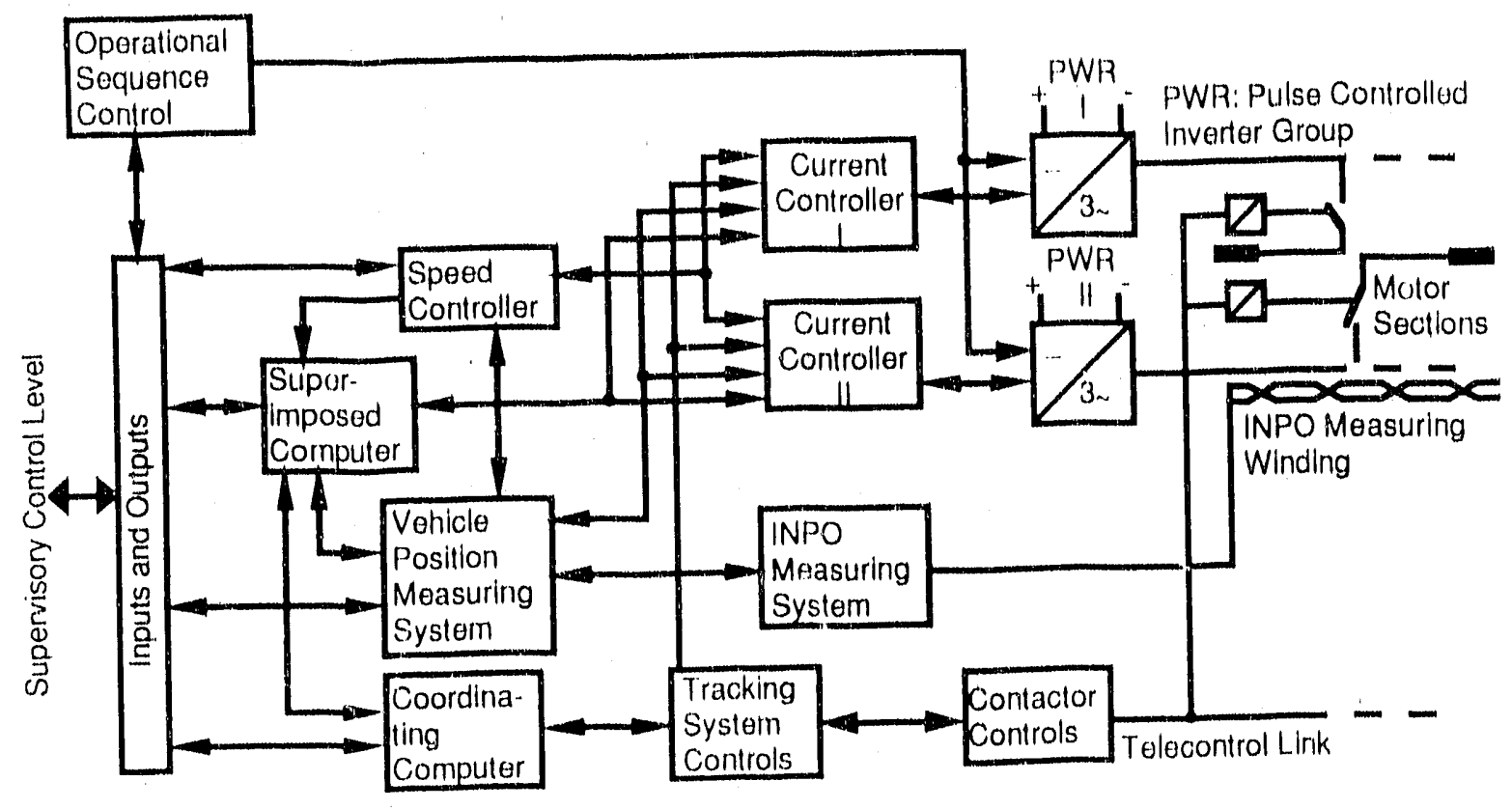

FIGURE 11.3 Blocik Diagram of 'TR-(16 Drive-Control System

$270 \mathrm{~Hz}$ necessitate shorter sampling times of $\leq 100 \mu \mathrm{s}$ for TRANSVEKTOR ${ }^{(i)}$ control. Other improvements aro:

- The modular design, particularly for the power and control equipment, offers easy mantenance and diagnostics capability.

- An optical-fiber cable is used for all data links.

\section{Japanese ML-50(0) to MLU-002 Vohicles}

The Japanese Miyazaki Maglev 'lest Track uses air-cored linear synchronous motor's to drive their EDS series of vehicles from morlel ML-500 to MLU-002 (see Reference 2 ), the latter reaching a maximum speed of $420 \mathrm{~km} / \mathrm{h}$. A cycloconverter is used in the power supply. The LsiM propulsion-control equipment is shown in Figure 11.4.

'The matjor features of the LatM propulsion-control system are:

- Position signals are ohtained from inductive transposed wires and from the detection of the levitation coil reaction flux.

- The propulsion conil current is controlled by the synchronized position signal and thrust calculations, depending on the actual and proset specerts.

- A phatse-locked loup is amployed to keep a smooth sine-wave pattern, even if the position signal is disturbed. 


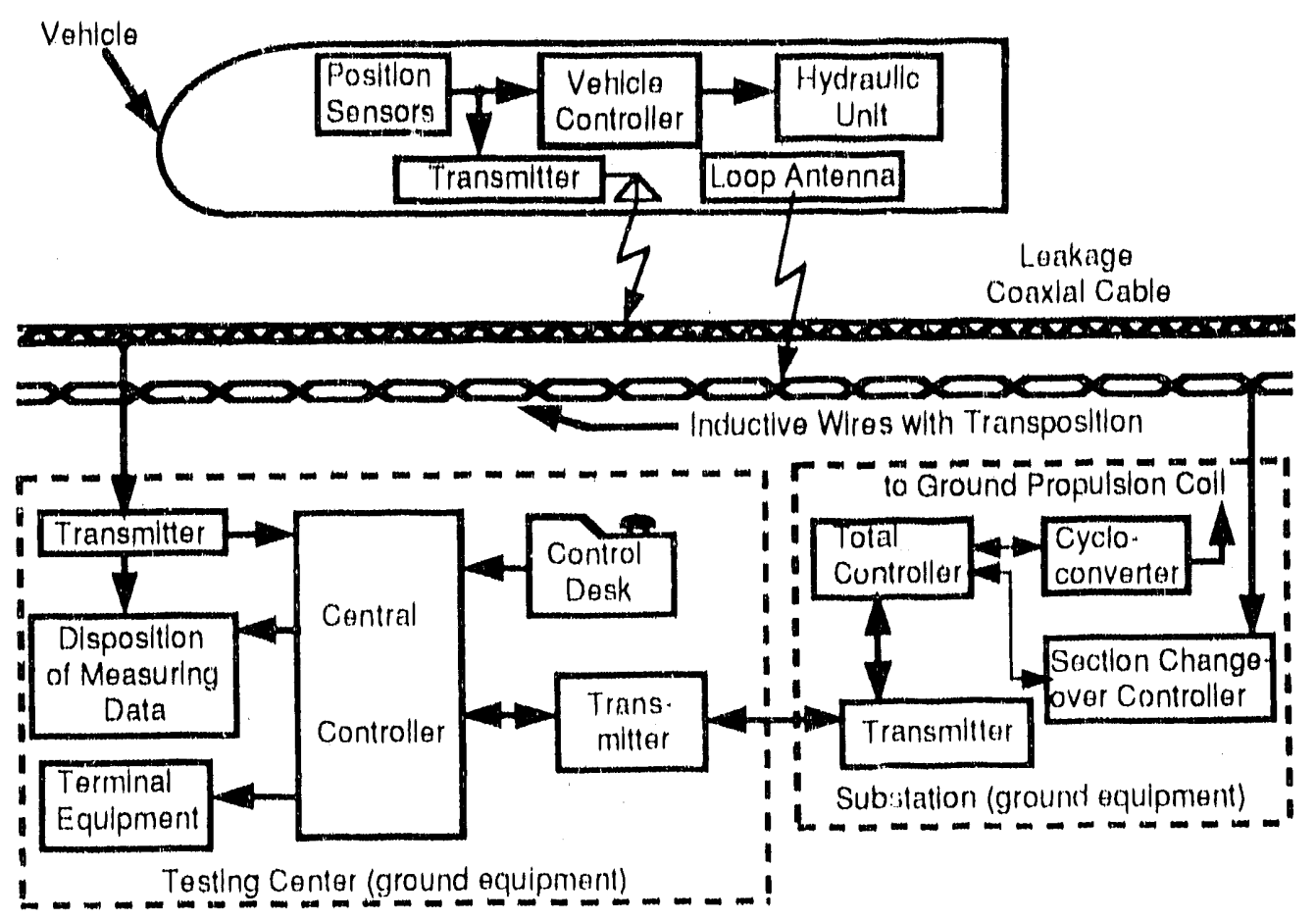

\section{FIGURE 11.4 I3lock Diagram of MLU-(0)1 Drive-Control System}

- Electromotive force feedhack and compensation are used to improve ride quality.

- The propulsion control circuits alre analog.

According to published seports, these propulsion control systoms have performed sarficincilorily.

\subsection{2 'Test Facility Propulsion-Control Design}

The LSM propulsion-control-system design is mosented in this section (see? Roferences 2 and 8). The principal data are listed in Table 11.1, and the configuration and sprecifucations are indicated in Figure 11.5 and 'l'able 11.2.

'lhe propulsion control system consists of the following main compononts:

- A control center, which sends the preset rumning pattern and other prepulsion comm ands to the propulsion controller in the powere station.

- A propulsion controller combining a speed controller, a phasosyonchronization controllere, a speed palderen controllere, and an adaptive controller. 
TABLE 11.1 Specifications of the Linear Synchronous Motor

\begin{tabular}{|c|c|}
\hline Item & Specification \\
\hline Langhth of motor section (m) & 320 \\
\hline Number of motor sections & 10 \\
\hline 'Total power requirod (MVA) & 4 \\
\hline Thrust (kN) & 16 \\
\hline Maximum speod $(\mathrm{km} / \mathrm{h})$ & 240 \\
\hline Froquency $(\mathrm{Hz})$ & $0-133$ \\
\hline Number of phases & 3 \\
\hline \multicolumn{2}{|l|}{ Pole pitch (m) } \\
\hline EMS & 0.25 \\
\hline EDS & 1.0 \\
\hline Voltage/phaso (V) & 3,000 \\
\hline Curront/phaso (A) & 230 \\
\hline
\end{tabular}

- A pair of power inverters that ill ternately feed the VVVF power to motor sections, depending on the vehicle position and phase information.

- Section changeover control, performed by the distributed switch controllers CR, which control all contactors SG and switches SW.

- Braking rewistors for emergencies.

\subsubsection{Speed Control}

'The major fouture of the speed-control system designed for the test facility is its achaptive capability, as diagrammed in Figure 11.6. An adaptive controller will perfurm a real-time estimation of the time-varying plant model (in a dashed block) based on the following measurable information: the actual vohicle speed $\mathrm{V}$, the motor section current $\mathrm{I}_{s}$, and the electromotive force $f_{0}$ sent from the vehicle. 'The parameters of the speed controller are updated by the estimation. Thus, the magnitude of the control signal will precisely match the neod of the timo-varying plant (air gap and vehicle). 


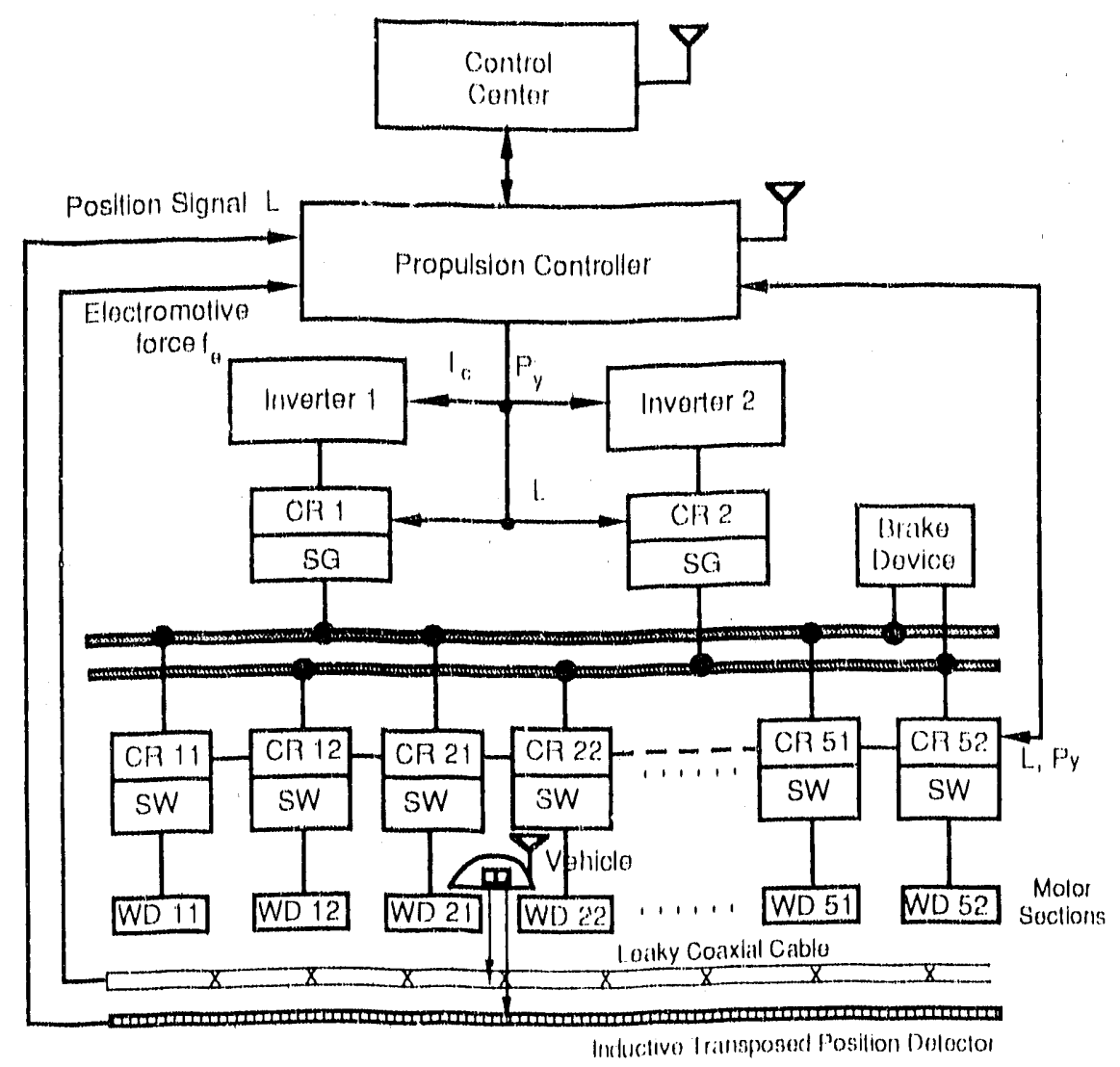

\section{FIGURE 11.5 'Test Fucility Propulsion-Control System}

Tho speed controller provides a simusuidal control signal $I_{p} \sin ((1) t+\delta)$ for the desimenl VVVF power supply. Its amplitude $I_{p}$ is the output of the speed controller, and its phase is provided by the phase synchronizat tion controller (PSC).

The PSC (Figure 11.7) calculates the phase value from the position signal $L_{1}$, then prorluces a unit sine wave through a phasolocked loop. 'The unit sine wave, modulated hy $I_{1}$, is sent to the power inverters for the desirent VVVF. The actual vohiche speed $V$ is alsin calculated by the PSC:
TABLE 11.2 Specifications of the Propulsion-Control System

\begin{tabular}{|c|c|}
\hline Parameter & Specification \\
\hline Spered $(k m / h)$ & 240 \\
\hline Accoleration $\left(\mathrm{m} / \mathrm{s}^{2}\right)$ & 2.0 \\
\hline Maximum jork $\left(\mathrm{m} / \mathrm{s}^{3}\right)$ & 0.3 \\
\hline $\begin{array}{l}\text { Iavitation air gap (mm) } \\
\text { EMS } \\
\text { EDS }\end{array}$ & $\begin{array}{c}10 \pm 1.5 \\
100 \pm 10\end{array}$ \\
\hline Samplings timo (ms) & 1 \\
\hline Migritization & $8-16$ bit \\
\hline
\end{tabular}




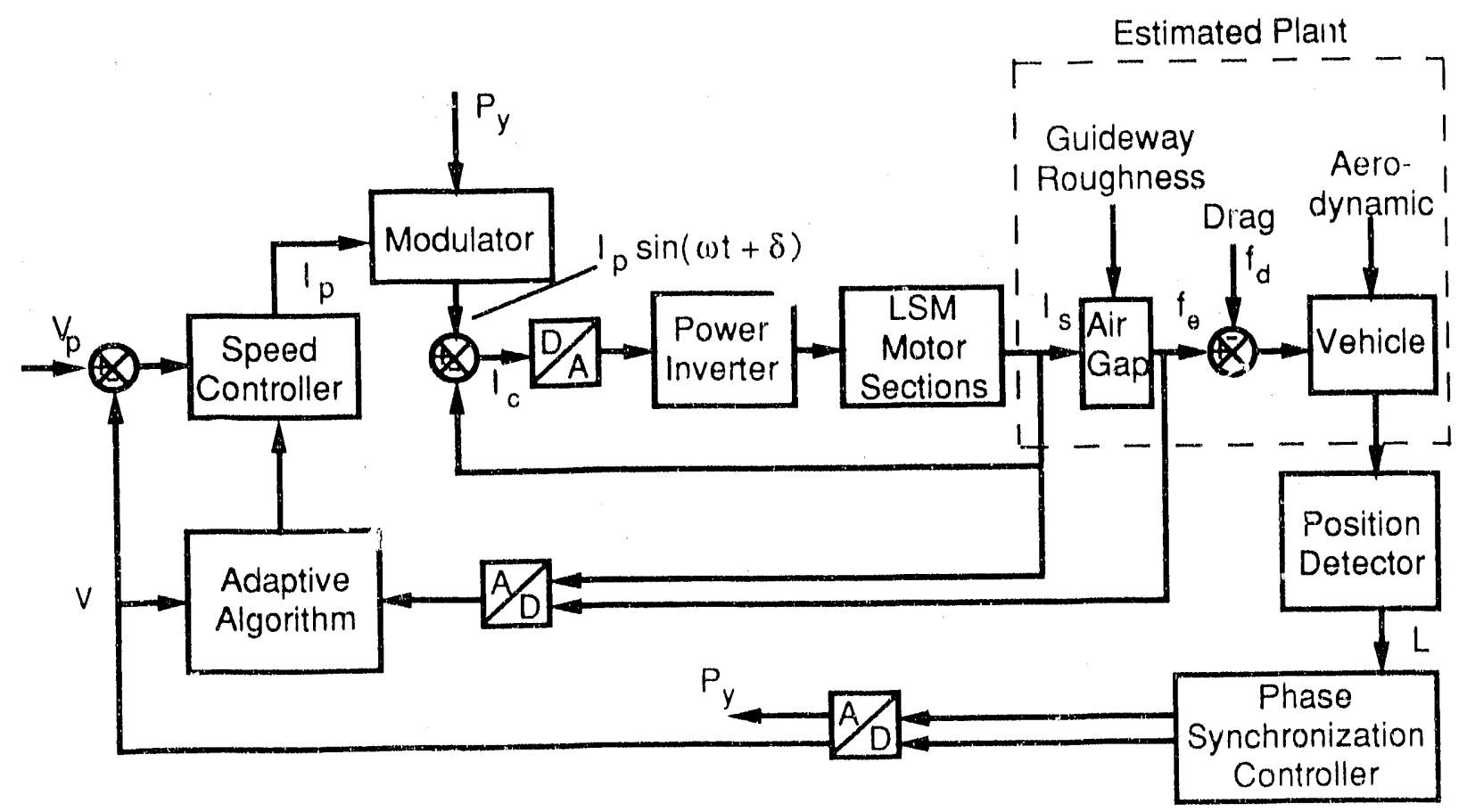

FIGURE 11.6 Adaptive Speed-Control System

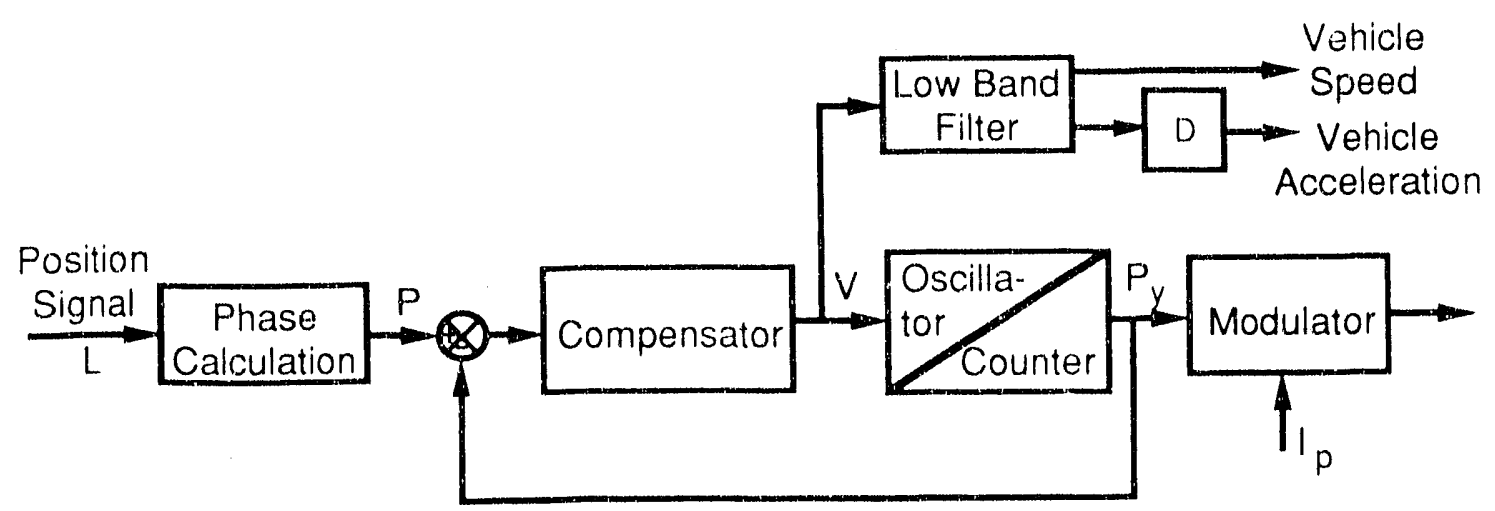

FIGURE 11.7 Diagram of the Phase Synchronization Controller

For consideration of the limits of jerk, acceleration, deceleration, and speed, the speed pattern received from the control center is reproduced by a speed pattern generator, shown schematically in Figure 11.8 .

\subsubsection{Position Detection}

Two position detection systems are proposed for propulsion control. One is the inductive transposed position system, which employs a medium frequency transmitter on the vehicle and a cross coil measuring winding on the guideway. The pole position of the motor is derived independently of transmission exuipment external to the drive. The other system 


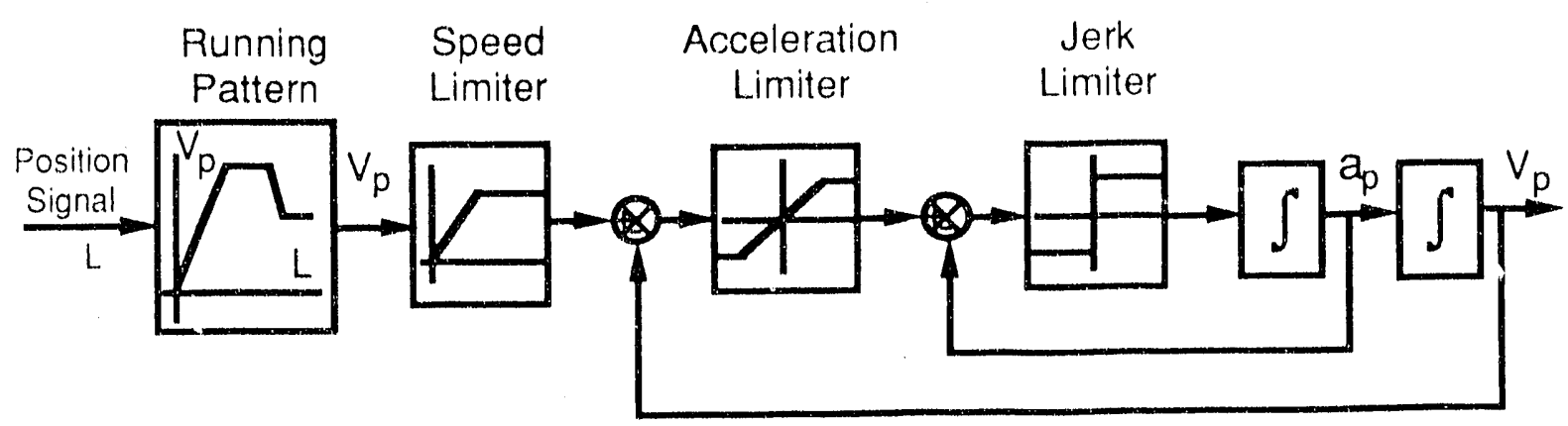

FIGURE 11.8 Diagram of the Speed Pattern Generator

performs position detection by on-board calculation of the levitation coil reaction fluxes. $A$ leaky coaxial cable is employed for the data transmission. 2,9

\subsubsection{Motor-Section Control}

Motor section changeover control controls the motor sections in two blocks, depending on the vehicle's position and phase signals. When the vehicle passes over the junction of two sections, it will be propelled by two different motor sections for a short period, and both motors will operate for a preset time of about $2 \mathrm{~s}$ (Figure 11.9). The phase signal ensures a smooth propulsion wave produced by the adjacent sections. ${ }^{8}$

The other control functions provided by the propulsion control system are standstill control, landing drive contrcl, and brake control for emergencies. They are operated by programming open loops.

\subsection{OPERATIONS CONTROL, SYSTEM}

The operations control system covers all the functions and technical installations that scrve the safety, control, and supervision of the vehicle operations and their intercommunications. It is important that the facility be highly automatic, effective, economic, and fully functioning if a new design is to be realized. 5,10

\subsubsection{System Description}

The functions of the operations control can be subdivided into soveral functional complexes (see References 4 and 11):

- Protection

- Vehicle safoty fposition and speed detection, monitoring, distance assurance, and automatic brake application) 


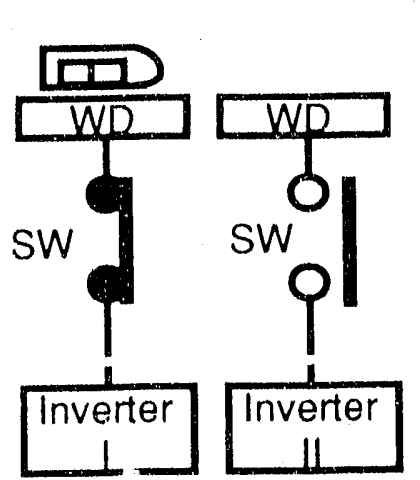

(A)

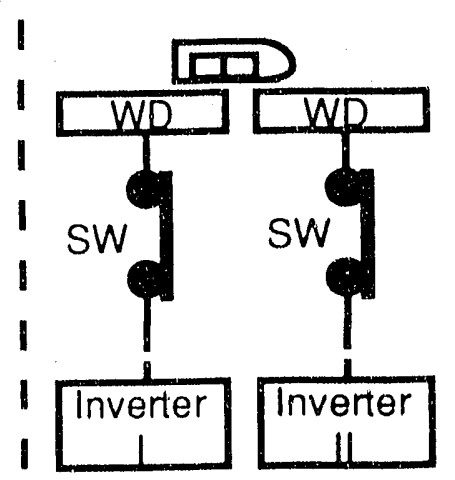

(B)

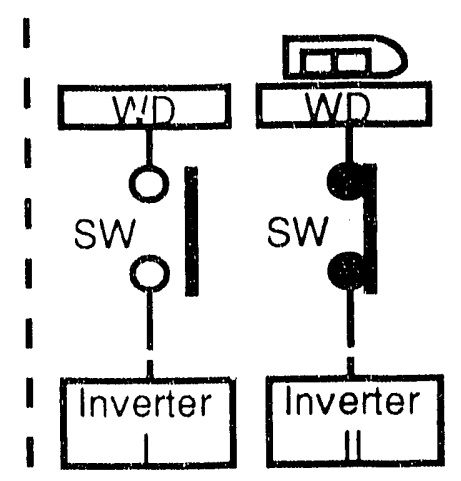

(C)

\section{FIGURE 11.9 Motor-Section Changeover Process}

- Propulsion switch-off and monitoring

- Route protection (route locking, proving and releasing function)

- Power switch protection (fail-safe, monitoring)

- Safety data transmission

- Control

- Route setting (different test formats)

- Motor section changeover

- Route optimization (energy save, riding comfort)

- Manual test mode of vehicle control (position, speed, and target braking)

- Supervision (operation and disposition)

- Input and storage of test tasks

- Determination of alternative solutions in the event of breakdown

- Fault diagnosis and emergency procedures

- Documentation of test data

- Prognosis of the test state 
- Data transmission

- Between vehicle and central installations (power station and control center)

- Between trackside units along the guideway

- Between trackside units and central installations

- On-board data transmission

- Peripheral systems (connection with adjacent systems)

- Substation control and propulsion regulation

- On-board control systems

- Power supply

- Communication systems

- Station/halt equipment

\subsubsection{Protection C'ontrol Design}

In the design of the operations control system for the test facility, one must consider the specific tasks that the system will be required to perform and the equipment that will be installed. ${ }^{11}$

The design of the protection control system emphasizes the following aspects:

- It is based on a microprocessor network technology.

- It is completely independent from other control systems and the signal transmission system.

- It is a multilevel decision system, ensuring high reliability and intelligence. For example, the primary level performs self-inspection and auto-repair functions. The secondary level executes emergency procedures. On both levels, the information will first be sent to the control center for privilege decisions made by the operation staff.

- The redundancy design of the OCS provides high reliability and the failsafe property. The protection system is composed of three parts: wayside protection, on-board protection, and central control protection. 


\section{Wayside Protection}

In the proposed facility, 10 three-phase motor sections (WD11-WD52) are installed along the 3.2-km guideway (see Figure 11.10). The odd-numbered motor sections are fed by power invertor 1 , whilo the even-numbered motor sections are fed by power invertor 2 . Each motor section is operated by a switchgear. $\mathrm{SW}$ and a switch controller CRij embeded in a microprocessor. 'The wayside distributed prolection control consists of a set of electronic logic circuits that receive and process the signals from the switch controllers. The multilevel protection decisions are then sent to the vehicle controllers, the control center, or to the brake devices in accordance with safety criteria.

The functions performed by the protection controller might be:

- Power supply protection

- Motor section protection

- Switch malfunction protection

- Speed and position protection

- Wayside brake protection

\section{Protection Aboard the Vehicle}

The protection system aboard the velicle is shown in Figure 11.11. The EMS vehicle evaluated in this design has $5 \times 2$ suspension magnets mounted beneath it and $2 \times 2$ guidance magnets mounted on the sides. Sensors L1-L20 measure the levitation gap, and sensors G1-G8 measure the lateral gap. A1-A6 are six accelerometers for three-dimensional measurement. The protection controller can detect any malfunctioning sensors and make the appropriate protection decisions. 'Two levels of protection decision are made according to the number and position of abnormal sensos's. If the vital safety standard is not exceeded, the protection decision is to deploy the landing gear. The vehicle continues to the next stop. If the vital safety standard has been exceeded, the protection decision is to actuate the braking devices and the other emergency procedures. The protection criteria will be explored through the analysis of the trial results.

Other protection functions included are:

- Actual routing calculation and protection

- Vehicle position, speed, and acceleration protection

- Supporting wheeds protection

- Standstill protection 


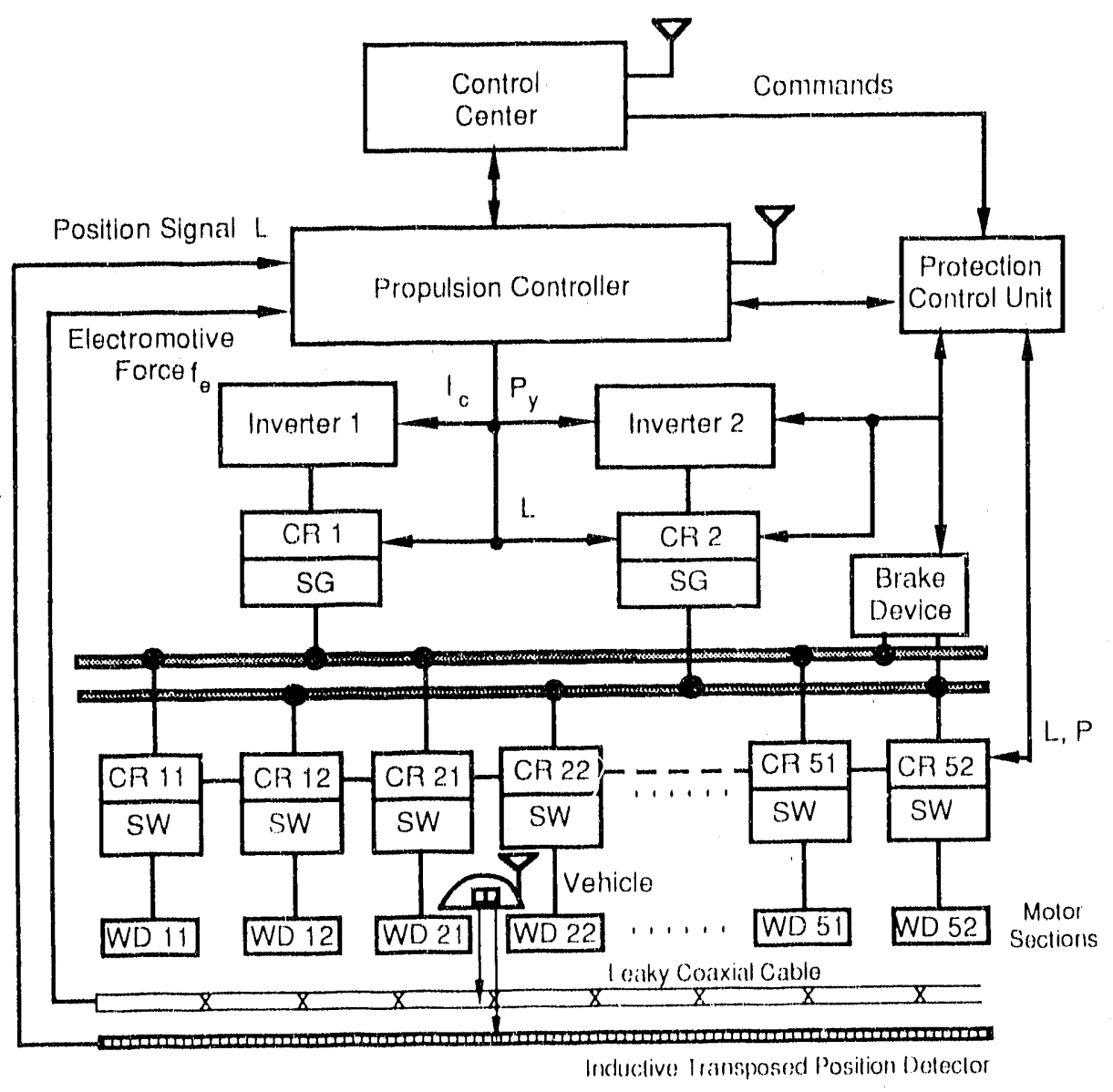

FIGURE 11.10 Test Facility Wayside Protection Control System

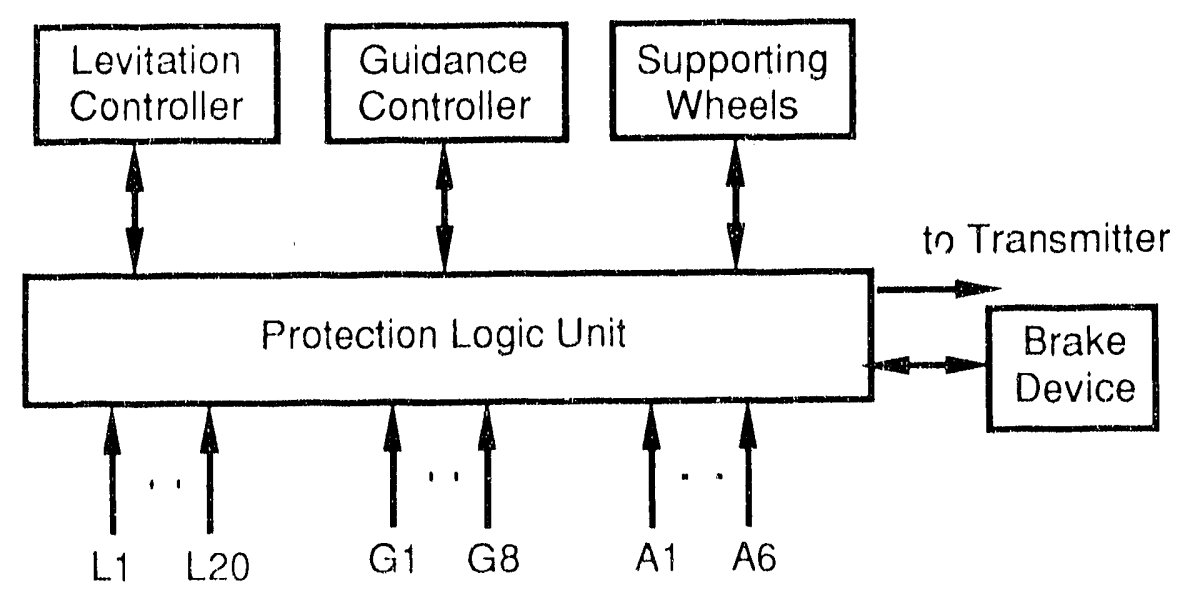

FIGURE 11.11 On-Board Protection Control 
- Bad weather and disaster protection

- Guideway obstacles protection

- Brake devices (brako shoes, slides) protection

\section{Central Control Protection}

'The control center is the operation headquarters for handing all test programs and line information. 'The protection functions are to be partially carried out by the operating staff in a manual mode. There are several emergency or normal protection procedures predetermined and stored in the central protection controller. The operator can manually choose the best measure in compliance with the particular situation. If possible, the emergency brake should be avoided.

\subsubsection{Fault-Tolerant Design}

\section{Fault-'Tolerant Configuration}

A reliable arrangement for the fault-tolerant function is shown in Figure 11.12.4 Redundant units 1-3 can be sensors or accelerometers. The C's are comparators, the output of which is 1 if two inputs are the same, or 0 if the difference exceeds a certain preset limit. A two-of-three vote makes the protection decision. This voting function is implemented by a microprocessor'. 'The practical voting protocols for levitation and guidance sensors will be much more complex than illustrated and will be embedded in the software.

\section{Hardware Implementation}

The microprocessors are the main components in the operations control system. Most of those associated with the sensor's, switches, or braking devices will be 8-bit processors with 1-5 kilobytes of memory. 'The software for these devices will be written in assembly language. The processor in the control center will require 16 -bit or 32-bit processors and $20 \mathrm{MB}$ of memory. The software for the control center will be written in Cor PASCAL so it can be more easily read and modified by system operators. The microprocessors related to the sensors and the emergency procedures will be redundant to ensure reliability.

\subsection{SUSPENSION-SYSTISM CONTROI, OPTIONS}

\subsubsection{Introduction}

As discussed on (hapter 10, a smoth, rigid guideway could be constructed and mantained to such a degreo that an acceptable ride quality would result with a simple and 


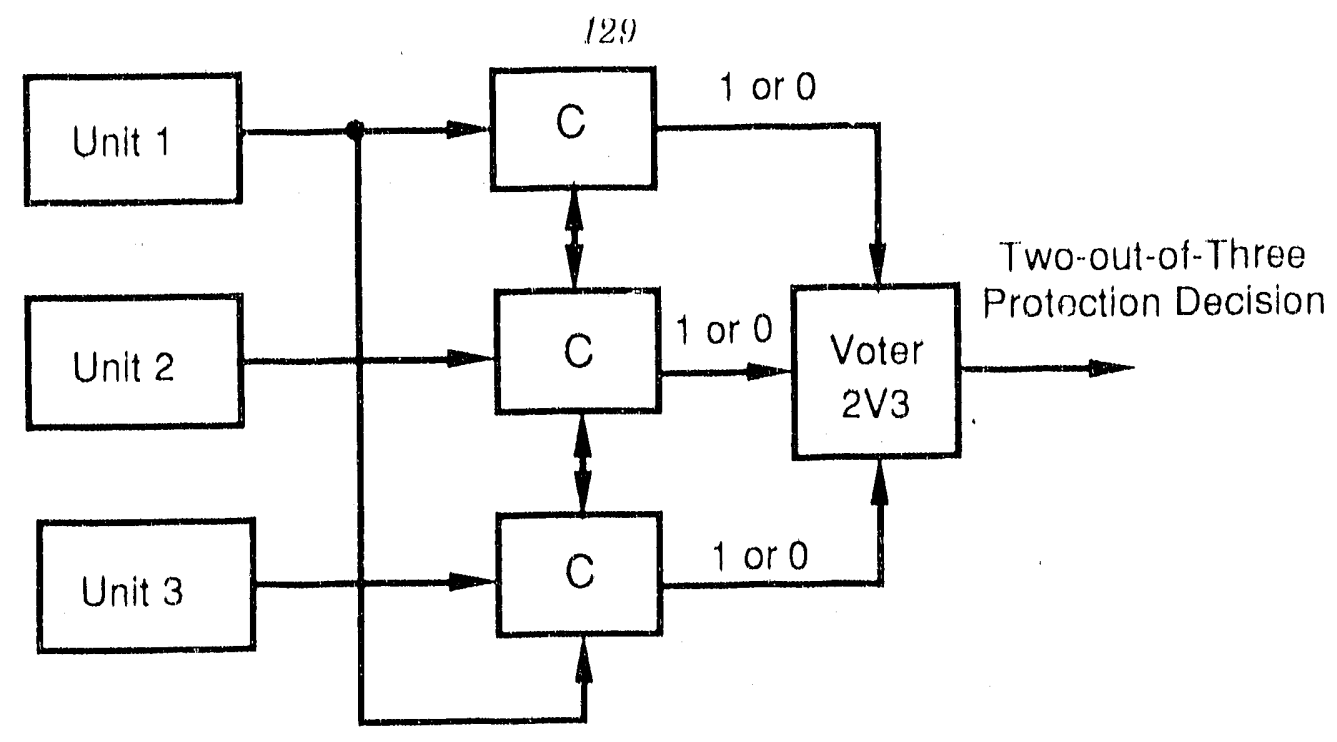

FIGURE 11.12 Fault-Tolerant Configuration

inexpensive means of controlling the forces exerted on the vohicle, but the initial and maintenance costs of such a guideway would be prohibitively expomsive. ${ }^{12}$

It should be possible, on tho other hand, to employ a rolativoly less-expensivo guideway (neither as smooth nor as rigid) in conjunction with a relatively more-expensive methol of controlling the forces such that an acceptable ride quality can be achieved at a rerluced overall system cost. The options available for controlling the forces are enumerated, and justifications for the recommended course of action are made in this section.

\subsubsection{Flectromagnetic System}

The electromagnetic system is inherently unstable, so a force control system is a necessity. It has been shown that ride quality considerations can roadily be taken into account when designing such a control system, so the only apparent option is whether or not a secondary suspension is employed. This decision is dictated by the ride quality specification to bre met in conjunction with the design speed of the vehicle and the roughness of the guidrewy. Experience has shown that a secondary suspension is not required for low-speed, intracity vehicles, but will probably be recuired for high-speed, intercity vehicles.

\subsubsection{Electrodynamic System}

The electrodynamic system is inherently stable though highly under-damped, so the primary reason for controlling the forces is for ride quality. Before this issue is addressed, however, mention should be made of a unique aspect of superconducting magnets that hats an impact on the discussion to follow. Specifically, alternating currents should be avoided sincre Ar: currents produce Joule losses in superconducting materials. As mentioned in Chapter 10, these losses put an additional demand on the refrigeration system and could mate the system impractical if they are not kept at a low value. For this reason, it is common in the EDS system to use short-corcuited metallic longs or plates to shoded the 
superesonducting magnet from the fluctuating currents in the guideway, which would otherwise induce alternating current in the superconducting magnet. These shields produce some damping of mochanical vibrations, but not enough to solve tho ride-quality problem. Several options are available for this systom, and, as indicated in 'Table 11.3, they can bo categorized as follows:

Primary suspension only: oach supereonducting magnet and any other magnetic force componentry are rigidly attachod to the vehicle.

Primary and secondary suspension: each superconducting magnet can exhibit limited motion relative to tho vehicle. Conventional mechanical springs would be used to transfer the nominal load from the magnet to the vehicle. Auxiliary componentry would be rigidly attached to the vehicle or to the magnet, or would be attached botween the vehicle and the magnet.

Option 1 can be rejected because of the unaceptable ride cuality that would result. Option 4 is not practical because a power supply with a very latge power rating would be required, an excessive anount of heat would be transported into the cryogenic environment, and $\Lambda C$ losses would occur in tho magnet. Option 2 can probably be rejected when compared with option 3, since a passive coil cannot provide a sufficient amount of damping unless the coil itself is cooled to cryogenic temperatures: this puts a burden on the refrigerator, which cian be avoided by employing option 3. Similarly, options 6 and 7 can probably be rejected when compared with options 8 and 9 .

The remaining options are viable, but a tradeoff analysis and final selection cannot be made until the ride guality, design speed, and guideway roughness are specified. For the worst-case sconario (i.e., high-speed operation and very stringent ricte quality specifications), consideration should also be griven to the following:

- The vehicle will experience molion in all six of its degress of freedom, and the frepuencies of these nscillations can be significantly different. For example, vertical oscillations will occur at about $1 \mathrm{~Hz}$, whereas lateral oscillations will most likely he at several hertz. Consequently, a single force-controlling system optimized for one of the motions would not be optimal for the others. Similarly, a system designod to accommodate all degrees of freedom would somewhat compromise the optimal design for each degree of freodom.

- 'The force controlling system would ideally be able to control any one of the oscillations without inducing any of the others. 'This suggests that at least three forcencontrolling devices must be designed (one each for vertical, lateral, and longitudinal motions) in such a way as to be decoupled from one another. It is impossible to decouple a force controlling system based on "controlled coils" unless the lift, guidance, and propulsion foress are derived from independent magnets reacting 
TABLE 11.3 Options for Controlling Forces in the Electrodynamic System

\begin{tabular}{|c|c|c|}
\hline Suspension & Option & Control \\
\hline \multirow[t]{4}{*}{ Primary } & 1 & None \\
\hline & 2 & P'assive coil \\
\hline & 3 & Controlled coil \\
\hline & 4 & Controlled magnet current. \\
\hline \multirow{6}{*}{$\begin{array}{l}\text { Primary and } \\
\text { secondary }\end{array}$} & 5 & Dashpot, comnected between magnot and vehiche \\
\hline & 6 & $\begin{array}{l}\text { Passive coil rigidly attached to superconducting } \\
\text { magnet and interacting with guideway currents }\end{array}$ \\
\hline & 7 & $\begin{array}{l}\text { Passive coil rigidly atlached to vehicle and } \\
\text { interacting with magnet current. }\end{array}$ \\
\hline & 8 & $\begin{array}{l}\text { Controlled coil rigridly attachod to suporconducting } \\
\text { magnet and interacting graideway currents }\end{array}$ \\
\hline & 9 & $\begin{array}{l}\text { Controlled coil rigidly attached to vehicle and } \\
\text { interacting with magnet current }\end{array}$ \\
\hline & 10) & $\begin{array}{l}\text { Controlled forcing dovice (such as a pnoumatic or } \\
\text { hydraulic cylinder) between magnet and vehicle }\end{array}$ \\
\hline
\end{tabular}

with independent guideway surfaces. As most practical maglev designs integrate the functions of the magnots and the reaction surfaces, it would appoar that options 3, 8, and 9 may need to be rejected, depending on how stringent the ride-cuality specification is.

For high-speed and stringent ride-quality specifications, we may thus be left with only two options (5 and 10 ) for achieving an acceptable ride quality with a low-cost guideway. Both would have the magnets attached to the vehicle via mechanical springs in such a way that vertical, lateral, and longitudinal motions would be decoupled. The springs would provide the nominal forces, and a conventional dashpot would he associated with oach spring (option 5) or an independent controlled forcer (option 10). Cloarly, option 5 would bo less expensive to implement and maintain, and as shown bolow, this option may be capable of' providing an acceptable ride quality. 


\subsubsection{Analysis of a Systen with a Dashpot}

In this section, a simplified malysis of a systom based on option 5 is pressentod, the purpose being to obtain some preliminary insight into the viability of this option, fior simplicity, the analysis is based on a small signal approximation, so all oquations have been linoarized about an assumed oporating point. A complete nonlinear analysis would noed to be carried out before a final decision could bo made as to whether or not option 5 is viable.

Figure 11.13 shows a simplified model of a vehicle with a dashpot experioncing vertical motions. The linearized equations can be written as:

$$
\begin{gathered}
m_{v}\left(\ddot{z}_{v}+\ddot{z}_{g}\right)+k_{s}\left(z_{v}-z_{m}\right)+\alpha\left(\dot{z}_{v}-\dot{z}_{m}\right)=0 \\
m_{m}\left(\ddot{z}_{m}+\ddot{z}_{g}\right)-k_{s}\left(z_{v}-z_{m}\right)-\alpha\left(\dot{z}_{v}-\dot{z}_{m}\right)+k_{m} z_{m}=0
\end{gathered}
$$

where:

$$
\begin{aligned}
& m_{v}=\text { mass of the vehicle, } \\
& m_{m}=\text { mass of the magnet, } \\
& k_{s}=\text { spring constant of the mochanical spring, } \\
& k_{m}=\text { apparent spring constant of the magnet, } \\
& \alpha=\text { damping parameter of the dashpot, } \\
& z_{v}=\text { deviation of the vehicle from its equilibrium position relative to the } \\
& z_{m}=\text { guideway surface, } \\
& z_{g}=\text { deviation of the magnet from its equilibrium position relative to the }
\end{aligned}
$$

The following quantitios are introduced for incorporation in Equations 11.1 and 11.2:

$$
\begin{aligned}
& M=\begin{array}{l}
m_{y} \\
m_{m}
\end{array}, \quad \text { the vehiclo-to-magnot mass ratio; } \\
& K=\begin{array}{l}
k_{s}, \\
k_{m}
\end{array} \quad \text { the vehich-to-magnet spring constant ratio; }
\end{aligned}
$$




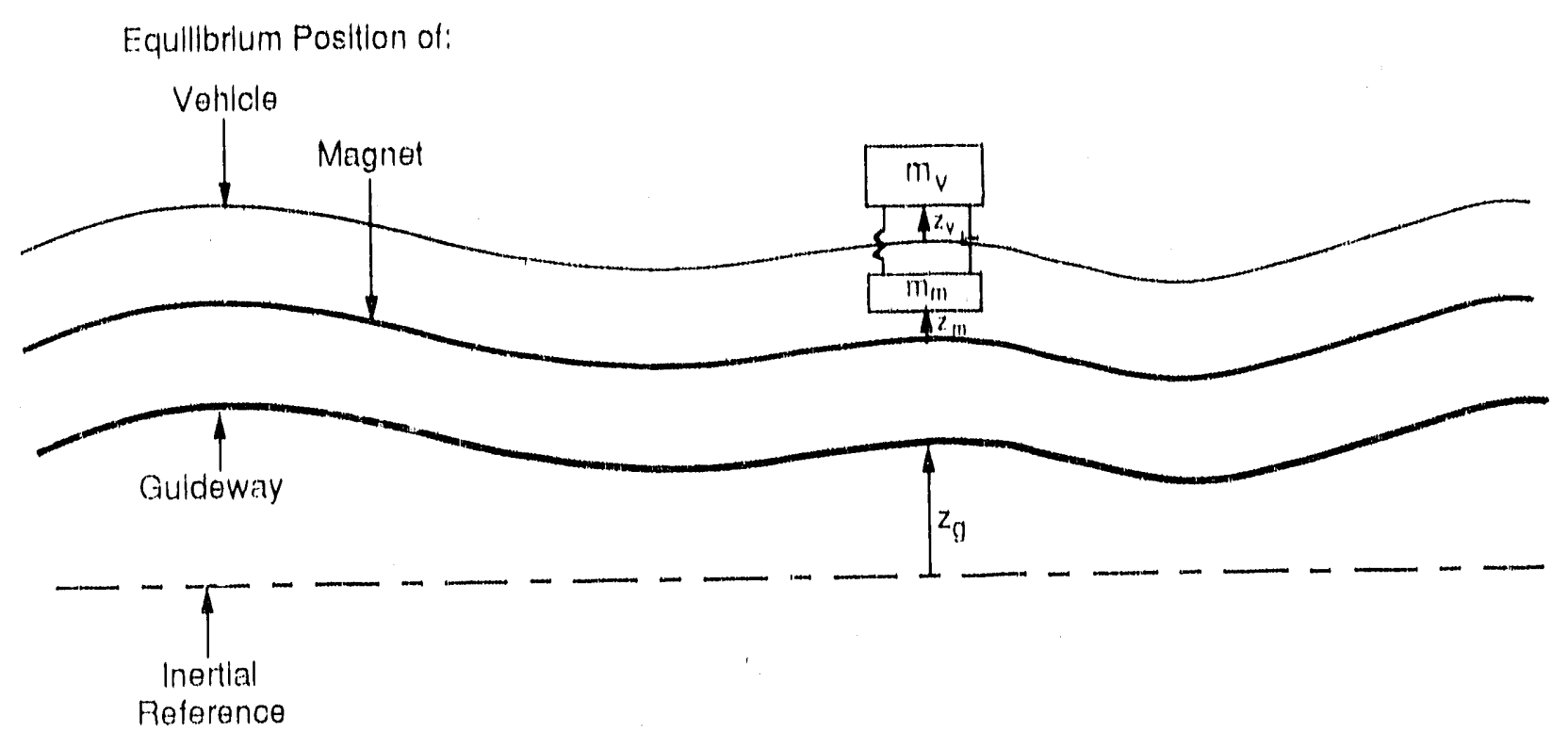

FICIIR 11.13 Simplified Model of Vehicle with Dashpot

$$
\begin{aligned}
& \omega_{o}^{2}=\frac{k_{m}}{m_{v}+m_{m}}, \begin{array}{l}
\text { the natural frequency of total mats with mangotic } \\
\Omega=\frac{\alpha}{m_{v}+m_{m}},
\end{array}
\end{aligned}
$$

'This loads to:

$$
\begin{aligned}
& \frac{M}{M+1}\left(\ddot{z}_{v}+\ddot{z}_{g}\right)+K \omega_{0}^{2}\left(z_{v} \quad z_{m}\right)+\Omega\left(\dot{z}_{v} \cdots \dot{z}_{m}\right)=0 \\
& \frac{M}{M+1}\left(\ddot{z}_{m}+\ddot{z}_{g}\right)-K \omega_{o}^{2}\left(z_{v} \cdots z_{m}\right) \cdot \Omega\left(\dot{z}_{v} \cdot \dot{z}_{m}\right)+\omega_{o}^{2} z_{m}=0
\end{aligned}
$$

Figure 11.14 shows the results of a computer simulation used to predict the power armeral density of vertical accolerations experienced by a vehicle travoling over a guideway with an assumed power spectral density of vertical porturbations givon by:

$$
P_{z_{z^{2} z}}(\omega)-\frac{A v}{\omega^{2}}
$$




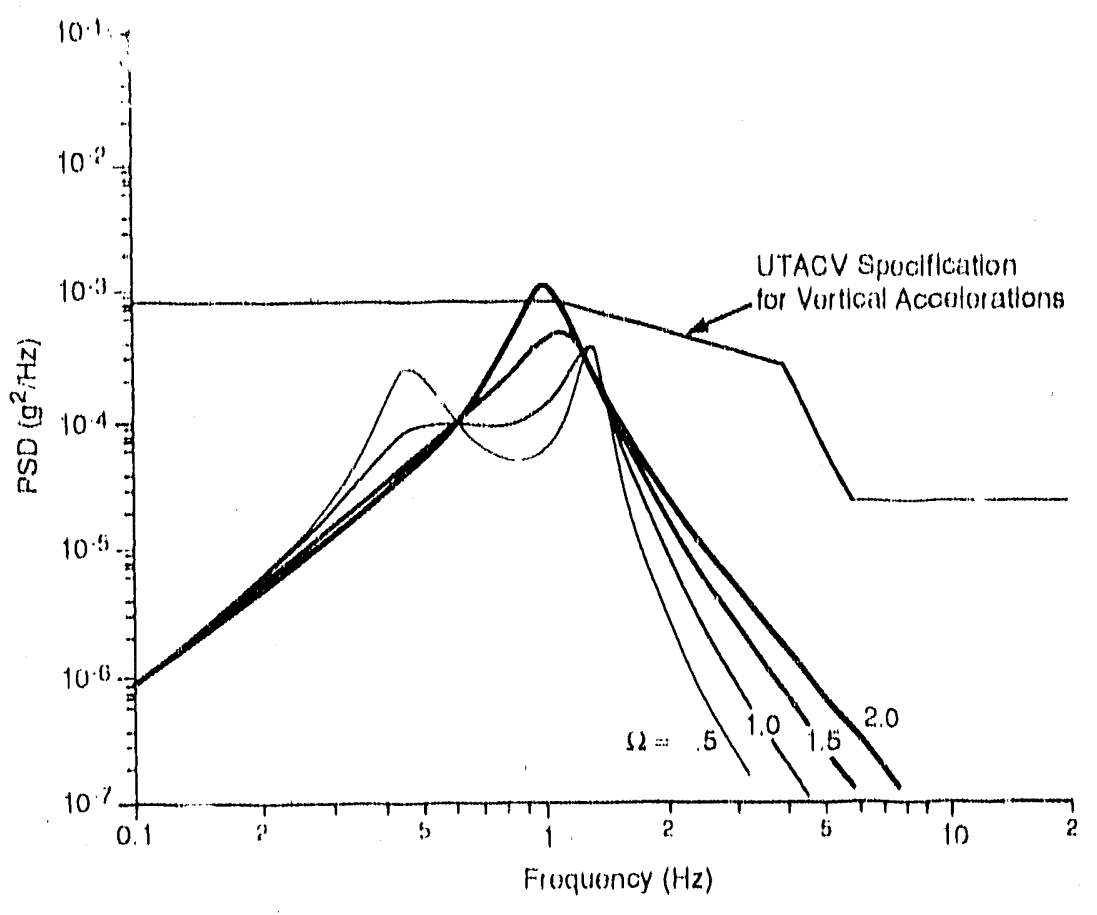

FIGURE 11.14 Power Spectral Density of Vertical Accolerations Exporienced by Vohicle

To obtain these curves, tho damping frequercy was varied while the remaining parameters were assumed to havo the following values:

$$
\begin{aligned}
& A=1.5 \times 10^{-6} \mathrm{~m}\left(5 \times 10^{6} \mathrm{ft}\right), \\
& v=134 \mathrm{~m} / \mathrm{s}(300 \mathrm{mi} / \mathrm{h}), \\
& M=0.666, \\
& K=0.1, \text { and } \\
& \omega_{o}=2 \pi \mathrm{rad} / \mathrm{s} .
\end{aligned}
$$

'The value of $\Lambda$ above is the value typically used by researchers in assessing predicted ride quality, and the vehiche-to-mitgned mass ratio is the specified value for the MLU-0()1.

Also shown for comparison in Higure 11.14 is the U'TACV ride-comfort specification for random vertical viluations, and it would appoar that a simple dashpot with a damping frecquency $\$ 2$ of $0.5,1.0$, or 1.5 would provide an acceptable ride. Figure 11.15 and shows the response due to a grudeway step, and these curves suggest that a damping frecuency of 1.5 would he superior. It would appear, therefore, that a simple dashpot is sufficient for vortical vibrations for the parameters assumed. 


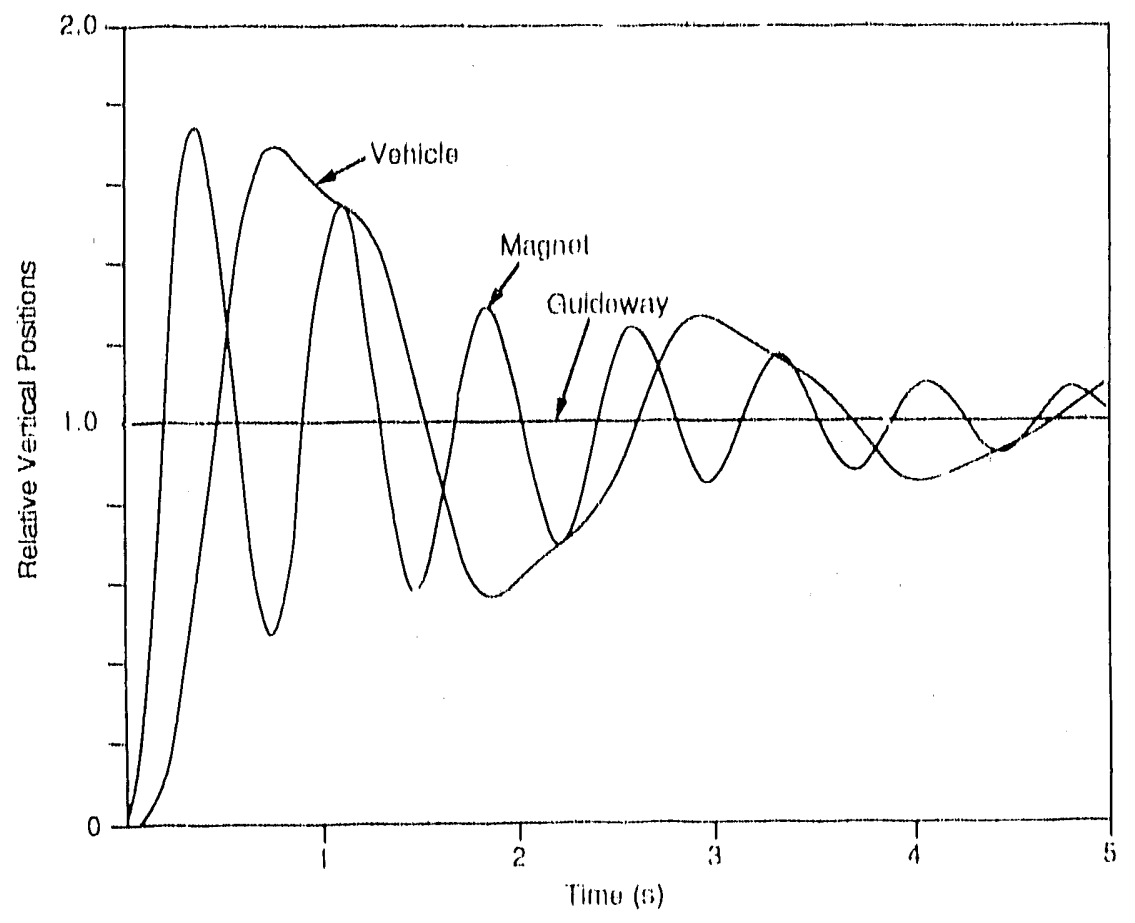

FIGURE 11.15a Response due to a Guideway Step, $A_{A}$

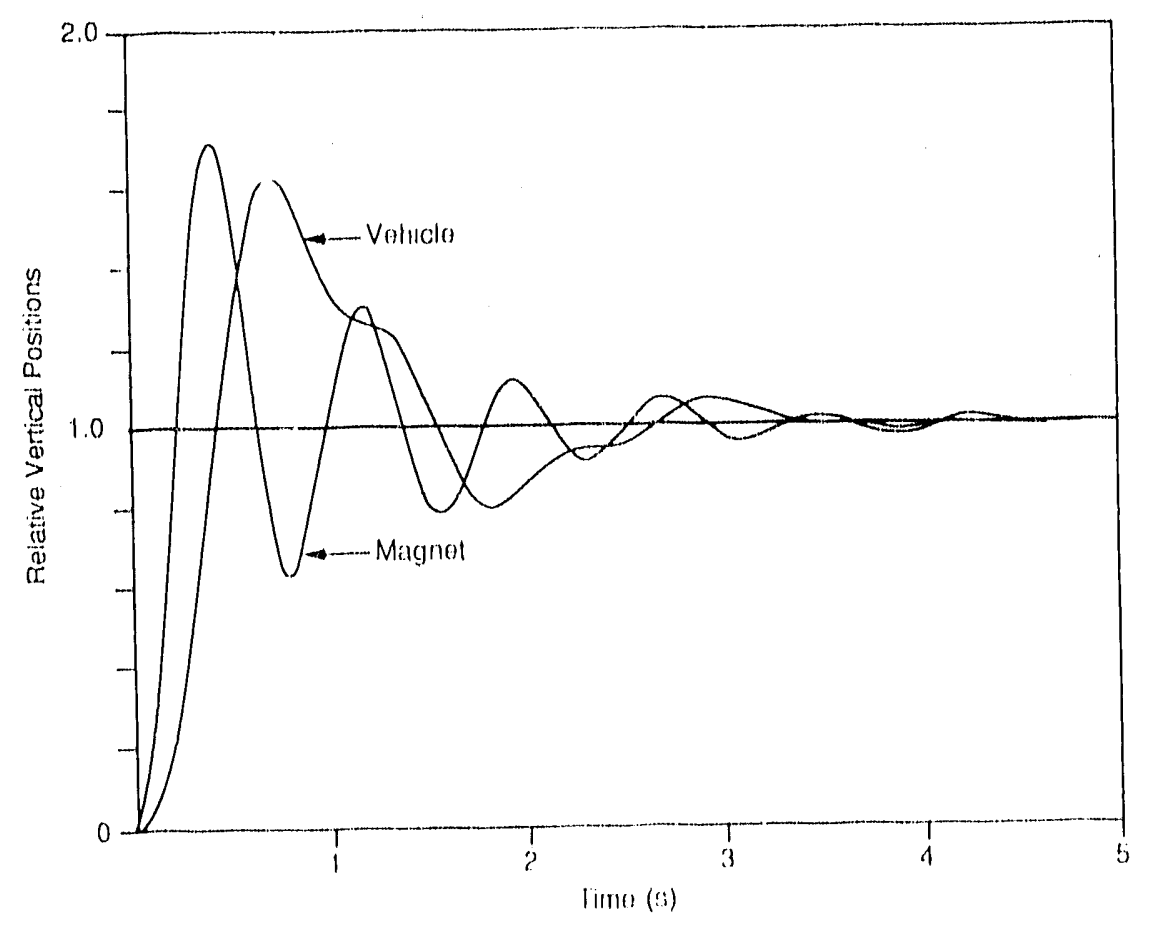

FIGURE 11.15h Response due to a Guideway Step, IS 


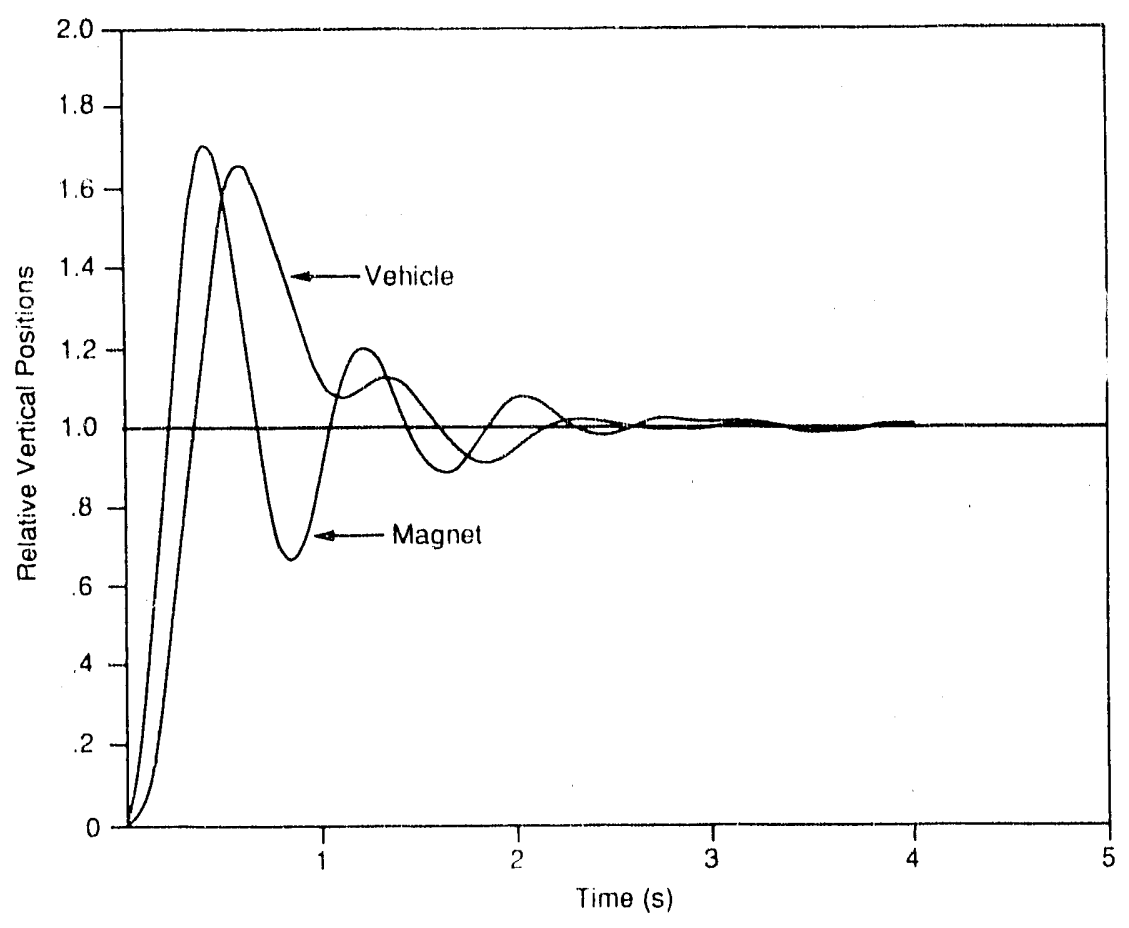

FIGURE 11.15c Response due to a Guideway Step, C

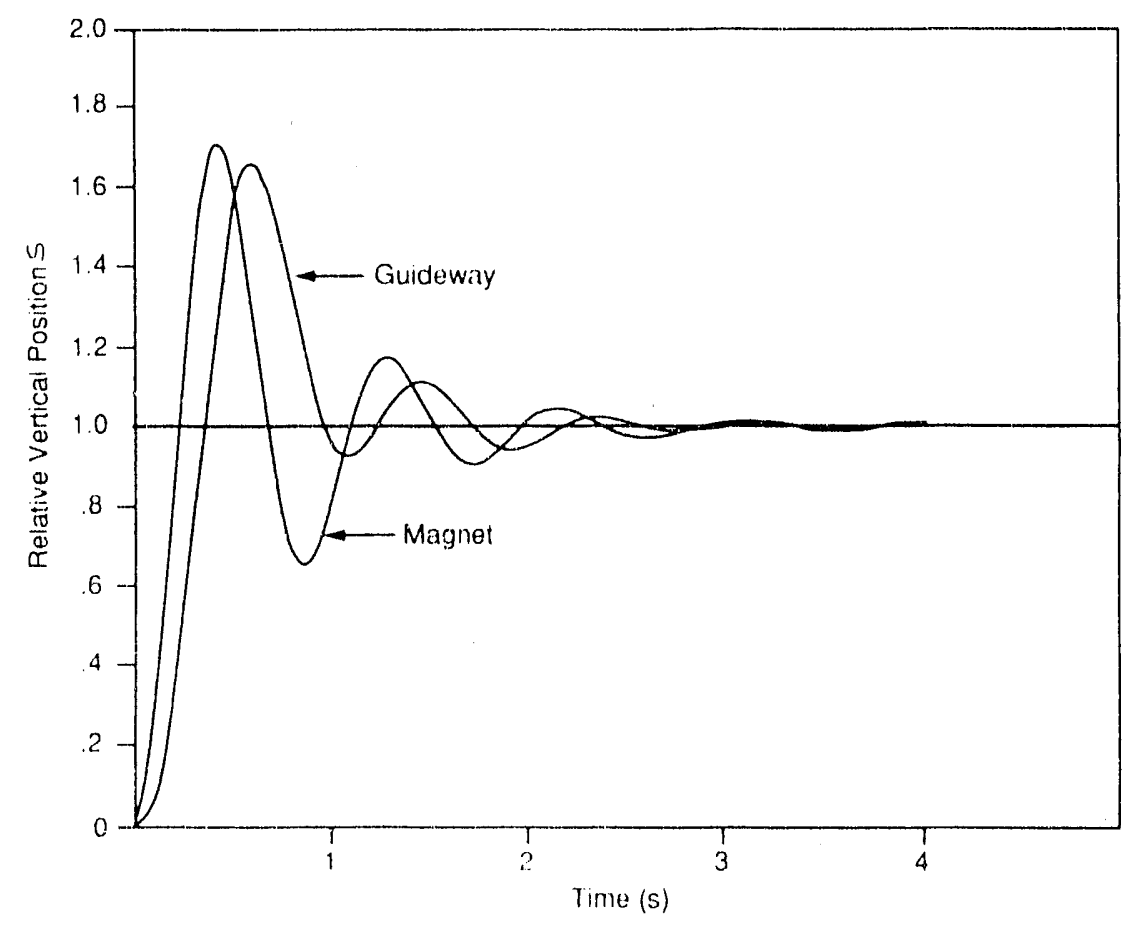

FIGURE 11.15d Response due to a Guideway Step, D 
Similar theoretical results have shown, however, that the UTACV specification cannot be satisfied for all assumed values of the vehicle-to-magnet mass ratio. Furthermore, lateral vibrations are more difficult to compensate for than are vertical vibrations. This is because (1) the UTACV specification is more demanding for lateral vibrations and (2) the lateral vibrations are expected to have a higher natural frequency. Active control of a forcing device, such as a hydraulic or pneumatic cylinder, may thus be required for lateral and longitudinal vibrations.

\subsection{COMMUNICATIONS}

A data-acquisition system (DAS; will be required to monitor and record the outputs of on-board transducers of a maglev vehicle, as well as to serve as a component of the control systems. The DAS will forward information to a radio transmission link, which will provide data transport to a control station receiver/decoder. A survey of available systems was made to determine the availability of commercial data acquisition and radio communications equipment relevant to the maglev program. $\Lambda$ suitable system was found that provides inputoutput cards to a computer bus, permitting acquisition and storage of sensor data aboard the vehicle. The same data can be transmitted by a radio link in analog form, or in digital form after $\mathrm{ND}$ conversion.

The transducers deliver outputs to interface/conditioning models that proviae signals to a hybrid analog/data-channel multiplexer (MUX). The analog and the digitally encoded signals are managed under program control to meet the system requirements of data/signal throughput rates and accuracy required for real-time control and system functional data storage.

The DAS will properly select those channels (analog or data encoded) necessary for system real-time control. These signals will be processed, according to assigned priorities, through algorithms derived to comply with system operational specifications. The transducer channels can be properly conditioned and subsequently output to the radio link or stored as required. Those transducer outputs at priority levels lower than system real-time control can $p^{i t h e r}$ be stored in a variety of data storage media and/or be processed at lower-priority levels on a time-sharing basis.

It might be necessary to use multiple DAS units (as well as multiple radio links), depending on the required data transfer rates, the number of data channels, and the nature of the data. The number of FM channels required will depend on the available radio signal rates and bandwidths.

\subsubsection{Data-Acquisition Technology}

The data-acquisition system identified can process multiple channels of mixed analog and digitally encoded datat under program control, with the capability of managing various iypes of añalog, digital, and more complex tyrne of transducer outputs (such as that from 
bridge transducers). The control system can output the data as analog or digitally encoded data through standardized analog, digital, or hybrid interface input-output (I/O) modules.

The maximum multiple channel sampling rate is five nanoseconds per sample, providing a sampling rate of $2 \mathrm{kHz}$ for 100 channels, with a capacity of 112 channels/unit. The maximum sampling rate for a single channel burst is $625,000 / \mathrm{s}$.

The serial data (RS232C) output capability of the system is $57 \mathrm{kBaud}$ per DAS unit. The use of 12 -bit A/D converter $(0.025 \%$ accuracy) modules would allow a data output rate of about 2,850 samples per second.

The serial-mode data link will serve primarily as a supervisory communication link to the main control system. Although sample data can be sent over this link, the transmission rate is about a factor of 20 slower than for direct analog data throughput for the equivalent number of samples. Critical real-time data can be directly transmitted through the $\mathrm{I} / \mathrm{O}$ modules under program control.

The chief advantages of serial data transmission include reduced bandwidth requirements, ease of data handling/storage, and error checking/validation capability. However, there is a reduction in data transmission rates, compared with $\mathrm{FM}$ transmission, on separate or multiplexed channels.

The data management and sampling algorithm program resides in the DAS. This program can be interfaced with and supervised by the remote-control console via the RS232 link. The remote console will pass parameters, such as signals to start/stop, and actuate emergency condition responses. The on-board program will provide the bulk of the detailed data collection and management functions.

The system, under resident program control, can accomplish the following:

- Change sample rates.

- Set/arm trigger events.

- Scan channel groups.

- Analyze or throughput data.

- Communicate supervisory signals to the main control.

The resident program can be controlled by supervisory commands from the main control console.

The radio link will require a custom design, because the technology needed is available in components, but not as an off-the-shelf integrated system. 
For a leaky-coax (coaxial cable) approach, the frequency must be below $1 \mathrm{GHz}$, since higher frequency systems suffer unacceptable losses. Because of the number of channels required, the maglev data-communication system must have a bandwidth greater than 100 $\mathrm{kHz}$. This bandwidth would accommodate 50-100 analog transducer channels, each with signal bandwidths of $1 \mathrm{kHz}$, without resorting to a complex channel-separation schome.

Using serial $\mathrm{RS} 232$ data transmission, the bandwidth relates to the baud rate, which is roughly equivalent to $1 \mathrm{bit} / \mathrm{s}$. Radios are available using frequencies between 1 and $5 \mathrm{GHz}$ and having bandwidths up to $4 \mathrm{MHz}$. Most commorcial units, however, operate in the 400-900 MHz range and have bandwidths of $5-10 \mathrm{kHz}$.

\subsubsection{Cost}

The overall cost of the entire data collection and transmission system is estimated to be between $\$ 175,000$ and $\$ 225,000$, the major cost being the radio portion of the system. Because of the necessity of a custom-designed system and the number of unknown factors, a more definitive cost figure cannot be determined at this time.

\subsection{RESEARCH AND DEVE .OPMENT' OPPOR'TUNITIES}

The proposed test facility provides many challenging research opportunities for control system designers. On the basis of an examination of the existing maglev systems, the following research topics are suggested for study in order to develop the most advanced control systems for the test facility.

\subsubsection{Modeling Study}

The design of a successful control system depends largely on tho plant model that is adopted. A good mathematical model is determined not only by how closely it corresponds to the real system, but also by its use of practical rather than ideal control strategies. A reasomable yet simple model might lead to a powerful, economically feasible control system.

The LSM and vehicle models are two major plant models to be employed in the control system design. They are essentially nonlinear and time-varying, with unpredictable factors due to the effects of variations in the payload, guideway deflections, electromagnetic parameters, and aerodynamic drag. So far, the current control system design has been applied to the linear motor and vehicle models. 'The following aspects will be examined for new LSM and vehicle models:

- Iinear model (and its order) or nonlinear model.

- Constant parameters or time-varying parameters 
- Deterministic or stochastic.

- Time-continuous or time-discrete.

If the model is time-discrete, then it is an input-output model, a difference model, or a state-space model. The control strategy, system specifications and implementation depend on the model selected.

\subsubsection{Suspension Stability Study}

An exact analysis of the suspension stability has not been made for the EMS system because of its nonlinear electromagnetic properties. If an exact solution could be found, it would be possible to design a feedback control with the maximum stable margin.

For the EDS system, it has been suggested that the air gap can vary by as much as $20 \%$ of the desired value. This suggests that it would be interesting to conduct a design study of an active suspension-control system in which the air gap measurement is used by the propulsion system to decrease the fluctuation error in the air-gap. This new idea requires an in-depth stability study.

Since the excitation force to the suspension system is a two-dimensional stationary stochastic signal, a stochastic stability analysis and control design could be beneficial. For example, the application of a Kalman filter to a suspension control might provide acceptable ride quality over a rough guideway.

\subsubsection{Adaptive Control Algorithms}

Numerous control methodologies could be exploited, but all efforts should be based on developing an adaptive control design, as discussed briefly in Chapter 4. Although the effects of small changes on the dynamic characteristics are attenuated in a feedback control system, if changes in the system parameters and environment are significant, a satisfactory system must have the ability to adapt. Adaptation implies the ability to self-adjust or selfmodify in accordance with unpredictable changes in conditions of the environment or structure. The control system that detects changes in the plant parameters and itself adjusts the parameters of the controller is called an adaptive control system.

In the propulsion-control design, the parameters of the LSM are considered as functions of the levitation gap, which, in turn, varies with the load force and the guideway roughness. Usually the load force and the guideway roughness are affected by unknown timevarying variables, which are also encountered in the suspension control system. Therefore, the deviations of the vehicle speed and the levitation air gap from the preset values will change with these factors. The adaptive control scheme will be designed to estimate the time-varying parameters in terms of measurable information. This will allow the controller to provide precise signals to minimize these deviations and hence to reduce sudden changes 
in velocity and acreleration. The major research work might emphasize the development of real-time adaptive algorithms with more rapid convergence rates.

\subsubsection{Study of Discrete Control Systems}

Unquestionably, an American maglev design will stress the use of digital technology in the designs of control and communication systems. It is clear that a sampled system behaves like a continuous-time system if the sampling period is sufficiently small. This is true under very reasonable assumptions. However, the discretization would change important system properties (such as the stability rogion, controllability, observability, etc.). Discrute system designs present engineering and theoretical problems. The following are some of the urgent research needs in this area:

- Discrete modeling: input-output model, difference model, state-space model.

- Sampling rate and quantitization error analysis.

- Application of digital control strategies: dead-beat control, self-turning control, etc.

- Discrete algorithms for sampling, holding, and control policy.

- Evaluation of various market DSP (D)igital Signal Processor) and DACA (Data Acquisition and Control Adapter) devices.

\subsubsection{All-Ground Propulsion-Control Design}

Another possibility to be considered is that of a propulsion-control system operated by all-ground-based-measurements, without any need for on-board measurements. The advantiges of this system are:

- Increased reliability.

- No time delay for data transmission, permitting a higher sampling rate.

- Reduction of the measurement error (usually on-board measurement errors are large).

- On-board equipment cost savings.

The key to the solution is to develop a set of formulas that describe the interactive relations between the motor sections and the vehicle via a time-varying air gap and to devel(o) a sot of on-line estimation algorithms. Because of the flexible expansion capability and the tremendous speed of digital technology, the future of this research topic is promising. 


\subsubsection{Simulation of the Control Systems}

Computer simulation is an indispensable tool for the research and development of the test facility control systems. The simulation of dynamic control systems is conventional for vehicle design, but the simulation of the operation control system is a new topic. In this study, the development of an expert system and a data base for accumulating test results would be a reasonable goat.

\subsubsection{Development of New Measuring Systems}

Vehicle position and levitation air-gap signals are vitally important to the propulsion control system as well as to the suspension control system. The Transrapid TR-06 installed three different measuring systems for position detection. None of the systems is completely satisfactory. On the other hand, the levitation sensors are the most troublesome devices, according to reported operation experiences, and a redundant design has been used to take this situation into account. However, the development of new air-gap sensors and position measuring systems could directly increase reliability and control stability.

\subsection{REFERENCES FOR CHAPTER 11}

1. Friedrich, R., and J. Eikermann, The Symehronous Long-Stator Propulsion System for Transrapid, Proc. Eleventh International (onf. on Magnetically Levitated Systems and Linear Drives, (Maglev '89), Yokohama, eapan, July 7-11, 1989 (1989).

2. Nakamura, K., and S. Koike, L.SM Propulsion System of the Miyazaki Maglev Test Track, International Conf. on Maglev 'Transport'85, pp. 91-98 (1985).

3. Friedrich, R., and K. Dreimann, Propulsion and Pouer Supply System of the Transrapid O6 Vehicle Design and Test Results Part 1: Propulsion, Proc. International Conf. on Maglev Transport '85, pp). 75-82 (1985).

1. Bimmermann, H, et al., Highly Reliable Control and Protection for the Transrapid High Sipeed Maglev Transportation System, Proc. Eleventh Intermational Conf. on Magnetically levitated Systems and Linear Drives (Maglev'89'), Yokohama, Japan, July 7-11, 1989, pp. 297-301 (1989).

5. Schneider, E., The Operations Control for Super Speed Magnetic Trains, in Transrapid Maglev System, K. Heinrich and R. Kretzschmar, eds., HESTRA.VERLAG, Darmstadt, Germany, pp. 60-64 (1989).

6. Dreimann, K., and R. Friedrich, Propulsion and Power Supply System of the Transrapid 06 Vehicle Design and Test Results Part 2: Power Supply, Proc. International Conf. on Maglev Transport '85, pp. 83-90 (1985). 
7. Ciessow, G., and R. Friedrich, The Long-Stator Propulsion System and Its Pouer Supply, in Transrapid Maglev System, K. Heinrich and R. Krotzschmar, ods., HESTRAVERLAC, Darmatadt, Germany (1989).

8. Ikeda, H., and 1. Kawaguchi, LSM Comtrol Method for Multiple Ponere Connersion Stations Proc. Eileventh, International Conf', on Matgnetically lovitatod Systems and Linoar Drives, (Magrlev '89), Yokohama, dapan, July 7-11, 1989)(1989).

9. Schulin, G., The Vehicle Location, in 'l'manswapid Maglov System, K. Heinrich and R. Kretzschmar, eds, HESTRA-VERLA(i, Darmstadt, Gormany (1989),

10. Schneider, E., K.H. Kraft, and H. Gückel, Automated Oporations Control System for Itigh Speed Magleu Tromsportation, Proce International Conf. on Maglev and Linour

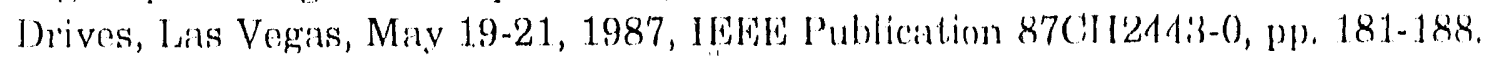

11. Sreki, A., S. Kato, and T. Kawakami, Concept of the Operationct safety System for the C/mo Linear Express, Proc. Eleventh Intermational Gonf, on Matgnotically Lovitated Sy'stems and Linoar Drivos (Maglev '89'), Yokohama, eapan, July 7-11, 1989 (1989).

12. Sinha, P.K., Electromagnetic Susponsion I)ynamin's and Comtrol, Poter Peregrinus, Lut., l.ondon, U.K. (1987). 


\section{2 'TES'T SI'TE DEFINITION}

\section{1 (OBJLCIIVES ANID REQUIREMENTS}

The ultimate goal of the maglev design program is to promote the development of new, sufe, cost-offective techniques of mannetically lovitating high-speed ground vehicles. The maglev test facility design presented here is intended to be used to (1) verify experimentally the preticted performanco of maglev vehicles propelled, suspended, and guided by means of different maglev technologies; (2) determine the dynamic interactions of these vehicles with guideways constructed using different materials, designs, and construction techni(ques; and (B) validate control and communication strategies and equipment. 'The oxperimontal results will bo used to validate computer programss simulating larger-scale vehicles and so assist. American industry in developing future prototype and revenuemoducing maglov systems. 'I'o meet this goal, it is necessary to perform the tests at a scale that can be reasonably extrapolated to full-sized vohicles. We believe the facility proposed here meets those recquirements.

The program will not test all aspects of full-scale vehicles. Ultimately, the size, configuration, amenities, and ride quality of maglev vehicles will be the responsibility of industry. Industrial designers will determine these characteristics, together with the performance of systems at higher speods, where aerodynamic considerations in the incompressible-fluid regime become critical, in their larger-scale vehicle-development programs. Safety, howevor, is a public concern and will be addressed throughout this program. The ultimate responsibility for safety of these vehicles lies with the Federal Railuad Administration, which will judge the efficacy of these and other tests in assuring the saffety of these systems.

'To meet these objectivos, the intermediate-scale experimental facility will allow maglev vehicles weighing up to 7 metric tons to operate at speeds up to $67 \mathrm{~m} / \mathrm{s}$ (150 mph) (one-half the nominal operating speed of $134 \mathrm{~m} / \mathrm{s} 1300 \mathrm{mph})$ ). 'I'o attain this speed with accolerations comprarable with those expected for operational vehicles $(0.2 \mathrm{~g}$ 's $)$ and to allow ar rotsonable time $(15$ s) for making experimental measurements while at top speed, a straight guideway of about $3.3 \mathrm{~km}$ (two miles) in length is necessary (see Figure 12.1). In later phases of this program, a second guideway section could offer the capability of testing vehicles on curved and graded sections of gruideway. 'This second guideway section would allow maglev systems of proven conceptual design to be tosted under more realistic conditions. The initial site must provide space for the later installation of this second section. The site also must accommodate a smaller, 300-m (1,000-ft) straight guideway to the major guideway. This smaller guddeway has not been evaluated in detail, but it would be used to validate concepts at a scale botweon that of laboratory tests and the intermediate-sized 


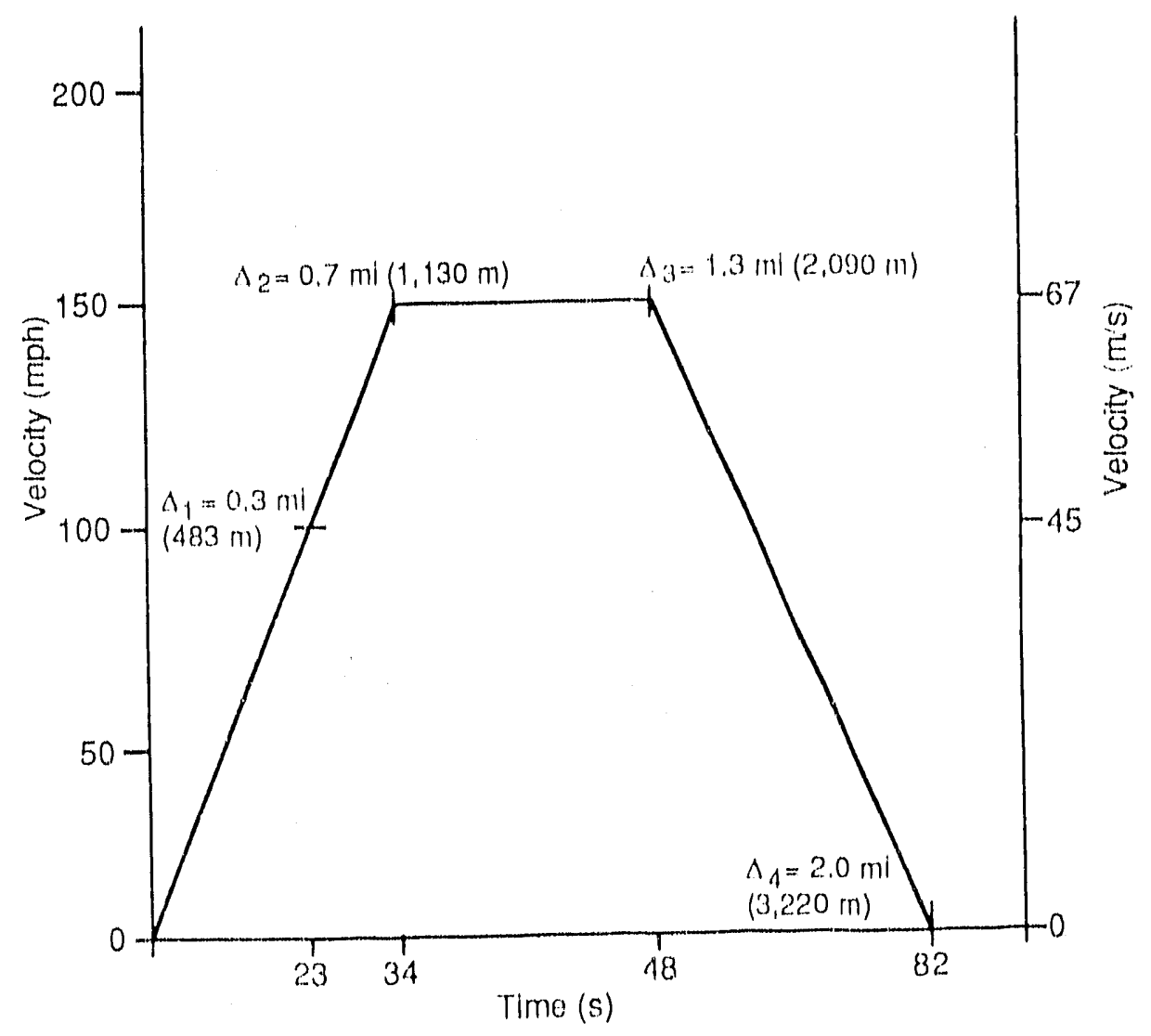

FIGURE 12.1 Speed Profile

system discussed here. In addition to the vehicles and these guideways, the test facility will also comprise the following:

- A central station for directing operations and monitoring salfoty.

- A garage to maintain and house the vehicle(s) botwoen tosts and to store supplies.

- A power station to provide electricity to the facility buildings and to condition and power the linear synchronous motor on the gruideway.

- A potahlo-water supply for the facility buildings and for cextinguishing firc.

- Oporations and offico rooms for personnel and visitersis.

Such a site is presented conceptually in Figure 12.2, which illustrates the difforent infrostructures respuired to operate the test facility. 'T'o holp dofino the sizo ropuirements of' the site, each individual structure of the site is first defined and its size ovaluated. 'fhen, a cost estimate of the site facility is assessed based on the cost of each individund structure. Finally, important site chatracteristics and considerations for tho soldection of a test sito ande diserssed, together with further actions to be taken. 


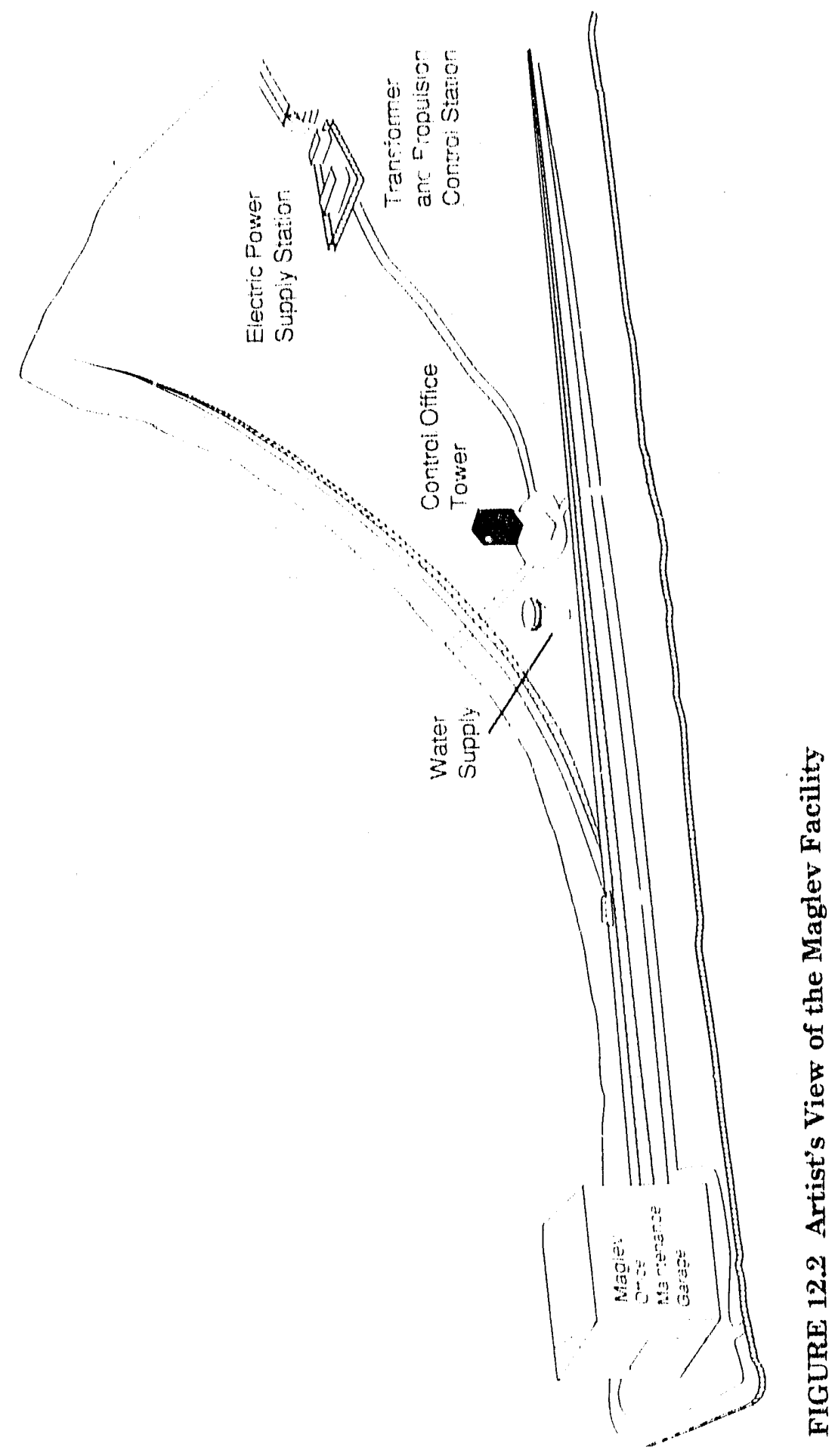




\subsection{FACIL.I'Y S'TRUG'I'URE}

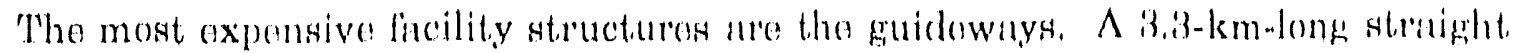
gruidoway and (lator) a curved gruideway aro proposod for the oxperimontal facility, (On the

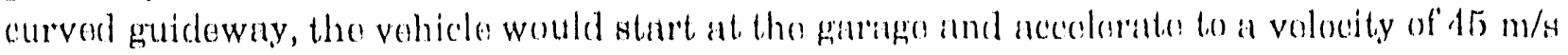
(about $100 \mathrm{mph}$ ) before negotiating the curve. The voliche would bo ablo to accelemates

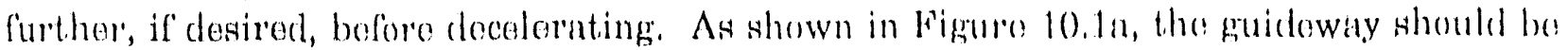
hanked at about. $6^{\prime \prime}$ for a coordinated turn at. this spoed. If the vohiche is to accelomto to $67 \mathrm{~m} / \mathrm{s}(150 \mathrm{mph})$, the curve should spiral into a bank angla of about 12 " to achievo coordination.

In this assessment, we are only interested in the extent, ho which tho radius of curvature affects the site dimensions. The greatost laternl dimomsion is nocessary with the $12^{\circ}$ angle of bank and operation at $67 \mathrm{~m} / \mathrm{s}$, as illustrated in Figures 12.3 and 12.4 for tilt angles of $12^{\circ}$ and $6^{\circ}$, respectively. The site length of about $3.5 \mathrm{~km}(2.2 \mathrm{mi}$ ) is ample for tho $3.3 \mathrm{~km}(2.0 \mathrm{mi})$ guideway, and space is available for tho mantonance garage, safety extensions at the ends of the guideways (in case tho vohiche exporionces a complete failure of britsing), and safety nets at the ends of the gruideways. The litcrial distance necessary to accommodate the two guileways is about $0.16 \mathrm{~km}(0.1 \mathrm{mi})$ at the beginning of the guideway. At the $0.5 \mathrm{~km}$ point on the straight guideway, the site must widen to accommodate the curver guideway, reaching a maximum width of $1.9 \mathrm{~km}(1.2 \mathrm{mi})$. Since the $12^{\circ}$ bank-anglo calse is the most stringent, we will consider its dimensional requiremonts as a basis in the

following discussion. The size of the site is a dotermining factor for the cost assessment of land rontal or purchase, sito fencing, and road construction.

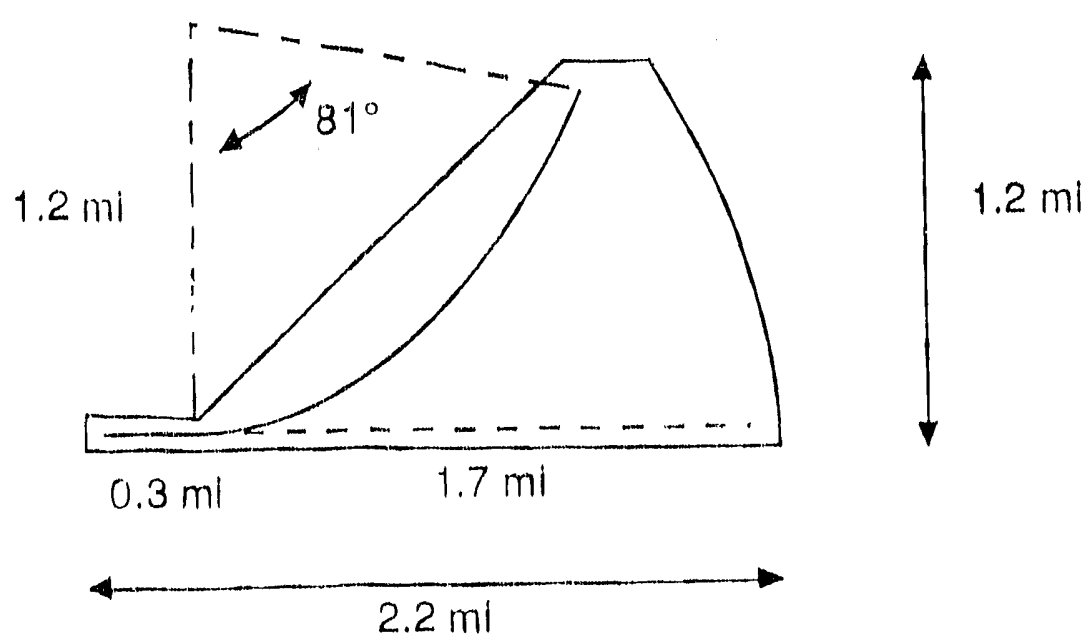

FIGURE 12.3 Sizo Requirements for the Experimental 'I'ust, Facility with Bank Angle $\phi=12 \circ$ (straight guideway, $\cdots$; curved guideway, -) 


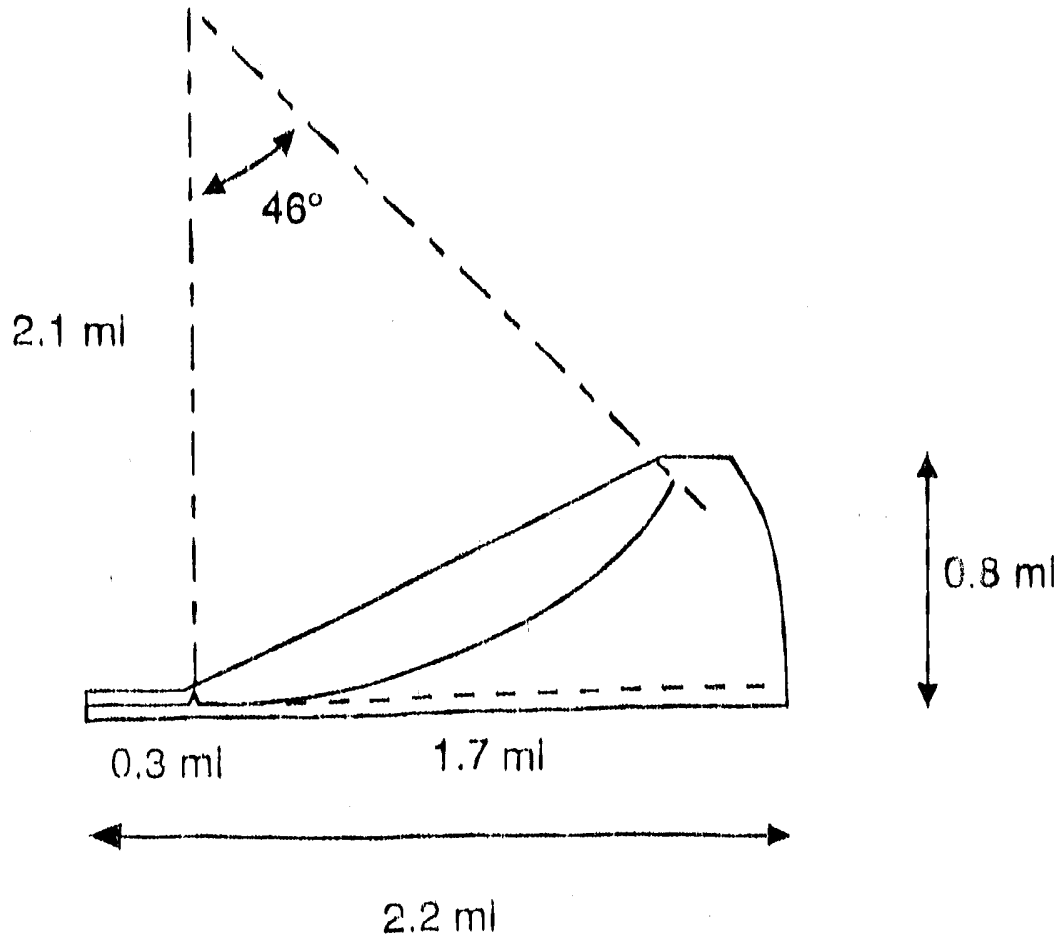

\section{FIGURE 12.4 Size Requirements for the Experimental Test Facility with Bank Angle $\phi=6^{\circ}$ (straight guideway, -...; curved guideway, ...)}

The dimensions stated above provido enough space for trees at the periphery of the site, for safety in case the vohicle goes beyond the guideway, for windbreaks and limiting of snowdrifts (except in the experimental aroa), and for noiso abatomont. On the basis of the astimated $\$ 3.57$ million cost of a single guideway (Soction 10.6.5), the two guideways would cost about twice this amount (noglecting superstructures). The second structure will bo somewhat more complex due to its curves, but it will also be about $480 \mathrm{~m}$ shorter.

\subsubsection{Maintenance Garage}

A hoated and air-conditioned maintonance garage will bo necessary to house the matglev vohicless). A schematic representution of the garage is givon in Figure 12,5. Tho fiarage is $12 \mathrm{~m}$ long, $12 \mathrm{~m}$ wido, and $6 \mathrm{~m}$ high. It can house two vohicles and has room for two officos, heating, ventilating, and air-conditioning (HVAC) systems, restrooms, and some storige, $\Lambda$ small platfirm (1.5-m wide) will support liquid nitrogon and helium ports and electric panols that will be used to recharge the batteries of the EMS vohiche(s). Licquid nitrogen and liguid holium will bo supplied from 250-L and 500-L storage tanks, respectively, locatcel outside with adequate protection from the olemerits. lifectricity and water will be providen from the oloctricepowor supply and water-supply stations, respectivaly. Electric crancs will be installed to move and olevate vehicles in the garage and to place them on the 


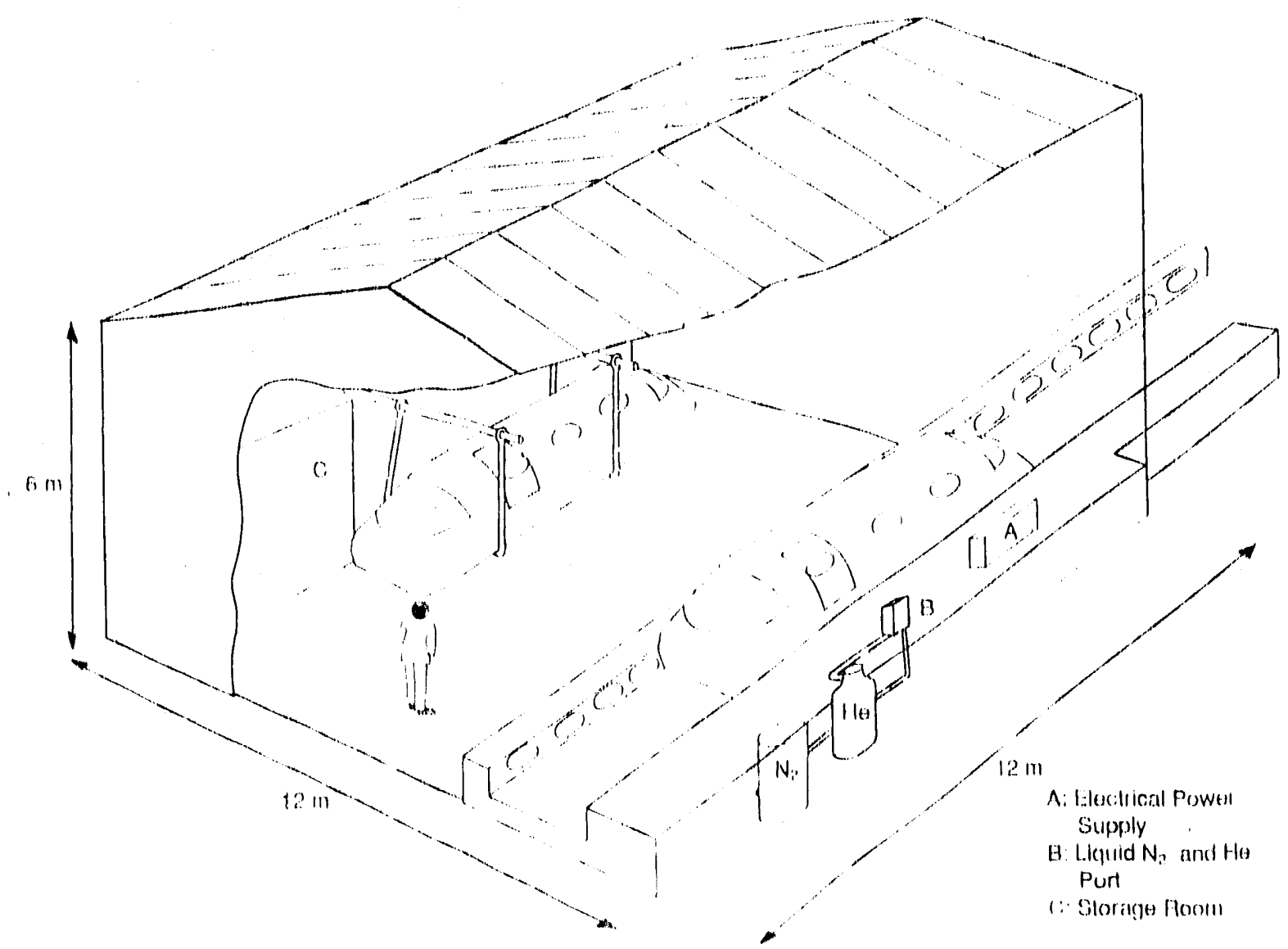

FI(aURE 12.5 Cutaway View of Maglev Vehiclo Maintenanco (arage

guidenay. As shown in ligure 12.5, the gruideway extends through the garage at floor lovel. If' more space is nooded, the garage can be oxtended in eilhor direction at rolatively morlest cost. The maintenance garage specifications are summarized in l'able 12.1.

The maximum electrical power recpured to operate the gurage is not expected to exceed $100 \mathrm{~kW}$, including the power for the crane, machining and welding tools, electrical utilities, HVAC systems, otc.

\subsubsection{Electrical Powor Station}

A A-MW electrical substation will provide power to the guideway and buildings of the facility (see Figure 12.2). It will comprise high-voltage transforments, two isolation trinsformors, two input transformers, the propulsion conterol unit, and high-voltage circuit. hrenkers.

Alarm and safoty devices, such as fïre protection, automatic (C) fire oxtinguishors, smolse detectors, and fire alarms, should ho installed in tho station. Shods may be necossiry to house the switch pancls and control units. It is estimatod that a fenced space of about

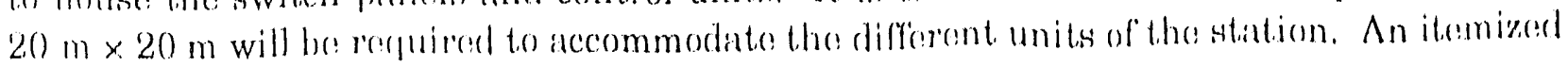


TABLE 12.1 Specifications for Maintenance

\section{Garage $^{a}$}

\begin{tabular}{|c|c|}
\hline Item & Specification \\
\hline \multicolumn{2}{|l|}{ Size (m) } \\
\hline Width & 12 \\
\hline Length & 12 \\
\hline Height & 6 \\
\hline Nitrogen/helium storage (L) & $250 / 500$ \\
\hline Offices & 2 \\
\hline Restrooms & $1-2$ \\
\hline Septic treatment & If required at site \\
\hline Electrical service (kW) & $<100$ \\
\hline Estimated price $\left(\$ 10^{3}\right)$ & 200 \\
\hline
\end{tabular}

a Includes 20-ton crane.

breakdown of the electrical power supply costs (see Table 12.2) yields a total of about $\$ 2.2$ million. Costs associated with supplying electrical power from the nearest electrical supplier to the site are not included.

\subsubsection{Control Station}

A two-floor control station will be provided for observation of the vehicle during operation. This station will be located at the midpoint of the guideway but at a safe distance from it, as indicated in Figure 12.2. The station will be heated and air-conditioned for operation year-round. A preliminary layout of the control station is shown in Figure 12.6; its approximate size (width, length, and height) will be $8 \mathrm{~m} \times 12 \mathrm{~m} \times 6 \mathrm{~m}$. Four offices and one conference room are planned on the first floor. The system will be controlled and monitored fro:n the operations room on the second floor. Remote television observation of the guideway and site will be provided for recording the operations and to ensure that the guideway is clear and that no personnel are in danger. Electrical power required is expected to be $50 \mathrm{~kW}$. Office trailers can be used for additional office space or for minimizing costs for decommissioning, demolition, and land reclamation when the program is completed. The main features of the control station for which costs remain to be estimated are sanitary facilities, HVAC equipment, safety sprinklers, alarms, and observation equipment. The total cost is estimated to be $\$ 170,000$. 
TABLE 12.2 Electrical Power Supply Station Costs

\begin{tabular}{lc}
\hline \multicolumn{1}{c}{ Item } & Cost $\left(\$ 10^{3}\right)$ \\
\hline Guideway switches & 700 \\
Three-phase cables & 750 \\
Power supply (4 MW) & 900 \\
High-voltage transformer (1) & 360 \\
Isolation transformers (2) & 50 \\
Input transformers (2) & 50 \\
Alarms and safety equipment & 30 \\
Control & TBD \\
Sheds & 10 \\
Fencing (1.8 m) & 5 \\
Total estimated cost & 2,200 \\
\hline n To be determined. & \\
n Space required is $20 \mathrm{~m} \times 20 \mathrm{~m}$. & \\
\hline
\end{tabular}

\subsubsection{Water Supply}

Potable water is required on site by the Occupational Safety and Health Administration (OSHA). Since the site is not yet known, it is assumed that community water supplies will be unavailable and that well water will be used. If water is unavailable, a water storage tank can be used as an alternative. U.S. Department of Energy (DOE) order 5680.7 (fire protection, revised 1981) requires that facilities operated by DOE or its contractors have water lines that are at least $8 \mathrm{in.}(20 \mathrm{~cm})$ in diameter and that a minimum of two hours of fire-protection water be stored if municipal supplies having this capacity are not available. Distribution of this water must be provided to the appropriate sites to be protected. Although this order does not explicitly require dutomatic sprinklers for structures of less than $5,000 \mathrm{ft}^{2}\left(465 \mathrm{~m}^{2}\right)$ in size, sprinklers might be required if the maximum possible firc loss (MPFL) exceeded $\$ 1,000,000$. This loss estimate is based on the assumption that both the fire-suppression system and municipal fire-fighting efforts fatil. 'The loss of the maglev vehicle and structures would exceed the $\$ 1,000,000$ limit, so it, is assumed that water. lines, sprinklers, and fire hydrants will be required. A preliminary estimate of these costs is given in Table 12.3 . 


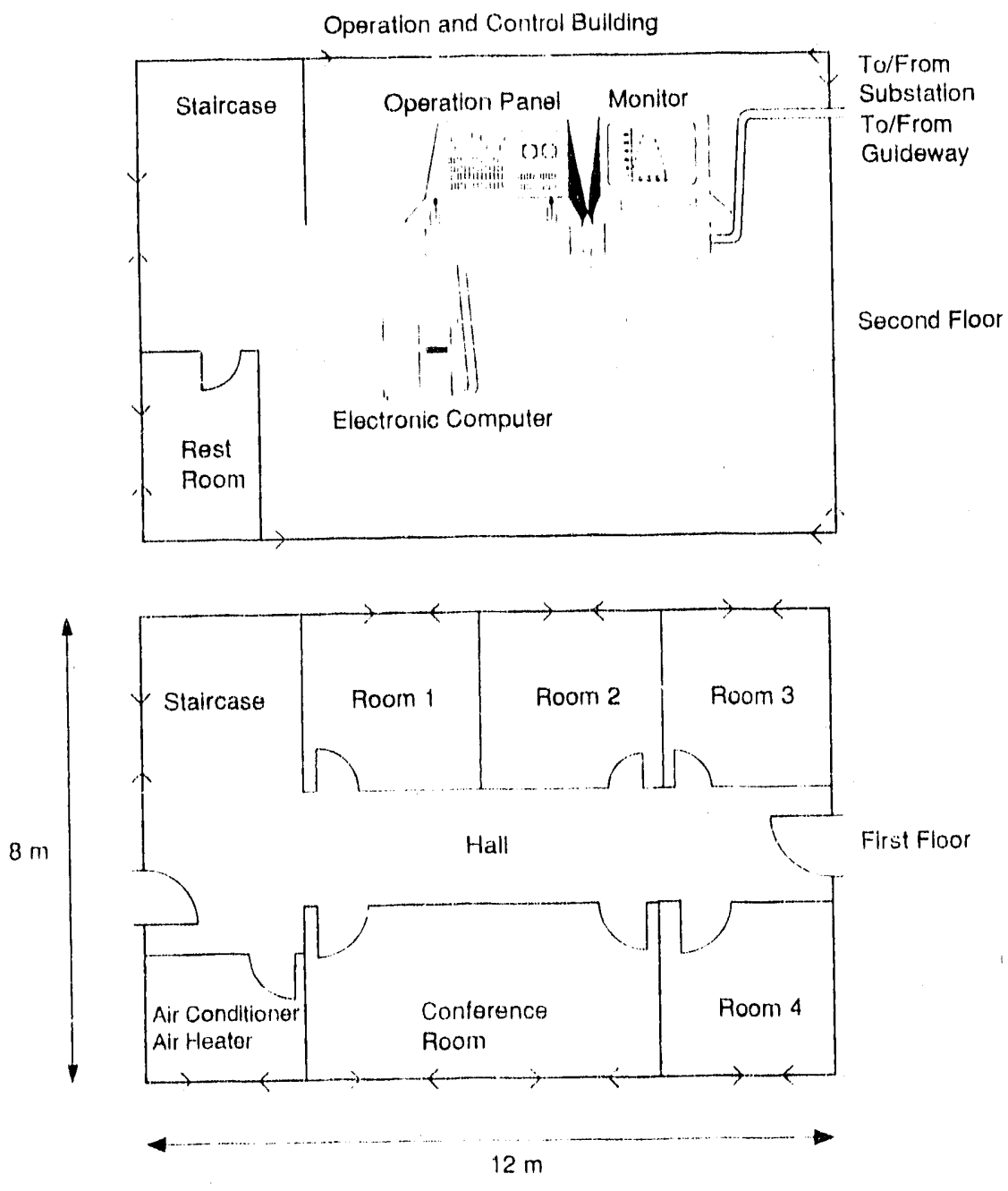

FIGURE 12.6 Control Station

TABLE 12.3 Water-Supply System Costs

Elevated water tank $(250,000 \mathrm{gal}$ for two hours of storage)

Water treatment

Garage and control station distribution ( $k$-in. lines)

T'otal estimated cost 


\subsubsection{Waste Treatment}

Waste-treatment services (solid and liquid wastes, sewage systems) are required by OSHA and are expected to he supplied by community waste-disposal services. Solid wastes will be generated by the maintenance facility and control tower/station. Liquid wastes can be treated with septic tanks if the properties of the soil are adequate.

\subsubsection{Fences}

Fencing of the facility, at least in the vicinity of the guideway, will be required to prevent access by vehicles, animals, vandals, etc. Entrance gates will be necessary to permit. access and to comply with site emergency plans. A 6 -ft $(1.8-\mathrm{m})$ fence is expected, at a cost of about $\$ 670,000$. Manned security sheds or othor means of limiting access to the site will be recpuired at each entrance. Fences will be placed far enough from the guideway that they will not interfere with weather measurements and effects in the vicinity of the experimental section of the guideway.

\subsubsection{Roads/Parking Lots}

Gravel roads will be necessary for access by vehicles used in constructing and maintaining the guideway and for emergencies. Access roads to the main buildings will be required, as will parking facilities at these locations. Bituminous road paving is not recommended, because its use would increase not only the construction costs, but also the cost of land reclamation at some future time. Maintenance of these roads, as well as possible road extensions (e.g., snow and ice removal), is expected to be available from nearby communities when needed. The cost for grav' roads and parking lots is estimated at $\$ 200,000$.

\subsection{ORGANIZATION AND ADMINISTRATION OF THE SI'TE}

Potential users of the facility will be requested to submit their proposals to the Users Committee for evaluation and scheduling of experiments. The committee is expected to consist of reviewers from industrial, academic, and governmental institutions. A conceptual organizational structure is presented in Figure 12.7. A site manager will supervise the safety and health (S\&H) office, the site maintenance personnel, the financial offices, security, and some technical support personnel. These offices can be either on site or off site. The site managor might be required to reside on site during off hours, and a 21 -hour security servico might be required to maintain the safety and security of the site. Other maintenance personnel will be required only on a part-time hasis and will not require full-time offices. Finaneial and technical support offices will be off site. An S\&H organizational structure is ropured by IDOE. For example, such items as firt-protection procedures, the emorgency plan, a site-evacuation plan, S\&H training, emergency coordination and communication, etc. must he developed and amprover in the site phase by the appropriate anthorities. 


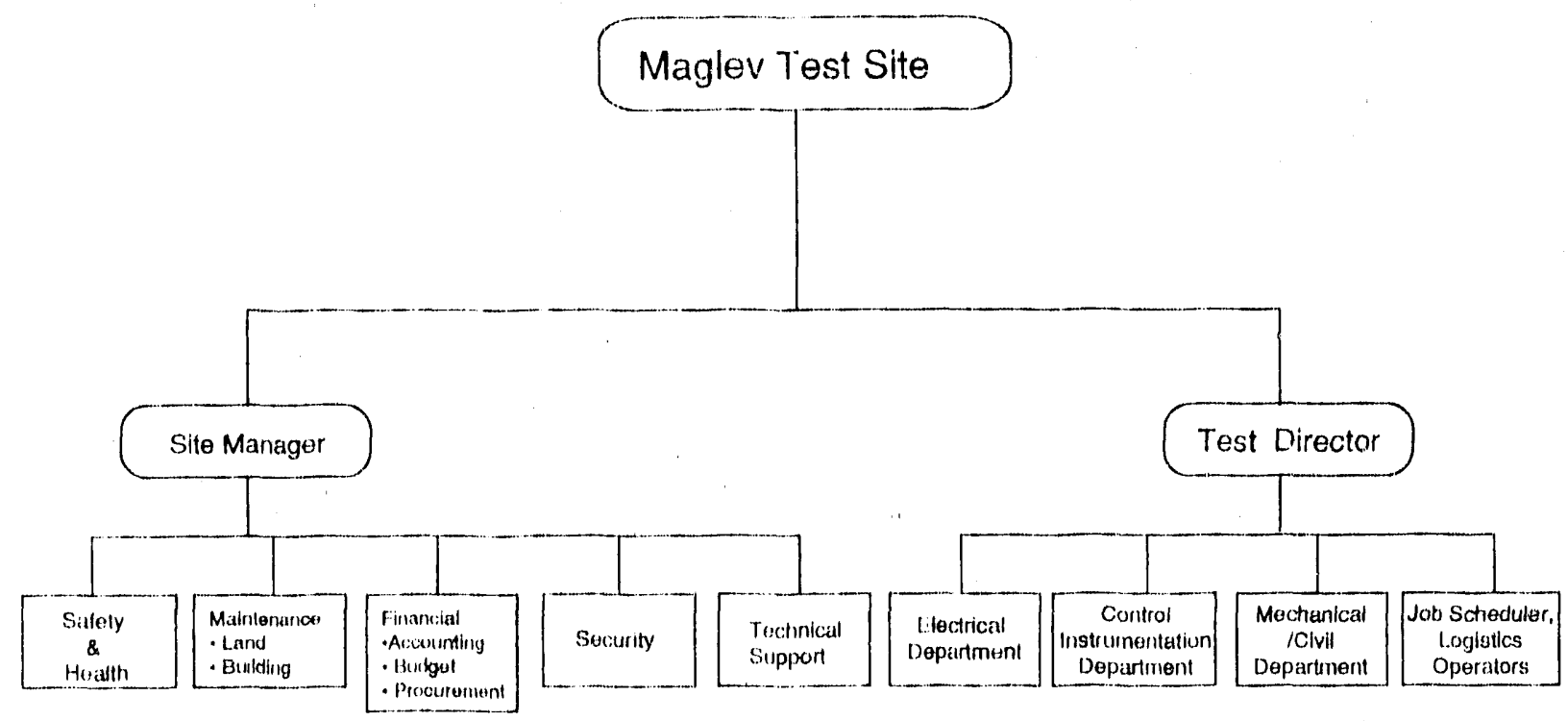

FIGURE 12.7 Organization Chart - Conceptual

\subsection{SITE SELECTION CONSIDERATIONS}

Once the site and its infrastructure components are defined, the geographical location of the site can be selected. Tho parameters affecting the site selection are discussed in this section.

\subsubsection{Climate}

Climatic data are important for infrastructure construction. Average medium and minimum temperatures, water and snow precipitation, and wind data throughout the year are critical to the design and construction of infrastructures (roads, buildings, etc.). Rains and melting snows seep slowly through the soil, causing physical and chemical changes. Uncoated steel or concrete can be subject to corrosion by the soil, depending on the sulfate content, texture, and acidity of the soil. Frost can damage the pavements and other structures by frost heaving, and soil strength may be low after thawing. Texiure, moisture content, porosity, permeability, and organic-matter content are the most important soil properties that affect this phenomenon. Climate changes may produce severe flooding, rendering the land difficult to use for infrastructure construction. Meteorological instruments should be provided to monitor the conditions under which the experiments are performed and to determine the effects of the weather on the condition of the equipment and structures.

Occurrences of tornadoes in a particular region would require that tornado shelters be provided. If noeded, these shelters could be constructed near the facility buildings. Building evacuation procedures in the site plan will have to deal with these particular dangers. Anemometers should be provided to observe the wind velocity on and near the guidoway before and during operations. 


\subsubsection{Soil Physical and Engineering Properties/Soil Limitations}

Soil properties are critical parameters affecting the final design and cost of the facility. Soil characteristics may include grain size distribution, licquid limit, plasticity, soil reaction, depth to bedrock, soil wetness, depth to seasonable high-water table, slope, likelihood of flooding, natural soil structure or aggregation, and soil density. Other soil properties that would guide the choice of a particular site geographical location are erodibility, permeability, corrosivity, shrink-swell potential, available water capacity, shear strength, and compressibility. Some soil types impose severe limitations on the construction and maintenance of roads, pipelines, foundations for small buildings, drainage systems, and sewage and refuse disposal systems. The soil properties listed above can have a great influence upon the design of the guideway and other infrastructures. For example, the guideway structures have been designed for a soil pressure of about 4,000 psf (sec: Table 10.1). If the soil cannot safely handle: this pressure throughout the year, then supplemental structural design would be required, with attendant higher costs.

\subsubsection{Vegetation and Wildlife}

Vegetation can help to abate the noise level, serve as a windbreak, reduco the amount of precipitation (rain and snow), beautify the site, and foster wildlife. The amount. of wildlife depends largely on the vegetation that is available as food and cover and on how much surface water is available. The construction of infrastructures, such as guideways, may aiter wildife habitat and the behavioral patterns of both animals and vegretation. In order to limit the impact of infrastructures on vegetation and wildlife, an environmental impact assessment will have to be performed once a sito has been selected (seo section 12.5).

\subsubsection{Availability of Natural Resources, Water, and Electrical Power}

In planning the construction of infrastructure on a site, ono may take advantiace of the site's natural resources, such as stone, gravel, clay, and sand; these are commonly awailable on site as a result of grading. The use of these natural resources can only be obtained with the permission of the owner of the land and if it does not have environmental impacts upon the site.

Availability of electrical power is also a critical parameter that affects the selection of a particular geographical location. The closer the site is to an electrical grid node, the more economical it will be to supply electrical power to the site. Another important rosource is water. An economic analysis will be necessary to assess whether the use of commercial water or ground water is more appropriate. Such decisions can only be made whon the physical location of the site has been determinerl. 


\subsection{5 'Topological Requirements}

To limit construction costs, the site terrain grade should be as small as possible. For example, the Japanese Miyazaki test track, which extends over four miles, has a total terrain grade of less than $0.5 \%$. For the Argonne test facility, an average guideway height of $3 \mathrm{~m}$ is heing considered, which permits an average guideway grade of less than $1 \%$. Such a limit may prevent substantial increases in guideway costs over those estimated in Chapter 10. For the curved/uphill guideway, a grade of approximately $4 \%$ would be acceptable to reduce guideway costs.

\subsubsection{Restoration and Decommissioning}

The facility has been designed to keep restoration and decommissioning costs and deliays to a minimum so the land can be quickly reclaimed for other uses. Only as many reinforced-concrete structures as are needed will be constructed, in order to reduce demolition costs. The removal and disposal of the guideway piers and beams would cost about $\$ 500,000$ for each guideway. $\Lambda$ breakdown estimate of the demolition costs is shown in Table 12.4. Note that demolition and disposal of the guideway is the most expensive restoration task.

\subsection{REMARKS}

Since the geographic location of the site is unknown, we have assumed the availability of electrical power and water supply in the process of site definition. Therefore, the estimated costs in this chapter. are only indicative; more representative cost estimates can be derived once the geographic location of the site is known. Site-dependent analyses, such as health and safety analyses, still have to be performed to ascertain that the site structures comply with local community standards and with the requirements of institutions (DOE and others) involved in the program.
TAIRLE 12.4 Cost Estimate for Infra. structure Demolition

\begin{tabular}{lc} 
Item Demolished/Removed & Cost $\left(\$ 10^{3}\right)$ \\
\hline Water system & 8.5 \\
Maintenance garage & 6.0 \\
Control station & 6.0 \\
Fences & 31 \\
Fire hydrants & 2.6 \\
Guideways (2) & 1,000 \\
Roads/parking & 50 \\
Electrical power station & 5.0 \\
Total estimated cost & 1,109 \\
\hline
\end{tabular}




\section{SIMULATION OF MAGLIEV MO'TION}

\subsection{IN'TRODUC'TION}

The safety and ride-quality aspects of a high-suleed, ground-transportation system based on magnetically levitated vehicles were discussed in (haptor 10, and the various magnetic levitation, guidance, and propulsion subsystems that aro currently being evaluated or considered for maglev vehicles have been discussed elsewhore. 'The development of dynamic models is needed to predict the dynamic behovior of such a wide range of vehicle and guideway designs for a broad range of operating conditions, but existing computer simulations have been writton only for very specific designs.

The objective of the effort described in this chapter was to devolop a genoral computer code that could simulate the dynamic behavior of virtually any vehicle and guideway design under virtually any operating conditions. The following general concepts are brhind the development of the program:

- A user-friendly input package based on computer screens that permit the display/change of all necessary input data pertaining to the vohicle, magnets, and initial conditions of the system. Timo-dependent output variables are written to an output file, where they can be accessed by the user.

- The program is hased on the fourth-order Runge-Kutta method of integrating the twelve differential equations that characterize the dynamics of the vehicle. Large displacements of a rigid body in all six degrees of freedom are permitted.

- The main program passes the task of calculating the instantaneous magnetic forces to external subroutines, some of which are written by the user for his or her particular mothod of generating propulsion, levitation, yuidance, and drag forces. Similarly, time-dependent magnet. currents, the dynamics of time-dependent secondary suspensions, and the dynamic effects of wheels used for low-speed or emergency conditions are handled by other user-supplied external subroutines.

- The guideway can be assumed to contain, for example, curves, hills, surface irregularities, and a bank angle, which varies with location along the guideway, depending on a userwupplied input file. This file is used by certain subroutines to determino distances between the magnets and the guideway surfaces so that the magnetic forces can be determined.

This program originated with the program MOTION, which was devoloped at SRI Intornational in the early 1970s for analyzing a maglev test siled levitated over a continuous-shect aluminum gudeway by moans of suporconducting matgnots. 'The present 
program was initiated with the intent of modifying that program, but the changes becume extensive enough that it is an ossentially new program with much broader applicability to maglev system analyses.

\subsection{GOVEIRNING EQUATIONS}

For a translating and rotating body, it is necessary to distinguish between a coordinate system aligned with the axes of the body and one aligned with an inertial frame. The Euler angles $\psi, 0$, and $\phi$, which are the angles of heading, attack, and roll, respectively, are convenient for linking these two coordinate systems. In terms of the Euler angles, the transhational and rotational equations of motion for a rigid borly can be expressed as:

$$
\begin{gathered}
\frac{\overrightarrow{d v}}{d t}=\vec{G}+\dot{v} \times \vec{\Omega}+\frac{1}{M}\left(\vec{F}_{m}+\vec{F}_{a}+\vec{F}_{w}\right) \\
\frac{d \vec{\Omega}}{d t}=\omega^{2}+\tilde{l}^{1} \times\left(\vec{F}_{m}+\vec{F}_{a}+\vec{F}_{w}\right)
\end{gathered}
$$

where the elements of $\overrightarrow{\mathrm{G}}$ and $\vec{\omega}^{2}$ are defined by:

$$
\vec{G}=\boldsymbol{g}\left\{\begin{array}{c}
-\sin \theta \\
\cos \theta \sin \phi \\
\cos \theta \cos \phi
\end{array}\right\}
$$

$$
\dot{\omega}^{2}=\left\{\begin{array}{l}
\frac{I_{y}-I_{z}}{I_{x}} \Omega_{y} \Omega_{z} \\
\frac{I_{z} I_{x}}{I_{y}} \Omega_{z} \Omega_{x} \\
\frac{I_{x}-I_{y}}{I_{z}} \Omega_{x} \Omega_{y}
\end{array}\right\}
$$

In the above, $M$ is the mass of the vehicle; $\vec{V}$ and $\vec{\Omega}$ are the translational and rotational velocities measured along the axes of the body; $\vec{F}_{m}, \vec{F}_{a}$, and $\vec{F}_{w}$ are the magnetic, acrodynamic, and wheel forces; $\tilde{I}$ is the diagonalized moment of inertia tensor; and $\vec{F}_{m}, \vec{F}_{a}$, 
and $\vec{F}_{w}$ are the magnetic, aerodynamic, and whosel momonts acting an the vehido. 'Tho lime derivatives of the angles $\psi$, 9 , and $\phi$ are related to the rotutionul volocitios by:

$$
\begin{gathered}
\vec{R}_{\text {linertal }}=\left\langle l_{v}\right\rangle \cdot \vec{R}_{\text {hroxty }} \\
\frac{d \psi}{d t}=\sec \theta\left(\Omega_{z} \cos \phi+\Omega_{y} \sin \phi\right) \\
\frac{d \theta}{d t}=\Omega_{y} \cos \phi-\Omega_{z} \sin \phi
\end{gathered}
$$

A vector $\overrightarrow{\mathbf{R}}_{\text {pody }}$ on the body is related to a vectorr $\overrightarrow{\mathbf{R}}_{\text {duestial }}$ in the inertial reference by the transformation:

$$
\frac{d \phi}{d t}=\Omega_{x}+\tan \theta\left(\Omega_{x} \cos \phi+\Omega_{y} \sin \phi\right)
$$

with the transformation matrix given by:

$$
\left\{l_{v}\right\}=\left\{\begin{array}{ccc}
\cos \theta \cos \psi & \sin \psi \cos \phi & \sin \psi \sin \phi \\
& +\cos \psi \sin \theta \sin \phi & +\cos \psi \sin \theta \cos \phi \\
\cos \theta \sin \psi & \cos \psi \cos \phi & -\cos \psi \sin \phi \\
+\sin \psi \sin \theta \sin \phi & +\sin \psi \sin \theta \cos \phi \\
\sin \theta & \cos \theta \sin \phi & \cos \theta \cos \phi
\end{array}\right\}
$$

This transformation is required to convert forces from ono coordinate to the other, because the applied forces depend on the distances between tho vehicle and the guidoway surfaces, hut all compononts of the forcess and moments in the equations of motion aro to be expressed along the axes of the vehicle.

The variables $V_{x}, V_{y}, V_{z}, \Omega_{x}, \Omega_{y}, \psi, 0$, and $\phi$, as woll at the location of the conten of mass relative to an inertial reference point, are taken as the state variables, and theso lwolvo quantities (together with their derivatives) are cevaluated and stored in a data filo hy the progriar.

\subsection{PROGRAM SEQUENCE}

All calculations are carried out in varous subroutines. 'The main program contains the logeic to call the subroutines, which, in turn, inpul and oulput datal calculate dynamic foreres, and integrate the twolve differential ecpuations. 'The advantage of this concept is that. 


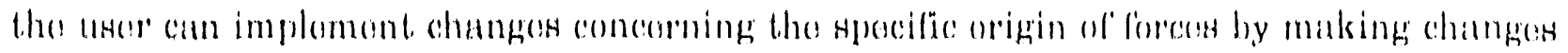
only lo tho appropriater subroulino.

'The program seguonco is shown in Figure 13.1. INPU'I and PARAM aro first callod

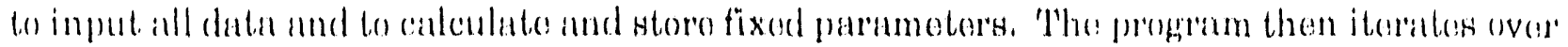

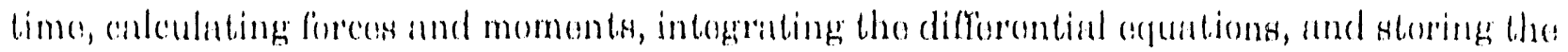
renultis in an output filus.

Bocuuse the calculation of magnotic forces and moments is so important and complicatod, a specific culculating sequence is introduced in the subroutino MAGli'. 'I'he details of this sequence aro shown in Figuro 13.2. First, MAGis initializes all foress and momonts to zero, and it thon iteratos over the number of magnets (up to 40 magnets aro fremitted). During each iteration, MAGF calls CURREN'T(N) if the current of the Nth magnet changes with time; if there is a socondary suspension associated with the Nth magnot, MAGF calls tho subroutine SLCONDF(N) to generate the secondary suspension forece. Next, MAGF calls subroutines MAGP(N), MAGL(N), MAGG(N), and MAGD(N), if the Nth magnet gonorates a propulsion, levitation, guidance, or drag force. These forcos are calculated in a coordinalo system aligned with the guideway, the distances between the magnets and guideway having boen provided by the subroutine TRACK for oach timo step. Finally, MACiF transforms the individual magnet forces from guideway to vehicle coordinates (1) obtain the total magnetic forcos and moments acting on the vehicle.

\subsection{GAMPLE SIMUIAATIONS}

'To varify tho grogram, a number of rums have been carried out for certain trick profiles and vehicle data. Results for a shaped guideway and a gradeway with a step are described in this section.

\subsubsection{Shaped Guideway}

'T'o test the program over a roalistic guideway, one with a curve and a hill was assumed (see Figure 13.3). The curve begins at $\mathrm{x}=75 \mathrm{~m}$, where $\mathrm{x}$ is the distance along the track from an initial reference point and extonds $1 \mathrm{~m}$ (the $y$ dimension) before roturning to

zero. Note that the hill is assumed to begin at $\mathrm{x}=150 \mathrm{~m}$ and roaches an elevation of $1 \mathrm{~m}$ (the a dimension) at, $\mathrm{x}=300 \mathrm{~m}$.

'Typical results of the simulation for a hypothetical vehicle aro shown in Figures 13.4 and 13.5. Figure 13.4 shows that the vertical (heave) motion of vehicle smoothly follows the guideway mofile going up the hill. Figure 13.5 shows the lateral (slip) motion of the vehicle, and from this curve, it is apparent that an insufficient amount of lateral damping was assumed. 


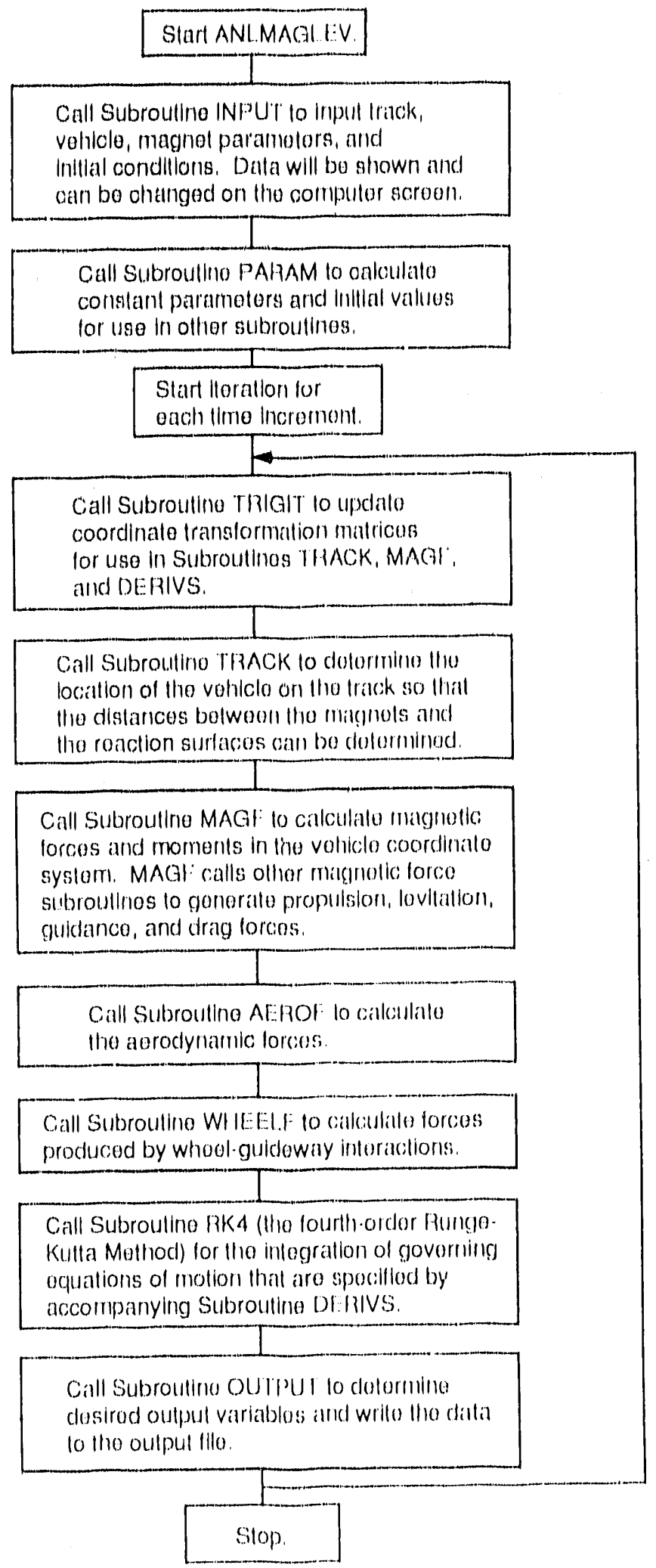

\section{FIGURE 13.1 Block Dingrinm of Progrnm ANI,MAGIJIS}




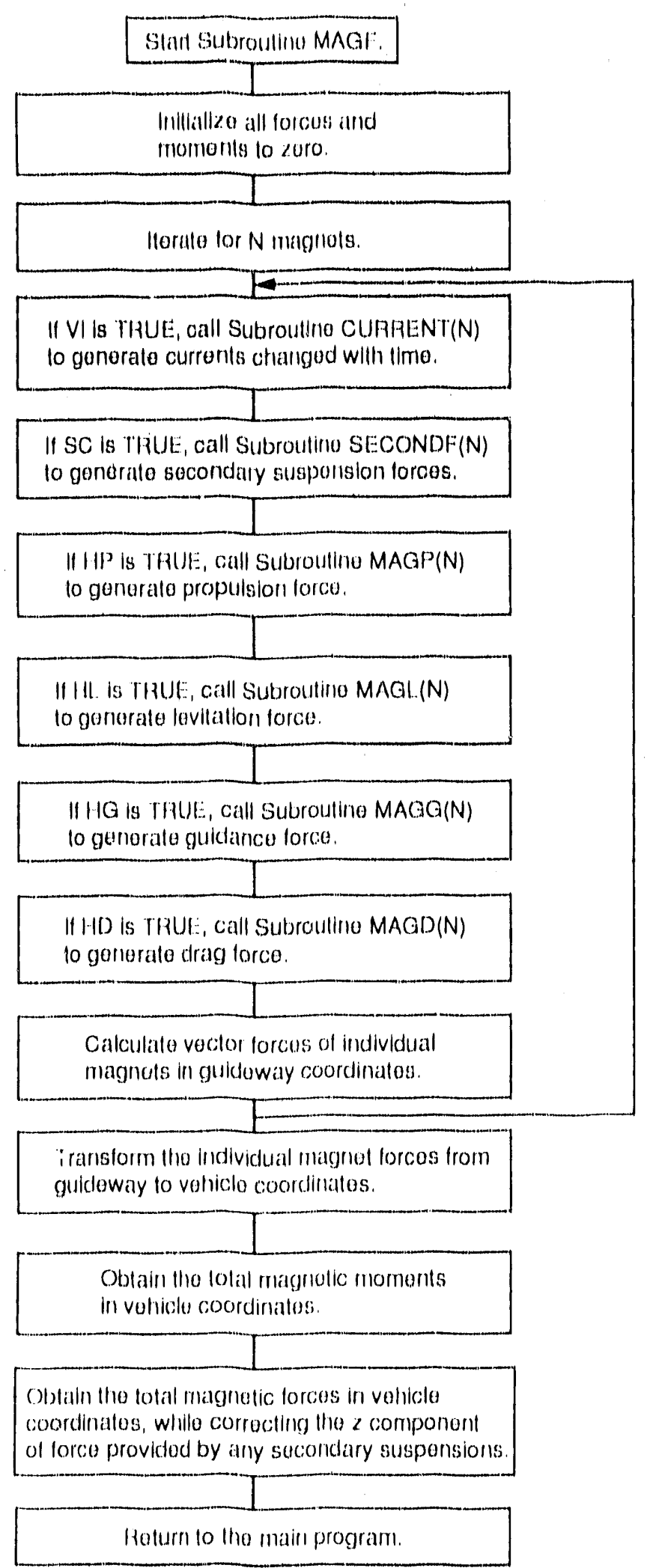

Wl(iURE 13.2 IBlock Diagram of Subroutine MACF 

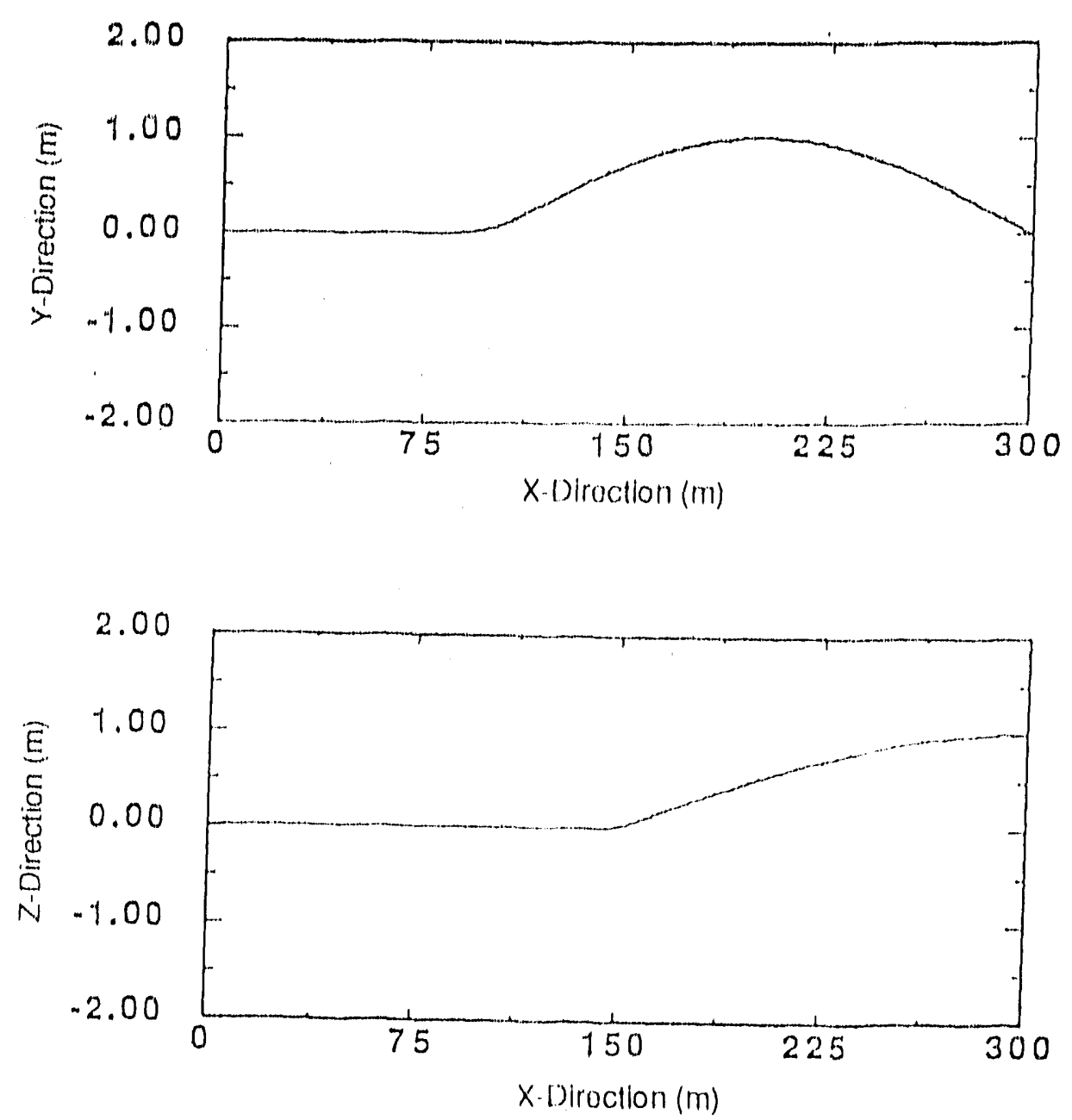

\section{FIGURE 13.3 Curved Guideway}

\section{1 .2 Guideway with a Stop}

A test case was investigated to comparo tho thoorotical rosults of this program with the atcual test results (as woll as with the thenretical results obtained with MO'IION, a similar program devoloped and vorified by Stanfond Research Institute). I'he comparison was batsed on test run \#34 of SRI's magnetically levitated vehicle, which incorporated an active: dimping system. Halfway down the track, 1.9-cm-thick aluminum plates were placed on top of the standarl aluminum sheot guideway to produce a vortical symmeteical stop in tho gruideway. The actual profile of the left and right sides of the gruideway are shown in Figure 13.6\%

The results of the lest case are shown in Figures 13.7 and li3.8. Simulation results

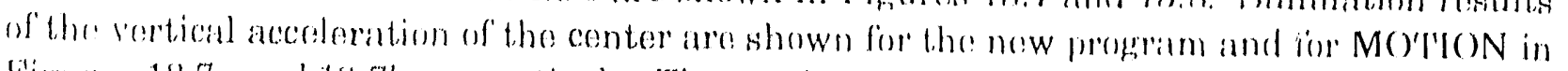

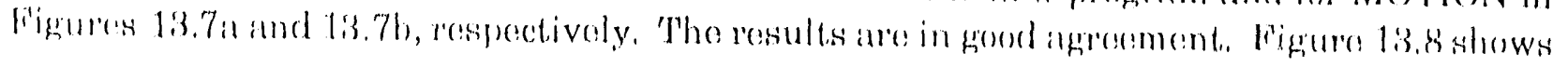




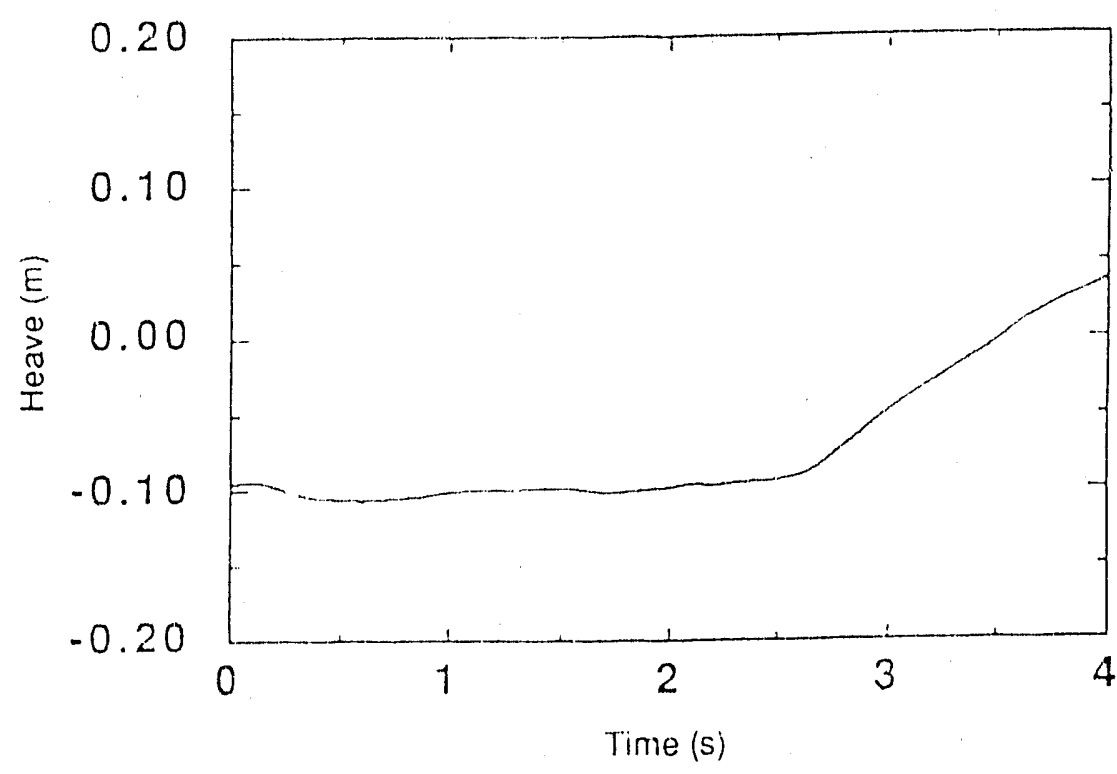

FIGURE 13.4 Heave Motion with Hilly Guideway

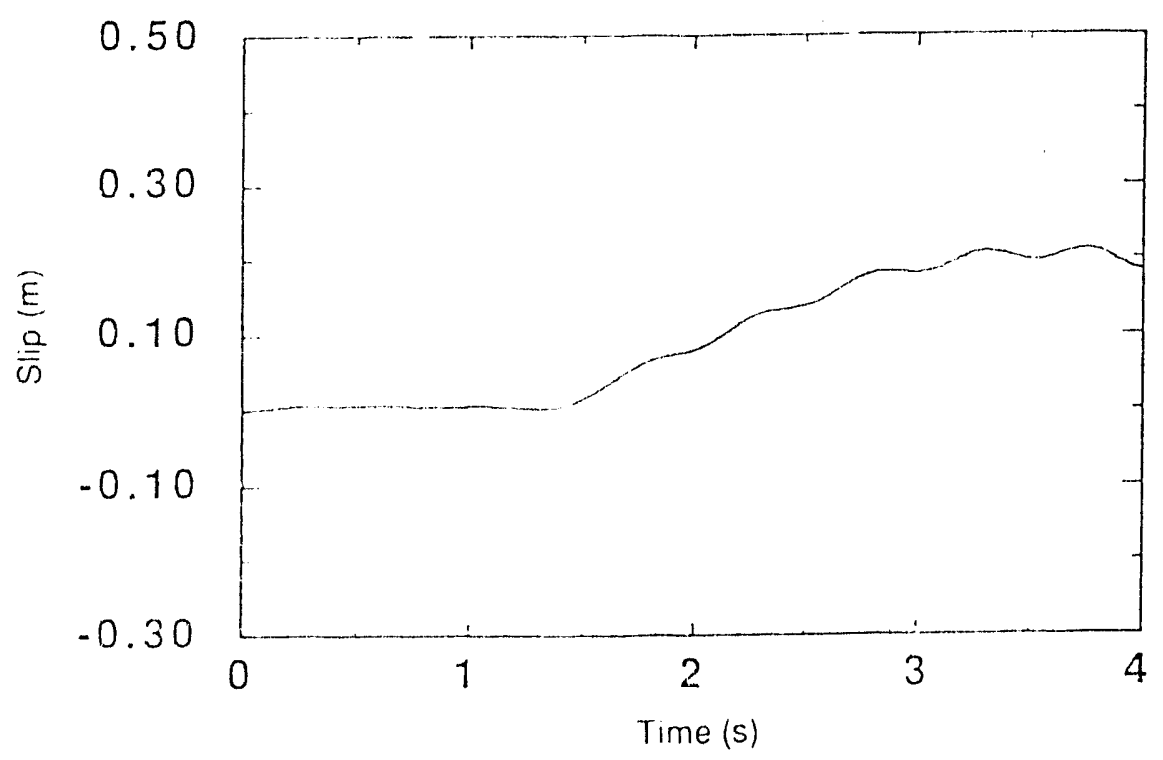

FIGURE 13.5 Slip Motion with Curved Guideway

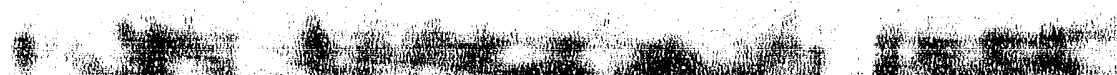



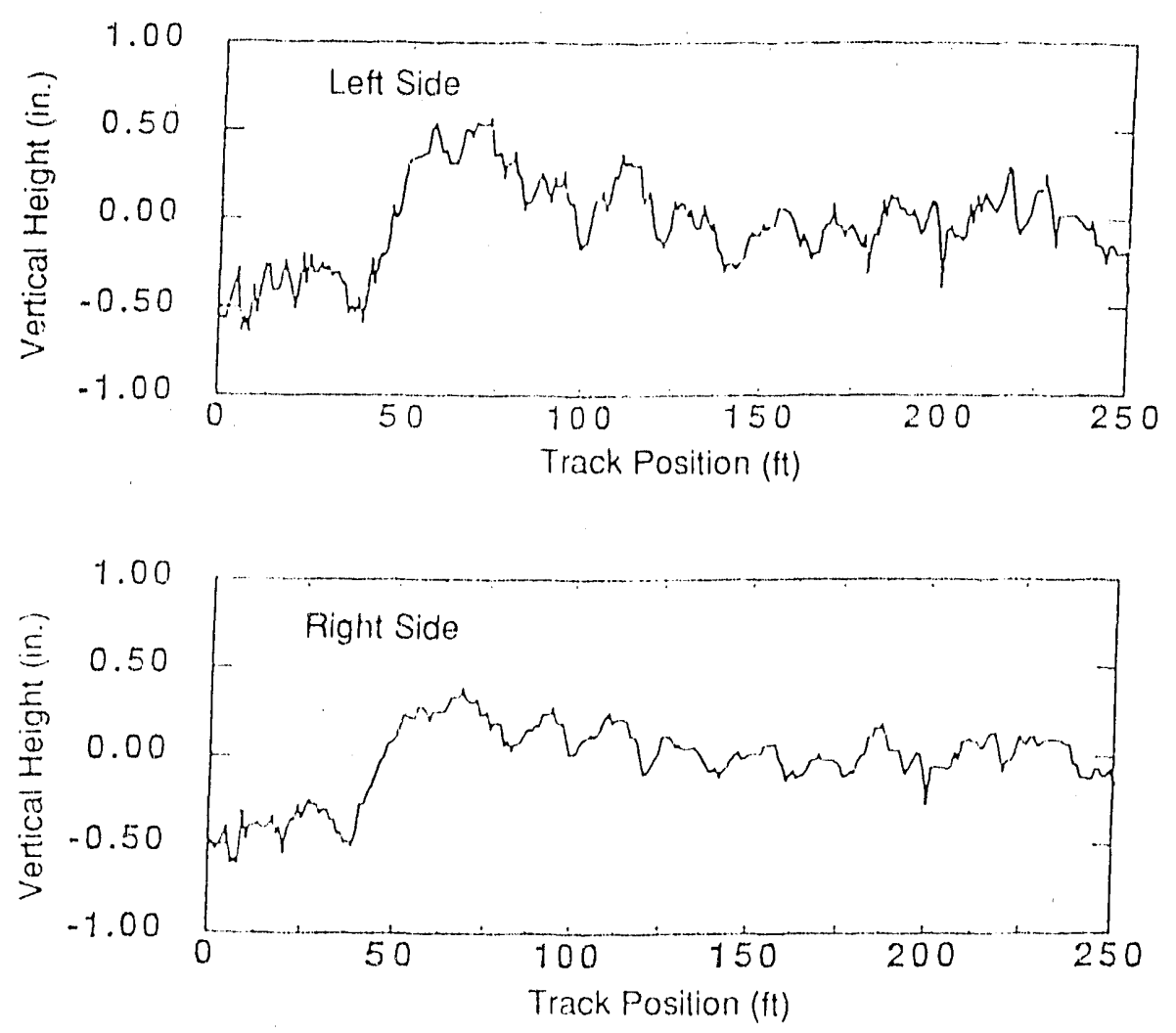

FIGURE 13.6 Vertical Profile of the Test Guideway

the rosults of heave motion; the test data ar: shown in Figure 13.8c. The effects of the symmetrical step can clearly be observed in both simulations and in the experimental data. The new program appears to correlate better with the test data than does MOTION. Nonetheless, a high degree of correlation is lacking. The lack of a high degree of correlation is attributable to inaccurate information on the initial conditions of the vehicle or inaccurate equations for calculating the magnetic forces near a vortical step in the guideray.

\subsection{CONCLUSIONS}

A computer code has been developed to provide a simulation of the nonlineil" dynamics of a magnetically levitated vehicle following a realistic snuideway. Examples of simulations show that the program works well and can be used to simulate a wide range of conditions. However, certain operating conditions (such as time-dependent currents and secondary suspensions) have yet to be validated, and further work is needed to accurately predict magnetic forces associated with various maglev designs. 


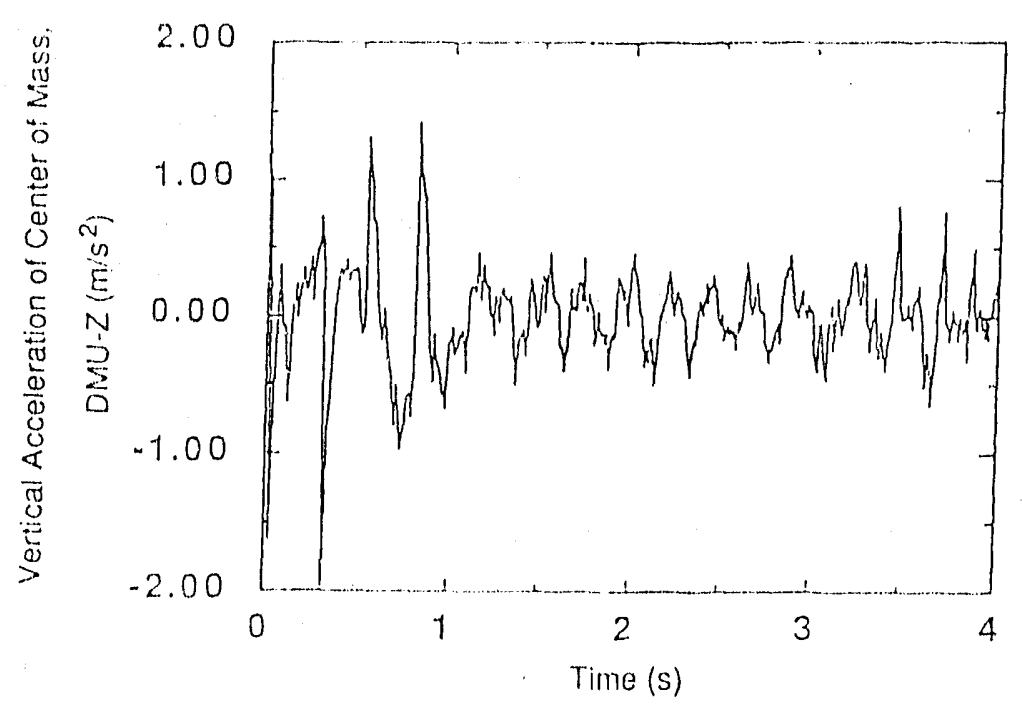

(a) BY ANLMA.GLEV

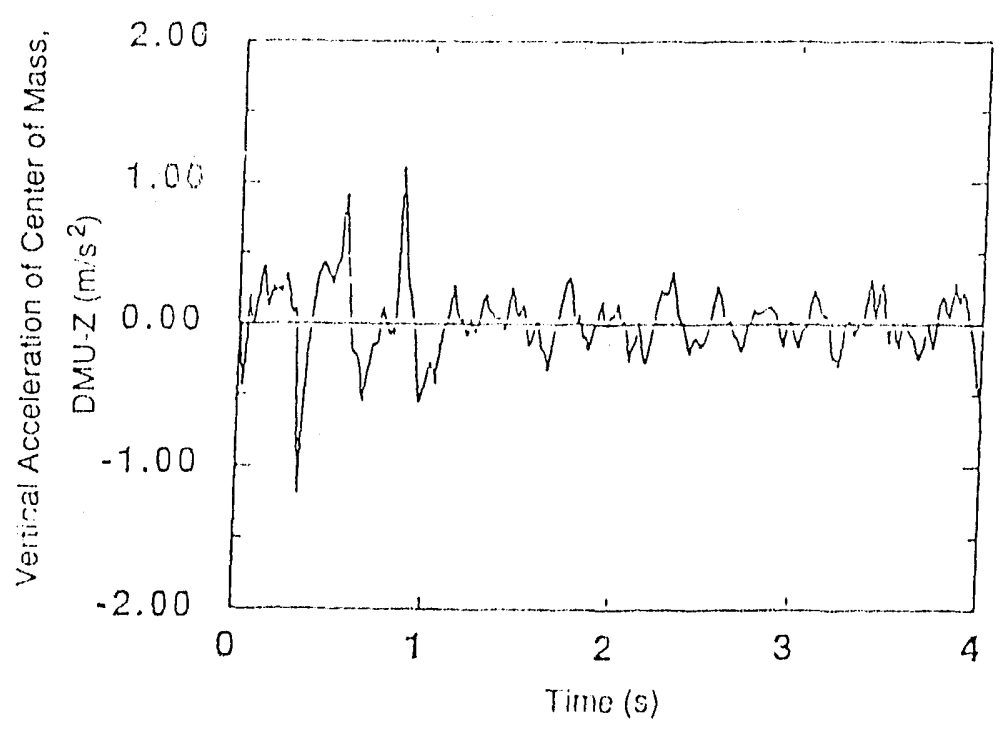

(b) By MOTION

FIGURE 13.7 Simulated Vertical Acceleration of the Center of Mass 


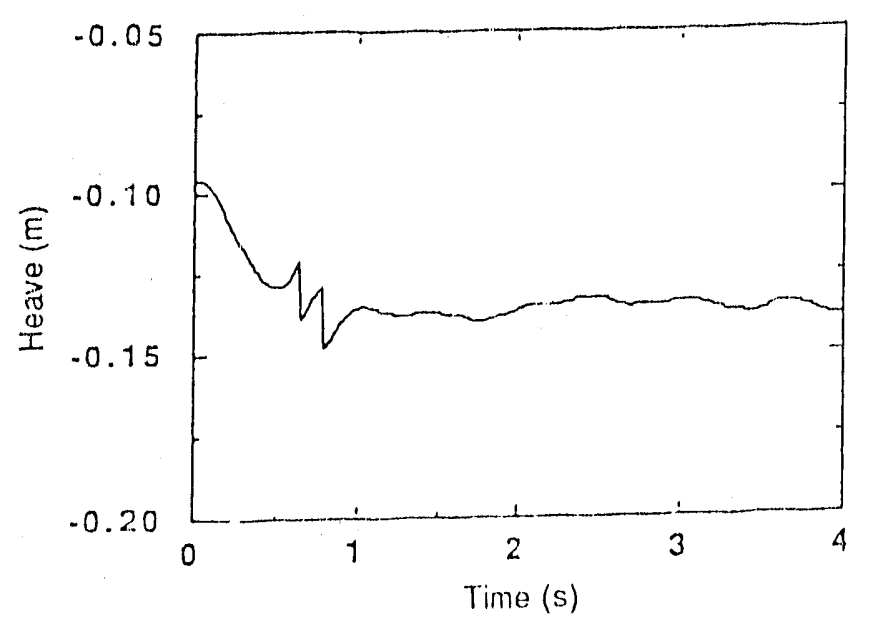

(a) Simulated by ANLMAGLEV

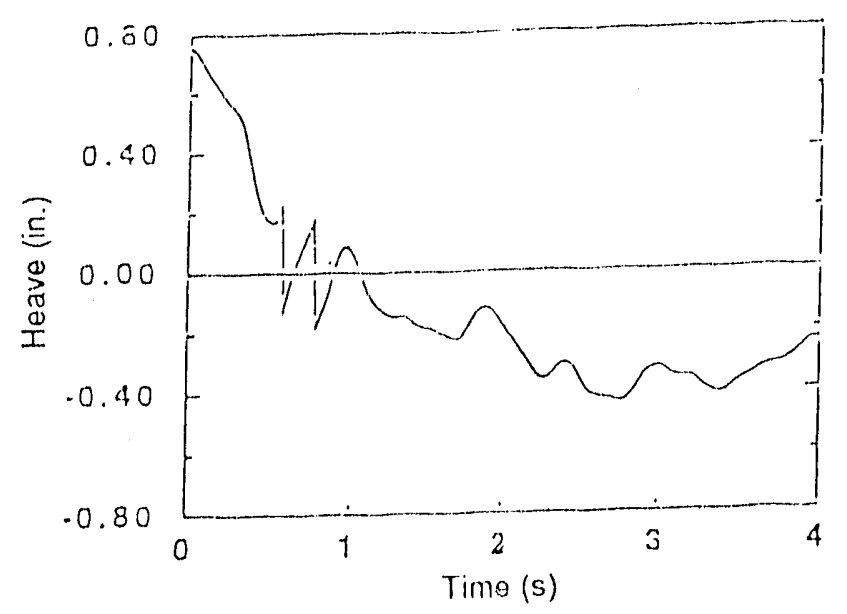

(b) Simulated by MOTION

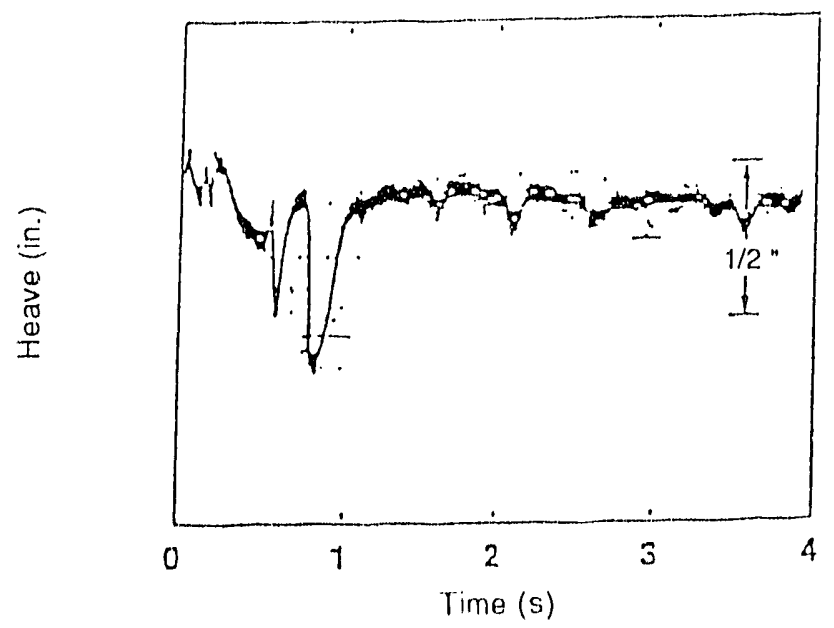

(c) Experimental Measurement

FIGURE 13.8 Simulated and Measured Heave Motion 


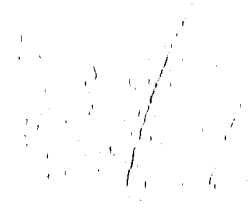

\section{APPENDIX}

\section{SUMMARY OF ILLINOIS MAGLEV DESIGN CONFEIRENCE,} HELD A'T ARGONNE NATIONAL I ABBORATORY, NOVEMBER 28-29, 1990 


\section{APPENDIX: \\ SUMMARY OF ILILINOIS MAGLNV DESIGN CONWEIRWNCE, HELD A'T ARGONNE NA'TIONAL IAABORA'TORY, NOVEMBER 28-29, 1990}

\section{A.1 BACKGROUND}

\section{A.1.1 Illinois Program}

This program was undertaken to design and establisly a national user facility for the development of magnetic-levitation technologies. It is funded as a "Challenge Grant" hy the Illinois Department of Commerce and Community Affairs, Office of'Technology Advancement and Development. The program complements other efforts on magnetic levitation that are in progress at Argonne National Laboratory and funded by other sourees. The total program spans activities from basic research on the interaction forces of moving magnots over conducting surfaces to the proposal for an experimental test facility.

Although there is little current effort on magnetic levitation in the United States, efforts have been under way for two decades in Gormany where the Transrapid system, which uses the attractive force between magnets, is being developed, and in Japan whore the electrorlynamic system, which uses the repulsive forces botween mannets, is being developed. Theso systems are discussed elsewhere in tho body of this report. It is noted that a National Maglev Initiative has been formed cooperatively between the Departmonts of Transportation and Energy and the U.S. Army Corps of Engineers to evaluate these technologies and to recommend a national maglev strategy. One possiblo recommendation would be that the United States undertake the development of an entirely new maglev system. if that option is selected, test facilities for developing the tochnology will be required.

The proposed facility is intended to be a national user facility available to governmental, industrial and academic institutions soeking to develop magnetically levitated high-speed ground transportation systems in the I nited States. The facility will be available on a nonproprietary basis at no cost to the user, provided that the results obtained are made available to the public. The facilities can be used for proprietary research and development if the user pays the "full recovery cost" of the facility. Schedules for the use of typical user facilities at ANL are determined by a user committee.

The availability of a test facility is expected to promote the ovaluation of marglev concepts by investigators who, faced with the exponse of such a facility to test their concepti, would not otherwise participate. The facility will provide the opportunity to small businesses to participate in the development of maglev systems or compononts.

The facility's only purpose is to develop technologies for the magnetically levitated high-sipeed gro.nd transportation of passengers and time-sensitive freight. Consecpuently, it was folt that the first step in designing the facility was to costablish the broad 
characteristics of the operational system as onvisioned by potential builders and aser's of the system. These charactonistics would be used as a guide to the experiments that must. bo performed with the facility and those in turn would govern the design of the facility. It was for this purpose that about forty experts in transportation and maglev technologies assembled for this conforence. 'The participants included members of the National Magles Initiative. 'The "strawman" design included here was plesented to participants to stimulate discussion. 'Ihis design should not be construed as a design approved by consensus. Many of the specifications in the strawman dosign wero discussed (and eliminated) in the conference; other topics were not addressed.

The conference was loosely structured, functioning as a kind of "brainstorming" session. The pace was fast. Tho summary given here was assembled from comments on particular topics that were made over the two-day period. We are deeply appreciative of the time and effort the conforees devoted to this program. A list of participants is included herein.

\section{A.1.2 Systems undor Development}

As stated above, there is little technical maglev work under way in the United States, but studies of tho systems now under development have been included in the transportation planning and analysis of several states and entities. Among these are the Las Vegas-Anaheim study, the 'lexas High-Speed Rail study, a study by the Florida HighSpeed Rail Commission, a New York State study, and the Tri-State High-Speed Rail study. Contributors to the latter two studies participated in this conference.

Words that are shown in italics in the text refer to related sections of the design report that can bo consulted for information on these topics.

\section{A.2 SYSTEM CONSIDERATIONS}

\section{A.2.1 Aerodynamics - Power and Noise}

The aerodynamic design of a maglev system is important, since at sufficiently high speeds aerodynamic drag is the primary source of drag and therefore of electrical power requirements. This drag is a function of the shape and frontal area of the vehicle, the vehicle length, and the proximity of the vehicle to the guideway.

Aerodynamic loads occur both in the direction of motion of the vehicle and on the vehicle's sides. 'The datter loads can be significant, since the side of a long vehicle has a much larger area presented to the wind and is less streamlined. The side wind loads from this source might be greater than centrifugal forces in turns. 'These forces must be compensated by the guidance forces of the suspension system. Unlike the case for airplanes, compensation cannot be achieved by pointing the vehiclo into the wind. The importance of these side wind loads can bo reduced by using shorter but wider vehicles. Using wider vehicles, however, 
requires that tunnels through which the vohiches pass he wider. 'This could proclude using many existing tumnels. Aerodynamic loads are also caused by passing vohicles.

Aerodynamic noise from the vehicle will be the major sourco of noise, since these vehicles have no moving parts and will not touch the puideway. In judging the severity of these limitations, it is important to note that the vehicles will travel at high speeds only outsicle the cities. In or near cities, their speeds will be reduced (for slowing them to a stop) or accelerating them to reenter the system), and the aerodynamic noise from the body of the vehirle will be less.

The aerodynamic drag is also a consideration in designing the guideway, since structures constructed to protect the gaideway from dobris will increase tho acrodynamic: drag. The need for such structures can be reducod by olevating the guideway. Since some parts of the guideway will be elevated to significunt heights, the offects of acrodynamic londs on the guideway structure must be evaluated. 'This consideration appears to be capable of evaluation by standard engineering practices, but questions of passonger comfort might, renain. It might be necessary tu evaluate those factors experimentially.

Tunnels present a unique aerodynamic problem at maglov operational speeds. 'Tho major portion of the new test facility in the Yamanashi Prefocture of Japan will bo in tumnels. It was noted that a simulation might be possible with the tost facility by using a culvert or clamshell type of structure that surpounded the guideway. No analysis of the adcuacy of such an approach has been mads.

\section{A.2.2 Accelerations}

Accelerations are usually considereci in the sense of oporational accelerations affecting the speed of the vehicle and the comfort of the passengers. In the strawman design, these normal, operational accelerations woro taken to bo 0.15 to $0.20 \mathrm{~g}$ 's. Lateral and vertical accelerations of $0.03 \mathrm{~g}$ 's were suggestel. Commercial aircraft accelerate at 0.20 to $0.25 \mathrm{~g}$ 's. STOL aircraft accelerate at up to $0.40 \mathrm{~g}$ 's. It was suggested that for economy of the right-ofway, some curves might have to be taken at higher than ordinary accelerations and that at these times, which could be anticipated and announced in advance, assengers would be seated and belted. Eriergency stopping was recognized as a problem that probably will require the design acceleration to be higher. With lower accelerations, it was recognized that turnouts would have to be longer at station stops and that the headuay between vehicles would increase. It was noted that if the stops aro infrequent, the question of passongers stand ag to prepare to depart the vehicle is of little concen, sinco the time they require will be but a small increment of the overall trip. The same number of passengers cam be tratroported in a single train having a long hearlway or in several discrete volicles traveling with shorter headways. Trains might increase the comfort of the passengers on board, while the use of discrete veliceles would provide more frefuent service. (Ono problem is that vohicles and trains must stop short of any accidents occurring ahead of them, whoreas airplanes can manouver to avoid accidents.) Uranticipated changes in accoloration (jerk) aro

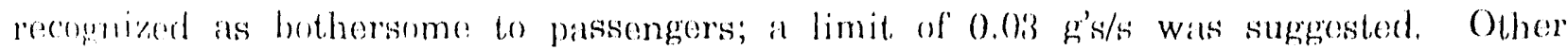




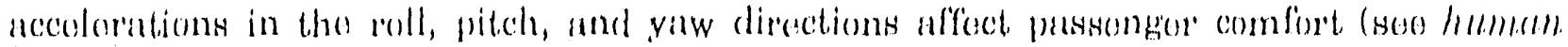
factors) and possibly equipment cong, liquid halium in the cryostats combining

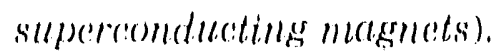

\section{A.2.3 Air: 'Travol}

In ovaluating the potential demand for maglev corridors on the bass of air-truvel datia, it is important to note that a major part of the traffic between two terminals can bo for through passengers, rather than for passengers with their origins and destinations in these terminals. It was printed out that in the (hicago-Detroit corridor thore are three timos as many passengors passing through as there are passengers having these citios as their origins or destinations. It is important to look not at the traffic between two cities, but rathor at the traffic between all city pairs using this leg of the trip. In large motropolitan areas, several airports might be locatod in the vicinity of the origin or destination airport, and much of this travel might be diverted to a single maglev line.

\section{A.2.4 Automobile 'Traffic:}

Tho enormity of automobile traffic compared with airline traffic was noted, but it was concluded that it would be very difficult to capture a significant portion of this traffic for maglev, since people ignore the sunk capital cost of their automobile and consider only the variable costs in evaluating the expense of travel. Businesses do recognize the true cost of operating an automobile. Although diverted automobile traffic might provide incremontal revenue at low additional costs, it was not regarded as a major market for the maglev industry.

\section{A.2.5 Baggage}

Baggage must be expected for intercity passengers. Loading and unloading will not be a problem if the platform is elevated to tho height of the vehicle floor. It was felt that usual baggage can bo handled with the recommended one-minute station stops.

\section{A.2.6 Belts}

Seat belts will be required if the planned maximum decoleration is such that the safety of the passengers would be compromised during an emergency stop, fior these belts to be effective, an attendant will be refuired on board. TeiV, which accelerates slowly, does not have seat belts, permits standing at all timos, and is composed of multiple cars departing at relatively long intervals. T'ransmapid was said not to require seat belts at speeds of 220-230 mph. Bolts aro used in the dapanese exporimental system. 


\section{A.2.7 Caproity/Demand - Operations}

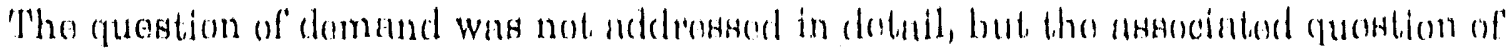

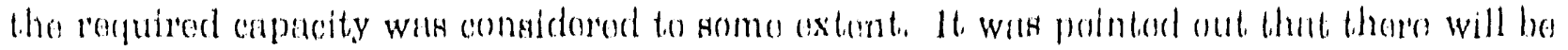
approciable variation in domand, with many hoors of tho wook whon tho vohichos will bo

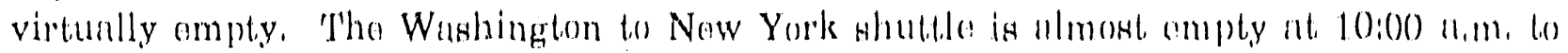

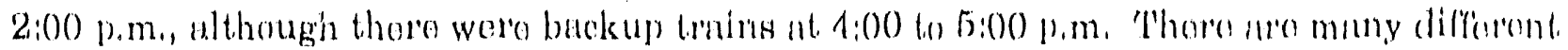

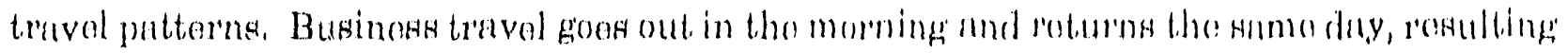
in morning and ovening powk, with tho ovoning ponk boing grontor, (othors will ho positioning themselves for the next morning. Studont domand is chandotorizad by travol out on Friday night and returning on Sundav night. Vachtion pataens poak anound hondays and summor months. Ordinary travel ponks when pricing is hotion, mas neg it probably the only market subject to demand pricing. There will ho huge peaks on Firday night and sunduy night. Tho anulysis starts with the peaks and valloys and how lhoy ande going bo bo handled,

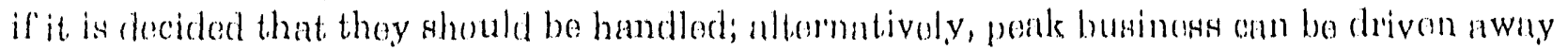
to Amtrik, as the airlines do (especially in tho Nordhonst corriclor). Many studios havo boon made for transit purposes that turned out lo bo wildly erromoous.

It whe considered fruthess to considen the dotalled intermediato stops of the system, since those decisions will be political decisions if foderal funds ane involvod. If laft to

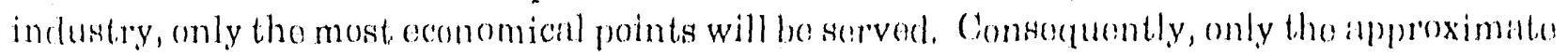
capacity required and the ability to adjust this to difforent corridors and to lator timos whon demand will increase can be considered.

Power for trains as well as for individual cars is available, at least in tho Midwost, so expansion of capacity by stating with vohicles and lateg using tratins is fousiblo from this point of viow. 'The cost of building the civil structures for uso by lwo couplod vohiceles is mobably about $25 \%$ more than for fliscroto vehiclos, unlose train-dynamice considorations ariso that recpuire a significant redesign. Ising two- of throe-car units with tho Hamo headway as one volicle would double or triple the capacity of the system. 'The cost of the installed powor' and the cost of the propulsion system will increase, however. The suggention was maldo that. the civil structure should be designed for the heaviest, londs expected.

There is a question as to tho desirability of incorporating too much capacily intor ono: guideway, since an accident on the system would he moro disruplivo to transportation in the: corridor. At some point it will be desirahle to huild a second guadeway that would avoid lhis moblem and could also provido tomsportation services alongr a slightly difforent. route,

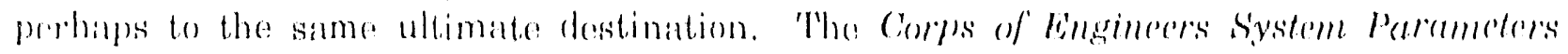
recommends that cross-overs le provided on a two-tway system to pormit limited operations if one direction of the gudedeway is hocked for any reatson. 'Tho system dosigned must he naiblite in all parts of the comatry. 


\section{A.2.8 Commutor's}

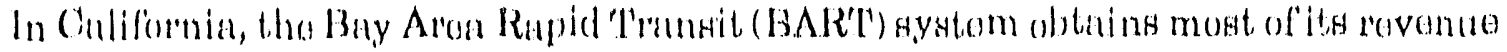

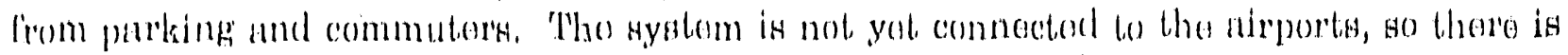

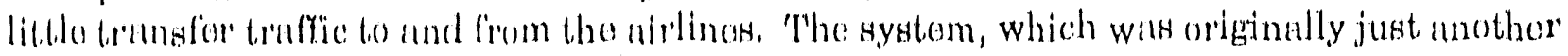

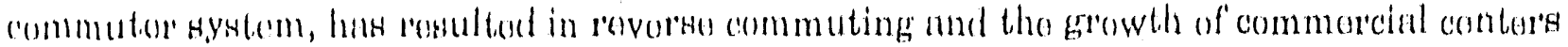
around tho buy aren. Gommuting to Gonten Gosta Gounty is standing roum only, morning and oveniag. 'Tho addition of' the next, 40 miles to the system will result in a grontly incrensed rovorts commuto, 'I'ho absence of purking facilities around the Washington, D.C., melen was called the Achillos' heol of the systom.

On long Inland, in Now York, a magley system is seon by some ats offering a substintial bonofit, to commutors if it travols at only $120 \mathrm{mph}$, providing 45 -minute commuling time from Riverside to Now York City, compared with a two and one-half hour commulo by Long laland Railway. It was montioned that the 'TGV now provides a 42-minute commuto lor passongors in a bodroom comrrunity that was two and one-half hours from Paris liy inutomobilo.

\section{A.2.s) Control - On-Board Porsonnol}

'Lhe stritwman design called for contral control of the system, but it was observed What there needs to be a central supervisory system and a lot of distributed local control activitios, Reliance camnot bo placed on a bingle point for control. A pyramid approach to control would bo employed, in which a vohicle entering a sector activates the sector and takes over preominent control of that soctor and downstream sectors of tho system. Messages from this system would be sent back up to the central control activity. The train would be made to trivel at a speed determined hy the voltage and frequency of the propulsion system. That speed command would be a function of two levels, one of interklock relationships and then " larger integration of multiple blocks. Thore are two controls. One is the control of the velhicke, and tho other is the control of the system, and these can he broken up).

Tho cuestion of whether a pilot, monitor, or cabin attendant will be on board and whethor such pertons would have any authority or capability to participate in the control of the system was discusserl. Such persons would be recuired to observe and aid passengers, hut (heing the slowost pint of the system), they would probably not have an operational function. 'Thore wats not unanimity on this lattor proint; some participants suggested that the onboard personnel could intercedo but that tho way they interceded would immediately be mblyed to the central control system, which would then adjust the balance of the system. Others folt that it will ho psychologically necessary to have employees on board but that their function would bo evolutionary, like that of operators on elovator:s. It was agreed that antomatic operation will he resuired in eithen avent.

'The San Paule motro system moves 4.5 million people per day at 50 mph and 3(1)-second headways with no oporator. 'lhis system has boon in service for 19 years and had its lirst dernilmont in a tunnol, with three fatalities, just in the last soveral months. 
Vancouvor operates trains without operators. 'There are two matroads in the U.S, with no one on bond: the Black Mosn and Lake Powoll, conl-tompower-plant railroad, which is aboul.

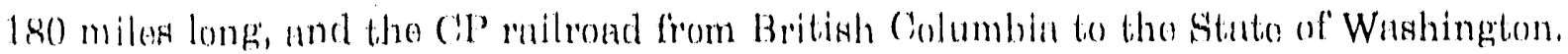

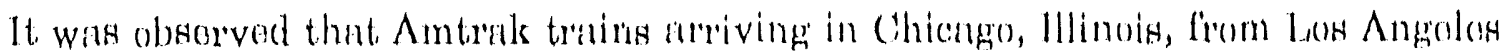

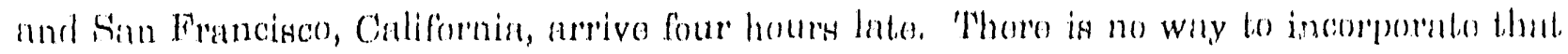
t.ypo of systom into an automated system of the l.ypo discussorl.

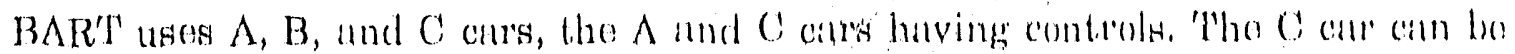
introduced during the day to increase capucity without going buck lo tho yard.

\section{A.2.10 Costs}

Gosts were addressed in many difforont contoxts and onn only bo addrossed as itoms, since thore was no foctsed discussion.

It is generally acknowlodged that the guideway is the most. costly portion of the system, but the cost is divided into tho cost of land, tho costs of the foundations and piors, the costs of the spans, and the costs of the propulsion and levitation equipmont installod on the guldeway. These costs oan vary, doponding on the design of the systom. 'The thransuruid systom is expected to cost almost. \$20 million por milo for a completo two-way systom, oxcluding land. In the Tris.state High-Spoed Rail program, the cost of roul proporty was rogarded as a minor part of the systom, while on Long lstand, the cost of land was regarded as so expensive as to probably bo prohibitive, unless necoss to an oxisting right-of-way, such as the interstite highways, is permitted.

For roference, the cost of a four lano interstate highway in Iluntsville, Alabuma, is ahout, $\$ 7.5 \mathrm{mill}$ ion/mile total. Renovation of $1-80$ in Now Jersoy is costing about $\$ 8-10$ million/mile, and in urban areas, the cost for now construction can reach $\$ 50$ million/milo or mor's.

The Transrapid systom is installed so procisely that a smooth rido is implicit in tho installation of the guideway. The Japanose systom should be moro tolorant of imporfections and therefore less expensive.

'The problom with a vehicle traveling at 5 miles nor minute (330) mphl) with a two-minute headway is that it has 10 miles of guidoway atsociated with it that must he amortized. If tho guideway costs $\$ 15$ million por milo, the vohiclo must amortize and maintain itsolf plus \$150 million of guideway, He seems oconomical to provido additional technolory in the vehicle and increase its cost if this technology will permit the vehiche lo lavel comfortably and safoly over a less axpensive guadowny.

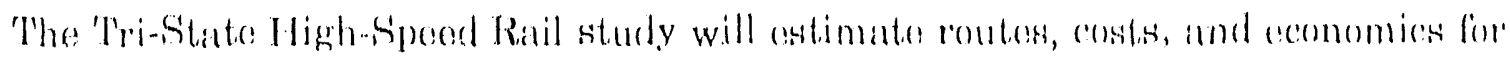

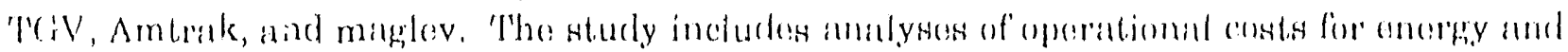

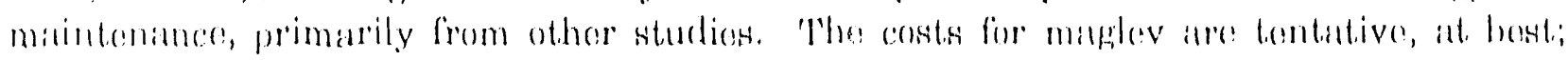

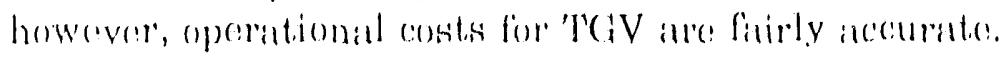


Aluminum sheet guideways were regarded as being less expensive than aluminum coil guideways, but there might be other problems (such as incorporating a propulsion system).

The cost of power has been the most rapidly escalating cost of the BART system. Maintenance cost is an important consideration.

The cost for a full-scale evaluation of a revenue maglev system on a 15-to-30-mile guideway might be $\$ 450$ million. The experimental facility being studied here is expected to cost perhaps $\$ 15$ million. A $\$ 1$ billion development cost could be financed by a gasoline tax of 0.1 cents per gallon over the development period.

The cost of coils in the guideway is expected to be more expensive if they are made rigid. One suggestion for coils in a U.S. system is to make the coils less rigid and less expensive.

Except for the cost of the Embarcadero station (which was not in the original plan), BART did not attempt to cover costs through the increased value of land. In Los Angeles, special benefit districts were formed around the stations. Lines were drawn around the city, and the tax increments that came from the districts paid for the stations.

\section{A.2.11 Earthquakes}

The California earthquake of October 1989 caused virtually no damage to the operating Bay Area Rapid Transit (BART) system. It was noted that passengers in the transbay tube, the most sensitive structure in the system, did not know there had been an earthquake until they came out of the tube. Overhead structures were constructed on substantial footings and were also built on pilings. They suffered no damage and required no realignment. After the earthquake, a rolling check was made of the system to inspect for damage, after which the system was restarted at full capacity. It was suggested that conservative earthquake standards be applied nationally. The incremental cost of including these more stringent standards was not available. Obviously, the cost of not including them could have been substantial. No comparable information was available for the Transrapid system. The Japanese were said to have inserted offsets of several tens of millimeters in their test system to evaluate the effects of displacements in the maglev guideway, and the Japanese high-speed Shinkansen train was said to automatically shut down if an earthquake was sensed. Of more than 100 earthquakes, only one was suspected to have shifted the track alignment.

People responsible for funding large projects are not generally receptive to incorporating features designed for a contingency that might never occur. One of the best investments made in BART was the conservative engineering that preserved its structures, whereas a structure like the freeway in San Francisco was ultimately torn down rather than repaired. 


\section{A.2.12 Freight}

The transportation of time-sensitive freight and mail was projected to be a good source of revenue for maglev systems. Such freight would be of high value, much like that transported by express companies. The freight could be carried during the day (while passengers are carried) or in specialized containers that can be transferred to airfreight airplanes.

\section{A.2.13 Grades}

The Tri-State High-Speed Rail project used a maximum grade of $3 \%$ for TGV and maglev in its study. The Transrapid system claims a grade capability of $10 \%$.

\section{A.2.14 Handicapped}

Seating and entryways for handicapped persons must be provided. 'The use of platforms at the vehicle floor height was considered adequate for the needs of handicapped persons. If handicapped passengers are provided special seating near doorways, the aisleways will not have to be widened beyond the width required for other passengers (see velicle).

\section{A.2.15 Human Factors}

The ride quality of a maglev vehicle is one of the prime considerations in a system design. The objective of an innovative design is to attain a safe, comfurtable ride while minimizing the cost of the overall system (sce Rishts-of-Way). This objective will most likely be achieved by incorporating technology in the vehicle that permits the vehicle to ride comfortably over an inexpensive guideway.

Many human factors are not well-known, however, and must be established in order to determine the design criteria. Among these criteria are the assessment of the visual impact of traveling at high speeds and at relatively low heights while rounding curves with the vehicle in a bank and topping hills with the resultant negative g-forces. These effects cannot be adequately simulated in existing aircraft simulators. The vehicle will not fly like an airplane in which passengers are seated and belted while the airplane takes off; and when an aircraft reaches a cruising altitude, passengers can move around the cabin before finally strapping themselves in for the landing. There will be variations in speed and curves that might be uncomfortable for some passengers. It was noted that pilots can get sick when they do not feel the motion but see it on the simulator. The flicker of objects passing at high speeds has been speculated to be a problem, but it was noted that this does not seem to be a problem because passengers focus on more distant objects. In England, where the rights-ofway are narrow, the problem was said to be more pronounced, but minor in comparison with the effect of being startled by abrupt changes. 
In the rail industry, perturbed tracks with the maximum deviations permitted by safety standards are built and vehicles are run over them. The sensations are very interesting and speed-independent. It is the unexpected motions that are bothersome. It was also noted that we talk about ride quality in terms appropriate to airplanes flying in smooth air, but the ride quality will be mor like a commuter plane flying through not-so-smooth air. This ride quality can be improved, but there is a serious question about the cost of the work to do so. The Japanese system has segmented coils for propulsion and levitation that result in some perturbations, and it was speculated that the final system would have to be at least this good. A continuous-sheet guideway would be smooth on a local basis, but subject to variations in height caused by settlement and installation tolerances at piers and temperature variations in the guideway. The Transrapid system was said not to have objects close enough to the guideway to cause a problem.

Both the Japanese and Germans plan routes that are straight as an arrow, while in this country we seem to have focused on the use of interstate highways. One potential problem is cutting off part of a usable farm, which need not happen with maglev on an elevated guideway.

A lot of money might be saved if the ride conditions could be violated part of the time, say once every 30 minutes. The fact that the curves and hills can be anticipated might relieve part of the problem.

A system with perturbations will probably have to be constructed and tested to resolve the issue, but a closed-loop simulator gives a repetitive pattern and might not be adequate.

As noted in the sections on accelerations and suspension, these considerations have a pronounced effect on the design and cost of the system. This is clearly a topic for further research.

Magnetic fields produced by maglev systems are a concern for operating systems because of possible detrimental health effects. These effects appear to be related primarily to alternating fields rather than dc fields, like the preponderant field of maglev systems. A temporary design goal of 5 gauss $(0.0005 \mathrm{~T})$ was suggested for a current design, since this is a low field (compared with that of many devices currently in use) and can be fairly readily shielded to a lower level by known technologies at a later time, if necessary.

\section{A.2.16 Intermodality}

Maglev systems will interface with and enhance the utility of other transportation modes. Guideways might be used for both urban and interurban transportation systems in an over-under configuration. Ultimately, superspeed systems in evacuated tunnels, if constructed, would have to interface with this and other existing modes of transportation. Rights-of-Way for highways/railroads might be used in a dual mode for maglev, enhancing the intorfacing of tho systems. Maglev systems will be connected with airports and urban 
centers. Some workers currently prefer to have the main node in the urban center with secondary lines to the arports, while others would prefer to locate the main terminals at airports with access lines to the urban centers.

Since maglev vehicles will operate more slowly in and near heavily populated areas, their headways will be longer and it will be possible, in principle, to intersperse lower-speed urban commuter vehicles on the same guideway.

The interface between maglev and other transportation systems is expected to bo more than a transfer point. A maglev system, like canals, seaports, and other transportation modes before it, will give new form to the communities it serves. The interface node is expected to become a destination itself, and this consideration should be included in early plamning. Space must be allowed for intermodal transfers to automobiles, personal rapid transit, rental cars, taxis, buses, airplanes, holicopters, VSTOL is, ferries, and urban rapid transit systems. As a regional focal point, the transfer point should be planned to include regional activities such as recreation, shopping, medical care, ctc. The Bay Area Rapid Transit (BART) system was estimated to have resulted in $\$ 20$-30 billion of construction.

\section{A.2.17 Public Awarencss}

It was agreed that the public does not know what we are trying to do with maglev.

\section{A.2.18 Rights-of-Way}

One of the major factors distinguishing a high-speed maglev right-of-way from lowerspeed corventional ground transportation rights-of-way is that passenger comfort dictates that only small amounts of vertical and lateral curvature be permitted. Acquiring the land for such a right-of-way is complex in that decisions must be made regarding tunneling through or climbing over hills and slowing the vehicle to make sharper turns or purchasing expensive real property that might be in the straight-ine path.

When turning comers, the vehicle and passengers experience radial accelerations given hy the expression $\mathrm{V}^{2} / r$, where $\mathrm{V}$ is the velocity of the vehiche and $r$ is the radius of curvature. To assure the comfort of the passengers, these acceleritions must be limited to a level that is imprecisely known. Consequently, the speed of the vehicle and the radius of curvature of the turns it makes (or the hills it tops) are interrelated. A lateral acceleration of $0.03 \mathrm{~g}$ 's (proposed by some as being comfortahle in the lateral direction) occurs at $100 \mathrm{mph}$ when the radius of curvature is $6.79 \mathrm{~km}(4.22 \mathrm{mi})$ and at $300 \mathrm{mph}$ when the radius of curvature is nine times greater or $61.1 \mathrm{~km}(38.0 \mathrm{mi})$.

The comfort of passengers, however, is disturbed about equally by accelerations of $0.10 \mathrm{~g}$ 's (a total of $1.1 \mathrm{~g} \mathrm{~g}^{\prime} \mathrm{s}$ ) on the seat of the pants and $0.03 \mathrm{~g}$ g's laterally, and this fact can be userl to decrease the rallus of curvature of the guideway while maintaining passenger comfort. If the vehicle is permitter to tilt into the curve by an anglo of' 24 . $6^{\prime \prime}$, the acceleration on 
the seat of the pants is $1.1 \mathrm{~g}$ 's, and the velocity and radius of curvature are related by $\mathrm{V}^{2} / \mathrm{r}=0.458 \mathrm{~g}^{\prime} \mathrm{s}$. The radii of curvature are then $0.445 \mathrm{~km}(0.277$ miles $)$ and $4.00 \mathrm{~km}$ (2.49 miles) respectively, at 100 and $300 \mathrm{mph}$. The radius indicated at $100 \mathrm{mph}$ is shorter than currently found on some rights-of-way and is not really needed, but the $4.00-\mathrm{km}$ radius at $300 \mathrm{mph}$ would greatly reduce the problem of acquiring a suitable right-of-way. Consequently, some tilting of the body of the vehicle with respect to the horizontal plane is expected to be provided in a maglev system.

Three considerations arise by allowing the vehicle to tilt at this angle. First, there is concern that the visual perception of this angle will disturb passengers. Second, the vehicle must be prevented from toppling over on its side if it stops in the curve. (Some forms of maglev avoid this by allowing the vehicle to roll along its axis in the guideway.) Finally, if the vehicle comes to a stop at this tilt angle, the passengers might not be able to safely get out of their seats and exit the vehicle. If any of these factors govern the design, the radius of curvature will have to be increased. Decreasing the tilt angle to $12^{\circ}$ (about the maximum angle on which people can conveniently walk) reduces the acceleration on the seat to $1.022 \mathrm{~g}$ 's and the velocity and radius of curvature become related by $\mathrm{V}^{2} / \mathrm{r}=0.2125$, resulting in radii of $0.96 \mathrm{~km}(0.60 \mathrm{mi})$ and $8.6 \mathrm{~km}(5.37 \mathrm{mi})$ at 100 and $300 \mathrm{mph}$, respectively. Railroad beds are typically tilted (superelevated) by about $6^{\circ}$ maximum.

Routes. Argonne National Laboratory's studies indicated that maglev routes should connect airports for a variety of reasons, including the following:

- The airline fare structure is generally higher than that of the railways, and the higher fares could be charged to maglev passengers.

- There is a lack of expansion capability in the airports that maglev can help alleviate by handling some of the short-haul passengers who world otherwise be carried by the airlines.

- Connecting airports permits through-passengers to use the maglev system.

The Tri-State High-Speed Rail study elected to study routes from downtown-to-downtown, but it considered links to airports to eliminate long drives and delays to be an important selling point.

It was noted that TGV has a dedicated right-of-way, except where it enters Paris and Lyon.

Highways/Railroads. In a New York study of maglev, it was concluded that the cost of land was high enough that existing highway rights-of-way should be used. The New York thruway right-of-way has a typical width of 200 feet and a maximum grade of 4 ". "The varying curves will cause the average speed to be limited to $240 \mathrm{mph}$ if a $24^{\circ}$ bank angle is 
used and $169 \mathrm{mph}$ if a $12^{\circ}$ bank angle is used. The speed would have to be varied frequently to keep it near the optimum for the individual curves. The Tri-State High-Speed Rail study showed the cost of the right-of-way to be only $2-5 \%$ of the total system costs (rural property at $\$ 8,000$ per acre) and concluded that an entirely new right-of-way should be acquired. Land near railroads is relatively cheap and available since the railroads have downplayed their passenger operations, and their freight operations can be conveniently located at the outskirts of town.

Like maglev, high-speed rail systems would also require new rights-of-way for effective utilization, but since trains cannot stop on as steep a bank as some types of maglev systems, the rights-of-way would have to be straighter.

If a maglev system is located on a highway right-of-way, an accident on one system might affect the other. The question as to whether it is desirable to have two transportation systems so interrelated needs to be considered.

Power Lines. Extensive rights-of-way exist between major population centers for the use of power lines. The use of these rights-of-way for maglev was discussed, since maglev will require both similar routes and electrical power. Two concerns arise. The first concern is for the safety of the vehicle when a maglev vehicle is operating under or near power lines. The second concern is for the steep hills and sharp turns that occur in these rights-of-way and whether these would be compatible with maglev operations. These rights-of-way, which are typically 200 feet wide, might be usable in some cases. There is an economic advantage to being near the transmission lines, since $138 \mathrm{kV}$ of power was considered to be needed by maglev (to avoid flicker on the lines) and since the lines cost several hundred thousand dollars per mile. Since the maglev system will cost in excess of $\$ 10$ million per mile, it appears more cost-effective to reroute the power rather than the maglev guideway.

Eminent Domain. The price of land in a right-of-way will increase after the decision to acquire it is known. The only way to acquire it will be through eminent domain proceedings in which the courts establish the price.

Multiple Uses. Auxiliary uses of the right-of-way for maglev might have major economic benefits and need to be evaluated. The use of optical fiber was mentioned as one supplemental use that would be compatible with maglev operations and would provide a synergistic benefit to the area served by providing new information transportation as well as passenger and freight transportation. The superdata project was cited to have as a goal a thousand-fold increase in communication capacity so supercomputers can communicate in a real-time network. The possible use of the same right-of-way for high-and low-speed vehicles, perhaps on an over-and-under basis, was suggested. The two systems could interconnect at terminals in a manner that would be simple compared with interconnecting an entire train of vehicles. Superconducting power transmission lines were projected to 
become available within the lifetime of the structure, and the supplemental use of the rightof-way for this purpose was recommended for consideration.

Fencing. High-speed guideways at ground level, such as those used for TGV, will have to be fenced to keep vehicles, animals, and vandals off the right-of-way. If the maglev system is elevated, the fence can have gates, which will permit greater use of the land under and around the guideway and will presumably lead to reduced acquisition costs. Fencing over the vehicles might be required in both systems in the vicinity of overpasses, where objects might be dropped on the vehicles.

\section{A.2.19 Related Effects}

Going back to canals, seaports, and other forms of transportation, transportation systems have served as urban form givers. What effect will maglev have? A city that was two and one-half hours from Paris by automobile is now 42 minutes away by TGV, and it is now a bedroom community. Similar effects have been experienced in the Bay Area, where reverse commuting now occurs as a result of the growth of suburban communities. The opinion was expressed that the interface between maglev and urban transit systems will not be simply a transfer point, but a destination.

Space must be provided to get on and off the system and transfer between different modes in the system, including the potential for autos, personal or rental; taxis; buses; airplanes; helicopter; VSTOL; ferries; and urban rapid-transit systems. The ability to attract and house regional-scale activities (such as recreational facilities) that are attractive to passengers from 300-500 miles away must be recognized. No major real estate decisions are made without considering BART, which has more untapped potential for real estate growth. It has 30,000 parking spaces and 25 or 26 lots large enough to accommodate mixed-use developments on the order of $\$ 300-500$ million. Consequently, BAR'T has $\$ 4$ billion to $\$ 6$ billion of assets or properties that can be utilized for mixcd-use development.

Within the life of these structures, superconducting cables will become available, and the possibility of including these in the structure in the future should be considered. Optical fiber communications in retworks can be included in the guideway. It is also important to consider multiple vehicles, urban vehicles, intercity vehicles, and perhaps superspeed vehicles as well, and not fight the question of winding up with structural members that are hig enough to support some of the alternative uses. By considering the rights-of-way structurally and architecturally, there is the potential to change the complete economic picture.

It was conjectured that a maglev system between San Diego and the Bay Area would be the major west-coast route and would follow the Amtrak route along Interstate 5 (which goes in a fairly straight line from San Diego to Vancouver) and pick up small cities like Bakersficld and Fresno. Both rail and maglev were envisioned to be used. Upgraciing Amtrak alone would buy some short-term benefits, but the upgrade would not solve the longr-term transportation problem. 


\section{A.2.20 Startle Effect}

High-speed vehicles that suddenly come into the view of existing traffic modes or that produce a sudden noise can startle the operators of vehicles. An example of this effect is that produced by low-flying aircraft crossing highways while landing. The startle effect is not reduced with time, and in the Paris-Lyon corridor, so many accidents have occurred that areas were constructed in which cars could park to watch the trains. The hope was expressed that by building the guideways 35 to 40 feet high and by constructing them so the visibility of and noise from the vehicles would be limited, the impact would be lessened. The fact that the guideway would frequently cross the highway if the interstate highway rights-of-way were used was mentioned in connection with the startle factor, but no unanimity of opinion was obtained on this point.

\section{A.2.21 Stops}

The locations at which the vehicles stop in any transportation system funded by the public will be dictated by public needs, as well as by economic considerations. Excessive stops reduce the average speed of the system, making it less competitive with other modes of transportation. Too few stops reduce its service to the public. In a practical system, the distance between stations will be greater than in conventional railway systems, but the travel time between terminals can be reduced. One-hundred-mile trips can be completed in 20 minutes at $300 \mathrm{mph}$ ( 5 miles per minute). (One study advocated maglev vehicles for systems operating at $120 \mathrm{mph}$ in highly populated areas and having stops spaced as closely as 1520 miles apart. In another study, only three stops were projected for a 400 -mile system in a relatively sparsely populated area.)

The desirable acceleration and deceleration of a stopping or starting vehicle is determined in part by its passenger-carrying capacity and the corresponding headway. A "train" transporting 1500 passengers in ten cars is equivalent to ten "vehicles" transporting 150 passengers each. If 3000 passengers per hour are to be transported, one train can be operated each half hour, while ten separate vehicles would be required operating with 3-minute headways.

Although it is probably desirable to load and unload trains off-line, it is not compulsory, since the headway is much greater than the time stopped in the station. Accelerations as low as 0.07 g's are used for accelerating or decelerating. Discrete vehicles will have shorter headways and must load and unload off-line to avoid compromising the headway of trailing vehicles and to permit trailing vehicles to pass a vehicle in the station. This will require higher rates of acceleration and deceleration (about 0.15 to $0.20 \mathrm{~g}^{\prime} \mathrm{s}$ ) and fast-acting switches. (It was noted that airplanes accelerate and decelerate at about 0.20 to $0.25 \mathrm{~g}$ 's and attain speeds of $150-170 \mathrm{mph}$ in 30 seconds and in a distance of less than one mile.) The service provided to the passengers differs significantly in the two modes of uperation. 


\section{A.2.22 Switching/Turning}

If separate high-speed vehicles are used, it will be necessary to incorporate switches into the guideway to permit off-line loading and unloading of vehicles (see stops). The faster the vehicles exit the guideway, the less impact they have on the operation of later vehicles. The Transrapid switches were said to operate in about 1.5 seconds and the Japanese switches in about 30 seconds, although the latter are still in development. Headways are sufficiently great that following vehicles can stop if the switch fails catastrophically.

It was generally acknowledged that any mechanical system can fail, but a vehicle can be switched in a system with a passive switch either by deploying wheels that lift and guide the vehicle off the guideway onto the siding or by varying the propulsion to guide the vehicle off the guideway. Early tests of mechanical switches showed that they seldom suffered partial failure but that they frequently failed to operate at all. It was stated, but not discussed, that a system in which the guideway does not move and in which multiple, redundant means are used for causing the vehicle to move sideways off the guideway is failsafe.

The speed at which vehicles should traverse the switch was not agreed upon, since the range of systems being considered by different participants varied significantly (see stops). The turnaround time for a single vehicle will be less than that for a train, unless a circular turnaround track is provided at the end of the route.

\section{A.2.23 Trunk Lines}

It was noted that the airline traffic between city pairs, especially those serving as airline hubs, frequently comprises more through passengers than passengers having those two cities as origins or destinations. In the Chicago-Detroit corridor, three times as many passengers pass through as have these cities as their origin or destination. The TGV system from Paris to Lyon operates 50 to 100 trains per day, but some of these are routed through to Switzerland and others are routed on South in France. The Paris-Lyon leg serves as a trunk line for all these trains.

Althongh airline data are compiled between city pairs in the Northeast corridor, the relevant maglev data combine the ground traffic between these city pairs on one trunk line. Boston, Hartford, New York, Philadelphia, and Washington traffic could be on one trunk th a connecting trunk line to Philadelphia, Pittsburgh, Cleveland, and Chicago. Similarly, in California, six of the top 50 airline city-pairs are located between the San Francisco metropolitan district and the Los Angeles metropolitan district. One guideway along Interstate 5 would support all the maglev travel. Different guideways are not needed for each city pair. In addition to connecting airports and possibly downtown areas of these cities, maglev offers the opportunity to serve intermediate cities, since the vehicles can be switched off the track and loaded and unloaded offline. Between Chicago and Detroit, there are six cities with populations of 100,000 or more. 
Maglev vehicles will operate at reduced speeds in urban and suburban regions to avoid the generation of excessive noise. The headway between vehicles can be safely reduced at low speeds and additional, lower cost vehicles using the same technology can safely be incorporated into the guideway traffic stream for local commuter service.

These capabilities of maglev vehicle systems should be of considerable benofit when commuter and intercity routes are evaluated in detail.

\section{A.3 GUIDEWAY CONSIDERATIONS}

\section{A.3.1 Bridges/Elevated Structures}

Maglev systems are presumed to operate on elevated guideways requiring little earth preparation for their installation. It will be economically advantageous to prefabricate and standardize prestressed concrete beams and perhaps piers to the maximum extent possible where the weight of the span is such that it can be lifted. Piers are usually cast in place on the foundation and prefabricated beams are installed on them. If the span is long cr curved, steel beams are more economical, but the interaction of the magnetic field with the beam must be considered. In the interstate system, both concrete and steel are used. With the low stresses generated by a maglev system, the governing design parameter is the deflection of the beam, not its strength; consequently, higher-strength concretes would be of little use. Other materials might be useful. This deflection will be greater in steel spans than in reinforced concrete spans. The German system with a small clearance requires more rigid and more precisely installed guideways than the Japanese system with larger clearances. These deflections can be calculated. A guess was made that the load-bearing capacity of a bridge could be doubled at a cost that probably would not exceed $25 \%$ of the base cost, depending on the foundation, since the major cost of labor for installation will increase only slightly.

A rule of thumb used as a starting point in setting span lengths of bridges is that the cost of the substructure and the superstructure should be equal. Another economic factor is the tolerable deflection of the bridge. The greater the deflection, the more economical the bridge.

It was generally felt that curves and hills should be considered in the test facility.

All the bridges and trestles were laid out in the Tri-State High-Speed Rail study. The use of highway rights-of-way was dismissed in this study because it was felt that the guideway would move on and off the highway too often and require costly long-span bridges

Bridges have heen a source of malicious vandalism where objects are dropped on passing trains. 


\section{A.3.2 Capacity/Demand}

The question of demand was not addressed in detail, but the associated question of the required capacity was considered to some extent. It was pointed out that there will be appreciable variation in demand, with many hour's of the week when the vehicles will be virtually empty. The Washington to New York shuttle is almost empty from 10:00 a.m. until 2:00 p.m., although there were backup trains at 4:00-5:00 p.m. that same afternoon. There are many different travel patterns. Business travel goes out in the morning and returns the same day, resulting in morning and evening peaks, with the evening peak being greater. Others will be positioning themselves for the next morning. Student demand is characterized by travel out on Friday night and back on Sunday night. Vacation patterns peak around holidays and summer months. Ordinary travel will peak when pricing is better, which makes it probably the only market subject to demand pricing. There will be huge peaks on Friday and Sunday nights. The analysis starts with the peaks and valleys and how they are going to be handled, if it is decided that they should be handled, or they can be driven away to Amtrak as the airlines do, especially in the Northeast Corridor. Many studies have been made for transit purposes that turned out to be wildly erroneous. It was considered to be fruitless to consider the detailed intermediate stops of the system since those decisions will be political decisions, if federal funds are involved. If left to industry, only the most economical points will be served. Consequently, only the approximate capacity required and the ability to adjust this to different corridors and to later times when demand will increase can be considered.

Power for trains as well as for individual cars is available, at least in the midwest, so expansion of capacity by starting with vehicles and later using trains is feasible from this point of view. The cost of building the civil structures for use by two coupled vehicles is probably about $25 \%$ moro than for discrete vehicles, unless train-dynamic considerations arise that require a significant redesign. 'The use of two- or three-car units with the same headway as one vehicle would double or triple the capacity of the system. The cost of the installed power and the cost of the propulsion system will increase, however. The suggestion was made that the civil structure should be designed for the heaviest loads expected.

'There is a question as to the desirability of incorporating too much capacity into one guideway since an accident on the system would be more disruptive to transportation in the corridor. At some point that was not established, it will be desirable to build a second guideway that would avoid this problem and could also provide transportation services along a slightly different route, but perhaps to the same ultimate destination. The Corps of Engineers System Parameters recommends that crossovers be provided on a two-way system to permit limited operations, if one direction of the guideway is blocked for any reason.

\section{A.3.3 Dynamic Interactions}

Dynamic motions of the guideway caused by the passage of a maglev vehicle will differ if a single vehicle or a train of vehicles passes over the guideway. The motion will probably have little effect on the elevated structure but could result in the need for additional 
suspension control for ride comfort on the vehicle. The interaction between entrained vehicles on the guideway is not simple. Testing a single vehicle and ostablishing its motions is the first step in assessing this problem. It was felt that if the motion of one vehicle can be described adequately, the effect of a second vehicle would be amenable to calculation. The ultimate system will have to be evaluated experimentally for this feature if coupled vehicles are used.

\section{A.3.4 Obstacles and Their Detection}

The detection of obstacles on the guideway is an important task in view of the speed of the vehicles and the damage that can be done by relatively small objects. Low-light-level TV or other means of observing the entire guideway would be desirable.

\section{A.4 POWER SYSTEM}

\section{A.4.1 Introduction}

Maglev power requirements are dominated at the highest speeds by the aerodynamic drag power, which varies as the third power of the vehicle speed. Consequently, the instantatneous propulsion powers required at high speeds are comparable for high-speed vehicles of comparable sizes. Differences arise, however, with various propulsion systems. Most U.S. trains generate power on-board. High-speed trains use catenaries and pantographs to pick up power from the wayside, while must maglev system concopts use linear synchronous motors connected directly to the power grid and built into the guideway. The motor and power conditioning equipment is carried aboard trains, while the power conditioning, propulsion and system control for linear synchronous motors are located at the wayside. Discrete vehicles require less installed power than trains of vehicles. T'he aerodynamic resistance is greatest on the first vehicle in the train, but the power required on a grade will include power proportional to the mass of the vehicle or train. The cost of power has escalated faster than any other factor in the BART system.

\section{A.4.2 Power Grid}

Vehicles or trains moving through the region served by an electrical utility will derive their power from that utility. No difficulty is anticipated in delivering 10-30 MW of power as the vehicle moves through the midwest area, but the system should be connected to a dedicated substation providing parallel $138-\mathrm{kV}$ lines to avoid flicker on the line. Some regions might have difficulties providing the power. It was suggested that the guideway be located near power lines to avoid long distribution lines that might cost several hundred thousand dollars per mile. It was noted that this cost is small compared with the cost of the guideway and right-of-way, but obviously these combined costs need to be minimized. 


\section{A.4.3 On-Board Power}

On-board power must be provided for a variety of functions, including the usual heating, ventilation and air conditioning (HVAC), lights, on-board control and communications, and in some cases the power for the suspension and guidance system and its control. This power must be picked up or stored aboard the vehicle. Details of this system were not considered.

If sufficient power can be picked up to propel the vehicle or train, the expense of installing a linear synchronous motor along the entire length of the guideway could be avoided In this case, a short stator linear synchronous or linear induction motor could be installed on the vehicle. Power pick-up is used on the TGV, which has operated to $300 \mathrm{mph}$ in a test. It was noted that in separate tests, $1500 \mathrm{~A}$ of current (probably at about $5 \mathrm{kV}$ ) has been picked up at $400 \mathrm{mph}$, but that the pantograph and catenary pick-up system wears out in about 1000 miles. The pick-up is acrompanied by a ball of fire around the pantograph, resulting in electromagnetic noise. These systems were regarded as not being ready for use since little development has been done on these systems in the United States in the past 20 years. It was suggested that contacts will have to be made of carbon fibers to succeed.

\section{A.4.4 Conditioning}

Variable-voltage, variable-frequency (VVVF) power systems are needed for the propulsion systems for discrete vehicles. The high-power electronics required are not manufactured in the United States but are available from Germany and possibly Japan. The Japanese are thought to be using gate turn off (GTO) electronics, since cycloconverters are limited in their upper frequency capabilities.

\section{A.5 VEHICLE CONSIDERATIONS}

\section{A.5.1 Suspension/Propulsion}

The rules of the conference were that no proprietary data were to be discussed, since the purpose of the conference was to scope the requirements for testing rather than to design a maglev system. Essentially no new basic information on suspension and propulsion system was discussed.

\section{A.5.2 Multiple-Car Operation}

It was stated that two-car configurations would probably be minimal. Using multiple cars will require an evaluation of multiple-car effects on both the vehicles and the guideway. The extra power for heavier vehicles or consists will be more difficult if GTO devices are used for power conversion and conditioning since they are not available in very high-power configurations. The capacity of the system seems adequate with single-vehicle operation, and 
the cost of the guideway and the installed power and propulsion systems will be less. If the vehicles are highly underdamped, undesirable resonances of the vehicles could occur. Modeling of the system is needed. It was pointed out that the number of trucks or bogies per car might be more important than the number of cars.

\section{A.5.3 Restrooms}

It was suggested in the strawman design that restrooms would not be aboard the vehicle, since the time between stops would be relatively short and vehicles frequent, so passengers could get off to use restrooms in the terminals with little impact on their trip time. If restrooms were on-board, the alert time before emergency braking commences would be increased excessively and the headways would be increased by a matter of minutes. For each minute of headway, however, the vehicle travels an additional 5 miles, and an additional 5 miles of guideway must be amortized by the operation of the vehicle. 'This would provide an economic disincentive that might well be insurmountable.

\section{A.5.4 Size/Configuration}

The size of potential revenue vehicles was estimated to be from 50 to 120 feet in length, with possible articulation of the longer vehicle to avoid interference with the guideway. Some participants expressed reservations about having a vehicle as long as 120 feet. The weight of the TGV was said to be about one metric ton per seat, while the Japanese maglev is about 0.2 to 0.3 tons per seat and the Transrapid vehicle about 0.5 tons. The capacity of the vehicle would be about 96 to 222 passengers per vehicle. The pitch of the seats was estimated at 36 inches and the width at 24 inches minimum. The aisles were estimated to be 32 inches wide, compared with about 24 inches for airliners. It was felt that handicapped passengers could be seated lear the doors, avoiding the need to widen the aisles. Seating in a 3 by 3 arrangement was not highly regarded, with a 2 by 2 arrangement being preferred. Tilting of the vehicle and banking of the guideway should be considered in a test facility.

\section{A.5.6 Speed}

If the system is used for both urban and interurban passengers, the speed of the system would vary widely. BART averages $38 \mathrm{mph}$, with a top speed of $85 \mathrm{mph}$. A commuting speed of $150 \mathrm{mph}$ was regarded as too high, but if the vehicles are to be interspersed with interurban vehicles, this speed might be required. Tunnel and passing vehicle effects need to be considered for ultimate testing.

\section{A.5.7 Superconducting Magnets}

Superconducting magnets are essential for the performance of the electrodynamic system with high suspension heights, and new technologies for the production of magnets 
with higher current densities were said to have been developed, primarily as a result of the studies of magnets for the superconducting supercollider. The utilization of these magnets in maglev systems must be carefully evaluated to see that they are appropriate for use in a maglev system where the safety of the vehicle and passengers is paramount. Magnets with high resistivity matricies for the conductor might operate with high current densities but could quench to the normal state very rapidly. If that occurred, provisions, possibly including multiply redundant magnets, would be required to assure that levitation and propulsion is not lost. High-temperature superconducting magnets were not considered in detail since they are speculative at this time. Low-temperature magnets will require liquid helium cooling. Such cooling entails a refrigeration power of about 4 kilowatts for each watt of power dissipated at 4.2 K. The Japanese were said to be developing a Sterling Cycle refrigerator with relatively higher efficiency. Considerable work remains in this area in the United States.

\section{A.5.8 Brakes}

The brakes to be used on a maglev system will be design-specific, but will probably include air brakes as one braking mode. Letting the vehicle fall onto something and use friction for braking is very effective if the normal braking mechanisms fail. "The system will be under automatic control, and on-board personnel will not be able to r rake the vehicle.

During high-speed testing of a research vehicle in Pueblo, Colorado, the redundant brakes failed sequentially. Braking systems were recommendéd for experimental development with the test facility.

Regenerative braking generates electrical power from the kinetic energy of the vehicle. 'This power is either dissipated in a resistor or fed back into the power system. The latter approach is obviously preferable, but the wave form of the power returned to the system might not be very high, and additional processing might be required. This is an area for R\&D.

\section{A.6 RESEARCH AND DEVELOPMENT}

The proposed National User Facility will be used for the research and development of magnetic-levitation concepts, components, subsystems, and systems. Such R\&D may include but is not limited to the following: new conceptual designs and configurations of primary or secondary suspensions and associated passive or active damping systems, guidance, passive or active braking, propulsion, power control and distribution, system control, communications, guideway switching mechanisms, passenger comfort measurement or means of attainment, guideway structures and construction techniques, guideway dynamics and interactions of the vehicle with the guideway, magnet construction techniques and magnetic field controls, magnetic shielding and effects of magnetic fields on other parts of the system (including the passengers), superconducting and cryogenic technologies, and related relevant aspects of maglev ground transportation systems. Such development may 
be undertaken in single- or multiple-vehicle consists as appropriate. Computer software describing such of the above items as seems prudent will be developed. Argonne National Laboratory will not manufacture maglev systems.

It is expected that the first system installed and operated in revenue service will not be the final system developed and that research and development will be required to modify and improve the systems for an extended period.

Scale models are appropriate for determining some properties of prototype vehicles. Such models typically embody the features of a full vehicle in a fixed ratio of dimensions of the model to the corresponding dimensions of a full-scale vehicle. Such models are not proposed for testing in the experimental facility since only industry will develop prototype and revenue-producing maglev vehicles. Industries may, at their option, present scale models to the facility for evaluation if such testing is compatible with the ficility. One participant was opposed to testing vehicles or components in any size less than full size. Others disagroed quite vigorously.

One industrial participant stated that the testing program should be driven by the necessity of validating computer codes and that all else will fall into place from that perspective.

Prior to its implementation in a revenue system, any new vehicle for transporting passengers must be tested in full size to determine its performance, assure its safety and reliability, and determine its manufacturability. Such tests are costly. Assuming a test system cost of $\$ 15$ million per mile and a 30 mile test guideway, a full-scale test system would cost $\$ 450$ million. By testing in a reduced-size facility, however, different concepts and configurations can be evaluated before cornmitting to full scale tests of the preferred design. Computer codes written to predict the parameters of the systems can be validated by these tests and used to design, and project tha performance of, full-sized implementations of the maglev concept. If the same cost per mile is assumed for a smaller system, a one- to two-mile facility could be built for $\$ 15-30$ million. (The ze of the test system is not established at this time and will be determined after further di ussions with industrial and governmental personnel with an interest in the program.) It will be possible to perform a substantial amount of the total required research and development on such a reduced-size experimental facility if it is properly designed.

Tests performed using the experimental facility will be those that will save time or money or that will entail risks that are unacceptable in a larger, more expensive system. Mistakes will be less costly at this size than in a full-sized system.

Vehicle. Multiple cars, suspensions, active and passive damping systems, ride quality, braking, superconducting magnets, cryogenic systems, and controls. 
Guideway. Structural dynamics, interaction with vehicle, construction and installation techniques, alignment and maintenance methods, instrumentation.

\section{A.7 COMPU'TER SIMULA'TIONS}

Computer codes describing the behavior of maglev systems and verified by experiment will be of considerable value to the design of full-scale systems in extrapolating the observed behavior in small vehicles. The testing program should be geared to developing the parameter's that allow the codes to be validated. Codes for calculating the suspension and guidance forces in a "U"-shaped continuous sheet guideway are available, and a code for a rigid-hody vehicle suspended and guided by four or six magnets is being revised. After developing a complete series of codes, another program in an industrial firm was able to design complete AWACS planes and radars without building anything.

\section{A.8 CONFERENCE PARTICIPANTS}

\section{Participant}

Armstrong, Richard

Balarzic, Joseph

Barchalt, James

Bertini, $\mathrm{Al}$

Biegalski, Jack

Blow, Larry

Carlson, Art

Clanton, Ronald

Coffey, Howard

Coltman, Mike

Gilcrease, Ed

Gross, David

Harding, John

He, JianLiang

Johnson, Larry

Key, F. Scott

Ladd, Russ

Mulcahy, Thomas

Odegatard, Ron

Peterson, Norman

Piper, Peggy

Proise, Michael

Randall, Bradley

Rooney, Kenneth

\section{Affiliation}

U.S. Army Corps of Engineers, Huntsville, Ala. Inland Steel Corporation

Inland Steel Corporation, Research Department

U.S. Army Corps of Engineers, Washington, D.C., NMi

Inland Steel Corporation, Marketing Department

General Dynamics, Space Systems Division

Illinois Dept. of Commerce and Community Affairs

Westinghouse Electronic Systems Group

Argonne National Laboratory, Center for Transportation Research

Transportation Systems Center, Cambridge, Mass.

Parsons Brinckerhoff, Atlanta, Ga.

Illinois Givernor's Science Advisory Committee, Ex. Dir.

Federal Railroad Administration, NMI

Argonne National Laboratory, Center for Transportation Research

Argonne National Laboratory, Director, Center for Transportation

Research

Hudson Engineering, Houston, Texas

Americon Holding, Babcock and Wilcox

Argonne National Laboratory, Materials and Components

Technology

Commonwealth Edison

Argonne National Laboratory, Strategic Planning Office

Inland Steel Corporation, Marketing Department

Grumman Aerospace Corporation

Lester B. Knight and Associates

Commonwealth Edison 


$\begin{array}{ll}\text { Rote, Donald } & \begin{array}{l}\text { Argonne National Laboratory, Center for Transportation Research, } \\ \text { Maglev Coord. Committee }\end{array} \\ \text { Salpaka, Glenn } & \text { ElectroMotive Division, General Motors } \\ \text { Stauffer, Jack } & \text { Transportation Test Center, Dir. Test Engineering } \\ \text { Stekly, John } & \text { Intermagnetics General Corporation } \\ \text { Sutton, Patrick } & \text { U.S. Department of Energy } \\ \text { Travis, Merrill } & \text { Illinois Department of 'Trinsportation, Chief, Dept. of } \\ & \text { Transportation } \\ \text { Uherka, Kenneth } & \text { Argonne National Laboratory } \\ \text { Ussery, Wilfred } & \text { Bay Area Rapid Transit System, Director } \\ \text { Vyas, Anant } & \text { Argonne National Laboratory, Center for'Transportation Rosearch } \\ \text { Watts, David } & \text { Transportation Test Center, Dir. Marketing } \\ \text { Williams, Jack } & \text { Alfred Benesch \& Co. } \\ \text { Wu, Jiing } & \text { Westinghouse Science \& Technology Conter } \\ \text { Youkey, Carole } & \text { U.S. Army Corps of Engineers, Project Management, Huntsville, } \\ & \text { Ala. } \\ \text { Zehrt, William } & \text { U.S. Army Corps of Engineers, Huntsvillo, Ala, } \\ \text { Zessin, Wayne } & \text { Commonwealth Edison }\end{array}$

\section{A.9 A STRAWMAN SYSTEM DESIGN}

\section{A.9.1 System Considerations}

One-Way Peak Capacity: 1,800,000 passenger-miles/h ${ }^{2}$. Equivalent to 6000 passengers per hour entering system and travelling at $300 \mathrm{mph}$ or 9000 passengers per hour entering system and travelling at $200 \mathrm{mph}$.

Fare: $\$ 0.25$ to $\$ 0.35$ per mile

Routing: Between major airports with one stop at a distance not less than 50 miles from each major terminal.

Operating Hours: 6:00 am to midnight (Passengers) Midnight - 6:00 am (Freight and Maintenance)

Minimum Duration of On-Board Supplies: 18 hours

Operating Speed: $500 \mathrm{~km} / \mathrm{h}(300 \mathrm{mph})$ with $50 \mathrm{~km} / \mathrm{h}(30 \mathrm{mph})$ headwind, speed reduced by headwind speed for greater wind speeds.

Acclerations (maximum):

$\begin{array}{lll}\text { Linear } & \text { (normal): } & 0.15 \mathrm{~g} s \mathrm{~s}\left(1.47 \mathrm{~m} / \mathrm{s}^{2}, 3.29 \mathrm{mph} / \mathrm{s}\right) \\ & \text { (emergency): } & 0.20 \mathrm{~g} ' \mathrm{~s}\left(1.96 \mathrm{~m} / \mathrm{s}^{2}, 4.39 \mathrm{mph} / \mathrm{s}\right)\end{array}$


Lateral (on passengers): $0.03 \mathrm{~g}$ 's

(on vehicle): $\quad 0.15 \mathrm{~g}$ 's

Downward (on passengers): $1.1 \mathrm{~g}$ 's
Pitch, Yaw Rates:
1 degree/s
Roll Rate:
2 degrees/s
Switching Speed:
$161 \mathrm{~km} / \mathrm{h}(100 \mathrm{mph})$ minimum
Time in Station:
$90 \mathrm{~s}$
Loading/Unloading:
Offline

Minimum Headway between Vehicles: $300 \mathrm{mph} \quad 250 \mathrm{mph} \quad 200 \mathrm{mph}$

$\begin{array}{llll}\text { Distance: } \mathbf{X}_{\mathbf{H}}=\mathbf{1 5} \mathbf{V}_{\mathbf{o}}+\mathbf{V}_{\mathbf{o}}{ }^{2} / \mathbf{0 . 4} \mathrm{g} & 4.11 \mathrm{miles} & 3.03 \mathrm{miles} & 2.10 \mathrm{miles} \\ \text { Time: } \mathbf{T}_{\mathbf{H}}=\mathbf{X}_{\mathbf{H}} / \mathbf{V}_{\mathbf{o}} & 49.3 \mathrm{~s} & 43.6 \mathrm{~s} & 37.9 \mathrm{~s}\end{array}$

Maximum Wind Speeds:

On nose: $\quad 45 \mathrm{mph}$

On side: $\quad 45 \mathrm{mph}$

Grade (at operating speed): $\quad 5 \%$ (at reduced speed): $\quad 7 \%$

Magnetic Field Exposure: To be minimized. 5 gauss $(0.5 \mathrm{~m} \mathrm{~T})$ as temporary design goal.

\section{A.9.2 Vehicle Considerations}

Capacity: $\quad 90,150$

Seating: $\quad 3 \times 3 \quad 0.91 \mathrm{~m}\left(36^{\prime \prime}\right)$ aisle, $0.56 \mathrm{~m}\left(22^{\prime \prime}\right)$ seats

Length: $\quad 22.1 \mathrm{~m}\left(72.5^{\prime}\right) \quad 1.07 \mathrm{~m}\left(3.5^{\prime}\right)$ seat pitch $+6.1 \mathrm{~m}\left(20^{\prime}\right)$

Width: $\quad 4.57 \mathrm{~m}\left(15.0^{\prime}\right)$ outside, $4.27 \mathrm{~m}\left(14.0^{\prime}\right)$ inside

Height: $\quad 3.20 \mathrm{~m}\left(10.5^{\prime}\right)$ outside, $2.13 \mathrm{~m}\left(7.0^{\prime}\right)$ inside

Frontal Area: $\quad 14.63$ square moters (157.5 square feet)

Weight (empty): $\quad 27.3$ metric tons $(60,000 \mathrm{lb}), 43.2$ metric tons $(95,000 \mathrm{lb})$ (loaded): $\quad 34.3$ metruc tons $(75,750 \mathrm{lb}), 55.1$ metric tons $(121,250 \mathrm{lb})$ ( $175 \mathrm{lb}$ per passenger and baggage) 
Restrooms:

Food Service:

Operating Temperature:

Ambient:

Interior:

Operating Weather:

Brakes:

On-Board Power:
None on board

None on board

$+50^{\circ} \mathrm{C}$ to $-30^{\circ} \mathrm{C}\left(+122^{\circ} \mathrm{F}\right.$ to $\left.-22^{\circ} \mathrm{F}\right)$

$+20^{\circ} \mathrm{C} \pm 5^{\circ} \mathrm{C}\left(59^{\circ}-77^{\circ} \mathrm{F}\right)$

Operation not affected by moderate rain, snow or ice. Weather not to disrupt electrical propulsion system.

Fail-Safe

Aerodynamic

Eddy Current

Reverse LSM Thrust

Electrical Regeneration

Mechanical, Parking:

As required for safety and comfort. Four-hour stall on guideway.

\section{A.9.3 Guideway Considerations}

Structure:

Propulsion:

Obstacle Detectors:

Power Substations:

System Control:
Elevated to avoid grade crossings

Integral to guideway

Attached to guideway

Spaced at 20-km intervals

Central

\section{A.9.4 Discussion}

One-Way Peak Capacity. This capacity is defined as the number of passengers entering the system in one hour multiplied by the speed of the system. Rates of 6000 passengers/hour at $300 \mathrm{mph}$ (forty 150 passenger vehicles) or 9000 passengers/hour at $200 \mathrm{mph}$ (sixty 150-passenger vehicles) result in the same capacity by this definition. Rush hour speed decreased to safely increase the number of vehicles and passengers handled. If 3000 commuters and 6000 intercity passengers are carried to a point 50 miles from the start at $200 \mathrm{mph}$, the extra time for the intercity passenger is increased by 5 minutes. If the remaning 6000 intercity passengers continue at a speed of $300 \mathrm{mph}$, the capacity of the system remains unchanged at 1.8 million passenger-miles $/ \mathrm{h}^{2}$, either in the commuter mode 
or in the intercity mode of travel. If a fixed revenue per passenger mile is charged, the revenue per hour would be the same throughout the system.

Vehicle Headway. Vehicles to be operated with spacings such that a safe stop can be made before reaching the position on the guideway where another vehicle has been involved in an accident. Deceleration will be limited to 0.2 g's. Fifteen seconds warning will be given to passengers prior to deceleration. Note: the headway (time) is not the same as the stopping time. Minimum headways expressed in time and distance are: Headway (distance) $=15^{*} \mathrm{~V}_{1}+\mathrm{V}_{11}^{2} / 2 \mathrm{a} ;$ Headway $($ time $)=15(\mathrm{sec})+\mathrm{V}_{11} / 2 \mathrm{a}$

\begin{tabular}{|c|c|c|c|c|c|c|c|}
\hline \multicolumn{2}{|c|}{ Speed } & \multirow[b]{2}{*}{$\begin{array}{c}\text { Time } \\
(\mathrm{s})\end{array}$} & \multicolumn{2}{|c|}{ Distance } & \multirow[b]{2}{*}{$\begin{array}{l}\text { Vehicles } \\
\text { per hour }\end{array}$} & \multirow[b]{2}{*}{$\begin{array}{l}\text { Passengers } \\
\text { per hour }\end{array}$} & \multirow[b]{2}{*}{$\begin{array}{l}\text { Pass-mi/h } \\
\text { (millions) }\end{array}$} \\
\hline $\mathrm{mph}$ & $\mathrm{km} / \mathrm{h}$ & & $\mathrm{mi}$ & $\mathrm{km}$ & & & \\
\hline 50 & 81 & 26.4 & 0.29 & 0.46 & 136 & 20,453 & 1.02 \\
\hline 100 & 161 & 37.8 & 0.73 & 1.18 & 95 & 14,284 & 1.43 \\
\hline 150 & 241 & 49.2 & 1.34 & 2.15 & 73 & 10,975 & 1.65 \\
\hline 200 & 322 & 60.6 & 2.10 & 3.38 & 59 & 8,910 & 1.78 \\
\hline 250 & 402 & 72.0 & 3.02 & 4.86 & 50 & 7,499 & 1.87 \\
\hline 300 & 483 & 83.4 & 4.10 & 6.60 & 43 & 6,474 & 1.94 \\
\hline 350 & 563 & 94.8 & 5.34 & 8.59 & 38 & 5,696 & 1.99 \\
\hline
\end{tabular}

Route Length. It is assumed that the point to point travel time by maglev will be shorter than for air travel for intermediate distances. For general design purposes, the route will be assumed to be 600 miles in length and to have two 50 mile long legs in each 300 mile segment.

Operating speed. The vehicle must travel at a speed that makes travel by this transportation mode as fast or faster than aircraft travel over the same distances. This can be accomplished at a speed of $300 \mathrm{mph}(500 \mathrm{~km} / \mathrm{h})$. Operating speeds will not be reduced by headwinds up to $30 \mathrm{mph}(50 \mathrm{~km} / \mathrm{h})$. Higher winds will result in a decrease in system speed.

Side Wind Load. This force increases from zero at ground level to a substantial force at higher positions on the vehicle. The force tends to roll the vehicle leeward and must be considered in addition to any inertial forces on the vehicle. The vehicle should operate in side winds up to $45 \mathrm{mph}$. At higher speeds, the system should be slowed appropriately.

Magnetic Fields. Magnetic fields are being investigated for their deleterious health effects. and the ultimate limits that might be imposed are not known. A level of 5 Gauss will be assumed. These fields can be shielded further if necessary. The observed effects are thought to be caused by alternating fields rather than the static fields expected from maglev.

Rest Facilities. On-board restrooms would remove three to six seats from the vehicle and defeat or at least confuse the use of the 15 -second warning before emergency deceleration. Increasing the warning time to two minutes increases the stopping distance by 
one minute and 45 seconds, or 8.75 miles at $300 \mathrm{mph}$. This additional 8.75 miles $\times \$ 7.5$ million/mile or $\$ 65.6$ million of assets associated with the vehicle must be amortized by the vehicle's revenues. Omitting restrooms probably has no serious effect on passenger comfort if clean, accessible facilities are provided at the terminals. Frequent departures will minimize the objection to use of the restrooms before departing. The maximum distance between stations is expected to be 200 miles or less and would be travelled in about 42 minutes. By omitting on-board food and beverage service, the deed for these facilities can be reduced.

Fare. Fares are based on a basic fare of $\$ 0.10 /$ mile and a premium charge of $\$ 15,00 / \mathrm{hr}$ for time saved compared with surface travel at $50 \mathrm{mph}$. A 50 -mile trip at $200 \mathrm{mph}$ would be accomplished in 15 minutes, saving 45 minutes from comparable surface transportation at $50 \mathrm{mph}$, and would cost $\$ 5.00+0.75 \times \$ 15.00$ or $\$ 16.25$. A 300 -mile trip at $300 \mathrm{mph}$ would save 5 hours and would cost $\$ 105.00$. Political considerations might reduce the commuter fare by subsidies to the system. These cannot be considered here. Examples follow for one hour trips. The revenues per lane mile are based on the minimum headways given above.

Note: If a system cost of $\$ 7.5$ million per lane mile is assumed, and a $30 \%$ recovery of cost is required per year, the recovery is $\$ 2.25$ million /lane-mile/year or $\$ 6,164$ per lane per day. All the scenarios above yield a greater return.

\begin{tabular}{|c|c|c|c|c|c|c|c|}
\hline \multirow{2}{*}{$\begin{array}{l}\text { Speed } \\
\text { (mph) }\end{array}$} & \multicolumn{4}{|c|}{ Fare } & \multicolumn{2}{|c|}{ Vohicle Revenue } & \multirow{2}{*}{$\begin{array}{l}\text { Max. Revenue } \\
\text { per hour per } \\
\text { System-Mile }\end{array}$} \\
\hline & Base & Premium & Total & per mile & $\$ / \mathrm{h}$ & $\$ / \mathrm{mi}$ & \\
\hline 50 & $5.01)$ & 0.00 & 5.00 & 0.100 & 750 & 15.00 & 2,613 \\
\hline 100 & 10.00 & 15.00 & 25.00 & 0.250 & 3,750 & 37.50 & 5,116 \\
\hline 150 & 15.00 & 30.00 & 45.00 & 0.300 & 6,750 & 45.00 & 5,049 \\
\hline 200 & 20.00 & 45.00 & 66.00 & 0.325 & 9,750 & 48.75 & 4,643 \\
\hline 250 & 25.00 & 60.00 & 85.00 & 0.340 & 12,750 & 51.00 & 4,220 \\
\hline 300 & 30.00 & 75.00 & 105.00 & 0.350 & 15,750 & 52.50 & 3,841 \\
\hline 350 & 35.00 & 90.00 & 125.00 & 0.357 & 18,750 & 53.57 & 3,513 \\
\hline
\end{tabular}




\section{DISTRIBUTION FOR ANL/ESD-14}

\section{Internal}

ANI, combrial copy

K.S. Mitcial (6)

ANI. Pillent Departament

H. Collory $(2())$

ANI, 'lerentical Publicillons Services (3)

\section{External}

U.S. Department of Energy Office of Scientific and 'Technical Information (12) Manager, U.S. Department of Energy Chicage Operations Office

ANL, Libmaries 

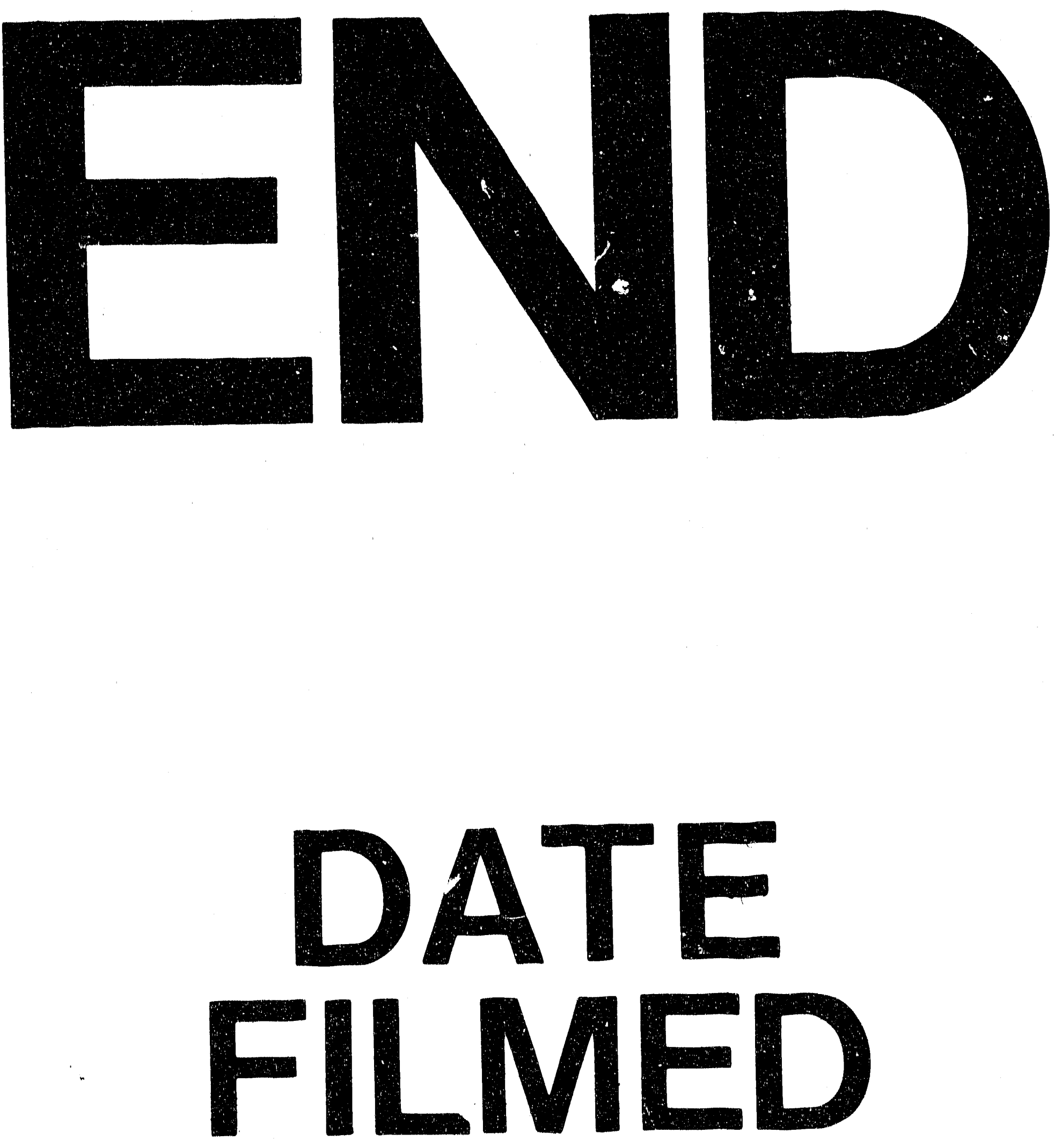

1

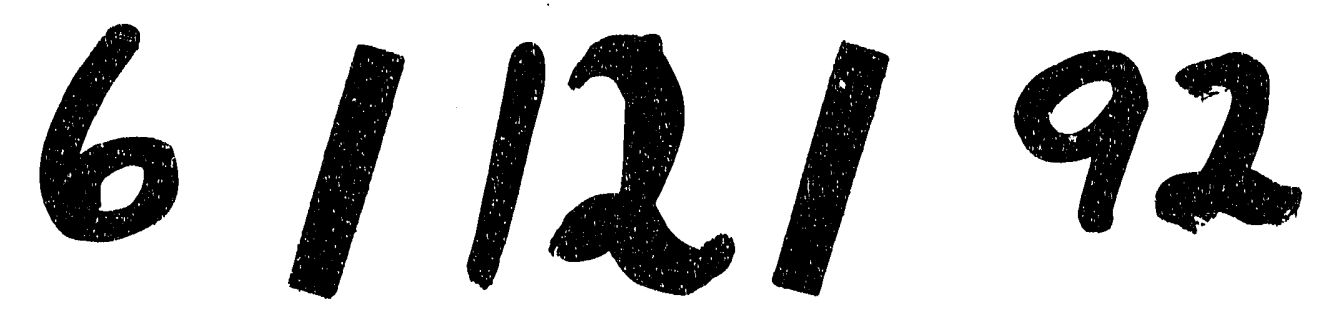


